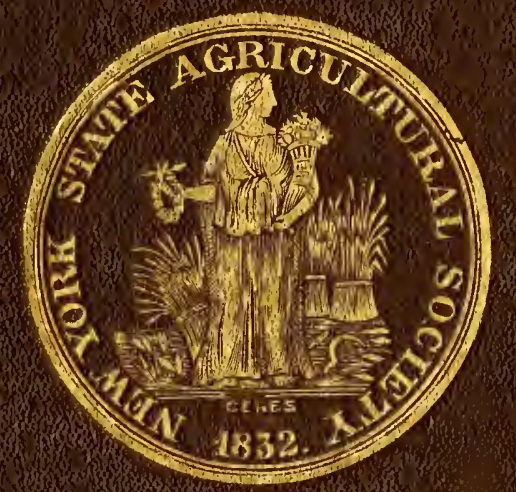




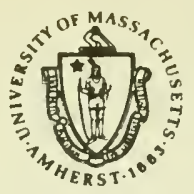

UNIVERSITY OF MASSACHUSETTS LIBRARY

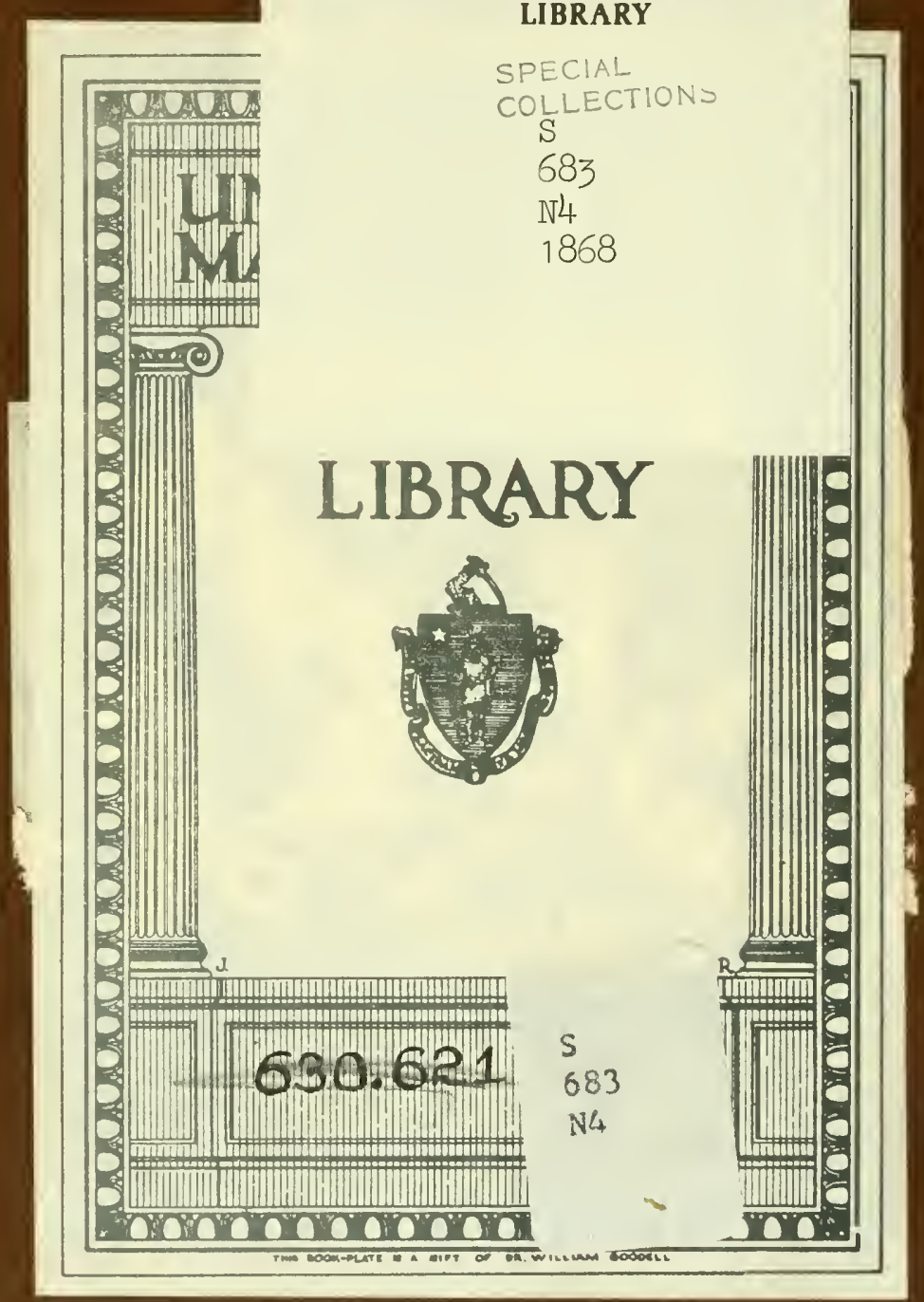


$\cdots$ 








\section{REPORT}

ON THE

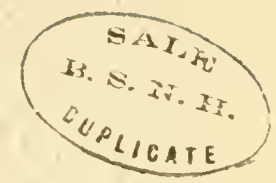

\section{TRIAL OF PLOWS,}

\section{HELD AT UTICA,}

\section{BY THE N. Y.STATE AGRICULTURAL SOCIETY,}

Commencing September sth, 1s6\%.

WITH A SUPPLEMENT SHOWING THE RESULTS OF A SPECIAL TRIAL AT BRATTLEBORO, TO DETERMINE SEVERAL DISPUTED QUESTIONS RESPECTING THE ACTION OF THE PLOW.

\footnotetext{
ALBANY:

PRINTING HOUSE OF VAN BENTHUYSEN \& SONS.

1868 .
} 



\section{REPORT ON TRIALS OF PLOWS.}

\section{INTRODUCTORY CHAPTER.}

In presenting their Report on the Trials of Plows, held at Utica, under the auspices of the New York State Agrieultural Society, the Board of Judges will not be required to spend much time in insisting on the value of that implement, or in proving its influence upon the welfare of society at large.

It is so generally acknowledged, that it has passed into a maxim, if not into an axiom, that the plow lies at the foundation of all wealth, and is the basis of all civilization. Like other truths of a similar character, which are reeeived without hesitation and without inquiry, it is believed that the real value of the implement is obscured by haze and mist in most minds, and that a few remarks upon this subject will not be wasted if they serve to give greater sharpness of delineation to this idea of its primacy among agricultural implements.

Its use dates back to a very remote antiquity. It is now generally admitted by Biblical critics that the Book of Job is the most ancient writing contained within the canon of the Old Testament. Yet this ancient work begins with an allusion to it: "And there came a messenger unto Job, and said, The oxen were ploughing and the asses feeding beside them; and the Sabeans fell upon them, and took them away; yea, they have slain the servants with the edge of the sword, and I only am escaped alone to tell thee."-Job i, 14, 15. In our History of the Plow we have given copies of sculptures on ancient monuments whieh date back four thousand years.

It is certainly strange, in view of the importance and the antiquity of the plow, that its construction should have received so little attention from scientific men, and the principles upon which it acts should have been so little observed by those who habita- 
ally use it. The only special treatise upon it, known to us, is the work of Small, which was published late in the last century, and even that tells us very little of its history, or its theory, being mainly devoted to practical details.

The census of the United States for the year 1860 gives the number of acres of improved land in the United States, but unfortumately we are not told how many acres are in grass, or how many under tillage.

We know, however, that in New York about two-thirds of the improved lands of the State is in grass, and that in the State of Ohio about one-third of the improved lands is in grass. The average ratio of the grass to the tillage land in these States is, therefore, as $1: 1$; or half of the whole of the improved lands are under tillage in these two States. If we may assume that this is the proportion throughout the Union, then, since there are 163,110,720 acres of improved lands, one-half of the amount, namely, $81,555,360$ acres are under tillage, or say, in round number's, $80,000,000$ acres. As Ohio and New York are the chief' grassraising states, it is probable that the average tillage in the other states is still greater than it is in them; but at all events, our estimate would not seem to be an exaggerated one. If now we assume that every plow turns orer fitty acres annually, it will require one million five hundred thousand plows to accomplish the work; and if a plow lasts on an average eight years, it will take one hundred and eighty-seven thousand five hundred new plows every year to supply the demands of our country, without referring to the large number exported to foreign countries.

There are 833,412 farmers in the United States who own from three to fifty acres, and 1,121,602 who cultivate farms between fifty and one thousand acres each. Or, there are 1,955,012 independent cultivators of the soil. The above calculation would agree with a purchase of one new plow by each cultivator every tenth year.

The number of establishments in the United States for the manufacture of plows, harrows and cultivators, is four hundred and twenty-three, and the total value of these products is $\$ 2,855$,248. If we suppose that one-third of this value is to be deducted for harrows and eultivator's, it will leave $\$ 1,903,499$ as the value of the plows manufactured annually; and if we assmme that the average value of each plow is ten dollars, we shall have a result which varies very slightly from the estimate we have given. 
Having, therefore, obtained a similar result by three dufferent and independent processes, we may with some confidence assume, as the annual production, 187,500 plows for domestic use.

We have endeavored to ascertain the annual value of the plows made in this country and exported to foreign countries, but, from the fact that all the agricultural implements exported are given in the oflicial tables under one head, without any attempt to specify the number and value of each machine, it is impossible to ascertain the number or value of the plows exported. The Ames Plow Company have for several years exported about one hundred thousand dollars worth ammually, and other makers, in the opinion of the revenue officers, export two hundred thousand clollars worth more, which makes the whole value of the plows cxported, three hundred thousand dollars. It is believed that the value of this export might easily be increased ten-fold.

The plowing of the land under cultivation in the United States requires, according to our estimate, the labor of one million teams of either oxen, mules or horses for eighty days in the year; and we do not think the average value of the men and teams required for this purpose can be reckoned at less than two and an half dollars a day for each plow. This would make the aggregate cost of the plowing in each year to be $\$ 20,000,000$.

We have shown in a subsequent chapter, that there is a difference of power required to perform the same amount of work by different plows, amounting to forty-six per cent, as shown by cirreful trials in England, and to forty-two per cent, according to the trials instituted by this Society in 1850 .

It follows from this, that if the plow having the least draught was brought into universal use, to the exclusion of those which require a greater power, it would reduce the cost of plowing in the United States forty-two per cent, or it would reduce it from $\$ 20,000,000$ to $\$ 11,600,000$, leaving $\$ 8,400,000$ in the pockets of the furmers, as a fund to be applied to the payment of taxes or the improvement of their farms.

If we suppose that the same number of men and teams were employed as heretofore, then they would be enabled to cultivate an area forty-two per cent greater with the same expenditure of power that they now employ; that is, they would cultivate an area of $(113,600,000)$ one hundred and thirteen millions of acres, without any more expenditure of power than they now do $(80$,000,000 ) eighty millions of acres. 
The annual value of the crops produced on the present area of plowed land in the United States, may be roughly estimated at $(\$ 900,000,000)$ nine hundred millions of dollars, or eleven and a quarter dollars per acre.

If, by the use of better plows, we can increase this amount forty-two per cent, the aggregate increase would he $(\$ 378,000$, $000)$ three hundred and seventy-eight millions of dollars.

We do not mean to assert that this sum would represent the actual increase of the annual valne of the products of agriculture, but allowing each reader to make the deductions which he may think necessary for the increased cost of cultivating this increased area, such as seed, planting, after-culture and gathering, it will be seen that the use of the best form of the plow will increase the aggregate profits of agriculture to an extent equal to the ammual national internal taxation of the United States.

In view of the benefits which we have shown will result from the adoption of the best form of the plow, it is obvious that no amount of labor or expense which our agricultural societies can bestow upon it with a view to its improvement, will be misilpplied or wasted.

We are not without hopes that our labors to this end at Utica will be thought by our agricultural brethren to have yielded some good fruits, and that this success will prove a suflicient stimulus not only to our own Society, but to other State Societies in the United States, to continue this rigid system of observation until all the laws of the plow shall have heen discovered and accurately stated for the benefit of the firmer's of our country. 


\section{CHAPTER II.}

\section{THE HISTORY OF THE PLOW IN EUROPE.}

It is impossible to say who was the first inventor of the plow. The earliest records speak of it as a well-known instrument of husbandry, and we are therefore left to conjecture respecting the origin of the mellowing of land to fit it for the reception of seeds and the growth of grain.

The inhabitants of the earth must have observed, at a very early period of its history, that ground which had been accidentally loosened bore a more abundant harvest; the rooting of hogs must have given them sufficient examples of this, if nothing else had suggested it to them.

The next step, after they had become firirly conscious of this fact, would be to imitate it at such places and at such times as experience had shown them was most desirable. Probably a sharpened stick would be the most likely instrument to suggest itself to their minds; then they would widen the end of it, sharpening it to a chisel edge with a view of making more rapid work.

Man in the hunter, and even in the pastoral state, is very averse to bodily labor. The little inventive power that he possesses will surely be directed to the making of contrivances which will role:se him from bodily toil. While working the land with his shirpenerl stick, with his mind intent upon some mode of ameliorating his condition, he sees the bulls and cows grazing on the hillsides around him; they are stronger than he, and he desires to subjugate their strength to his service. Seeing a forked stick in his path, a blight thought dawns upon his mind; he will tie the long ench of a stick to the horns of a bull, while the short end will r'un into the ground and stir it much faster than he could do it with sharpened stick, and with much less labor to himself. He tries his the experiment, and eriss, Eureka! or some barbarous equivalent for that Greek word. The germ of the plow is at length invented.

The process by which the first man arrived at this result may be pure conjecture; but that the forked stick was the origin of the plow, we have the most ample evidence. 
Fig. 1 is copied from an ancient monument in Asia Minor, made wholly of the natural crooks of the branch of a tree, the only artificial contrivances being the brace $e$, which strengthens the share $c b$, and the pins in the fore part of the beam $a b$, and connect it with the central division of the yoke $p r$. It was with a plow like this that the servants of Job were "plowing in the field when the Sabeans came upon them and drove them away." It was with such an one that Ulysses plowed among the sands of the shore at Ithaca, when he feigned madness before the messengers of Agamemnon.
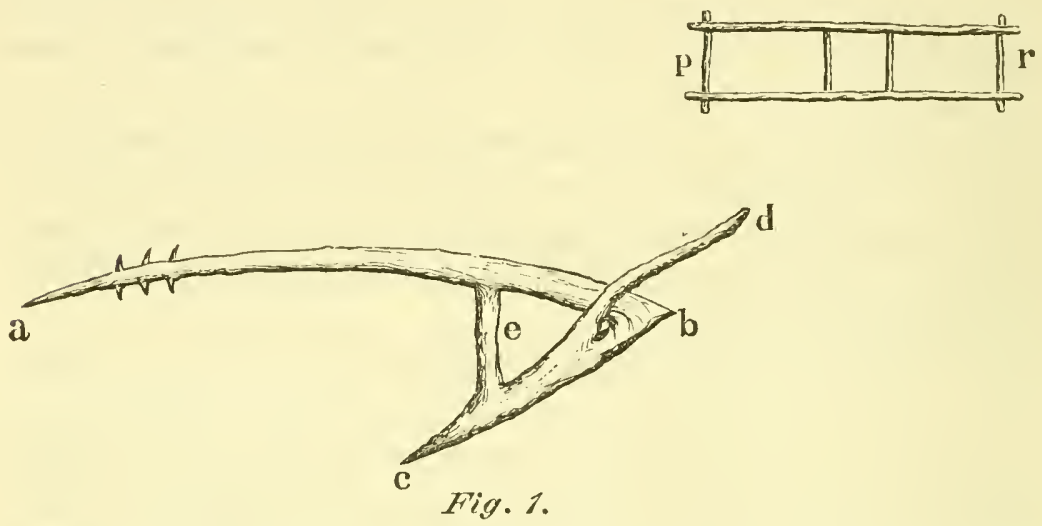

The most ancient monuments of Egypt, dating back at least three thousand year's before the Christian era, reveal to us a slight modification of this implement, quite as rude in form, yet somewhat more powerful in execution.

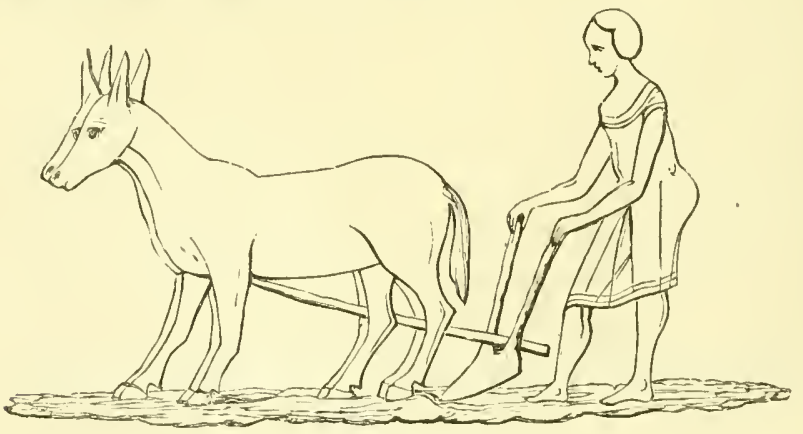

Fig. 2.

Fig. 2 is a copy of these figures. It will be seen that the share being triangular in form, will take a broader furrow, while two handles in the place of one give the plowman a greater command over the instrument. 
The most ancient form of the Roman plow usea in the days of the Tarquins, is given in Fig. 3 .

A more recent form of the implement, as used by Cincinnatus and Cato, is given in Figs. 4 and 5 , which will be found to aglee exactly with the deseription of the imple-

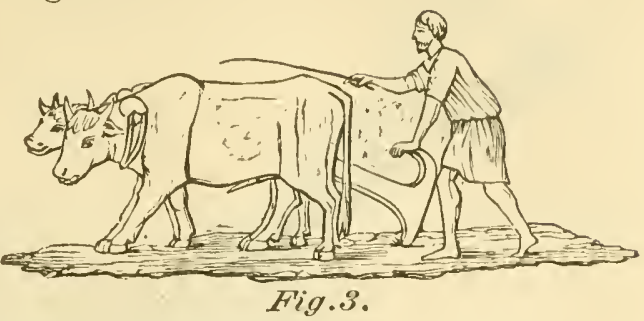
ment given by Virgil in the Georgies. The sole of the plow, A B, has two rectangular pieces of wood, $G$ and $H$, fixed to it on each side, forming an acute angle with it, in which the teeth,

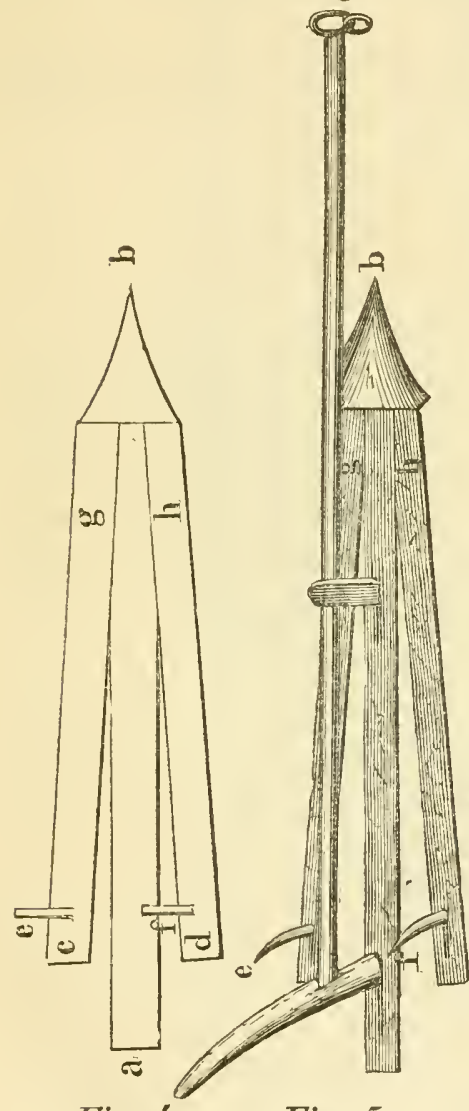

Fig. 4. E F (dentalia), are inserted. This exactly answers the description of Virgil: "Duplici aptantur dentalia dorso;" (the teeth are fitted to the double back.) $\mathrm{E}$ and $\mathrm{F}$ project obliquely upward, and perform the office of a mould-board. The share, $B$, was of metal.

The next improvement in the plow was to cover the point with iron. A very ancient implement of British husbandry, called the Caschrom, is given in Fig. 6, which is used as a plow at this day in some parts of the outer Hebrides and in the Isle of Sky. Like the preceding examples of the implement from Asia Minor and Egypt, the wooden portion of it is in one single piece, and has evidently been selected on accomnt of the natural crook which it had assumed in the tree, that permits the part $a d$ to run nearly horizontally, while the upward curve of the handle, $a$, rises to the shoulder of the plowman, and is allowed to rest upon it. When he desires to make it go deeper into the ground, he raises $c$ on his shoulder; when it runs in too deeply, he presses with his foot "pon the pin e. It is armed with an mon chisel at the point $b$, 
having a socket at the upper end, $d$, into which the fore end of the wooden part is firmly wedged.

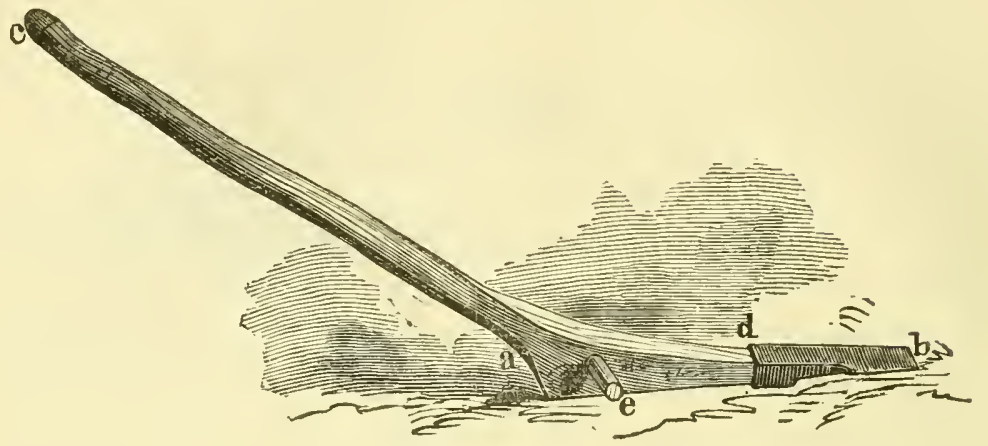

Fig. 6 .

Fig. 7 is the figure of an East Indian plow now in the Museum of our Society at Albany. Its form has not been altered for een1uries, and in some portions of India it is the only plow in use.

The Greeks, who always had a piece of history for every emergeney, tell us that Ceres, or Demeter, as she was ealled by them, who was the daughter of Saturn and Rhea, and the mother of Proserpine by Jupiter, was the inventress and guardian of agrieulture. The story goes, that one day as Proserpine was gathering flowers in the fields of Enna in Sicily, Pluto came and earried her away, to be the queen of the lower regions. Ceres was diseonsolate for the loss of her daughter, and for a long period devoted herself to searehing for her over the whole earth. While she thus devoted herself to this search, she neglected the earth, whieh thus beeome barren. Jupiter, and all the gods in suceession, besought her to abandon the seareh and return to Olympus, but she refused, and would not be consoled. At length the gods persuaded Pluto to allow Proserpine to revisit the upper world: remaining with her mother two-thirds of the year, while she was still to return to him for one-third of it. Ceres was appeased by this arrangement, and consented to return to Olympus; lunt ere she went, she taught to Triptolemus of Eleusis the art of agrieulture, giving him at the same time her chariot drawn by two dragons, in which, by her command, he traveled over the whole earth, distributing eorn to all the inhalitants. Triptolemus, uncler her inspiration, was the inventor of the plow.

The Greeks had two festivals in honor of Ceres, which were ealled Thesmophoria and Elensinia. The Romans, who were greatly devoted to agriculture, were ardent worshippers of Ceres, 


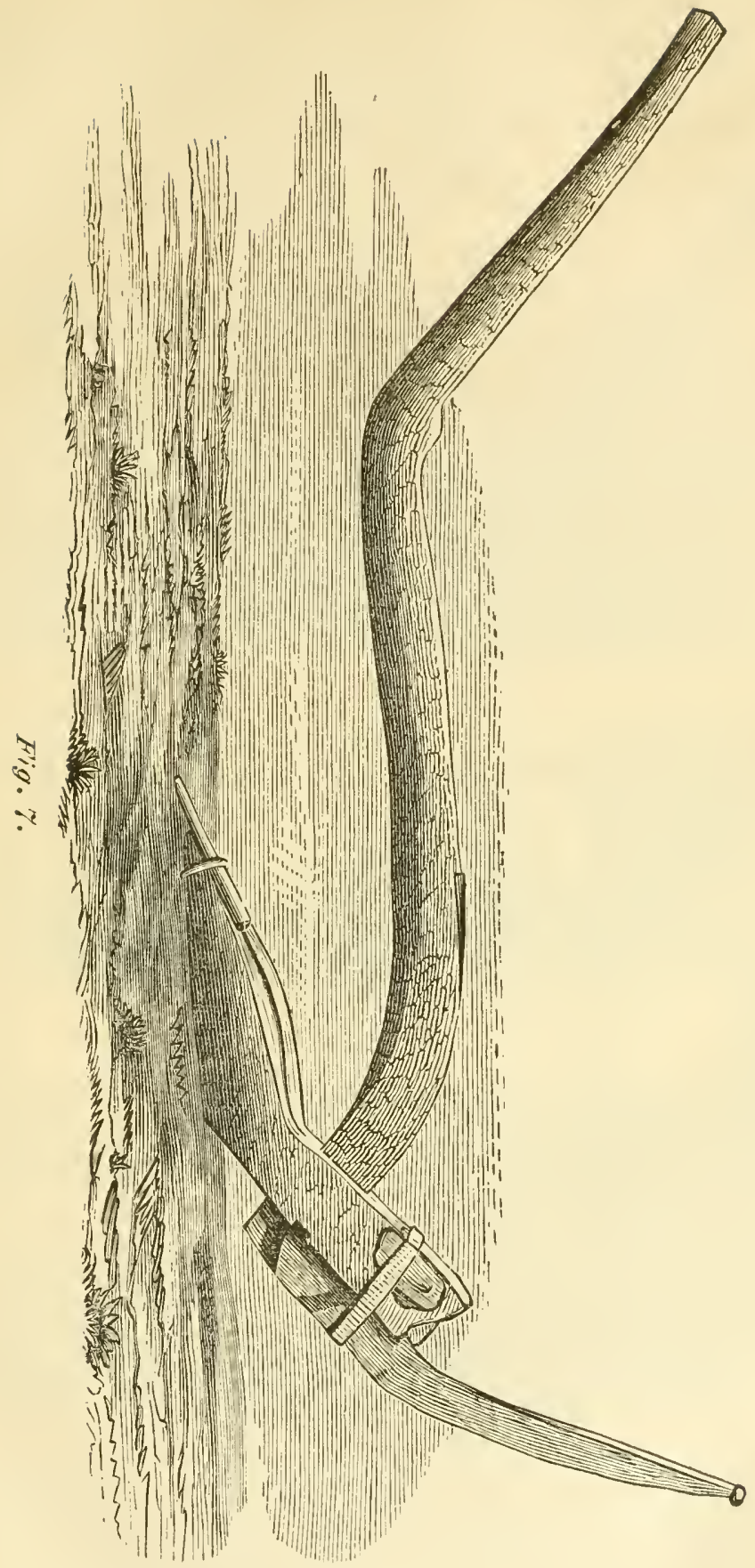


having many temples devoted to her service, and one annual festival called the Ceralia. This festival was celebrated by matrons holding burning torches in their hands, and whoever ventured to appear without previous initiation was punished with death.

This divine origin of agriculture was devoutly believed by the Greeks and Romans, as wcll as the Egyptians; but like all other false beliefs, it worked great practical injury. It was reckoned impious to change the processes which had bcen expressly revealed from heaven, lest they should appear to derogate from the wisdom of Ceres, and thus incur her displeasure; which, of course, was an absolute barrier to all improvement. In fact it would seem that the shadow of that delusion has reached down to the present day, since, in no art known to man, is it so difficult to give currency to new processes as it is in agriculture. A very large portion of the farmers still use implements as rude as those we have alleady figured. In fact the Caschrom is still in use in some parts of the Hebrides.

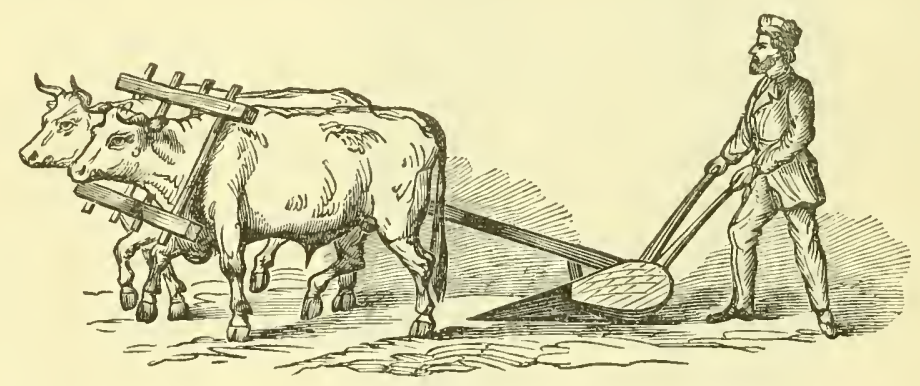

Fig. 8 .

In Fig. 8 we give the plow used throughout Egypt at the present day, which is but a very slight improvement on the ancient implement represented in Fig. 2. Fig. 9 is an accurate representation of a plow now in our muscum at Albany, such as is almost universally used in Mexico. Even in France, Spain and Italy the plows used are of the most awkward kind, incapable of doing good work, and excessively wasteful of power.

The next step in improvement seems to have been the substitution of a more decided wedge form in the plow for the triangular sticks of an earlier age. In some cases the leading idea of the plowmaker seems to have been to have the wedge act horizontally, lifting up the earth; in others the edge was formed to act laterally, pushing the slice eut off by the point over to the other side, so as to laave a free spalce for the next furrow. 
Fig. 10, Chinese plow in the musem of the New York State Agrieultural Society.

Fig. 11 represents a plow figured from the Harleism manuscript No. 4,374, such as was used in England in the reign of Edward

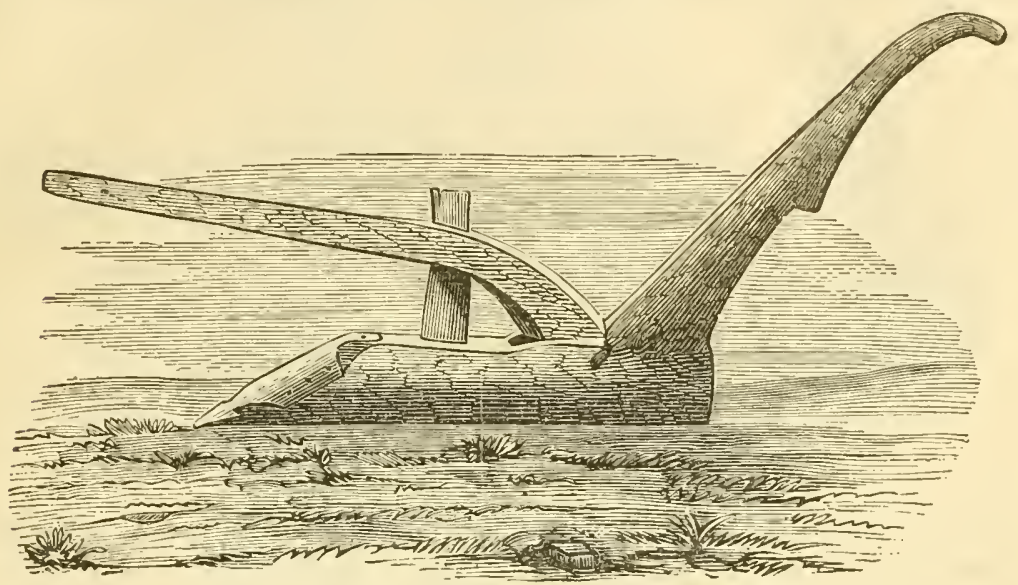

Fig. 9.

the Fourth, A. D. 1470. It is formed from a rhomboidal piece of wood, bent or grooved downward from the middle towards the front and rear, with the edges turned upward, the acute ends being turned towards the front and rear, the front being shoi

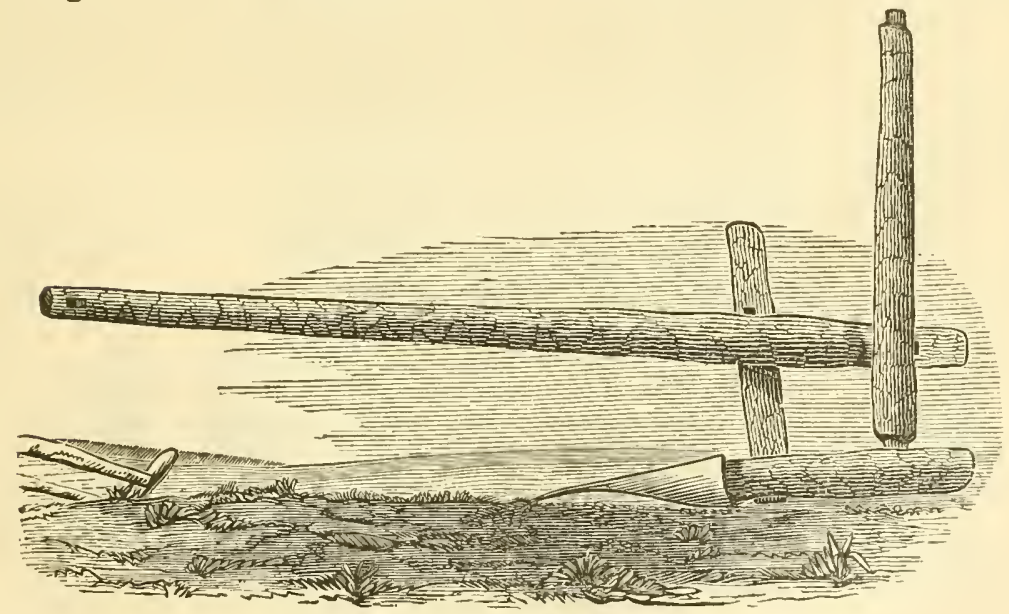

Fig. 10.

with iron. In this way the earth is scooped up from the solid earth, pushed backward and upward to the middle line of the share, when it falls backward in a pulverized state into the furrow from whence it was taken. 
Fig. 12 is taken from an old Saxon calendar, preserved in the Cotton manuseripts of the eleventh century, and used in the time of William the Conqueror. It was drawn by four oxen, and fastened to them by ropes made of twisted willows, and sometimes

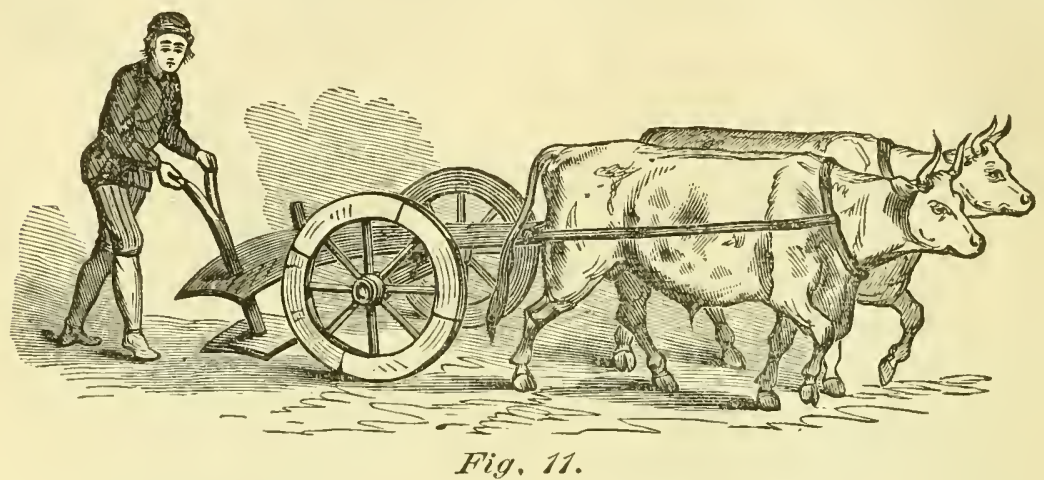

by the skins of whales. It consists of a simple wooden wedge covered with straps of iron, one side being placed parallel to the line of the plow's direction, the other swepping over to the left hand, clearing it from its own path, and leaving an unobstructed furrow for the next slice. A coulter, not unlike those now in use, is inserted in the beam, and a wheel is placed in front to regulate the depth.

We have met with nothing previous to this plate which shows a real coulter, or that which we now call by that name. Virgil's plow had none, nor were any of the Italian plows provided with one in Tull's day.

It will be seen from the two last illustrations that the idea of a wedge form for a plow had begun to dawn upon men's minds; some using the wedge aeting vertically, others laterally; but they

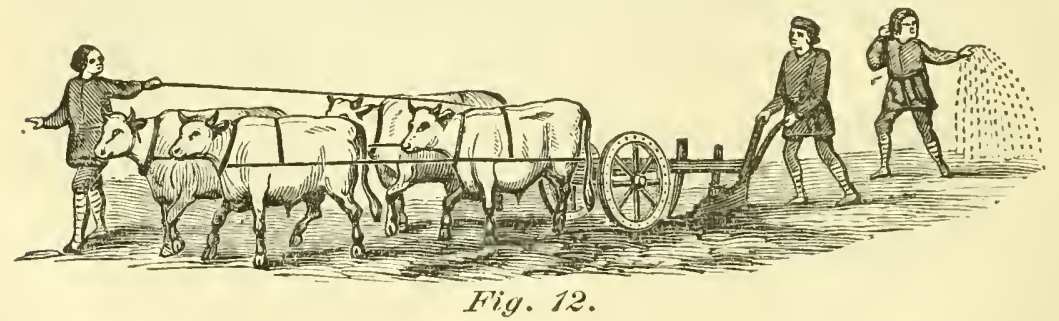

existed in the minds of plowmakers in too vague and misty a form to be of much practical benefit. No one had as yet grasped the idea of combining the two wedges in the same implement, nor had they any illea of the enres by which this could be effected. 


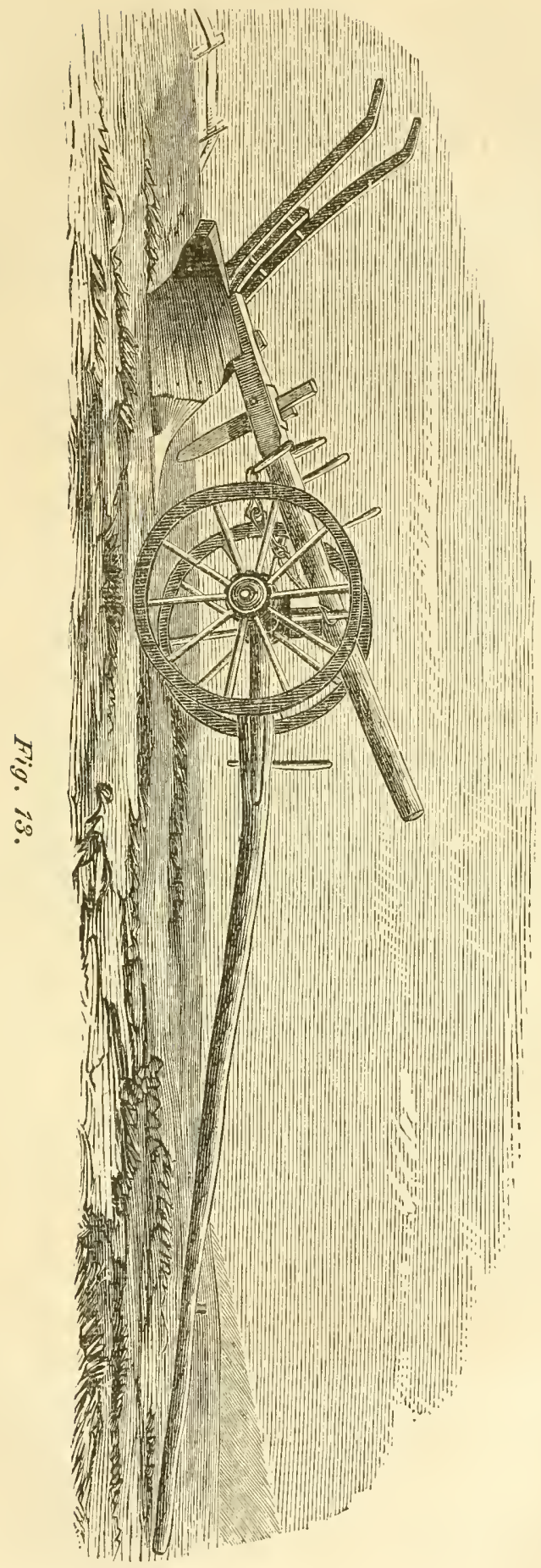


There is a plow now in the museum of the Society at Albany, from Canada, derived from France, which has been in use there unchanged for centuries, although no one knows how many, which seems to be the first feeble attempt to realize this idea. We give al drawing of it in Fig. 13.

It will be seen that this is the twisted wedge raising up the earth first and then twisting it to the right. It is furnished with two wheels to keep it steady in the furrow, and a coulter of the modern form. It is a rude affirir when compared with our modern implements, but it shows real genius in its author.

The begimning of the last century was signalized by a revival of interest in agriculture in England, and attention was more strongly turned to the improvement of the plow than ever before. A plow introduced from Holland, and known as the Rotherham plow (many persons suppose this name to be a corruption of Rotterdam), was first constructed by Joseph Foljambe of Yorkshire, which he soon after sold to Mr. Staniforth, who did not manufacture them himself, but charged a royalty of two shillings and sixpence on the manuficture by other's; but when he attempted to raise the price to seven shillings and sixpence, the validity of his patent was contested and set aside by the courts on the ground that it was not a new invention.

This plow became very popular among the more enterprising furmers; but notwithstanding its work was much better, and its draft was much lighter, it came very slowly into use among the masses.

Fig. 14, land side of Rotherham plow. Fig. 15, furrow side of Rotherham plow.

\section{DIMENSIONS OF THE ROTIERHAM PL.OW-FIa. 15.}

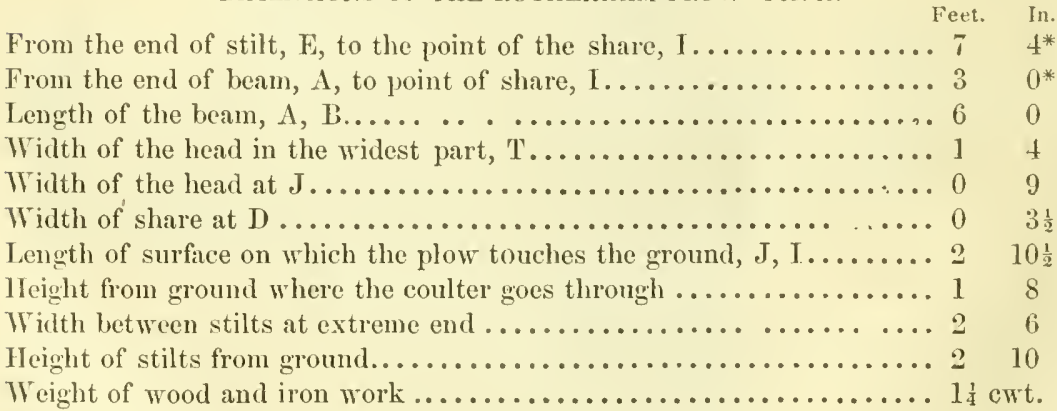

\footnotetext{
* These measures are taken by dropping a perpendicular to the plane of the sole, and then measuring horizontally.
} 
'This plow was made of wood, covered in the working parts with shcet iron, which needed frequent renewal. It is the first, so fal as we know, which provided a bridle, e, Fig. 16, by which the plow could be turned to or from land. The point is conical,

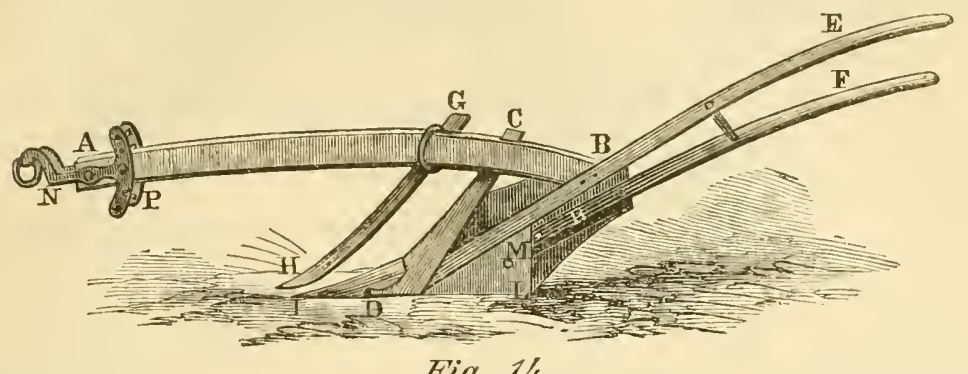

Fig. 14 .

which enters the laud on the principle of burrowing or mining, rather than by the clean chisel cut now adopted, which must have considerably increased the power required to operate it; still, a comparison of it with its predecessors shows that it must have

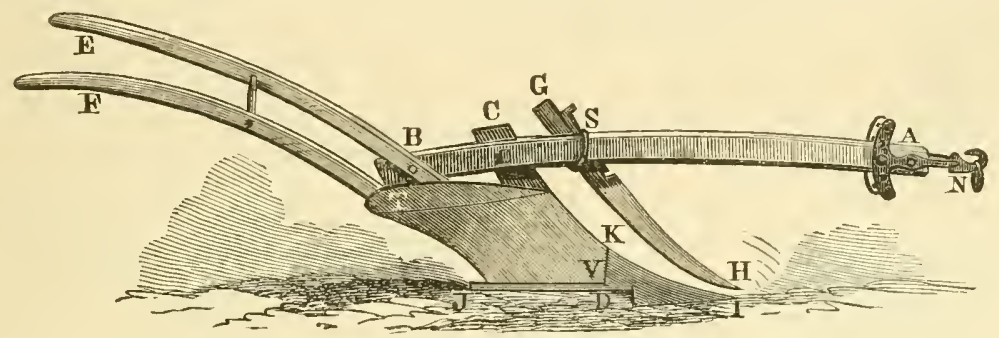

Fig. 15.

done much hetter work, and with less expenditure of power. It will also be seen, on examination of the mould board, that the maker had empirically approximated to the true theory, as the two wedges, lateral and vertical, are comnected by a curve line, so that the furrow slice is first raised a little and is then gradually turned over to one side.
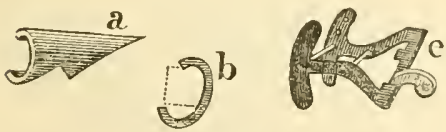

Fig. 16.

Ten years after the letter's patent were granted to Foljambe for the Rotherham plow, Jethro Tull pul). lished a work on "Horse-hoeing Husbandry," the first edition of which was published in 1730. In this work, althongh Tull was a thorough radical in the cause of agrieultural improvement, he gives the preference to the old Berkshire plow, which will be seen, on comparison with the Rotherham plow, to be far inferior 
to it in ease of management, in ability to do good work, and in lightness of draft.

We give this plow and its subordinate parts on Plate I, as illustrating the history of plows, and as a curious example of the slowless with which real improvements were adopted in agricultural communities. We may add, that Tull published another edition of his work in 1762 , thirty-two years after the introduction of the Rotherham plow, in which he still adheres to his preference for the old Berkshire.

Tull was strongly in favor of four coultered plows, such as is shown in Plate I, fig. 2. His eighteenth chapter is devoted to a dialogue between a farmer and himself, in which he gives his reasons for his preference of that form of plow. His chief reasons are briefly these: It divides the land more completely, affording greater access to air and moisture. The furrow being cut into four parts, it will have four times the superfices that it would have without the coulter cuts; but this is not all. "It is more divided crossways, viz: The ground wrest presses and breaks the lower (or right hand) quarter; the other three quarters, in rising and coming over the earth board, must make a crooked line about a fourth longer than the straight one they made before moved; therefore, their thinness not being able to hold them together, they are broken into many more pieces for want of tenacity to extend to a longer line, contrary to a whole furrow, whose great hreadth enables it to stretch and extend from a shorter to a longer line without breaking; and, as it is turned off, the parts are drawn together again by the spring oi the turf, and so remian whole after plowing."

The objects which Mr. Tull sought to accomplish were rery desirable, but the four coultered plow was never very generally adopted; and as the same objects have been since accomplished in a far more simple and philosophical manner, it has fallen into utter oblivion.

Fig. 1 represents the old Berkshire plow, pure and simple. The plow head consists of a pair of wheels, A B, and their axis. Two crow staves, D D, through which two rows of holes are perforated, by means of which the pillow, F, upon which the heam rests, is elevated or depressed. $H$, the tow chain which fastens the plow to the head. I, the bridle chiin, one end whereof is fastened to the beam by a pin, and the other end to the top of the stake, which is held up to the left crow staff hy the ring M. 


\section{Plate I.}
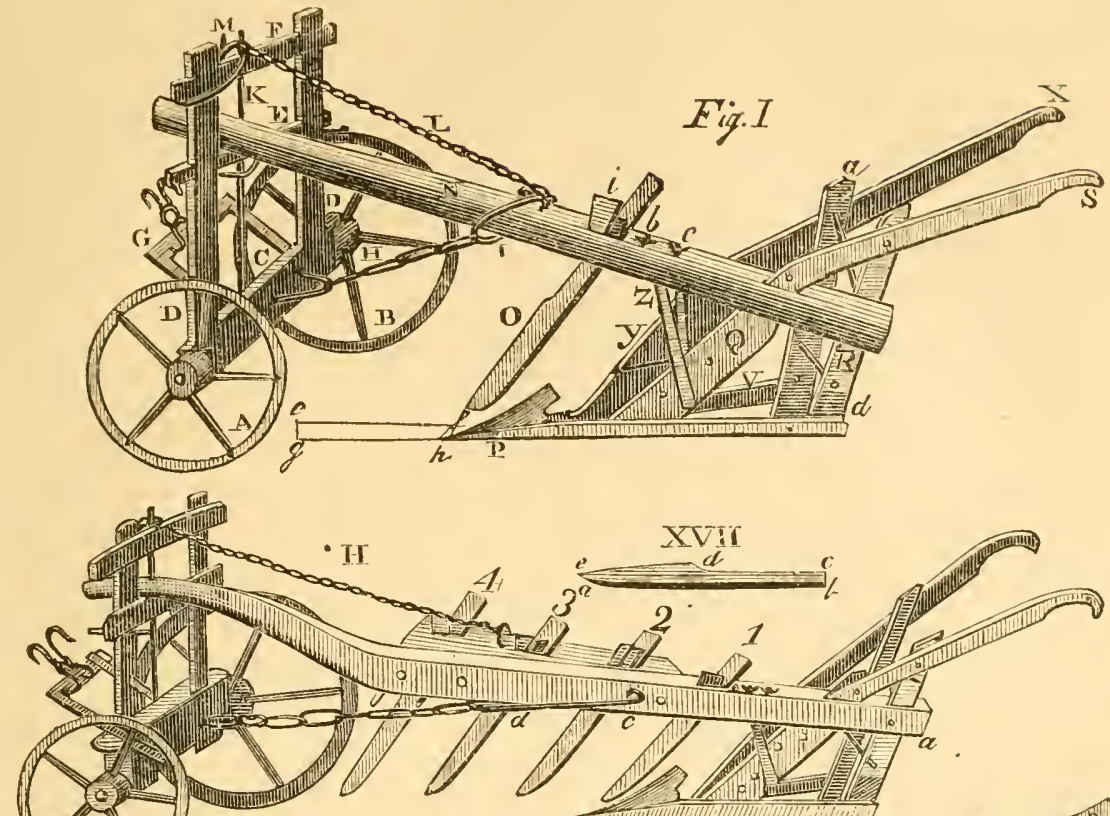




\section{Plate II.}

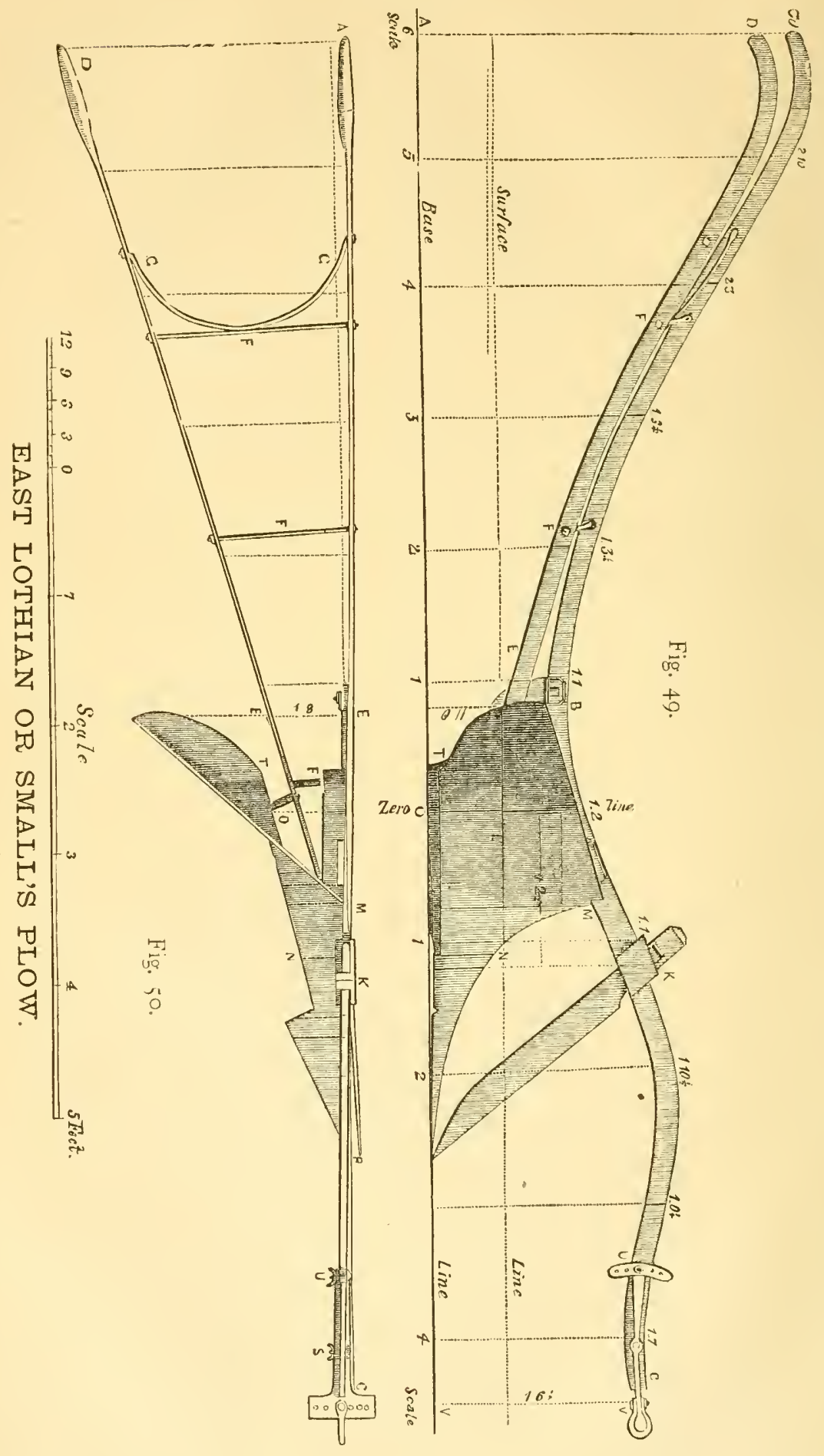


The plow tail consists of the heam, $N$, the eoulter, $O$, the share, $P$, and the sheat. Q; the hinder sheat, $R$, passing through the hoam near its end. $T$, the drock which belongs to the right side of the plow tail, and whereto the ground wrest, V, is fastened, as is the earth board, whose fore part, $W^{T}$, is seen before the sheat. $Z$ is the double retch which holds up the sheat.

Wre have retained the antiquated nomenclature of Tull in this description, as these words are still retained in some English works, and would not be understood by American readers without a plate with references were before them.

Fig. 2 represents the four coultered plow recommended by inll. The beam differs in length from the former one, being ten feet four inches long, or two feet four inches longer than the other. It differs also in shape, being only straight from $a$ to $b$, from thence curving suddenly upward, as shown in the figure. The perpendicular height at $a$ is eleven inches, at $b$ one foot eight inches, while the height of the bean where it rests upon the pillow is two feet ten inches above the plane of the sole.

From the end $a$ to the back part of the first coulter is three feet two inches; from thence to the back of the next conlter is thirteen inches; from thence to the fourth is the same. From $a$ to $b$ is seven feet.

'The beam is made of ash or oak, and is five inches deep and four inches broad at the first coulter.

Fig. 4 is the sheat, seven inches broad, with the iron retch upon it, the left leg of which must stand foremost. The ends pass through the beam, and are secured on the top by nuts; the sheat is also mortised into the beam and secured by a pin passing throngh the hole $a$. The angle $b c d$ must always be less than 45 deg.; from 42 deg. to 43 deg. works best in practice.

Fig. 5 is the share, $a$, the end of the point; $b$ is the tail of the share; length. from $a$ to $b$ is three feet nine inches; $c$ is the $f i n$; $d$ the socket into which the bottom of the sheat enters; $e$ a thin plate of iron to which the hinder sheat is riveted. From a to $f$ is the point, three and a half inches long, flat beneath and round above. From $f$ to $c$ is the edge of the tin, which should be of steel.

Fig. 6 shows the share with its right side upward as when plowing; the side $a b$ should he perfectly straight, but its under side, $c$, should be a little hollow. 
Fig. 7 is the share turned bottom upward, showing concavity a of the fin, which must be greatest in a stony, rubbly soil.

Fig. 8 shows the share right side upward, but leaning towards the left.

Fig. 3 shows the upper and right side of a four conltered plow, of which $\mathrm{V}$, the iron ground wrest, is shown in Fig. 9; it is two feet five inches long, four inches deep at the end $b$, and threeeighths inch thick, except at the end $a$, where it is thin enough to bend so as to set close to the share, as at $e$, fig. 6. The ground wrest has four small holes near its end, $a$, into one of which a nail is inserted, which fastens it to the sheat through the long hole in the side of the socket of the share, as at $a$, fig. 10, when it will stand in the position $e f$ in fig. 6. From the outside of the ground wrest at $f$, to the outside of the share at $b$, is eleven and a half inches. The ground wrest has several holes at the upper side of its broadest end, as at $b$, in fig. 9 , by which it is nailed to the lower part of the drock $\mathrm{T}$, as in fig. 3 , which drock, with its perforations, is shown in fig. 11

Fig. 12 is the earth board (monld board), with its inside upwards; the noteh $a b$ shows the rising of the wood which takes hold of the sheat, to which it is fastened by the holes $c$ and al, and at the other end it is fastened to the drock by the hole $e$; all which is seen at $W$, in fig. 3 . The pin with which it is fastened to the drock is larger in the middle than at either end, which prevents the earth board from coming near the drock; by this pin the distance between them is regulated, so that the rear end of the earth board may be thrown inward or outward, according to the requirements of the soil.

Fig. 13 is the long handle, five feet four inches long, and four inches in the widest part; it is pinned to the sheat through the holes $a b$, and to the drock through the hole $c$.

The short handle, $\mathrm{S}$, is fig. 14; is three feet nine inches long. and is pinned to the hinder sheat, fig. 15 , by the hole $\alpha$, and to the top of the fore sheat above the beam by the hole $b$.

Fig. 16 is the piece for the mortises in which the coulters are inserted; the lateral distance between them is two and a half inches. The fore part of every mortise should incline a little to the left, so that the backs of the conlters may not bear against the lett side of the incisions made by their edges. In setting the coulters, each should stand nearer to the perpendicular thatn the 
one behind; or, in other words, the forward coulter should have the least rike, and the rear coulter the most.

Fig. 17 is a coulter, $a b$; its length is two fect eight inches, $e$ $l$; its edge is sixteen inches long, $d c$; the length of its liandle is sixteen inches, one and seven-eighths inches broad, and seveneighths inch thick.

Fig. 18 is a nut with its two opposite corners turned up so as to be driven by a hammer.

Fig. 19 is an iron collar (bridle) by which the tow chain is finstened to the beam, as seen at $a$, fig. 3 . The notches are intended to facilitate the direction of the share to or from land. The length of each side of this collar is one foot.

The tow chain is shown in fig. 3 , where the link $\mathrm{Y}$ is secured by the stake, as shown in fig. 1 .

Fig. 20 is the iron wilds. The distance between the two legs is eight and a half inches; their length is nineteen inehes. Its position is seen in figs. 1 and 2; the notches are intended to give a broader or narrower furrow. $\mathrm{E}$ is the ring by which the two links and the two crooks, F and G, are held together, and on which they all move.

The diameter of the left wheel in fig. 2 is twenty inches; of the right, two feet three inches; their distance asunder is two feet five and a half inches.

The crow staves are one foot eleven inches high from the box to the gallows, and their distance apart is ten inches. The height from the plane of the sole to the hole in the box where the tow chain passes through it, is thirteen inches, which is two inches below the holes of the wilds on the rear face of the box. The height at the other end, where the crook of the collar takes hold of the pin of the beam at $c$, fig. 2 , is twenty inches high.

No other noticeable changes were made in the plow until near the beginning of the present century, when the conviction that there was a real law of nature which onght to regulate the shape of the plow, began in a vagne and misty way to take possession of men's minds. They felt instinctively that the implement was too complicated and cumbrous, and that it was quite possible to simplify it and to diminish its draft.

One of the earliest laborel's in this field was Thomas Jefler'son, late President of the United States, who, in a communication to the French Institute, attempted to solve the mathematical problem 
of the true surface of the mould-board, and to lay down intelligible and pratical rules for its formation, for the first time.

He saw very clearly, and we believe he was the first to discern it with distinctness, that the plow should consist of two wedges, one acting vertically and the other laterally, which should be so blended in a curve surface that the furrow should rise and turn over smoothly and continuously.

It is impossible to over-estimate the value of this contribution to agricultural seience. All the old writers complain that when the makers of good plows died, their art died with them. Their plans being purely empirical, they could not communicate the true mode of making them to others, and henee the art was lost as fast ats it was found. Indeed, the same maker was often unable to realize his own ideals in practice, making at one time a plow that gave perfeet satisfaction, and the next time one that was very inferior. Thus, Arthur Young tells us in his agrieultural report of Suffolk, that "a very ingenions blacksmith of the name of Brand" made a plow of iron, of which he says "there is no other in the kingdom equal to it;" and yet when he died no one else could make them. A drawing of this plow is given in Fig. 17.

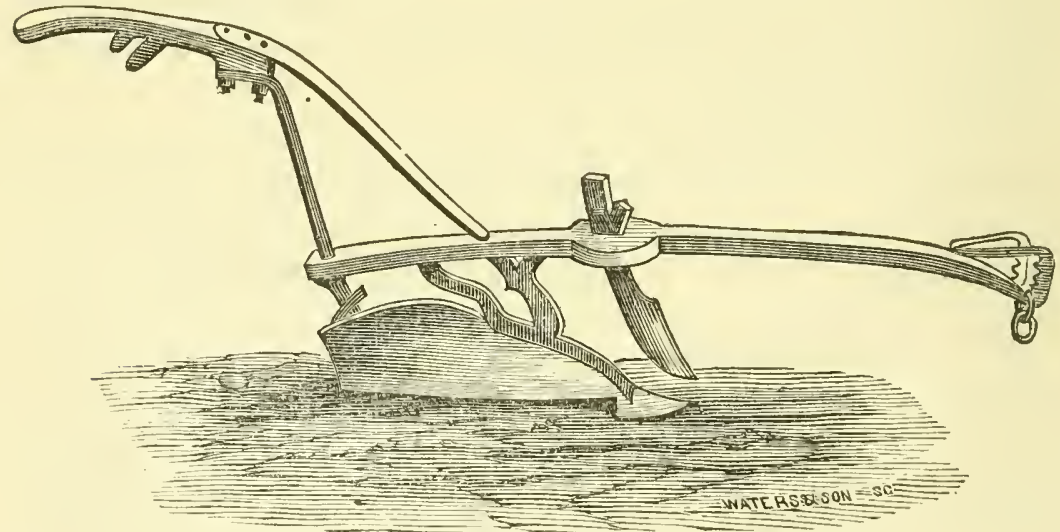

Fig. $1 \%$.

It was usual for the farmer to purchase the wooden part of his plow of a mechanic called the plow-wright, which he afterwards hat ironed by a blacksmith. Neither of these men paid any regard to the views of the other; the plow-wright made his part according to the comsel of his own will, while the blacksmith adhered to his own notions without the slightest reference to the plans of the plow-wright. The result was an implement, as a 
whole, which had no unity of plan, and the discordant parts could not, therefore, he expected to accomplish satisfactory results.

In view of these great difficulties in the way of making uniformly good plows, it must be almitted that the discovery of Mr. Jefierson, by which mould-boards conld be made by any one with the absolute certainty of llaving them all exactly alike, was an era in agriculture, and the root of all real progress in the manufacture of this all-important implement.

We have therefore thought that it would be desirable to give a full description of his method, which we hope will prove intelligible to every one who desires to understand it.

In order to obtain a clear idea of the curve of the monld-board which Mr. Jefferson considered to be the best, we give his ideas in his own words, except that we shall take the liberty of changing the antiquated names given by him, for those which are used to designate those parts at the present day:

"The mould-board of the plow ought not only to be the continuation of the shicld of the share beginning at its posterior edge, but it must also be in the same plane. Its first function is to receive horizontally from the sock the earth, to raise it to the height proper for being turned over; to present, in its passage, the least possibie resistance, and consequently to require the minimum of moving power. Trere its function confined to this, the wedge would present, no doubt, the properest form for practice; but the object is also to turn over the sod of earth. One of the edges of the mould-board ought then to have no elevation, to avoid an useless wasting of force; the other edge ought, on the contrary, to go on ascending until it has passed the perpendicular, in order that the sod may be inverted by its own weight; and the inclination of the mould-board must increase gradually from the moment that it has received the sod.

"In this second function the mould-board then acts like a wedge situated in an oblique direction, or ascending, the point of which receles horizontally on the earth, while the other end continues to rise till it passes the perpendicular. Or, to consider it under another point of view, let us place on the gromnd a wedge, the breadth of which is equal to that of the share of the plow, and which in length is equal to the share from the wing to the posterior extremity, and the height of the heel is equal to the height of the rear of the share above the sole: draw a diagonal on the upper surface from the loft angle of the point to the angle on the 
right of the upper part of the heel; slope the face by makng it bevel from the diagonal to the right edge which touches the earth: this half will evidently be the properest form for discharging the required functions, namely, to remove and turn over gradually the sod, and with the least force possible. If the left of the diagonal be sloped in the same manner, that is to say, if we suppose a straight line, the length of which is equal at least to that of the wedge, applied on the face already sloped, and moving backwards parallel to itself and to the two ends of the wedge, at the same time that its lower end keeps itself always along the lower end of the right face, the result will be a curved surface, the essential character of which is, that it will be a combination of the principle of the wedge, considered according to two directions, which eross each other, and will give what we require, a mould-board presenting the least possible resistance. This mouldboard, besicles, is attended with the valuable advantage that it can be made by any common workman by a process so exact that its form will not vary the thickness of an hair. One of the great faults of this essential part of the plow is the want of precision, because workmen having no other guide than the eye, scarcely two of them are similar. One may easily conceive and render sensible the manner in which the sod is raised on the mouldboard which we have described, by an attentive consideration of the following diagram, Fig. 18.

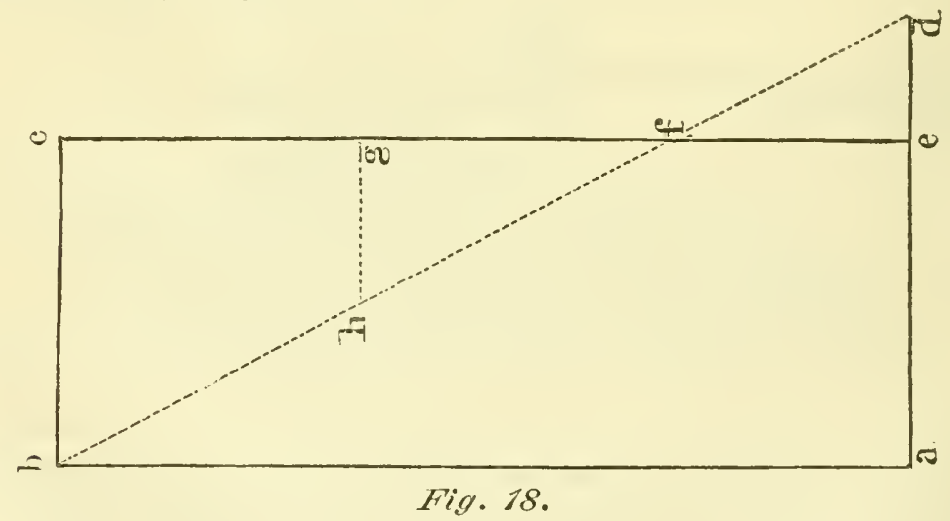

Draw on an horizontal plane or parallelogram, $a b c f e$ the lines $a b$ and $c e$, being each $=$ to twenty-four inches, = the leugth of the mould-board, and the lines $b c, d e$, each $=$ nine inches, $=$ the width of the sole at the heel of the plow, produce the line a $e$ to $d$, and make $e d$ four and a half inches, this being the overhang 
of the rear end of the mould-board beyond the perpendicular which Mr. Jeflerson thought the most convenient length in practice.

At the point $d$ erect a straight stick twelve inches long, which is twice the depth of the proposed furrow; then from the point $b$ streteh a string tightly to the top of the stick at $d$. When this is done, take a straight edge twelve inches long, and placing it on $b c$. where it will rest horizontally and will coincide with the plane of the parallelogram, move it backwards towards the line $a d$, keeping the point of the edge which was at first eoineident with the point $c$ along the line $c e$, and always preserving the parallelism of the edge with the vertical plane of $b c$, it is evident that as the edge resting on the diagonal $b d$ moves backwards, the end which at first coincided with $b$ will rise upward, and every successive removal towards the line $a d$ it will assume a larger angle with the horizontal plane. When the end which was at $c$ arrives at the point $g$, and the corresponding part of the edge is on the string at $h$, the line $g h$ will form an angle of forty-five degrees with the horizontal plane. When the end of the stick stands on the point $f$, and the edge coincides with $f$ on the string, the stick will be exactly perpendicular to the plane: passing on in the line $f e$, towards $a d$, the angles will assume an opposite direction, so that when the end of the moving stick rests upon $e$, and the edge rests on the string at $d$, it will make an angle with the plane of $110 \frac{1}{2}$ degrees. When the path of the straight edge from $b c$ to $e d$ is attentively considered, it is evident that it will have described a curved surface, which is the ideal of what we seek to reproduce in wood.

Let us assume that the depth of the furrow is six inches, its width nine inches, and the length of the mould-board two feet, these figures will decide the size of the block from which the mould-board must be cut.

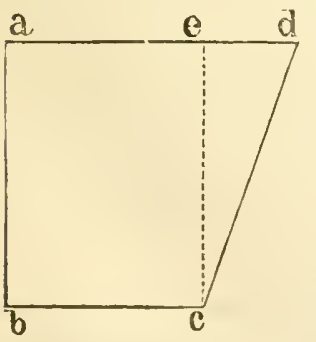

Fin. 19.

The transverse section of the block, Fig. 19, will then be nine inches at the base $b c$, thirteen and a half inches at its summit $a d$, and twelve inches at the side $a b$. The line $b c$ must be nine inches, because hat is the width of the furrow. The line $a b$ is placed at twelve inches, becanse Mr. Jefierson found that unless the height of the monld-board was twice as great ats the furrow (which we 
have assumed to be six inches), the earth, when the soil was friable and sandy, would rise up over the edge of the mould. board like waves, and fill the furrow behind the plow. It will he seen, however, since in the progress of discovery we havo obtained a much better form of mould-board, there is no recessity tor this great excess of height. The line $a d$ is taken at thirteen and a half inches, because in his opinion it was essential for the rear end of the mould-board to project four and a half inches

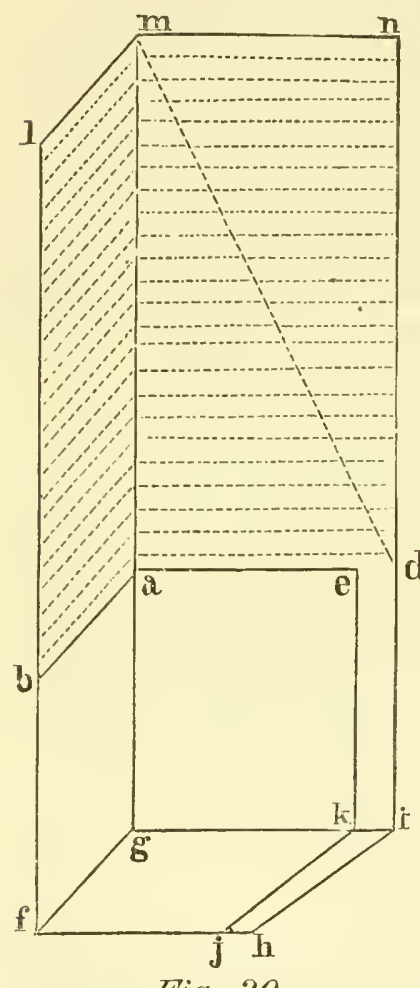

Fig. 20. beyond the perpendienlar, in order to make the sod fall on to the preceding slice by its own gravity. It is possible that this amount of inclination from the perpendieular would be sufficient to effect the object on level land, but it requires a much greater lateral projec tion to make the sod fall properly when the furrow is turned up hill. Mr. Jefferson's line of inelination is twenty and one-half degrees; modern practice, founded on the necessity of the case, g gives an inclination not less than fortyfive degrees.

A block having a transverse section, as in Fig. 19, and three feet long, is taken and smoothly planed on all its sides. This block is represented in Fig. 20. The first operation consists in torming the tail, by which the mouldboard is affixed to the stilt or hamcle, by sawing across from $a$ to $b$, on its left side, and at the distance of twelve inches from the end, $f g$; continue the cut perpendicularly aloug a $e$, until the edge of the saw comes to a line one and a hall inches above the side $n i$; then taking $k i, j h$, each equal to one and a half inches, and saw across the line $j k$, along the line $k e$, parallel to the right side. The piece $b$ a e $k j f g$ will fill of itsclf and leave the tail, $k$ e $d i h j$, an inch and a half in thickness. It is of the anterior part, $b$ a e $d \quad l m n$, lhat the mouldboard must be formed.

By means of a square, trace out on all the fices of the block, lines at an inch distance from each other, of which there will 
necessarily be twenty-three; then draw the diagonals, m d, Fig. 21 ,

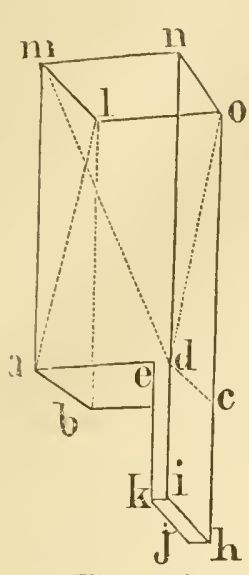
on the "lpper face, and $d o$ on that which is situated on the right; make the saw enter at the point $m$, directing it towards $d$, and making it descend along the line $m l$, nutil it marlis out a straight line between $d$ and $l, \mathrm{~F} \ddot{i} \underset{2}{ } .22$. Then make the saw enter at the point $o$, and preserving the direction o $l$, make it descend along the line $o l$, until it meets with the central diagonal, $d l$, which had been formed by the tirst cut; the pyramid, $m$ n $l d$, Fig. 23, will drop out by itself and leave the block in the form lepresented by Fig. 22.

Fig. 21.

It is here to be observed, that in the last operation, instead of stopping the saw at the central diagonal, $d$ l, if we had continued to noteh the $\mathbf{m}$ hlixk, keeping on the same plane, the wedge 1 m n o d a, Fig. 21, wonld have been taken away, and there would have remained another wedge, $l$ o $d a b$, which, as was observed before, in speaking of the principle in regard to the construction of the mould-board, would exhibit the most perfect form, were the only object to raise the sod; but as it must also be turned over, the left half of the upper wedge has been preserved, in order to continue on the same side the bevel to be formed on the right half of the lower wedge.

Let us now proceed to lay down the means of

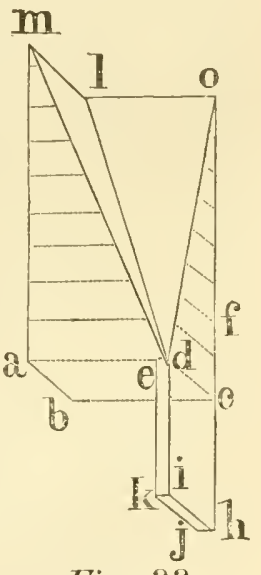

Fig. 22. producing this bevel; in order to obtain which we

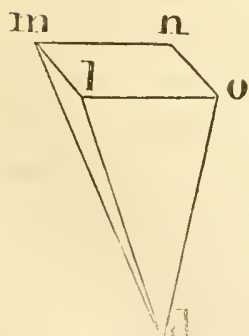

had the precaution to trace out lines around the block before we removed the pyramid, Fig. 23. Care must be taken not to confound these lines, now that they are separated by the vacuity left by the removal of that pyramid, Fig. 22.

Bearing in mind that the line $a d$ is thirteen and a half inches in length, the line $a b$ is twelve inches, the line $l c$ or $l o$ is nine inches in length

Fig. 23. and that the line $d c$ slopes downward and inward towards the left hand, as shown in Fig. 19. We make the saw enter in the two points of the first dofted line situated nearest to 
$m$ and $o$, Fig. 22, and on the diagonals $m d$ and $o d$, continuing the stroke on that first line till it reach on the one hand the central diagonal $d l$, and on the other the lower right edge, $o l l$, of the block, Fig. 22; the posterior end of the saw will come ont at some point situated on the upper trace in a straight line with the corresponding points of the edge and the central diagonal. Continue to do the same thing on all the points formed by the intersection of the exterior diagonals and lines traced out around the block, taking always the central diagonal and the edge $o h$, as the term and the traces as directors; the result will be, that when you have formed several cuts with the saw, the end of that instrument, which came out before at the upper face of the hlock. will come out at the face situated on the left of the latter; and all these different cuts of the saw will have marked out as many straight lines, which, extending from the lower edge, $o h$, of the block, will proceed to cut the central diagonal. Now, by the help of any proper tool, remove the sawn parts, taking care to leave visible the traces of the saw, and this face of the mouldboard will be finished.

An attentive consideration of the processes which have been gone through with the block, Fig. 22, will show that they are precisely equivalent to those described in elucidating Fig.18; the diagonal, $d l$, in the first, corresponds with the diagonal $b d$ in the second, and the line $o h$ in the one corresponds with the line $c e$ in the other.

It must not be forgotten that the point $d$ overhangs the point $c$ four and a half inches towards the right; hence there will be a point in the line $o h$, at $f$, which will be exactly vertical on the diagonal $d l$, it is obvious that in sawing the traces bewteen $f$ and $o$, the point of the saw will be directed upward and forward towards the line $a \mathrm{~m}$. At $f$ it will be directed vertically upward, and after it passes the point $f$, towards $c$, it will be directed lownwards and backwards towards the line $b l$; the saw marks which are left on the face of the mould-board are the representatives of the successive positions of the twelve-inch stick as it was progressively moved backward in a line parallel to itself from $c$ towards $e$, in Fig. 18.

It now remains to construct the opposite side of the mouldboard so as to be parallel at all points with the face. Invert the block, and make the saw enter at the points where the line $b l$, Fig. 24, meets with the traces, and remembering that the side, 


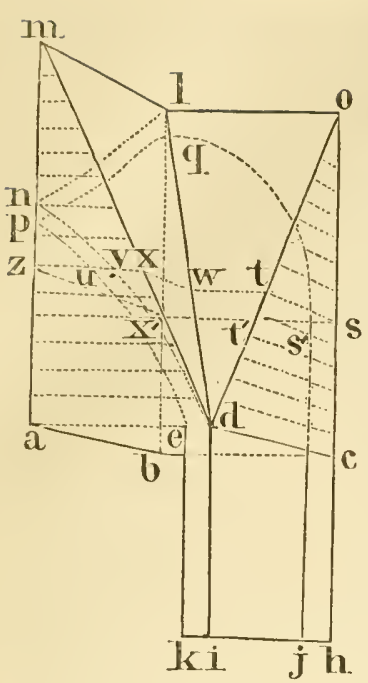

Fig. 24.

ab $\mathrm{ml}$, which in Fig. 22 laid vertically and to the left of the block, now lies downwards on its fice, while the side of the wedge $a d m$ ( $a d$ being thirteen and a half inches) now lies vertically and is on the left sicle of the block; now continue the stroke along these traces until both encls of the saw approach within an inch, or any other convenient distance of the finished face of the mould-board. When each of the traces have been thus sawn through, remove the sawn parts with some convenient tool, as before, and the mould-board is finished.

Any one who will have the patience to fix in his mind carefully the line left by the saw when its posterior end rests in the line $o h$, and its anterior end on the diagonal $d l$, through each of the twenty-three traces made upon the block, will be enabled to conceive of the exact twist of the surface of the mould-board; yet as some minds have a difficulty in realizing such warped surfaces, we give another method which may be more clear to such readers.

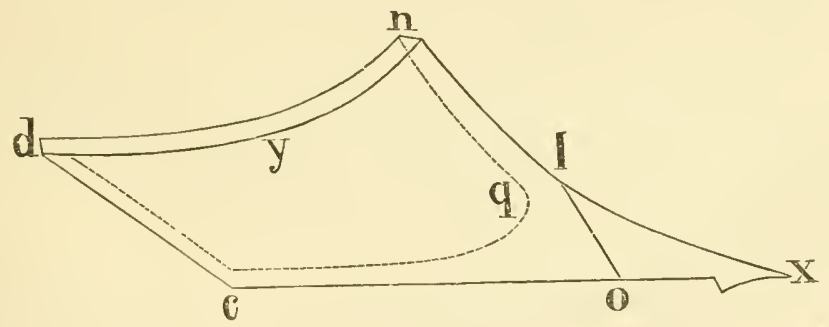

Fig. 25.

Suppose the saw cuts the lines $m d$ and $o d$, Fig. 24, in the points $x$ and $t$, in the traces $x \approx$ and $t s$, parallel to $a b b o$, and the prolongations of which on the triangles $m d l$ and $l d$ are the lines $x$ and $t w$; the saw must then penetrate the block, remaining in the same plane in question, until its point has reached the point $s$, and at the same time touch the point $w$ of the central diagonal $l l$. The fore end of the saw will come ont at some point, $y$, of the face $a m d$, so that three points, $s w y$, will be in the same straight line. But if this operation be repeated in different places of the lines, $m a$ and $o d$, bringing the edge down 
along the traces to the line $o h$, at the rear, and the line $d l$, in front, the fore part of the saw will come out on the fice, $a m d$, as we go on towards $c$, at constantly varyng elevations above the line $a \mathrm{~m}$. If we now connect the points thus made by the saw on the face, $a m d$, the line traced between them will be the line . y $d$, Figs. 24 and 25. Beyond this height the saw, directed in the same manner, will come out at other points situated on the posterior face, $a b \mathrm{ml}$, and a line connecting these points, as lhefore, will form the second of these curves on both figs., $n, l$, which will meet the first in the point $n$.

These two curves being traced out, let us suppose straight lines drawn to the places where the saw stopped each time that it touched the diagonal, $d l$, and of which one, as already said, passes through the points $s w y$; and let us conceive a surface touching all these straight lines, and whose limits, on the one hand, shall be the curves $d y n, l n$, and on the other the line $o l$, this surface, which must be uncovered by sections made with a proper instrument, will form one of the faces of the mould-hoard, which is represented by $d n l$ oc, Fig. 25 , where $c y$ represents the perpendicular and the point $d$ curves over towards the spectator four and a half inches beyond the point $c$. The share, $l o x$, has been arlded to show how the plow looks when finished.

To make the opposite face of the mould-board, the thickness thereof having been determined by the thickness of $d e k i$, Fig. 24 , at one and a half inches, let us first conceive that there has leen traced out, proceeding from the point $e$, the curve $c u p$, parallel to $d y n$, and then proceeding from the point $p$, the curve p) $q$, parallel to $n$.

Let us next suppose that the saw cuts the edge $l l$ of the fice $b$ a $m l$ in the point $x^{\prime}$, situated in the same plane as $z x, t s$, which plane has been taken, for example, in regard to the anterior face of the mould-board. The saw must be directed along the traces $x^{\prime} z$ and $x^{\prime} s$, in such a manner that its motion shall stop at the term where its edge, on the one hand, shall tonch the curve $e p$, in the point $u$, situated on the trace $x z$, and, on the other, shall be situated parallel to the line $s w y$, at which the saw stopped on the other side of the mould-board. The edge of the saw will then cut the face of $b l o c$, in some point $t^{\prime}$, so situated that the straight line drawn through that point and the point $u$, shall be parallel to the straight line which passes through the point $s w \%$. If you continue cutting in the same numner, with the saw, difler- 
ent points of the edge $b l$, those by which it comes out will form, on the face $b l o c$, a curve $j s q$; and if, through these points and those corresponding to them in the lines $e p$ and $p q$, there will be drawn straight lines, such as that which passes through z and u, which we have taken as an example, the surfice touching these straight lines, and, uncovered by means of any sharp instrument, will form the remainder of $j l$ o $l q t^{\prime}$ of the plane $b l$ o $c$, being the opposite side of the mould-bond.

It is fixed to the plow by mortising the fore part, o l, Fig. 25, into the posterior end of the share, which must be male double, like the handle of a pocket comb, that it may receive and secure this fore part of the mould-board. A screw nail is then made to pass through the monld-board and the handle of the share at the place of their contact, and two other screw nails pass through the tail of the mould-board and the right handle of the plow. The part of the tail which passes beyond the handle must be cut diagonally, and the work will be finished.

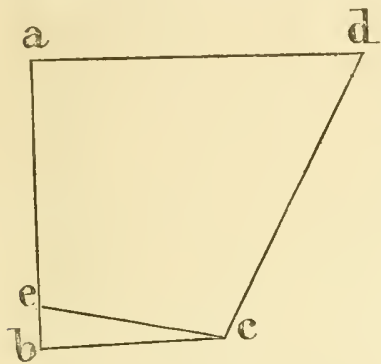

Fig. 26 .

a We have thus given the plan of forming the mould-board in full detail, so that the principle of its construction may be clearly understood; but Mr. Jeflerson found, in actual practice, that some modifications of it might be usefully made. Thus, he says: "Instead of beginning to form the block as represented by $a b c d$, Fig. 26, where $a b$ is twelve inches in length, and the angle at $b$ is a right one, I cut off towards the bottom and along the whole length, $b c$, of the block a wedge, $b$ ce the line $e b$ being equal to the thickness of the bar of the shate (which I suppose to be one and a half inches); for, as the face of the wing inclines from the bar to the ground, if the block were placed on the share, without taking into the account this inclination, the side $a b$ would lose its perpendicular direction, and the side $a d$ would cease to be horizontal. Besides, instead of leaving at the top of the block a breadth of thirteen and a half inches from $m$ to $n$, I remove from the right side a kind of redge, $n d i c p$, of one

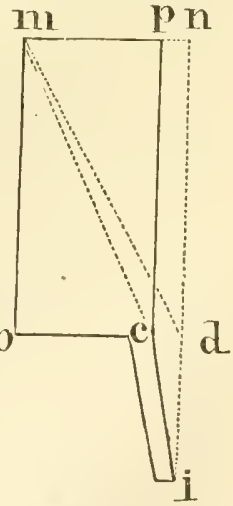

Fig. $2 \%$. and a half inches in thickness, Fig. 27; because experience has 
shown me that the tail which, by these means, has become more oblique, as $c i$, instead of $d i$, fits more conveniently to the side of the handle; the diagonal of the upper face is consequently removed back from $a$ to $c$, and we have $m c$, instead of $m d$, as ahove. These modifications may be easily comprehended by those acquainted with the general principle."

This method, devised by Mr. Jefferson, removing, as it does, the formation of the plow out of the domain of empiricism, and enabling workmen in different sections of the country, without communicating with each other, to form their mould-boards precisely alike, was one of the most valuable contributions towards the perfecting of plows that has ever been made by any one man, and will always entitle bim to a conspicuous place among the benefactors of agriculture.

But the eredit that we award to him must be confined to the service which he rendered in demonstrating that plows could be made by rule, and to the actual discovery of one of the many rules that are applicable to the formation of the mould-board.

A very slight examination of Mr. Jefferson's method will show its very great defects. For instance, the overhang of the wing to the right, $e d$, Fig. 19, is only four and one-half inches. This would only be sufficient to turn the furrow slice, when it was turned down hill, or, on some soils, it would answer on a level, but, on other soils, it would be quite insufficient to invert the slice, while it would be sure to tumble back into its original position when the furrow was turned up the hill. Modern practice shows that no plow ean be safely relied on to invert the furrow where the overhang is less than forty-five degrees.

To make this angle, the line $e d$, Fig. 18, must be made twelve mehes instead of four and a half inches. Then, to complete the plow, according to Mr. Jeflerson's rule, the perpendicular $f$ ' would be advanced six inches towards $c$, and the line $g h$ would be carried forward, so that it would stand within five and a quarter inches of the point $c$. It will be very obvious that such a degree of bluntness would be impracticable without an expenditure of power which no farmer could aflord to throw away. In other words, the rule is only applieable when we have an impracticable rear wing to the mould-board or an impracticable share.

The lower edge of the mould-board is quite too long, increasing the friction very unnecessurily. In our best modern plows the 
rertical sections of the mould-board are either concave or convex, aceording as the soil is too light or too stiff. The vertical sections of Mr. Jefferson's would be all rectilinear, which are not as fuvorahle fol good and easy plowing as curves.

The straight diagonal line, $m d$, used as the generator of $\mathrm{Mr}$. Joflerson's twisted surface, should have been a curve instead of a straight line.

The reception of the frout edge of the mould-board into a cavity in the posterior edge of the share, and secured by a single serew nail, suggests great weakness where great strength is required. The comnection of the tail of the mould-board with the handle, hy two screw nails, is quite too weak a conrection, and would of itsclf condemn the plow in modern markets.

Mr. Jeflerson seems to have confined his attention solely to the monld-board, overlooking the sole, the land side, the position of the beam and cutter, with reference to the plane of the land side altogether. It will be seen, as we advance, that these points are all of radical importance, and that no perfection of the mouldboard can compensate for their defects.

At the conclusion of his paper he says that, having satisfied himself that the plan that he has laid down is the best, he proposes in future to have his mould-boards made of cast iron. This is the first allusion that we have met with in an American author to the use of cast iron for the plow. If we are correct in this, it adds areatly to his eredit.

The nirst of any idea, on $\mathrm{Ir}_{\mathrm{r}}$. Jefferson's part, of improving the plow, which Mr. Randall finds among his papers, is contained in his journal of a toul in Germany, made in the year 1788, when he was American Ambassador in France. In passing through Lorraine, along the banks of the Meurthe, he frequently alighted to observe the teams and the implements of the farmers who were engaged in plowing by the wayside. Some of the plows thus examined were more remote from the improved forms of the present day than those traced in the hieroglyphics of early Egypt. Stopping for a night at Nancy, the capital of the ancient dutehy, he made an entry in his jommal, from which the following is an extract: "Oxen plow here with collars and hames. The awkward figure of their mould-boards leads one to consider what should be its form. The offices of the mould-board are to receive the soci after the share has eut under it, to raise it gradually and 
to reverse it. The fore end of it should therefore be horizontal, to enter under the sod, and the hind end perpendicular, to throw it over; the intermediate surface changing gradually from the horizontal to the perpendicular. It should be as wide as the furrow, and of a length suited to the construction of the plow." He then gives diagrams and descriptions, which have already been described in detail. The entries in the journal show that the whole plan was at that time clearly developed in his mind.

When he resided in Philadelphia, as Secretary of State nnder General Washington, he consulted the celebrated David Rittenhouse as to whether his proposed plow was founded on mathematical principles, and Mr. Rittenhouse, after a carceful examination of the whole question, male that fict demonstrable.

In $1793 \mathrm{Mr}$. Jefferson, as we are informed by Mr. Randall, put his theory to the test of practical experiment. He had several plows made after his patterns, and put into use on his estates, in Albemarle and Bedford counties, in Virginia, and became fully satisfied of their practical utility.

Mr. Strickland, a member of the English board of agriculture, travelled in this country and saw these plows in operation. Being much pleased with their operation, he took home drawings of them, which he submitted to his associates in the board. They were so highly approved that Jefferson was elected as an honorary nember of the board, and was requested by Sir John Sinclarir, its president, to forward a model and a full description of his invention. Mr. Jeflerson complied with his request, and the letter to Sir John was printed in the Edinhurgh Encyclopedia, from which we have compiled the preceding acconnt of his invention.

The originality of Mr. Jeflerson's discovery was contested lyy William Amos, in a communication published in 1808, hut he gives no proofs of it, and Mr. Jefferson certanly was not foolish enough to present his method as original to two learned societices, who had the means of at once detecting the impostme. The finct that these bodies, the French Academy and the English Board of Agriculture, acknowledged the invention to be his own, must forever set the question at rest.

The discovery has also been clamed for James Suall, but Sir John Sinclair distinctly states that Small perfected his plow cradually and experimentally, and withont the assistance of the key which Mr. Jeflerson's principle would have given him. His im- 
provements were empirical, and were not at first guided by any mathematical principles whatever. There can be no doubt whatever that Mr. Jeffer'son is solely entitled to the honor of inventing the first mould-board made on mathematical prineiples. We have inserted this account of Mr. Jefferson's discovery in the chapter on European plows, because his method was first published in Europe.

\section{CHAPTER III.}

\section{HISTORY OF THE PLOW-CONTINUED.}

The celelırated James Small, of Scotland, was the next great improver of the theory and practice of plow-making. He was the first inventor of the cast-iron plow, though the beam and handle were still made of wood. He took the Rotherham plow as the basis, and improved it in almost every particular.

He established his manufactory at Black Adder Mount, in Berwickshire, in 1763 , and died about thirty year's afterwards; having distinguished nearly every one of those year's by some new improvement in some of the parts. He left the implement at his death so nearly perfect that to this day it is used in many of the largest and best cultivated districts in Scotland, and prized more highly than any other. The cut, showing Small's chain plow, Fig. 28, gives his first efforts to improve the Rotherham plow, which will be readily seen on a comparison of the drawings representing them.

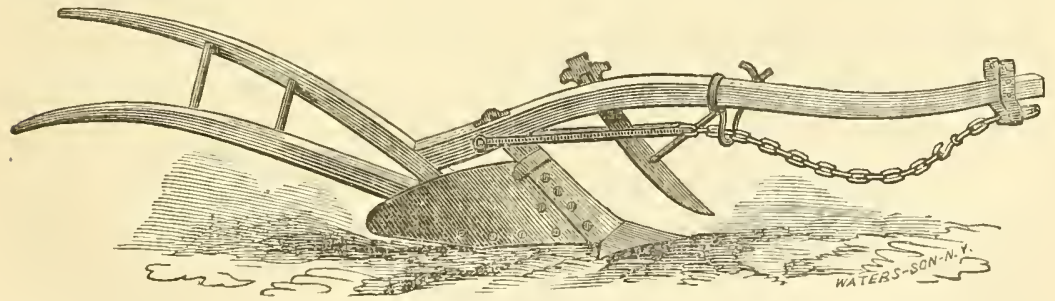

Fig. 28 .

The plow as finally perfeeted by Small, and generally known as the East Lotuman Plow, has attained to so high a degree of celebrity, and proved itself so advantageous to farmers, that we propose to give its details very fully, from Stephens' Book of the Farm. 
Plate II, fig. 49, represents an elevation of the plow on the furrow side, drawn to a scale of one inch to a foot, and Fig. 50, a horizontal plan of the same. It is found with various shates of difference, but not to the extent or of such marked character as to require separate description from what follows. The beam and handles are almost invariably made of malleable iron, the body fiame being of cast iron, the latter varying slightly with different makers. In its construction the beam and left handle are usually finished in one continued bar, A B C, possessing the varied curvature exhibited in Fig. 49, as viewed in elevation. When viewed in plan, as in Fig. 50, the axis or central line of the beam and left landle are in a straight line, though in this arrangement there are some slight deriations anong the different makersthe point of the beam being in some cases turned more or less to the right or furrow side, and this is found to vary from one-half inch to two inches from the plane of the land side. The right handle, D E, is formed on a separate bar, and is attached to the loody frame at its fore end by a bolt, as will be shown in detail, and farther connected to the left handle by the bolts F F F and the stays G G. The coulter, I, is fixed in its box, K, by means of iron wedges holding it in the proper position. Its office being that of a cutting instrument, it is constructed with a sharp edge, and is set at an angle of from $55 \mathrm{deg}$. to $65 \mathrm{deg}$. with the base line. The mould-board, L, which is fixed upon the body frame and to the right handle, is a curved plate of cast iron, adapted for turning orer the furrow slice. Its fore edge or hreast, $\mathrm{I} \mathrm{N}$, coincides with the land side of the plow's body; its lower edge, T, hehind, stands from nine to ten inches distant from the plane of the land side, while its upper edge, $\mathrm{I}^{\prime}$, spreads out to a distance of nineteen inches from $B$, the land side plane. In this plow the mouldboard is truncated in the fore part, and is met ly the gorge or neck of the share, the junction being at the line $N$. The share or sack, $\mathrm{N} \mathrm{R}$, is fitted upon a prolongation of the sole bar of the body frame termed the head, and fills into the curves of the mould-board, of which its surface forms a continuation. The brialle, $\mathrm{C}$, or muzzle, as it is sometimes named, is that part to which the draught is applied, and is attached to the point of the beam by two bolts, the one, $\mathrm{S}$, being permanent, upon which the bridle turns vertically. The other bolt, $U$, is movable, for the purpose of varying the earthing of the plow: the landing being varied by shifting the draught bolt and shatele, $V$, to right 
or left. The right and left handles are furnished at $\mathrm{A}$ and $\mathrm{D}$ with wooden helves, fitted into the sockets of the handles. If any one will take the trouble to compare the means employed in Jethro Tull's plow, Plate I, to make the plow run deeper or shallower, more to land or from land, with the arrangements for this purpose in the Rotherham plow, Fig. 16, they will see that a great advance has been made, but an inspection of Small's bridle, as shown in the plate, will demonstrate that much nore convenience and certainty has been attained by him in this respect, and nothing since has been invented to accomplish this object which ean be pronounced materially superior to it.

The general dimensions of this plow may be stated thus, as measured on the base line: From the zero point, $O$, to the extremity of the heel, $\mathrm{T}$, the distance is four inches, and from $\mathrm{O}$ forwards to the point of the share, $R$, the distance is thirty-two inches-giving as the entire length of the sole, three feet. Again, from $O$ backward to the extremity of the handles, $A^{\prime}$, is six feet two inches, and forward to the draught bolt, $V^{\prime}$, four feet seven inches, making the entire length of the plow on the base line ten feet nine inches; but, following the sinuosities of the beam and handle, the entire length from $\mathrm{A}$ to $\mathrm{C}$ is about eleven feet three inches. Although we have explained the word zero, used above, in the chapter "On the Mechanical Conditions of the Plow," yet, as it is a point of great importance in regulating the proportions of the implement, and has received rery little attention from American plow makers, we here observe that the zero line is that which, on the surface of the mould-board, where a vertical transverse section at right angles to the plane of the land side falls, which is distant from that plane by a space equal to the greatest breadth of the furrow taken by the respective plows. The zero point is found on this line, at an altitude above the sole the exact height of the furrow slice. Or we may define it as that vertical section of the monld-board which, in its progress under the slice, will just touch the latter when in a vertical position. The scalc in this arrangement counts right and left of zero.

In reference to the body of the plow, the center of the coulter box, $K$, is fourteen and a half inches, and the top of the breast curve, M, nine inches before the zero point, both as measured on the base line; but, following the rise of the beam, the distance from $\mathrm{M}$ to the middle of the coulter box will be seven inches.

The leeiglets at the different points above the base line are 
marked on the figure in elevation, along the upper edge of the beam and handle; but the chief points in height are repeated here, the whole of them being measured from the base line to the upper edge of the beam and handles at the respective points. At the left handle, $A$, the height is three feet, at the right handle, D, two feet nine inches; and a like difference in the height of the two is preserved till the right handle approaches the body at the middle stretcher, $\mathrm{F}$; thence the difference increases till it reaches the body. The height at the point of the beam is eighteen inches, and the centre of the draught bolt, at a medium, seventeen inches. The lower edge of the mould-hoard behinr, of this plow at $\mathrm{T}$, is usually set about half an inch above the base line, and at the junction with the share about the same height.

The dimensions in breadth, from the land side line, embrace the obliquity that is given to the direction of the beam and handles, compared with the land side plane of the body taken at the sole. The amount of obliquity, as exhibited by the dotted line, A C, Fig. 50, which coincides with the land side plane of the body, is that the axis of the beam at the extremity $C$ stands one and at quarter inches to the right, and, at the opposite end, the left handle, $A$, stands abont two inches to the left of the line. These points may, however, be raised slightly from the dimensions here given. In the first-the point of the beam-it is found in the practice of different maker's to range from one to two inches.

The dimensions of the parts of the frame work of the plow are: The beam, at its junction with the mould-board at $\mathrm{M}$, is from two and a half to two and three-quarter inches in depth, by one inch in breadth-the same strength being preserved onward io the conlter box, $K$. From the last point a diminution in breadth and depth begins, which is carried on to the extremity, $c$, where the beam has a depth of one and three-ruarter inches, and a breadih of one-half to five-eighths of an inch.

The enulter hox is formed hy piereing an oblong mortise through the bar, which has been previonsly forged with a protuberance at this place, on each side and at the upper edge; the mortise is two and one-half iuches by three-fuarters of an inch.

From the junction with the mould-board at M, backward, the beam decreases gradually till, at the hind palm of the body at 13, it is two inches in depth and five-eighths of an inch in breadth where it merges in the left hindle, A. This last member retains a nearly miform size thomghon of two inches by thee-eighths 
of an inch. The right handle, D, is somewhat lighter, being nswally one and onc-half inches by three-eighths of an inch, and both terminate in welded sockets which receive wooden helves of six or eight inches in length. The stretchers, F F F, which support and retain the handles at their due distance apart, are in length suited to their positions in the handles, and their thickness is alout threc-quartel's of an inch in diameter, tapering toward the cuds, where they terminate in a collar and tail bolt with a serewed mut. The upper stretcher has also a semicireular stay riveted to its middle, the ticils of the stays, G G, terminating, like the stretcher, with serewed tails and nuts.

Having given the general dimensions and outline description of this plow, there remains to be described the details of the body frame and its sheathing, all the figures of which are on a scale of one and one-half inches to one foot.

The Body Frame.-The different views of the body frame are exhibited in the Figs. 29 and 30 , wherein the same letters refer to

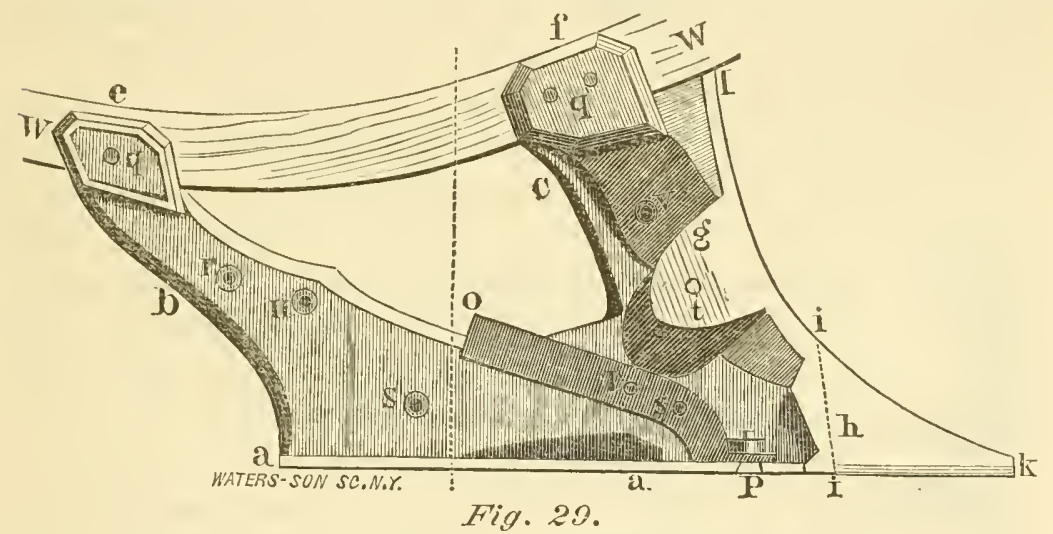

the corresponding parts in the different figures. Fig. 29 is an elevation of the furrow sicle; Fig. 30 a plan of the sole bar of the frame inverted; and a vertical section on the line $\mathrm{X} X$ is given in

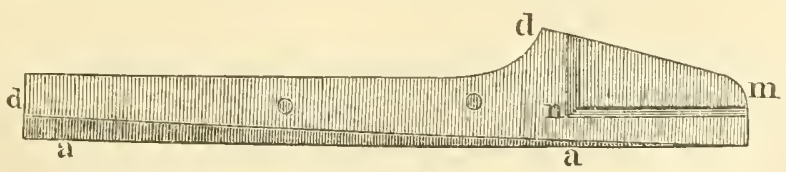

Fig. 30.

Fig. 31. In all the figures, then, a $a$ a is the sole bar, with two arms, $b$ and $c$, extending upwards, and having at the lower edge a flunge, d, rumning along the right hamd side. Each of the arms, 
$b, c$, terminates in a palm, ef, by which it is bolted to the beam. The arm, $c$, is furnished, besides, with an oblique palm or ear, $g$, upon which the fore elge of the monld-board rests and to which it is bolted. The sole bar, $a$, with its flange, terminates forward in the head, $h$, which is here made to form the commencement of the twist of the mould-board, and upon which the share is fitted, reaching to the dotted line, $i i$, Fig. 29 . The fore edge, $k i l$, of the frame is worked into the curve, answering to the oblique section of the fore edge or breast of the mould-board, and serves as a support to the latter throughout their junction. The curvature given to the arm, $b$, is umimportant to the action of the plow, but the general oblique direction here given to it is well adapted to withstand the thrust constantly exerted in that direction when the plow is at work. In Fig. 30, the sloping edge, $d m$, represents the enlargement of the sole bar on which the share is fitted and where the lower part of the fore edge of the mould-board rests. The depressed portion, $m n$, is that which is embraced by the flinge of the share. In the frame, $o$, is the lower extremity of the right handle broken off at $o$, to show the manner in which it is joined to the sole flange of the frame by the bolt, $p$. The bolt holes, $q q$, are those by which the beam is secured to the palms of the frame; $r r$ are those by which the land side plate is attached,

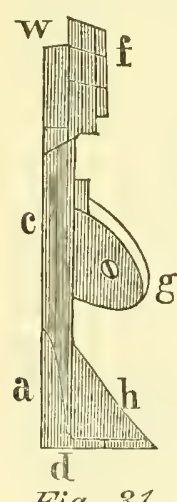

Fig. 31. and $s s$ those of the sole shoe, $t$, being that which secures the mould-board to the ear, and $u$ that which receives the lower stretcher of the handles. (See Fig. 50, Plate II, at $\mathrm{F}$ and $\mathrm{O}$.) The letter $v$ marks the second bolt hole of the mould-board, while its third fixture is effected upon the right handle by the intervention of a bịcket, or of a bolt and socket as seen at $o$, Plate II. The curved lines, $w$, mark the position of the beam when attached to the body, the beam being received into the scats formed on the land side of the palms, $e, f$, as seen more distinetly at $w$ in Fig. 31.

The body fiame being an important member of the implement, regard is paid to having it as light as may be consistent with a due degree of strength; hence, in the different parts breadth hals been given them in the direction of the strain, while the thickness is studionsly attenuated in such places as can be reduced with safety. The least brealth of the sole bar, $a$, is three and threequater inches, of the arm, c, four and one-half inches, and of $b$, 
two and one-quarter inches. The breadth of the sole flange is two inches, the greatest thickness in any of the parts is threequarters of an inch, and the total weight of the frame is thirty pounds.

The Share.-Figs. 32 to 37 are illustrations of the share and its configuration; Fig. 32 is a plan; Fig. 33 a geometrical eleva-

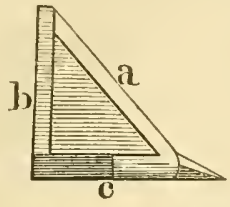

Fig. $34-35$.

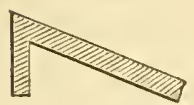

Fig. 36 .

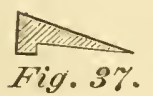

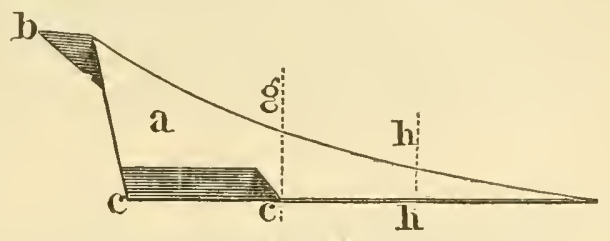

Fig. 33.

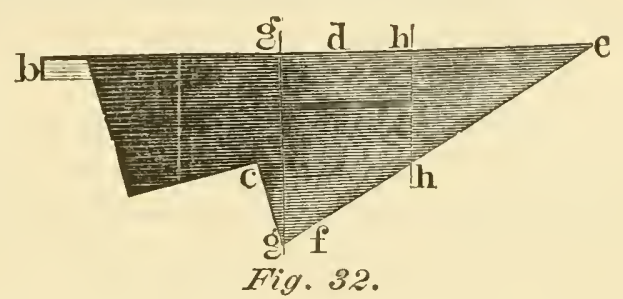

tion of the furrow side, and Fig. 34 is a direct end view looking forward, of which $a$ is the boss adapted to the curvature of the mould-board; $b$, the land side flange, which embraces the head of the land side; $c$, the sole flange, embracing in like manner the head below; and these three parts form the neck or socket of the share, fitting closely upon the head, and being in effect part of the mould-board. The part $d$ ef, Fig. 32, forms the share proper, consisting of $d c e$, the shield terminating in the point $e$, and of the feather or cutter rumning off at the point $e$. The extreme breadth of the share in this plow, measuring from the land side to the point $g$ of the feather (or the rear angle of the feather): varies from six to six and one-half inches; and its length in the sole, including the neck, $b$, is about sixteen inches, the feather, $g e$, being eleven inches.

The other figures, 36 and 37 , are transverse sections of the share on the lines $g g$ and $h h$, respectively, exhibiting the structure and relation of the shield, and the feather represented by the line $\mathrm{A}^{\prime} \mathrm{V}^{\prime}$, Fig. 49, Plate II, where, as will be observed, the cutting edge, through its entire length, lies within less than onequarter of an inch of the base line.

The share is of wronght iron, and is always formed from a 
plate forged for the express purpose at the iron mills, and known in the trade by the term sock plate. Fig. 38 represents the form

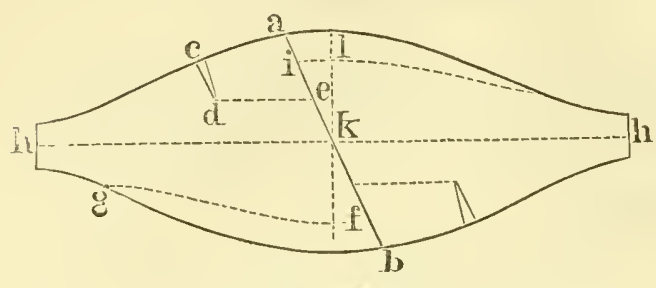

स्II. 38. in which those plates are manufactured, the thickness being from one-half to three-quarter's of an inch; they are afterwards cut in two through the ine $a b$, each half being capable of forming a share. To do this, an incision, $c$ a, is made on the short sicie to a depth of two inches; the part a $c d$ is afterward folded down to form the sole flange, and the part $b f g$ is in like manner folded down to for'm the land side flange. The point $h$ is strengthened, when requisite, to receive the proper form of the shield and point, the latter being tipped with steel. The edge, $h c$, is extended to the requisite breadth to form the feather. In order to cut a sock plate at the proper angle, so as to secure a minimum expenditure of labor and material, let a central line, $h h$, be diawn upon the plate, and bisect this line in the point $k_{i}$, the line upon which the plate should be cut will form angles of $70 \mathrm{deg}$. and 110 deg. nearly with the line $h h$, or mechanically draw $h l$ equal to five and one-half inches, at right angles to $h h$, and draw $l i$ parallel to $h h$, mark off two inches from $l$ to $i$, and through the point $a i k$ : draw the line $a b$, which is the proper direction in which the plate shonld be cut.

The Sole Shoe.-The figures 39 to 41 are illustrative of the sole shoe. Fig. 39 is a plan of the shoe, a a being the sole flange, and $b b$ the land side flange; Fig. 40 is an elevation of the same, and Fig. 41 a cross section, showing the filling up of the internal angle, opposed to where the greatest wear takes place.

The thickness of the sole flange at the heel $a$ is seven-eighthe of an inch, diminishing forward to three-eighths of an inch at three inches from the point, and thence it is thinned off to prr. vent obstruction in its progress through the soil. The brealth of the sole is two and one-quarter inches, and its extreme lenglh twenty and one-half inches. The side flange is one-half of an inch thick along the edge, by which it is attached to the sole, diminishing upward to one-quarter of an inch at the top edge, the height heing four and three-quarter inehes at the heel, and six inches at the fore and; the wright is about fourteen pounds. The uppere 
land side plate is eighteen inches in length on the lower edge, being one and one-halt inches longer than the corresponding edge of the sole plate, the purpose of which will be seen in the figure of the land side, Fig. 46 ; the length of the upper edge is twenty-

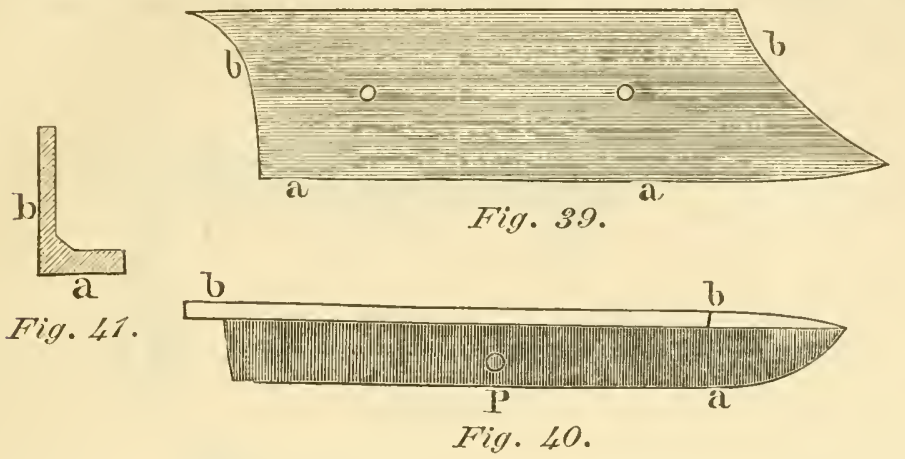

one and one-half inches. The breadth and the contour of the upper edge must be adapted to the form that may have been given to the beam. The thickness at the lower edge must agree with that of the sole plate, and be diminished to one-half of an inch at the upper edge; weight, nine pounds.

The conlter, Fig. 42, is an edge, and Fig. 43 a side riew of the coulter of this plow, in which the same letters of reference are

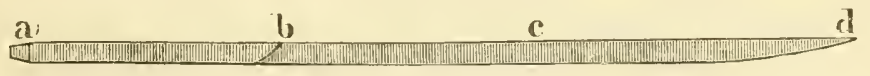

Fig. 42.

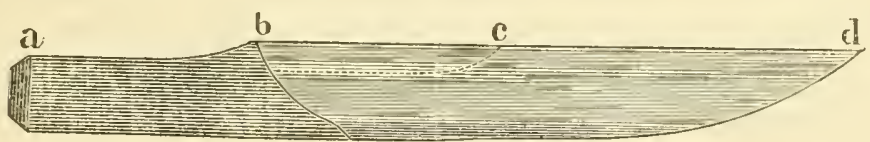

Fig. 43.

applied. The neck $a b$, by which it is affixed in the coulter box, is about ten inches long, though it may, with all propriety, be extended to $c$; the neck is usually about two inches in breadth, and three-quarters of an inch in thickness. The blade $b c d$ varies in length, according to the variety of the plow to which it helongs: from eighteen to twenty-two inches. The brealth of the blate is usually about three inches in the upper part, but is cnrved off behind, and terminating in a point at $d$. The thickness of the back at the shoulder $b$ is three-querters of an inch, and tapers gently downward to where the curvature of the back begins; thence it diminishes toward the point to one-cighth of an inch or less. It is formed quite flat on the land side, and on the furrow 
side is beveled off towards the cutting edge, where it is alout one-eighth of an inch thick throughont the length of the edge.

The Bridle.-Fig. 44 is a plan, and Fig. 45 is a corresponding elevation of the bridle, and of the manner of its attachment to the heam, where $a$ is part of the beam, $b$ the cross head, and $c c$ the

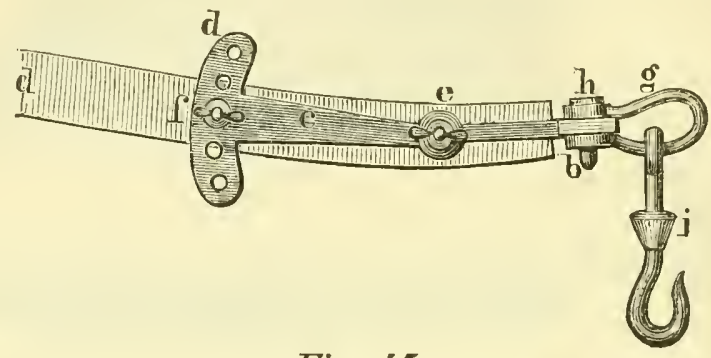

Fig. 45 .

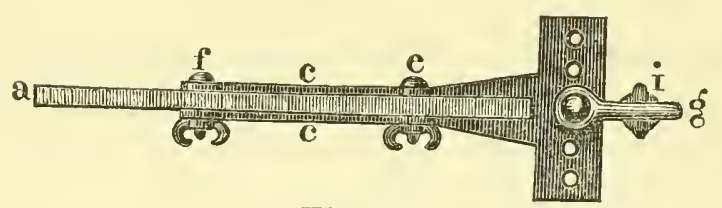

Fig. 44 .

tails of the bridle, with their are heads, $d$, embracing the beam on the two sides; $e$ is the joint bolt on which the bridle turns for adjustment to earthing ; $f$ is the temper pin or bolt, and by inserting it into any one of the holes in the are heads, and passing through the beam, which is here perforated for the purpose, the bridlo is held in any required position. The draught shackle $g$ is held upon its place upon the cross head $b$ by the draught bolt $h$ passing through both parts, and the cross head being perforated with five or more holes; the bolt or shackle can be shifted from right to left, or from left to right, for the proper adjustment of the landing of the plow. To the shackle is appended the swivel liook $i$, to which is attached the main dranght bar or swingle tree of the yolse.

The Land Side.-Figs. 46 and 47 are illustrations of the land side; Fig. 46 being an elevation of the body of the plow, repre sented in the working positions, but with the extremities cut off The point of the share and the heel rest upon the base line at a and $b$, and the lines of the sole lying between these form the very obtuse angle, which obtains in the sole of this plow; $a c$ is the shitre, and $d b$ is the sole shoe; $e$ is the land side plate, and $f g$ is a part of the beam. The lines a $d$ and $d b$, together with the 
hase line, form the very low triangle $a d b$, whose altitule at $d$ does not exeeed three-eighths of an ineh, or by extending the sole line $b d$ to $h$, the depression $h a$, of the point of the share below this extended line, will be one-half inch nearly. Fig. 47 repre-

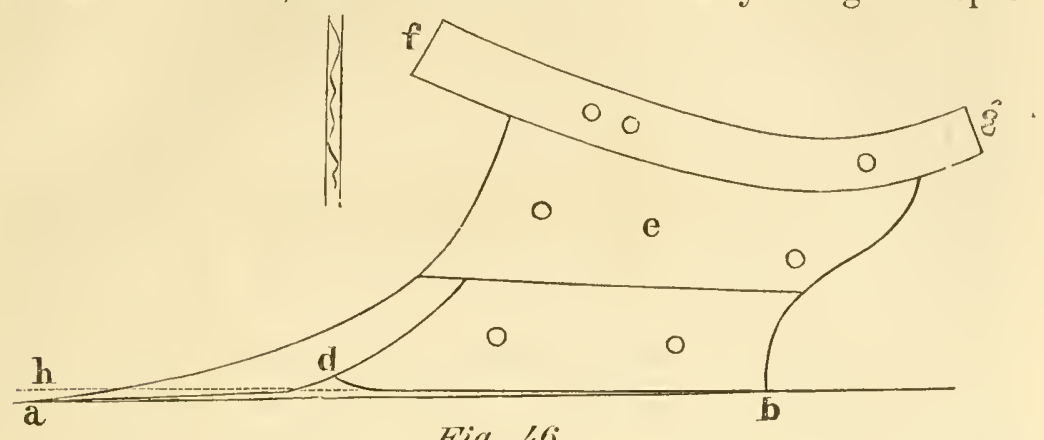

Fig. 46 .

Scale
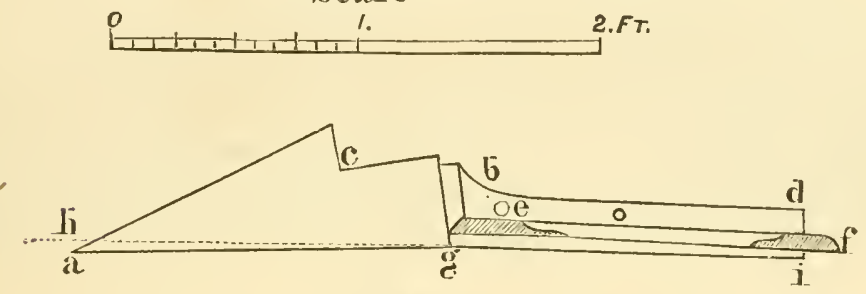

Fig. $4 \%$

sents a horizontal sole shoe. Here $a c$ is the share, $b d$ is the sole flange of the body frame, the bolt hole at $b$ being that by which the palm of the right handle is fixed to the flange; $e$ and $f$ the two arms of the frame as cut across in the section $g i$, the lind side of the sole shoe coineiding with the land side plane; the eontinuation of this line $g i$ to $h$ exhibits the inclination of the shatre to the land side, which, in this plow, may be taken at onelialf an inch.

The inclination downward given to the share is intended, and experience confirms the intention, to give steadiness of motion to the implement by giving it a lengthened base on which to stand. It is evident that if a base the converse of this were given to it, convex instead of coneave, so that it should rest on the point $d$, when in motion, the smallest obstruction occurring at the point of the share would give it a tendency to swerve from the horizontal line of progression, and to lose either depth of furrow or be thrown out, thus rendering the management of the plow very difficult and uncertain. Even a perfectly straight base is found 
not to grve the requisite certainty of actiou, without a greater amount of exertion, as well as closer attention on the part of the plowman. A like reason prevails for this inclination of the share landward as does for its earthward inclination; and, for the steady motion of the plow, the latter is eren more necessary than the inrmer; but there is another reason for this landward inclination, which is that, as the plow is seldom held with the land side truly vertical, but inclining a little landward, and it being desirable to eut the furrow slice, as near as possible, rectangular, the coulter has always a slight tendency laudward at the point; hence it becomes necessary to give the share a like bias. By this arangement of the parts the incision made by the coulter will be nearly vertical. While it is admitted that these inclinations of the share afford certain advantages in the action of the plow, it must not be concealed that the practice is liable to abuse.

The curves of the mould-board of this plow are given at Figs. 111 and 112, Plate III. As plow diagrams in this form are not familiar to farmers and plow-makers in this country, it may lie proper to give some explanation of the manner in which they are obtained and the precise lines of the plow which they represent. Fig. 48 represents the instrument by the aid of which these lines

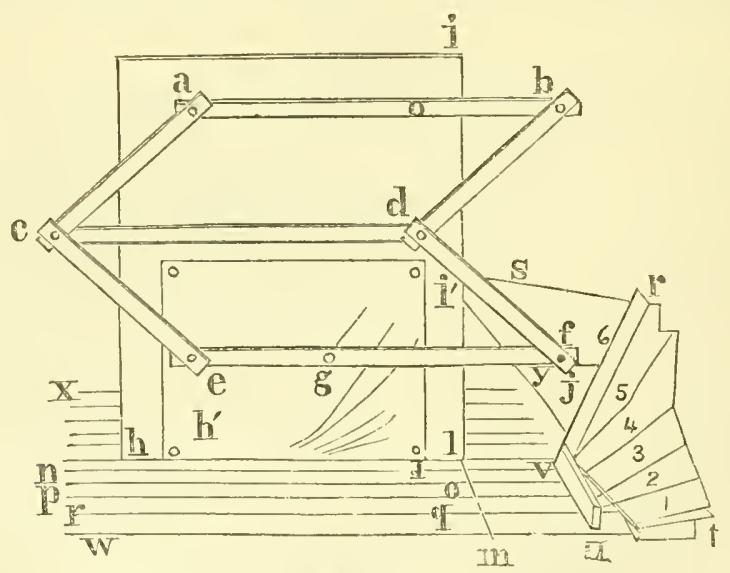

Fig. 48 .

are obtained. Lines $q \nu, \circ p$, ete., are ruled on the horizontal surface two inches apart. The plow to be analyzed is placed upon the table, with the plane of its land side perpendicular to the plane of the table, its sole line at right angles to the ruled lines and the front edge of the mould-hoard, $t$, on the line $v m u$; draw the line $l m$ at right angles to $w$ m, maing it as long as the monld-board 


\section{Plate III.}

ANALYTICAL SECTIONS OF MOULD-BOARDS.

Fig. 111.

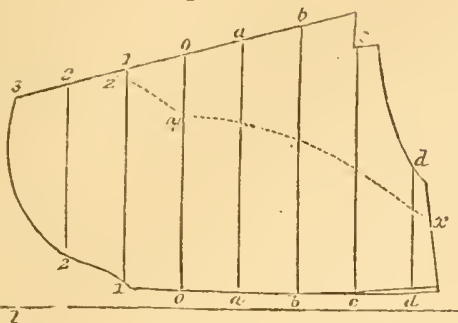

Fig. 112 .

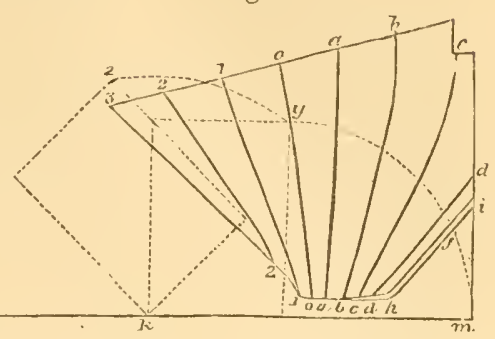

Fig. 114 .
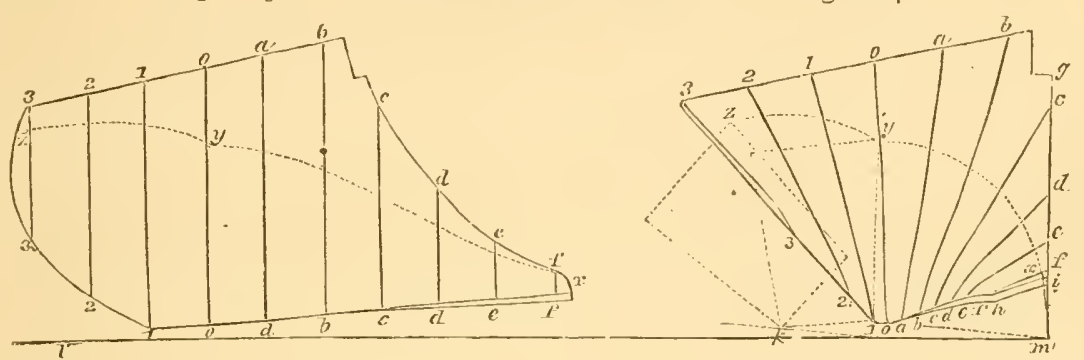

Fig. 115 .

The Berivickshire.

Fig. 116 .
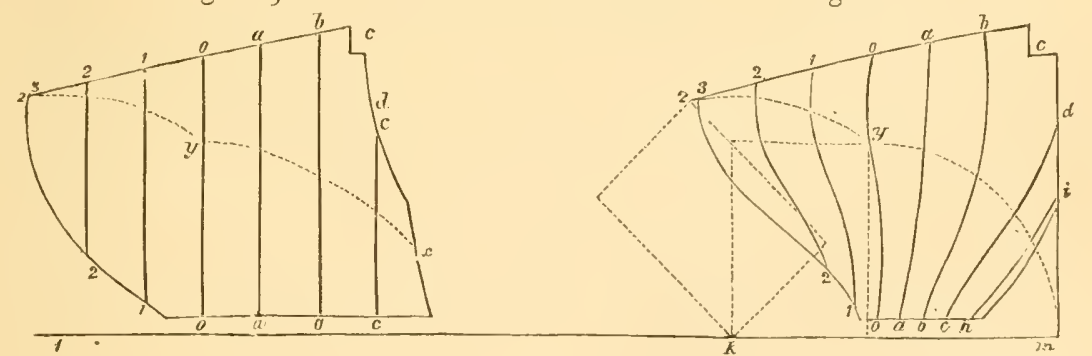

Fig. 117 .

Thi Lanarkslire.

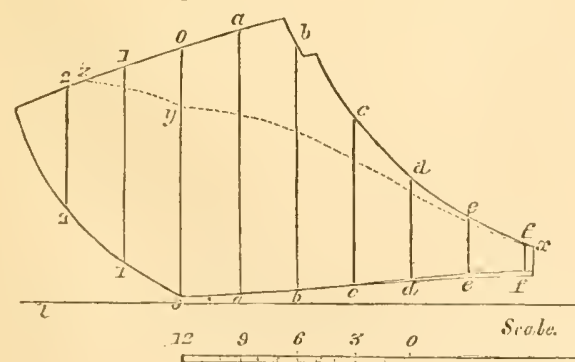

Fig. 118.

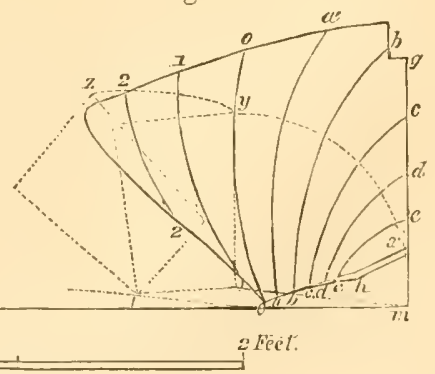



of the plow; $i t$ is a board about three feet square, provided with broad feet behind, which cin be fistened securely to the tahle, $w x m y$, by means of thumb screws. The two parallelograms, a b c d and c d c f, are connected ly pins, as shown in the figure, so that all the joints can work freely; the lower end of the bar, e $f$, his.s a stont wire, $j$, inserted into it for a tracer. A sheet of paper, $i^{\prime} h^{\prime}$, is tacked to the board, $i h$, at the four comers, and a trateing pencil is inserted in the socket, $g$. The filce of the board is now set on the line $q r$, the face of the square, $r r$, is set on the line $i$, the face, $v$, lying on the table parallel to $m$. The tracer, $j$, is then bromegt up to the top of the mould-board and is carried along to the bottom, touching the surface at every point in its passage, being lirected hy the fice, $v r$, the line of motion being recorded accurately by the pencil, $g$, on the palper, $i^{\prime} l$ '. 'The face of the hoard is now set on the line $o p$, and the face of the square, $v r$, is placed on the line 2 , and the line 2 is traced on the paper as hefore. In this way the board is suceessively set backward on all the lines ruled on the table, taking eare that its lower righthand corner is kept on the line $m l$ until all the lines of the mouldboard are transferred to the paper. A little attention to the action of the jointed parallelograms, $a b c d$ and $c d e f$, will show that the path of the pencil, $g$, must be exactly parallel to that of the tracer, $j$. If the point of the tracer passes down a vertical line, the pencil will trace a vertical line on the paper. If it passes along a horizontal line, or an angle of 45 deg., or over a convex or concave line, precisely similax lines will be traced on the paper, and it is by this method that the lines of the figures on Plate IV have been traced. It may be, perhaps, proper to say that the hals, $a b, c$ and $e f$, are each three feet long, one and one-half inches wide, and three-quarters of an inch thick. The four bars, a c, $b d$, ce and $d f$, are of similar breadth and thickness, and are all made of hard wood, and are jointed together on brass studs, care boing takeu that the perforations are all made exactly equidistant fiom each other.

Fig. 111 of Plate III is a geometrical elevation of Small's or the East Lothian plow in a plane parallel to the land side of the monld-board, $l d$ being its base line. The perpendicular lines of division, eommeneing from the line oo, or zero, and extending right and left, are the lines of section. Those to the right or fore end of the mould-hoard, marked $a a, b b$, ete. The curved line, $x y \approx$, represents the wath deseribed on the face of the monld-board 
by the lower land side edge of the furrow slice, as the mouldboard passcs under it, which is called the line of transit.

Fig. 112 is a front view in elevation of the same plow, and corresponding to Fig. 111, Plate III; $k m$ is the base line, $m g$ is the land side plane in a vertical position, $m$ also is the place of the point of the share, and $h i$ the line of junction between the neck of the share and the mould-board; the remaining lines beyond $t i$ exhibit the outline of all the sections taken by the instrument in reference to the lines in Fig. 111. Thus $\circ \circ g \mathrm{~m}$ is the section of the entire body of the plow in the plane of the zero, o y o being the outline of the mould-board at this section, and $y$ the zero point; a a g m, the first section forward of the zero, $b b \mathrm{~g} \mathrm{~m}$, the st.cond, and so on. In like manner, $11 \mathrm{~g} \mathrm{~m}$ is the first section backward from the zero, $22 \mathrm{gm}$ the next section backward, and so on, each section so lettered and numbered having relation to the divisions carrying the corresponding letters and numerals in Fig. 111. The entire series of lines 1122 , etc., and $a$ a $b$ b, etc., thus form a series of profiles of the mould-board, supposing it to be cut vertically by planes at right angles to the land side of the plow. In Fig. 112, also, the dotted line, $m y z$, represents the line of transit, as in Fig. 111, and $z k$ represents a transverse section of the slice as finally deposited by the mould-board.

Mr. Stephens, it will be observed, gives none of the horizontal lines, confining himself wholly to the vertical lines; in fact, very little attention is paid to these lines in any part of Europe, being left to arrange themselves by chance out of the arrangement of the vertical lines, which alone receive attention. In this respect it will be seen hereafter they differ very materially from the best class of American plows, $m$ which much attention is very properly given to the arrangement of the transverse lines.

The reason for this difference is found in the fact that the plowmen of Great Britain have an almost superstitious reverence for the high shouldered, crested furrow. The proprietor and the plowman both delight to stand on the headland when the work is done and survey the even furrows, laid so straight that the pencil rather than the plow would seem to have traced them. The furrows must be of precisely even thickness, in all their length. No departure from a mathematical straight line is tolerated. You must see a mouse running in the bottom of every furrow from end to eud. But the crowning glory in their eyes was to see the crowning angle of the furrow slice umbroken and maluraded from 
end to end. The plow which insures this result most certininly is the hest plow in their eyes, even though it should rerpuire more power to draw it, though it should wear ont faster, and though it were far more costly thill amother.

The English plowmen would not subseribe to our chapter on "The Ohjects to be Accomplished by Plowing." The plow is not the implement to pulverize, in their view, but the harow. Pulverizing properties would be objectionable to them, as it would interfere with a sharply defined crest. Since the vertical lines of the plow are those which determine the shape of the erest, it is not wonderful that their formation should have monopolized the ingennity of the English plow wrights.

Turning our attention to the sections of the various plows given in Plates III and IV, we shall see plainly enough that all the plows there given have been constructed with reference to this olject. On inspecting Fig. 112 we see that the lines of the plow in front, $c c, b b$ and $a a$, are concave above the line of transit, while those in the rear , 11 and 22 , are concave below that line. The lines in contact with the slice are all of them straight, or nearly so, agreeing in this respect with the plan of Mr. Jefferson. It differs from his in this, that as the generating line of this plow as Small finally made it, is a catenary curve, Mr. Jefferson's generating line is a straight line. This will be understood by a recurrence to Fig. 18, which represents Mr. Jefferson's method of forming the twist of his mould-board.

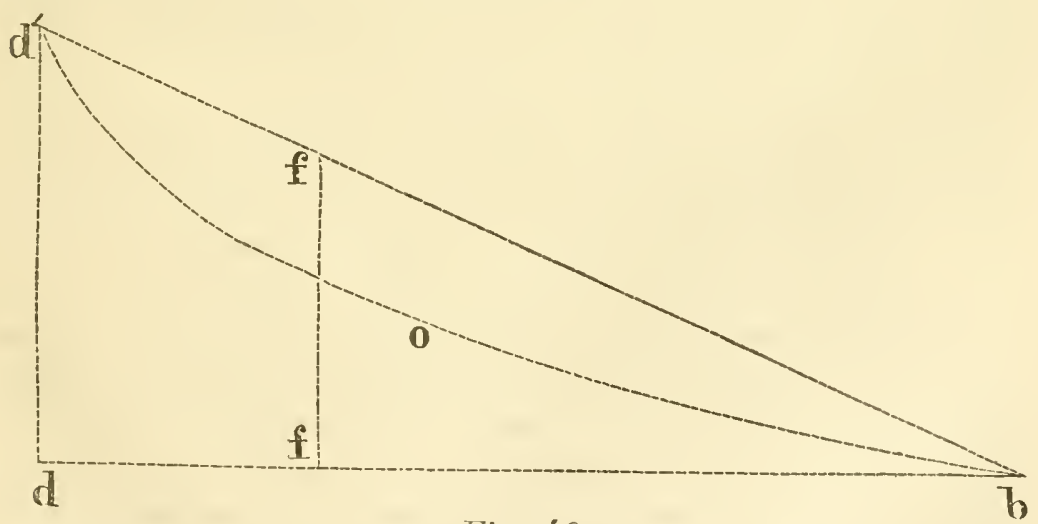

Fig. 4.9.

If we now take in elevation, Fig. 49, what is shown in pian in Fig. 18, by erecting a post, $d d^{\prime}$, twelve inches high at the point d. and stretching a cord tightly from $d^{\prime}$ to $b$, we shall lave Mr: 
Jefferson's generating line; one end of a twelve-inch rule carried along from $b$ to $d^{\prime}$, Fig. 49, and the other end along e c, Fig. 18, will describe the twist of his mould-board in the air. The twist of Snall's mould-board is obtained by extending the cord $l^{\prime} b$, and suffering the slack to fall by its own gravity, when it will assume the curve $l^{\prime} \circ b$. One end of the ruler being curried fiom $\&$ through 0 , along to $d^{\prime}$, Fig. 49, and the other along the line $e c, F i g$. 18, will describe in the air the twist of Small's monld-board. By the substitution of a curved line for a stuaght one, Small obtains a wider wing without making the fore part of the plow too blunt, and thus insures the lesult so highly coreted by the British plowman, of giving a high sharp crest to the furrow. It is difficult to imagine any practical purpose which is obtained in giving concavity to the parts above the transit line in the fore part, and below it in the hind part of Small's plow. The zero line $o$, it will be seen, makes a very small angle with the line which at first was the bottom of the furrow slice, but which hats now assumed a vertical position, and hence there is a correspondingly small temlency to break off or abrade the corner $y$, which, when finally deposited, forms the crest. The angle thus formed with the lower face of the furrow slice is much smaller than in the Rotherham plow, which had a tendency to break off the crest, and it is to this circumstance more than its superior lightness and its improved mechanical construction that the great popularity of Small's plow was owing.

The next improvenent in the plow was made hy Mr. Milkie, of Uddingstone, near Glasgow. We have used the word "improvement;" we had better have used the word alteration, for until this day it is not fitrly settled that it is really better than Sunall's. It is now generally known as the Lanarlishire Plou. The body frame, which in Small's plow, Fig. 28, is made of calst iron, is made of malleable iron in the Lanarkhire; the two arms, $b$ and $c$, instead of being bolted to the frame are welded to $\mathrm{it}$, and form prolongations from the beam and left handle. 'The bridle, coulter' and some other parts show trifling variations of form, lut nothing differs in principle from Small's, except that it is provided with two very useful appendages, which should be attached to all plows, as they save much time, and their presence will induce. the plowman to temper his irous and keep the plow in much better condition for work than he would do in their absence. 
They are the plow-stafl and hammer nut-key, represented in Fig. 50 and Fig. 51.

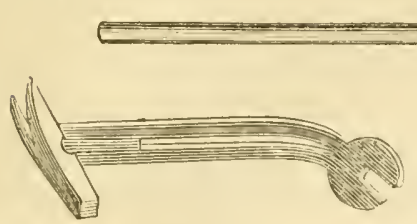

Fig. 51.

Fig. 50 .

Comparing the sections of this plow, Plate III, figs. 117 and 118 , it will be seen that the lines are sharply convex, which will increase its pulverizing power, as will be shown hereafter, and it will also be seen that the zero line o o coincides for half its length with the face of the furrow slice in its vertical position, and therefore has less tendeney to rub the angle at $y$ : than Small's plow. It is two inches narrower from the beam to the rear upper angle of the mould-board; the left bandle stands nine inches firther to the left. The edge of the feather rises from the point to the rear angle of the feather. The Mid Lothian Plow partakes of the characteristics of the Lanarkhile and East Lothian plows. The curves of its mould-board, as seen in Plate III, figs. 113 and 114, show a tendency to convexity in the extrense lower part, while the greater portion of the upper part are straight, like Small's. The zero line makes a smaller angle with the vertical furrow slice, and has thercfore less tendency to disturb it. Its share rises from the point to the rear corner of the feather, like that of the Lamarkshire, and it will of course leave the bottom of the furrow as represented in Fig. 98 .

Mr. Stephens has invented a mathematical method of forming a mould-hoard, which, though substantially on the plan of Mr. Jefferson's, has some modifications which are decided improvements. Instead of using a straight diagonal, like Mr. Jefferson, he uses the are of a circle, and, hy lateral additions to his block, he is emabled to make such an overhang to the wing of the mouldboard as to make it fall into its place with certainty, and, at the same time, to give an easy and gradual entrance to the breast of the plow. We give his method in his own words:

"From a carcful study of the foregoing diagrams (Plates III and IV), and from a comparison of numerous implements and their practical effects, together with a consideration of the dynamical principles on which the plow operates, I have been led to adopt a theoretical form of monld-board, which seems to fulfill all the conditions reruired in the investigation, and which is eapable, hy very simple modifications, of adaptation to the circum- 
stances of the medium on which it works. In the outset it is assumed that the soil is homogeneous, and that it possesses such a degree of tenacity and elasticity as to yield to the passing form of the plow, and to resume, when laid in the due position, that form which was first impressed upon the slice by the action of the share and conlter; the second consideration being the cutting of a slice from the solid land. In a theoretical view, this must be an operation throngh its whole depth and brealth; hence the share is conceived to be a cutting edge, which shall have a horizontal breacth equal to the brealth of the slice that is to be laised, and that the face or land side of the coulter shall stand at right angles to this. Another consideration is, that the slice now supposed to be eut his to be raised on one side and turned over through an angle of 135 deg., the turning over being performed on the lower right hand edge, as on a hinge, through the first 90 deg., the remaining 45 deg. being performed on what was at first the mpper right hand elge ( $m$, Fig. 97). 'The slice, in going through this evolution, has to mudergo a twisting action and be again returned to its original form of a right prism. To accomplish this last process, it is evident that a wedge, twisted on its upper surfice, must be the agent; and to find the form and dimensions of this wedge is solving the problem that gives the surfice of the mould-board required.

We have seen, Fig. 97, that the slice, in passing throngh the first nincty degrees, describes the quadrant $d h$ with its lower edge, and in doing so we can conceive a continued slice to form the solicl of revolution $a b c a$ e, Fig. 123, Plate $I V$, which is a quarter of a cylinder, as shown here in isometrical perspective; the radius $a b$ or $a c$, being equal to the breadth of the slice. Ite have next to consider the angle of elevation of the twisted wedge; and in doing so we must not only consider the least resistance, but also the most convenient length of the wedge. In taking a low angle, which would present, of course, proportionally little resistance, it would at the same time yield a length of mould board that would be highly inconvenient, seeing that the generating point, in any section of the slice, must ultimately reach the same height, whether by a high or a low angle. From experience, we find that from the point of the share to that point in the plow's body where the slice arrives at the perpendienlar position, which I have named the zero, that thinty inches form a ronvenient length. The length o d of the solid is therefore mate equal to 



\section{Plate IV.}

ANALYTICAL SECTIONS OF MOULD-BOARDS.

Fig. 119. The ll estern Fifestire. Fig. 120.
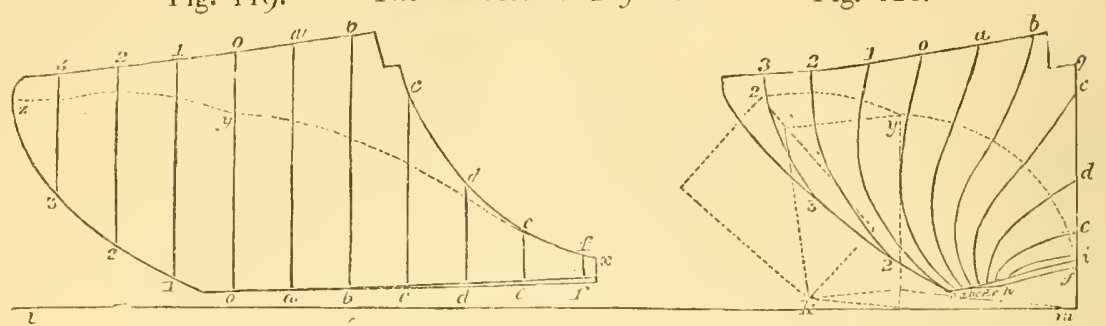

Fig. 121. Ransome's F F.

Fig. 122.
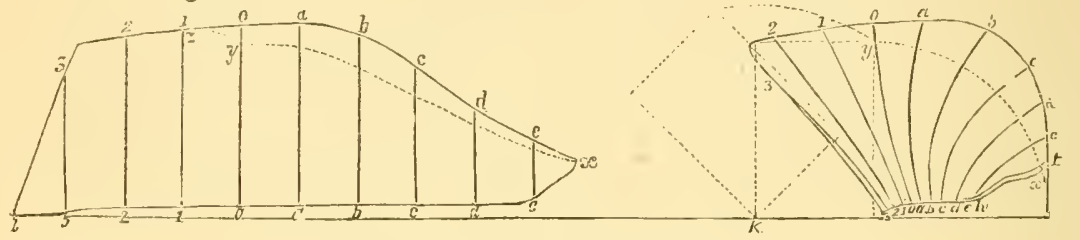

The New Mould-Board.

(Figs. 123-128.)

Fig. 127.

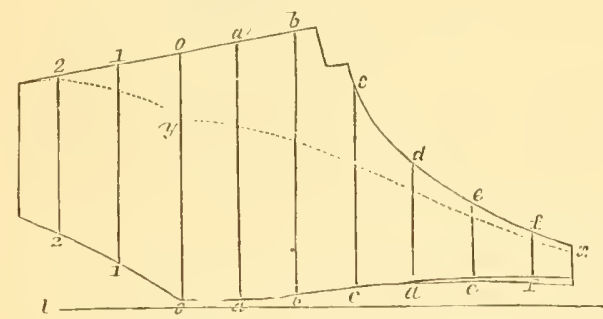

Fig. 128.

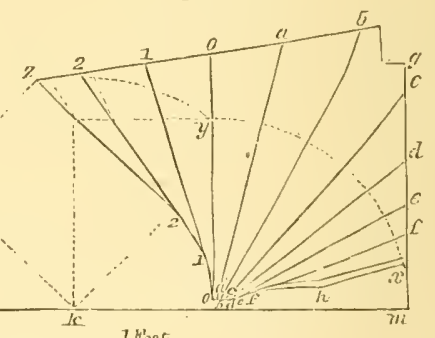

Fig. 124. If 1 13ort
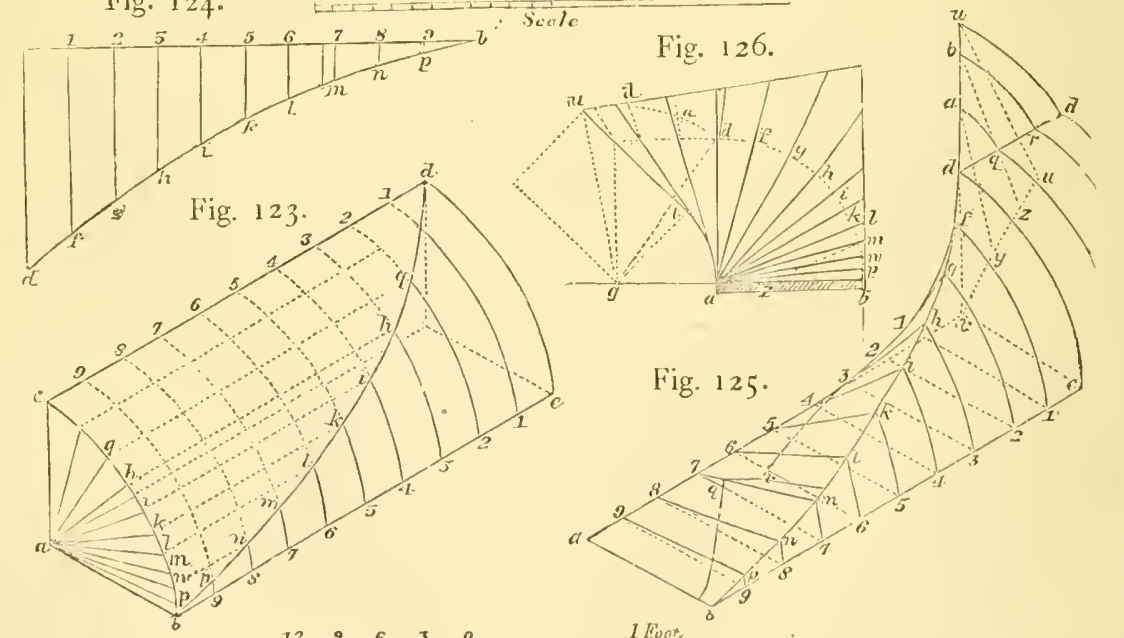

Fig. 125 .

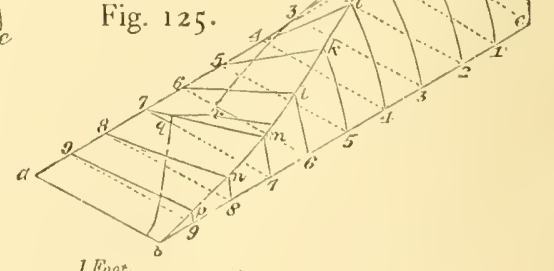


thirty inches or more, and this being divided into ten equal parts, the parallels $11,22,33$, de., are to be drawn upon the eylindrical surfice, and hetween the points $b d$ a curve has to be described that shall be the line of transit of the slice. After investigating the application of varions eurves to this purpose, I have found that the circular are is the only one that ean be adopted. It presents the least attainable resistance in the first stages of the ascent, where the foree required to raise the slice is greatest, and in the last stages where the force of raising has vanished, leaving only what is necessary to turn the slice over, there the resistance is greatest; and, above all, the circle being of equal flexure throughont, it is in every way best alapted to the objects here required. To determine the radius of curvature of this are, we must evolve the eylindrical surface, $c b d e$, and from it construct the diagram, Fig. 124, Plate IV. Draw $e b$ equal to $c d$ of Fig. 123; $e d$ equal to the length of the are, $c b$ or $d e$, and at right angles to $e b$; divide $e b$ into ten equal parts, and from the points of division draw the ordinates $1 f ; 2 g$, $3 h$, ete, parallel to $e d$; from $b$ set of ten inches for the length of the share along the line $b e$, which will fall one inch beyond the division 7 , and at this distance draw the dotted line parallel to $7 \mathrm{~m}$; upon this set off two and onehalf inches, and through the three points, $d m b$, describe an are of a circle, whose radins will be found equal to the cireunference of the cylinder, of which $a b c$, Fig. 123, is a quadrant. The circular are thus found is to be transferred to the eylindrical surfice $c b d e$. The transfer may be performed by drawing the arc on paper, and the paper then laid over the cylindrical surfice in such a mammer that the points, $l m d$, shall be brought to coincide with the points, 7 m $d$, of the eylindrical surface; when the remaining points $f g h i$, or any number more, may be marked on the eylindrical quadrant by pricking through the paper with a pointed instrument at short intervals along the are; or the lengths of the ordinates, $1 f, 2 g, 3 h$, of Fig. 124, may be transferred to the corresponding parallels of Fig. 123, when the lengths of the ordinates will cut the parallels in the points $f g h$, etc. In either anse the curve can now be traced through the points $b p n$ m, etc.. on the eylindrical surfuce. Through the points $b p n \mathrm{~m}$, ete., draw the dotted lines, $f^{\prime} f^{\prime}, g g^{\prime}, h h^{\prime}$, parallel to $c d$ or $b e$, and from the centre, a, dhaw the radii $a f, a g^{\prime}$, a $\ell^{\prime}$, etc; the unequal divisions of the are, $c b$, will thus show the proportion of angles of

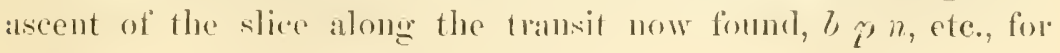


each division of the length, while the degree of flexmre in the curve or line of transit remains uniform by the same, from any one point to any other equirlistant points.

To convert the prism thus prepared and lined off into that of the twisted wedge, we have only to cut away that portion of it contained within the boundaries $a b c d x$, preserving the terminal clges $a b, a x$ and $d x$, and the prism will thus be resolved into a form represented by a portion, $a b d x e$, of Fig. 125, also in isometrical perspective. Of this figure, $a b d x$ is the true theoretical surfice of the mould-board; from the edge, $a b$, of the share to the zero line, $d x$; a $b e x$ is the sole; the curve, $b p n m l$, etc., is the line of transit of the slice, and the triangles, $1^{\prime} f 1,2^{\prime}, 2$, $3 ' \% 3,4^{\prime} i 4$, ete., are vertical planes, supposed to cut the solid thus reduced in the divisions $1,2,3$, 4 , ete, to the height of the line of transit, as in the analytical sections of the mould-boards.

The surface, now completed, ean only raise the slice to the perpendicular position; and, to complete the operation, we have to carry the twisted wedge back till it shall place the slice at the angle of 45 deg. To do this we have to extend the original prism, or suppose it to have been at first sufficiently elongated toward $d d^{\prime}$, Fig. 125, Plate IV., and to superimpose upon its liat side the portion $d d^{\prime} u x$, or $a d u$ of Fig. 126. The part $d d^{\prime} u x$ is now to be worked off into a part of a new eylindrical surfice, whose radius is $y d$ or $y u$, Fig. 126 , and upon this surface the line $d u$, Fig. 125, is to be drawn tangent to the curve $b d$ at $d$. $A$ continuation of the divisions of three inches is to be made upon the line $d d^{\prime}$, and the parallels $a^{\prime} q^{\prime}, b^{\prime} r^{\prime}$ and $u d^{\prime}$ continued on the eylindrical surfaces. Whatever portion of the superimposed picee, $a d^{\prime} u$, may be found to fall within the small are, $a t$, Fig. 126 , is to be cut away, forming a small portion of an interior. "ylinder concentric to the point $y$, which, being done, the remaining portions of the superimposed piece are to be cut away to the dotted lines $d x, a y, b z, u u^{\prime}$ of Fig. 125, or, what is the sime thing, to the lines $d a, a^{\prime} a, b^{\prime} t$ and $u t$ of Fig. 126, forming tansents to the emres at $a t$, and which will eomplete the surfiuce of the twisted wedge through its entire length, and to the height of the line of transit, produciug what I conceive to be the true theoretical surfuce of the mould-board.

Fig. 126, Plate IV, exhibits distinetly in the quadrints obd, the inequality of the angles of aseent for the slice, where the rarlii $" p^{\prime}, " n^{\prime}, " m m^{\prime}$, de. represent the aseents to the correspond- 
ing divisions of length in the transit of the slice through the curve l, d. u, which represents the periphery of the eylindrical surfaces at the line of transit. The parts of the figure lying above that line, represent those that must be superimposed above the quadrantal portion of the cylinder, to complete the upper regions of the mould-board; these parts acting merely as a preventive against the orerfall of the soil into the waste of the plow, are of less importance as to form, than those just described, but are quite necessary in the practice of plowing. The parallelogram $y d$ exhibits the relation in which the furrow slice stands to this form of mould-board, when the slice has been raised to the perpendicular, and $y u$ in its ultimate position.

Although I hold this to be the true theoretical form, it is not in this state fit to be employed as a practical mould-board; but the steps to render it so are very simple. The broad shovelmouth, $a$ b, Fig. 125, would meet with obstructions too numerous to admit for a moment of its adoption in practice; but we have only to remove the right hand portion of the edge, $a b$, in the direction $b q$, making the breadth, $\chi \mathrm{m}$, six and one-half or seven inches broad; that portion also contained in $7^{\prime} r 3$ is to be cut away, leaving $m r$ about four inches broad; $b q r m$ will then represent the share; the mould-board being thus of the prolonged form in the fore part. And, though this form has no peculiar adrintage over the truncated, in respect to working, it is better adipted to admit of the body being constructed of malleable iron, a practice which, though more expensive, is certainly the most preferable, by reason of its greater durability, and being less liable to fricture through the eflect of shocks when stones ar other obstructions are encountered.

Besides the removal of these parts of the theoretical mouldboard, other slight modifieations are admissible. When the parts lave been cut away as described, the edge, $b$, of the share will be found too thick for a eutting edge. If brought to a proper thickness by removing the parts below, making the edge to coincide with the eurved surfice, the share so prepared would have the character that belongs to the eresting plows. The lower edge of the mould-board, from $r$ to 2 , would be also rather high, and would present unnecessary resistance to the lower side of the slice; both parts, therefore, require to be reduced. The surface of the feather, $b q$, is to be sloped down till it becomes straight botween the points 7 and $\%$, q uot heing mole than one-quarter of 
of an inch above the plane of the sole, as at the dotted lines, $m z$, in Fig. 126. The lower edge of the mould-board is also to he rounded off as shown by the dotted lines along the lower edge from $h$ to $o$, Fig. 128. To prevent the abrasion of the edge of the slice in passing over the monld-board, it will also be expedient to make the lines from $d$ to $u$, in Fig. 126, fall in from below the line of transit upward, as shown in the dotted lines at $d^{\prime} a^{\prime} b^{\prime} u . "$

In order to complete this subject for the benefit of plow-makers, we give Mr. Stepliens' method of forming the pattern of a mouldboard, practically, as we have already given them theoretically.

The Moula-board Pattern.-In this operation the quadrant of a cylinder, upon which the principle is founded, may or may not be prepared. If it is to be employed, then the first process is cxactly as before deseribed in reference to the quadrant, Fig. 123, Plate IV, which must be formed and lined as there described ; but the same process may be pursued by lines alone, without the intervention of a solid, and in the following manner: Having described the quadrant of a circle, as $a b c$, Fig. 123, of ten inches radius, construct the diagram, Fig. 124, as before directed, the entire length, $e b$, being thirty inches, divided into equal parts of three inches each. The are, $b d$, is then to be drawn through the points $b, p, n, m$, which points, instead of being a transfere, ats before described, from the quadrant, may be drawn directly by a beam compass touching the three leading points, $b m d$, as before, which will intersect all the divisions, converting them into ordinates, $1 f, 2 g, 3 h$, ete, to the curve, $b d$. The lengths of these ordinates from the base line, $e b$, are now to be carefully transferred to the quadrant of the cirele, $b d$, of Fig. 126, and set of in the circumference thereof; thus, the point $b$, in Fig. 126, corresponds to the termination, $b$, of the base line in Fig. 124. The first ordinate, $q p$, is to be set of on the quadrant from $b$ to $p$; the second ordinate, $8 n$, is set ofi from $b$ to $n$; the third, $7 m$, from $b$ to $m$, and so on through the entire quadrant of the circle. the radii, a $b$, a $p$, a $n$, ete, being now drawn, will furnish the sncecsive angles of elevation, with the sole plane for each division of the length throughout the quadrant.

In applying these to the monld-boand, it is to be observed that the first three radii belong to the share, if it is a probonged mouldboard; or the tirst tive, if it be truneated. The quadrant, Fig. 126, with its radlii loeing thus completely drawn out at full size "pon a board, produce the line b" to $y$, and on $y$, as a centre 
with a ratius of seven inches, describe the arc $a t$, and concentric to it the arc $l u$. At an angle of 45 degrees, draw $t u$ a tangent to the arc $a t$, and the point of intersection of this tangent with the are will fix the extreme point, $\varkappa$, of the moald-hoard at the hoight of the line of transit, which point will be nineteen inches fiom the land side plane, $b g$, and twelve inches above the plane of the sole or hase line, $y b$. From $d$ lay oft divisions of equal parts on the are, $d u$, each equal to four and a half inches-the diagonal of a square of three inches-which completes the lines for the fabrication of the pattern.

The next step in the operation is that of building a block, out of which the pattern is to be shaped. Provide a deal-board of three and a half feet, or thereabouts, in length, with a breadth of ten inches; have it dressed of a miform thickness, and at least one end and edge straight and right angled, as seen at $a b c$ in

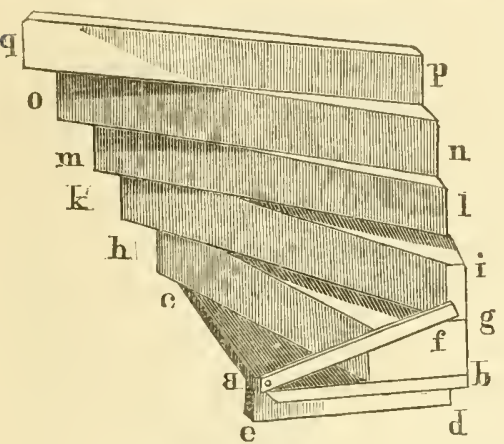

Fig. 52 . Fig. 52, and $a b$, fig. 126, Plate IV, forming a basement to the block, a being the right angle, and the continuation of the board being hid from view under the superimposed block. Let the edge, $a$ c, of the board be marked off in equal divisions of three inches, agleeing exactly with those of the diagram, Fig. 12t, marking the divisions with letter's or numerals corresponding to the radii of the quadrant, Fig. 126 , the end, $a b$, of the hoard corresponding to the raclius, $m$, of the quadrant, and to the oldinate, $7 m$, of the diagram. Provide, also, a suit-stock or bevel of the form represented by d e f, the stock, a $e$, being a straight bar with a head-piece at $e$ fixed at right angles to the stock, and into this blate, $a f$, is to be jointed in such a manner that when the blade and stock are set parallel to each other they shall just receive the thickness of the basement hoard between them, the length of the blade being equal to the breath of the slice. Five or more pieces of woll seasoned, clean, theeinch Memel or yellow pine deal are now to be prepared, each about thirty inches in length and fiom six to tom inches in breadth. Set the level to the angle, l ( m. Fig. 126, and, applying it at the end of the board, as in Fig. 52, it will point ont the position in which the first hlock must be placed on the boand in oreder that it 
may fill the lines of the pattern. The farther end of the block being set in like manner to face within the lines, it is to be firmly attached to the board by serew nails. The second block, $k i$, is to be joined to the first by the ordinary method of glueing, being set in the same manner as the first, to fill the lines of the patteln at both ends, and this requires its being set obliquely to the first. 'The thirel block, $l \mathrm{~m}$, is set in like manner', and so on with $n o$ and $p q$. The setting of the different blocks will he much facilitated by having the ends, $g i l n p$, cut ofl to the plane of the land side, that is, to coincide vertically with the land side edge of the board, and by keeping in view that the terminal line lies at an angle of 45 degrees.

The block being thus prepared, the process of working it off is plain and easily performed in this way: Having set the hevel at the angle, $b$ a m, Fig. 126, which answer's to the end, $a b$, of the block, the bevel is applied as in the figure, and the surplus wood is cut away to a short distance within the end, $a b$, of the board, until the blade of the bevel lies evenly upon the surface, and the kneed head-piece touching the edge of the bourd. Sut the bevel now at the angle, $b$ a $l$, and, applying it at the first division on the edge of the board, cut away the surplus wood with a gouge or other tool, in a line parallel to the end of the board or at right angles to its edge, until the edge of the blade, af, lies evenly on the surface, and the head of the stock touch the edge of the board as before. Repeating this operation at each successive division with the bevel, setting it to the corresponding angle up to the zero or vertical line, and we have a series of leading lines of draughts, each occupying its true position on the surfice of the monld-board to the height of the line of transit. By continuing these lines, each in the direction already given it, until they terminate in the breast or in the upper edge of the pattern, we have a corresponding series of points now determined in the hreast and upper edge; and by removing the surplus wool still vemaining in the spaces between the lines, and reducing the surface to coincide with them, we have the finished surfice fiom the neck of the share up to zero.

To complete the after portion of the pattern, we have to form a temporary bevel with a curved blade adapted to the small anc, $a t$, fig. 126, Plate IV, which blade is prolonged in a tangent, $t u$, at the angle of 45 degrees. With the guidance of this bevel, its strek being still applied to the boand as in Figg. 129, cut alway all 
the wood that occurs to interrupt it behind the zero, until it applies everywhere behind that line without obstruction. At the third division beyond the zero the pattern may be ent off in a roght vertical, though this is not imperative, as the mould-board may be made considerahly longer or a little shorter, without at all affecting its operation. At whatever distance in length its terminal edge may be fixed, that portion of the line of transit which lies between the zero and the terminus must leave the original eurve, $h m d$, Fig. 123, at a tangent, and it will reach the terminus as such, or it will grachally tall into a re-entry curve, according as the terminus is fixed, nearer to or farther from the zero line, the terminus of the line of transit being always nineteen inches distant firm the land side plane. That portion of the surface which now remains unfinished between the ares, $a t$ and d $n$, Fig. 126, is to be worked off in tangents, applied vertically to the arc, $a t$, and terminating in that part of the line of transit that lies between $d$ and $u$. Such portions of the interior cylindrical surface as may have been formed under the application of the temporary bevel to the are, $a t$, are now also to he cut away by a line passing through the junction of the tangents, $t a^{\prime}, t b^{\prime}, t n$, with the cylindrical arc, $a t$, forming a curved termination in the lower part, behind, as seen in Fig. 127, which completes the surfice as proposed. The breast curve and the form of the upper edge will now have assumed their proper curvature, and there only remains to have the whole pattern redneed to its due thicknesses. This, in the fore part, is usually alout one-half inch. increasing backward below to about one inch, and the whole becoming gradually thinner toward the top edge, where it may be three-sixteenths of an ineh.

We may now sum "p the modern history of the plow in Scotland by saying that all the plows now in use there are formed on one of the three models which we have described, viz. : Small's, Linarkshire and Stephens'. The Berwickshire hats the lines of the mould-board concave, and the western Fifeshire very sharply convex, but the differences are too unimportant to make a minute description necessary.

We now proceed to relate the more modern history of the plow in England. We have alrealy stated that the Rotherham plow was the basis of improvement in England, as well as in Scotland, although its progress in the latter kinglom was exceedingly slow, for reasoms which wo have mevionsly given. 
The wooden plows formerly nsed were very liable to get ont of order by warping, cracking, etc., and continually needed repairs, which were very expensive, and the going backward and forward to the plow-wright, who often was several miles distant, was a very serious tax upon the time of the farmer, particularly in a climate as variable as that of Great Britain, often cansing him to lose the proper time for seeding. To remedy this difficulty in some degree, plows were made of wrought iron, as we have seen in Brand's plow, Fig. 17 ; but this material being soft and liable to bend, as well is to wear away rapidly, it became very desirable to find a substitute which should be more rigid and less liable to alnasion. We accordingly learn from Mr. J. Allen Ransom's valuable work upon farm implements, that his grandfiather, Mr. Robert Ransom, of Ipswich, who seems to have been almost as successful in making improvements in agricultural implements as Sir Richard Arkwright was in cotton machinery, obtained a patent for making plow shares of cast iron in the year 1785. Mr. J. A. Ransom very justly remarks that this circumstance is well worthy of notice, not only als a very important and sucessful inprovement in the part in question, but as the means of drawing the attention of that individual and many others to further improvements in the plow, which were soon after earried into effect.

Another long step in the improvement of the plow was taken by the same gentleman in the year 1803, when he obtained a jaitent for case-hardening or chilling shares. When plain cast iron shares were used a little while, it was found that the sharp) edge of the feather wore away so that it, as well as the point, became thick and blunt. This, as can be easily seen, greatly impaired its efficiency; it lost its hold upon the ground; the weeds were passed over uncut, and a great increase of power was required to operate it. Mr. Ransom chilled the under side firom ome-sixteenth to one-eighth in thickness. This part wears'much more slowly than the upper part. The upper surfice grinds away while the lower part is maffected, and hence the edge is al ways sharp. The land side of the point wats likewise chilled in the same manner, and with the like results. When the share was finally worn out, the farmer himself could replace it at a trifling expense, withont the necessity of resorting to a blacksmith or any other mechanic, and the shape of the iron is always uniform, which it could not be when the point and feather were temperen by the blacksmith, guided hy his ege alone. 
Figs. 53 ( $a$ and $b$ ) show shares which have been broken, and the white lines at the edge show the chilled pats.

This new process proved of such practical ntility that it was soon extencled to other parts. A sullolk farmer invented for his own use a cast iron sole-shoe, which wats also chillerl at the bot-

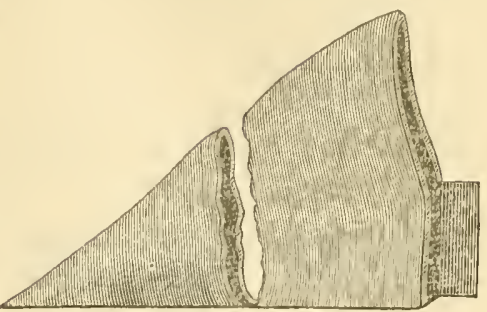

Fig. 58.- (a) tom. It was provided with mortises to receive the tenons of the wooden parts, and soon got into general use. It is represented at

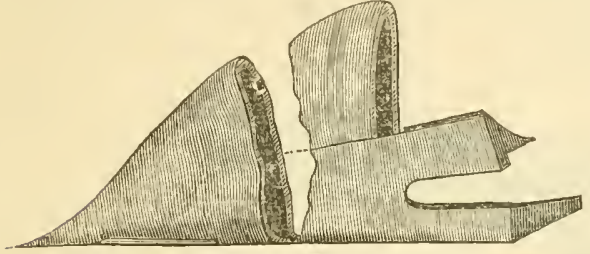

Fig. $53 .-(b)$

Fig. 54. The old diffienlty, however, still remained, notwithstanding these great improvements. So long as any portion of the plow was made by the blacksmith, changes would be made in the eurves and other parts mpon which its useful aetion depended.
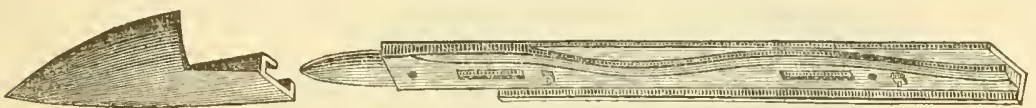

Fiy. $5 \%$.

and there was a consequent uneertainty on the part of purchasers whether the plows would perform good work. As improvements

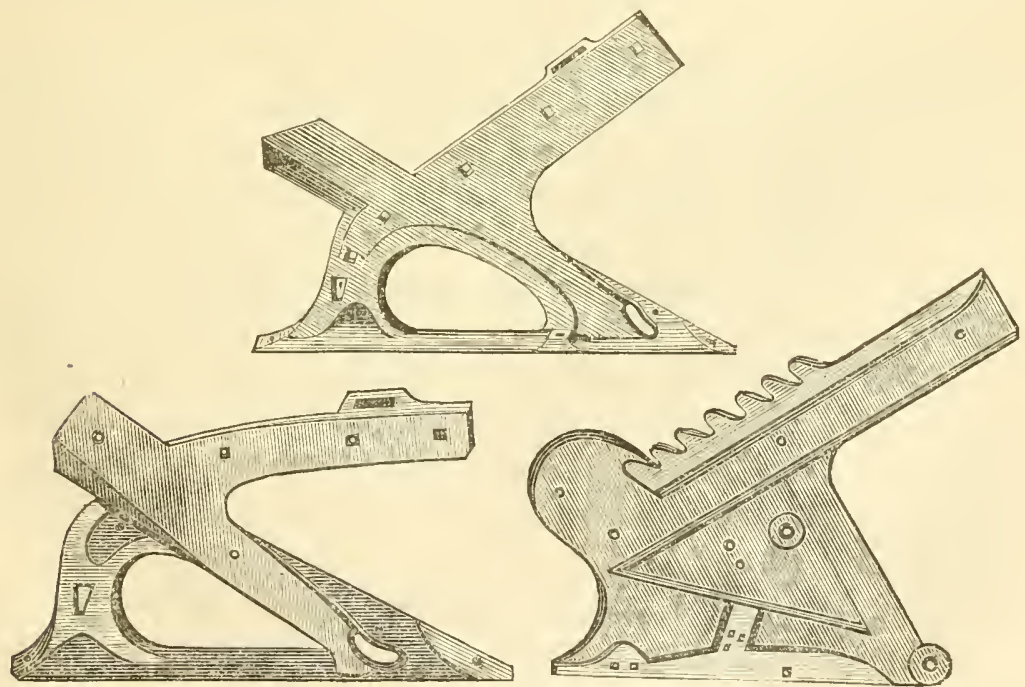

Fig. 5.5 . 
were made in monlding and casting, it became possible to make the whole plow of cast iron, so that when a farmer once had a plow that exactly suited him, it could be acemately and certainly reproduced, and multiplied to any extent, at a very small cost. The next step, after the adoption of the sole shoe, was to make the entire frame of iron. 'They were so constructed that all farts-the handles, beams and shares, the sole, the monld-board ancl the braces-conld be screwed upon with a much greater firmness and much greater capability of adjustment than had ever been attained before. Sketehes of three of these frumes are given in Fig. 55 .

The following figure (56) will show how the mould-board and share was attached to the frame.

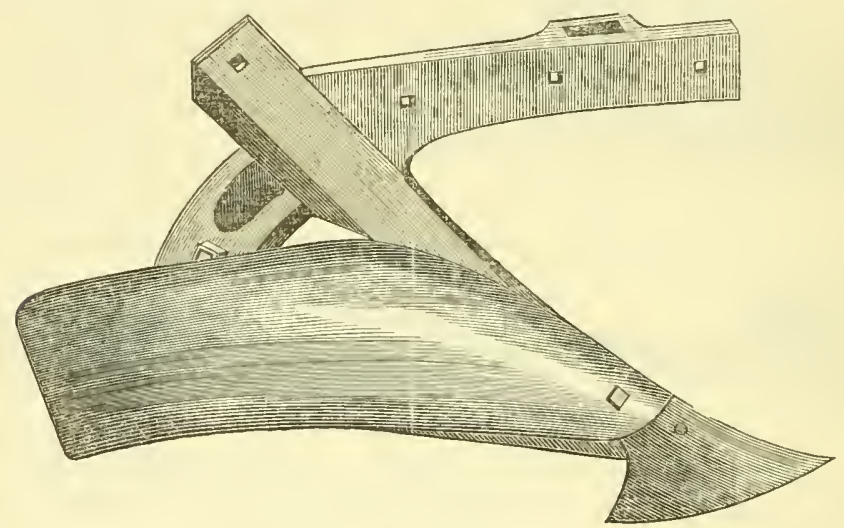

Fig. 56 .

The plow mate entirely of cast iron was introduced about the year 1800, and by 1810 was in very common use. The changes made in the plow for the next quarter of a century were very slight, and these were mainly in the adaptation of the momldboard to different kinds of soil, that is to say, eoneave vertical lines wero adopted in loose sandy soils; straight lines in medium mellow soils, and convex lines in hard elay and other stiff soils.

About the year 1840, Rev. W. L. Rham developed the dôctrine that the transverse lines of the plow should be straight; and so fir as we know, he was the first one who tanght this rule in Enrope, though he had been anticipated many years in this conntry.

Let A B C, Fig. 57, represent the hrealth of the furrow. On this diameter describe the semicircle, $A 4 \mathrm{C}$, and divide it into 



\section{Plate T.}

\section{PLOWS}

Howard's Plow.

$\frac{1}{24}$ of the full size.

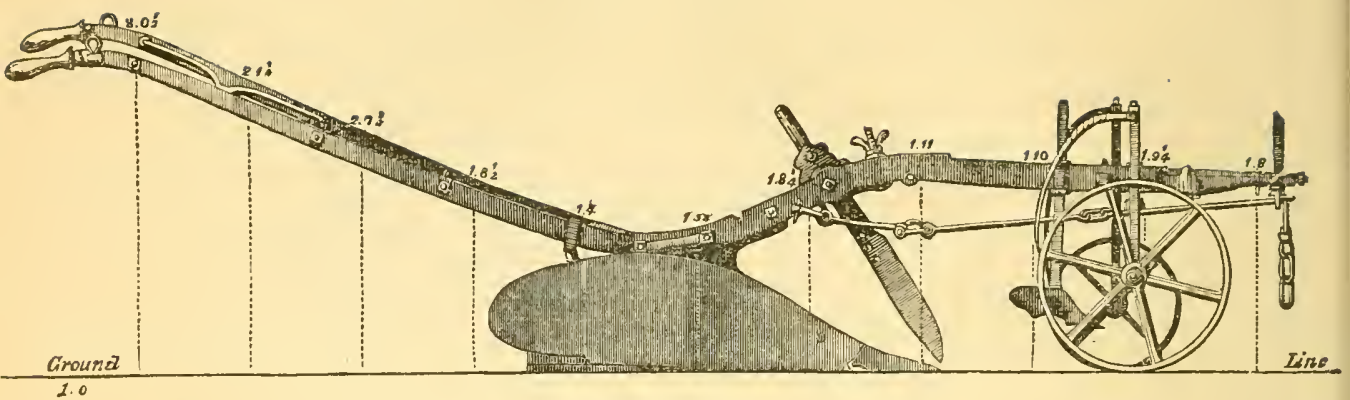

ELEVATION.

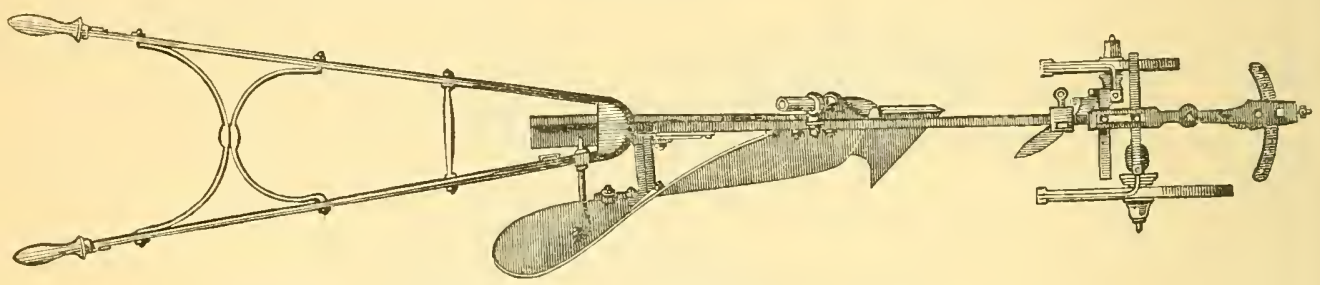

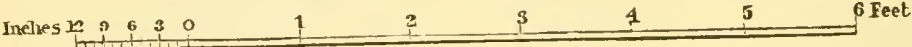

Ransome's Plow.

$\frac{1}{2 t}$ of the full size.
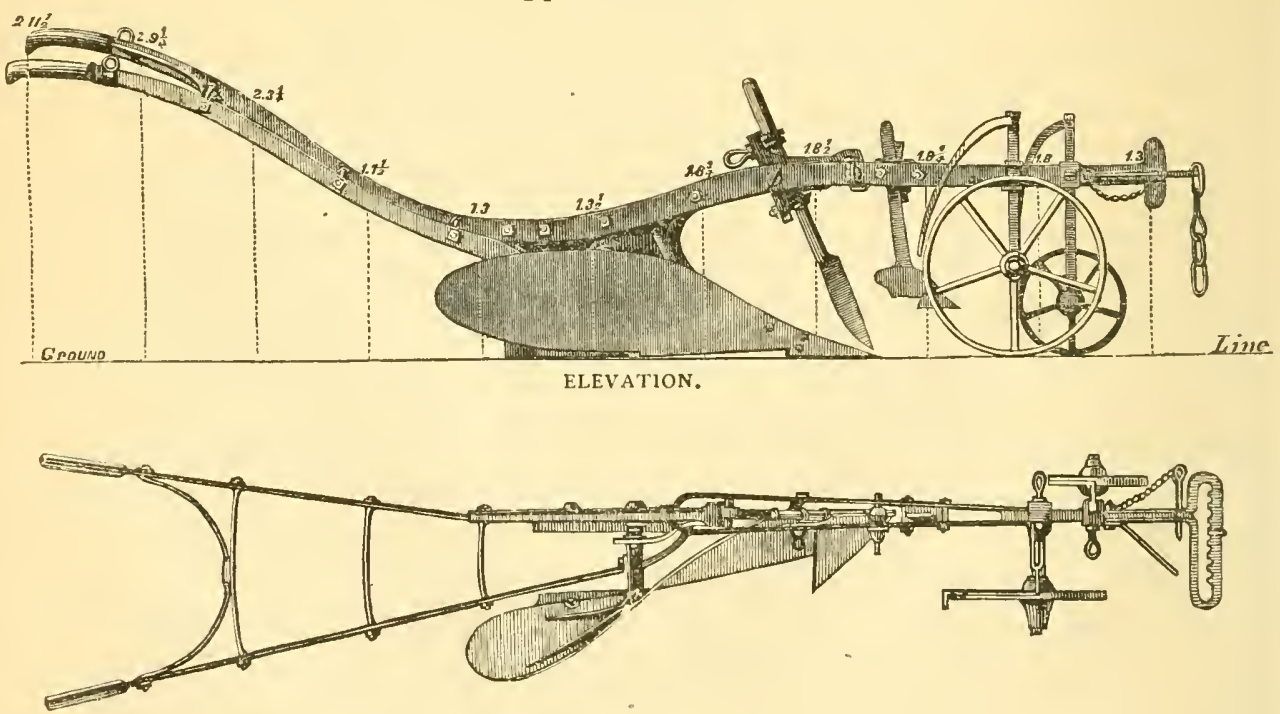
equal parts, 1, 2, 3, 4, ete., and draw the radii, B 1, 132, B 3 , etc., draw the parallel lines, $11^{\prime}, 22^{\prime}, 33^{\prime}$, etc. Draw the share, $d f^{\prime} g e$, and the lines $l e$, the neck of the shatre, and $3^{\prime} 6^{\prime}$, making the distance between them equal to the length of the mouldboard. Draw the diagonals $6^{\prime} d, 5^{\prime} 1^{\prime}, 4^{\prime} 2^{\prime}$ and $33^{\prime}$. 'These lines will represent the twist of the mould-board, the zero being at $h$.

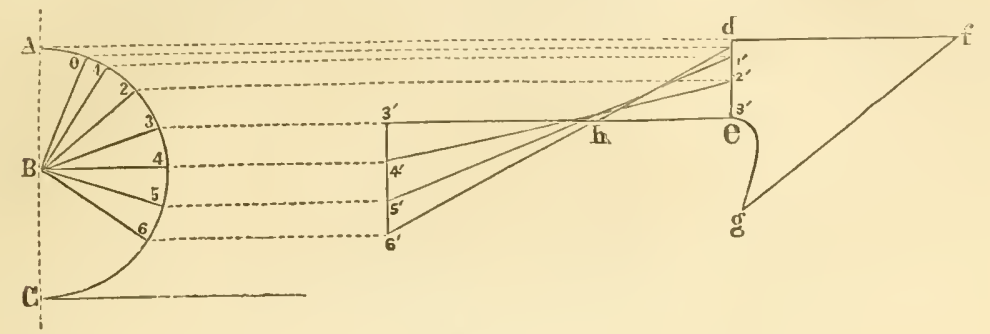

Fig. $5 \%$

Mr. Rham recommends that all plows should be thus made, with straight transverse lines, but that the vertical lines should be altered to suit different soils. So that, for medium mellow soils, the vertical lines should be straight; for stiff clays, convex, and for sandy and loose soils, concare; the degree of convexity to be proportioned to the stiffness of the clay, and the degree of concavity to be proportioned to the looseness of the sand.

Fig. 58 represents these various sections. A B represents the section contiguous to the neck of the share; $\mathrm{C} \mathrm{B}$ in the middle of its length, and D B at the heel. No. 2 represents the convex lines for stiff soils, and No. 3 the concave lines for loose soils.

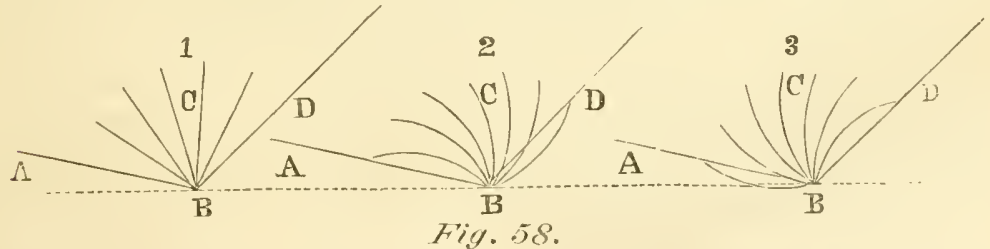

The tendency of plow-makers since the publication of Mr. Rham's views has been to approximate their mould-boalds to the lines indicated by him.

Tre give on Plate $\mathrm{V}$ figures accurately representing the plows of Mr. Howad and Mr. Ransom, which may be taken as representing the utmost perfection to which the art of plow-making has reached in Fugland up to the present time.

As the plan of Mr. Rham has been substantially adopted by some of the most eminent plow-makers in England, we will give 
it in fuller detail. It will be observed that Mr. Rhan's mould board is eurved in the form of the spiral thread of a screw, such

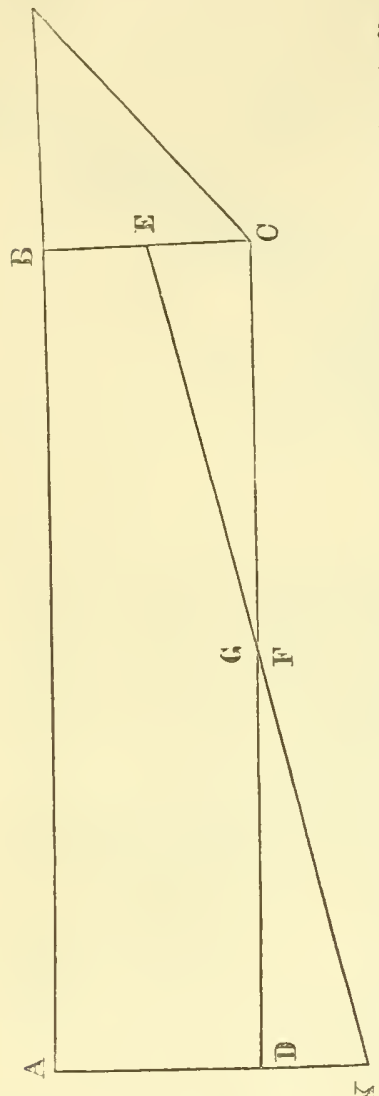

as would be generated by a line moved uniformly forward in a direction at right angles to its length, while it revolved uniformly round one of its extremities. This surface is thus generated mechanically-Fig. 59. Take a rectangular parallelogram, A B C D, of the width of nine inches, or as wide as the intended furrow, and of length equal to four times the width. Bisect $\mathrm{B} \mathrm{C}$ in $\mathrm{E}$, and $\mathrm{D} \mathrm{C}$ in $\mathrm{F}$; at Fraise a perpendicular to the plane of the rectangle at $\mathrm{F}$, and make it equal to $\mathrm{C} \mathrm{E}$; join $\mathrm{E} G$, and produce it to $\mathrm{K}$, making $\mathrm{K} G=\mathrm{E} G$ join $\mathrm{K} \mathrm{D}$. Draw from every point in $\mathrm{C} D$ lines at right angles to $\mathrm{C} \mathrm{D}$, meeting the line $\mathrm{E} \mathrm{K}$ in different points, these lines will form the required surface. The line $\mathrm{K}$ D will be found inclined 45 degrees to the horizon at the angle $\mathrm{K} \mathrm{D} \mathrm{H}$, which is the inclination at which the furrow slice is most advantageously laid. To those who are not fimiliar with solid geometry, these lines may be easily exhibited by means of a wire in-

Fig. 59. serted at $\mathrm{E}$ and bent at a right angle at $\mathrm{K}$, inserting the bent portion into the board, A B C D, Fig. 60, at $\mathrm{D}$, lying in the direction E K, Figs. 59 and 60. Care must be taken that $\mathrm{G} F$ be equal to $\mathrm{C} \mathrm{E}$, and $\mathrm{H}$ perpendicular to the board. It is evident that, as the plow moves on, a particle at $\mathrm{E}$ will slide along the line $\mathrm{E} \mathrm{K}$, become at $\mathrm{G}$ perpendicular to the plane of the sole, and at $K$ be at an angle of 45 degrees with that

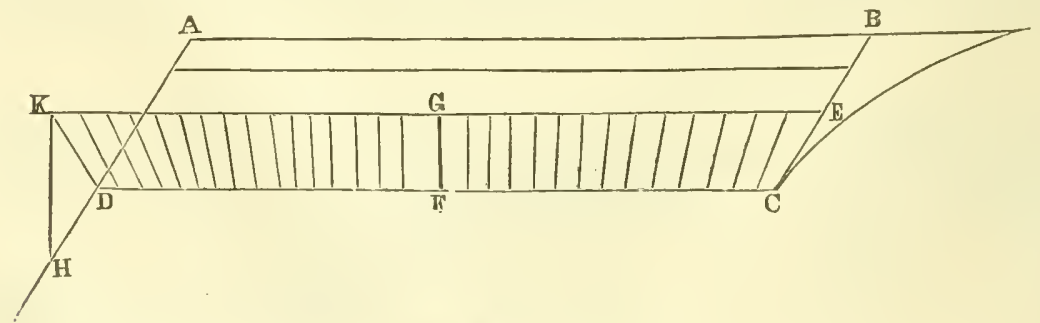

Fig. Go. 
line. If the slice were a solid substance, this line, $\mathbf{E} \mathbf{K}$, would be all that is required to turn it in its proper position; but as the soil is generally loose, and would crumble in pieces, a support must be given to it by a surface at least as wide as the slice. This surfice is generated by drawing lines from different points of $\mathrm{D} \mathrm{C}$ at right angles to the line and meeting the line $\mathrm{K}$ E.

\section{CHAPTER IV.}

\section{AMERICAN PLOWS.}

HISTORY OF THE PLOT-CONTINUED.

We now turn to the history of the plow in this country. Until the beginning of the present century the plows used were most deplorable implements, fabricated by the most careless and unintelligent mechanies, searcely any two being made alike. We cannot find, and we have never seen or heard of, a single plow having been made on the principle laid down by Mr. Jefferson in his day, except those made by himself; in fact the existence of his method was hardly known in this country until within quite a recent period, although it was well known and much talked of in Europe.

Mr. A. B. Allen, in the Transactions of the New York State Agricultural Society for 1856 , thus describes the primitive methods of the plow-maker's in this country in the early part of the present century :

"A winding tree was cut down, and a monld-board hewed from it, with the grain of the timber rumning so nearly along its shape as it could well be obtained. On to this mould-board, to prevent its wearing out too rapidly, were nailed the blade of an old hoe. thin straps of iron, or worn-ont horse shoes. The land side wis of wood, its base and sides shod with thin plates of iron. The share was of iron, with a hardened steel point. The coulter was tolerably well made of iron, steel edged, and locked into the share nearly as it does in the improved lock coulter plow of the present day. The beam was usually a straight stick. The handles, like the mould-board, split from the crooked trunk of a tree, or as often cut from its branches; the crooked roots of the white ash were the most favorite timber for plow handles in the northern 
States. The heam was set at any pitch that fancy might dictate, with the handles fastened on almost at right amgles with it, thus leaving the plowman little control over his implement, which did its work in a very slow and most imperfect manner."

It is curious, as well as humiliating, to see how little advance had been made in the fabrication of an implement which lies confessedly at the root of all human civilization. As we have seen, the original plow was a forked stick, with natural crooks which adapted it to the purpose; and after a lapse of three thousand years, the same idea as stated by Mr. Allen was still uppermost in the minds of plow-makers, the last differing mainly from the first in being protected from weur by nailing on old hoes, horse shoes, etc.

It is, however, instructive and interesting to observe that there was, after all, a certain blind instinct in the American farmers' minds which led them somewhat in the right direction. They invariably selected trees for mould-boards which had been accidentally twisted in their early growth, and thus, without knowing or suspecting it, they were approximating to a helicordal curved surfice.

The first American who set himself to work to improve the plows in common use, after Mr. Jefferson, was a farmer by the name of Newbold, residing in Burlington, N. J., who made the first cast iron plow ever made in America. He used it successfully himself, but so great was the antipathy to new-fangled notions that no one would imitate his example, and very few would even try his implement.

As this plow was the first that was made of cast iron in this country, and thus inaugurated a new era in the history of the implement, it is from this cireumstance invested with so much interest that we give his specification in full, viz. :

"The subscriber, Charles Newbold, of Burlington county and the State of New Jersey, has invented an improvement in the art of plough making, as follows, viz: The plough to be (excepting the handles and beam) of solid cast iron, consisting of a bar, sheath and mould plate. The shenth serves a donble purpose of conlter and sheath, and the mould plate serves for share and mould board, that is, to cut and turn the furrow!

"'The forms to be varied, retaining the same general principles, to meet the various uses, as well as inclinations, of those who use them.

"Philadelphia, 17th June, 1797.

"CIIARLES NEWBOLD.

$\left.\begin{array}{l}\text { "Joln Altan, } \\ \text { "URIau Tracy, }\end{array}\right\}$ Witnesses present at the signing." 
The letters patent were signed by John Actams, President, and Timothy Pickering, Secretary of State, and their legality was certified to by Charles Lee, Attorney General, on the 26th of June, 1797. Fig. 61 is a correet delineation of this plow.

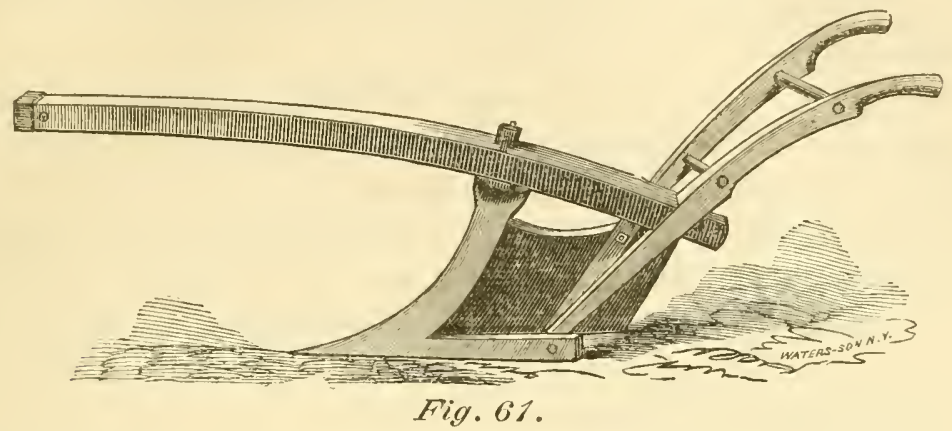

Charles Newbold, the inventor of the first cast iron plow ever made in Ameriea, was born in the township of Chesterfield, Burlington county, New Jersey, about the year 1780, and in 1804 , married Hope, the daughter of David Sands, who lived a few miles south of Newburgh, N. Y. He was endowed with a large share of energy and genius, which developed themselves in the formation of so many sthemes and contrivances, which succeded one another so rapidly in his teeming brain, that he had no time to earry any one of them into successful operation. He had at grand scheme for founding three cities on the Hudson river, to he. ealled Faith, Hope and Charity. These were to be the centres, lespectively, of trades, manufactures and commeree. They were to be comnected together hy the best possible rouds, as well ati water communication, and from the central city a grand road across the continent, similar to the Cumberland road, was to connect the Hudson river with the Pacific ocean. From this central trunk road numerous lateral roads were to be made to diveroe in every direction throughout the entire continent, so that the whole trade and commeree of the country should finally centre in Faith, Hope and Charity. His cotemporaries thought these notions exceedingly visionary, and some of them thonght they afforded unmistakable indications of insanity ; but a road already exists in an unbroken line, at this day, from Newburgh to the hase of the Rocky mountains, and in a few years more, though Faitl, Hope and Charity are yet unbuilt, his grand idea of a connection between their sites and the Pacific ocean, by a railroad over the whole ronte, with lateral communications orer the whole United 
States, have been fully realized. He who in that early day. with the eye of faith, could discern this vast system of internal improvement as a present reality, could have been no common man. Some time after his marriage he removed to Cornwall, N. Y., where his wife had formerly resided, and remained there until his death.

His plow, consisting of share, land side, sheath and mouldboard, was all cast in one piece by Benjamin Jones, Esq., at the Hanover furnace, Burlington county, some time between the years 1790 and 1796. This plow was put into operation in a young orehard belonging to Gen. John Black; the plowman soon afterwards broke the point, and it was never used afterwards. It is still in existence, and is the property of John Black, Esq. (a son of Gen. Black), of Monnt Holly, N. J.*

Mr. Newbold, although he had made a most valuable improvement, was unsuccessful in persuading the farmers of his region to adopt it. He spent upwards of $\$ 30,000$ in perfecting and introdncing his plow, and then abandoned the business in despair, as the firmers had in some way imbibed the strange notion that the cast iron plow poisoned the land, injured its fertility, and promoted the growth of weeds. Towards the latter part of his operations he substituted a wrought iron share for the cast iron, but it did not overeome the prejudices which had been engendered, and the furmers still adhered to the miserable bull plows that were in vogue, which took much more power and did not work as well.

There are traces of the use of a cast iron share still earlier than Mr. Newbold's. In the year 1794, it appears by the first volume of the Transactions of the Society for the Promotion of Agriculture, Arts and Mimufactures, that "Col. John Smith produced the model of a plow share, according to which it was proposed to have that utensil made of cast iron, in order to sare expense in husbandry, and come eheaper to furmers than those in common use, forged from wrought iron; and Mr. Smith and Judge Hobart were appointed to get several cast for trial." At the next meeting, Col. Smith reported that the cast iron share exceeded his most sanguine expectations. "It is cast in the form of a Dutch share (probably the Rotherham share), after the best model that conld be procured liy the society, with this exception, that the edge is not complete, and not so wide by about three inches as it will be when finished with the filse edge which is made of

* This original plow has been presented by Mr. Black to tho State Agricultural Society of Now York, for its Museum, in Albany. 
wought iron or steel and fistened on with rivets." He informs the society that they may be had, either with or without the false edge, of Mr. Peter T. Curtenius, in New York. The Col. Smith ahore named was afterward Gen. Smith, and was the proprietor of St. George's manor in the county of Suffolk. He was an eminent and extensive farmer, and was one of the original corporator's of the old Agricultural Society of New York.

The next plow patented was by John Denver, June 12th, 1804. He was a Marylander, and some old people in that State still remember such a plow, but we ean obtain little definite information respecting it; it probably never came into very general use. There is neither specification, drawing or model of it now in the Patent Office.

The next patent was granted to Hezekiah Harris, of Kentucky, February 24th, 1804. We can find no memorial of this plow either in the Patent Office or elsewhere.

A patent was granted to David Peacock, of New Jersey, April 1st, 1807. There is no reeord of this now in the Patent Office at Washington, all the old records having been destroyed by fire ; but we learn on very good authority that it was made of cast iron, and resembled Newbold's plow, except that it was east in three separate pieces, while Newbold's was east in a single piece. Newbold sued him for an infringement, but it was finally settled by the payment to Newbold of $\$ 1,500$. He was very much dissatisfied with his agents, who made this arrangement, and always thought that he had been betrayed by them. David Peacock took out another patent in 1822. There were some improvements made in other parts of the plow, but the chief feature was the famons lock coulter which it is believed he was the first to introduce (Fig. 90). The plows made by Peacock were very extensively used throughout the country, and many of them were to be found in use on farms in this State and in New Jersey and Pennsylvania as late as the year 1850 .

The earliest recognition of the importance of straight transverse lines in the mould-board that we have met with is contained in the following letter from the celebrated Timothy Pickering, who wats a most exeellent farmer, as well as an eminent statesman. It was addressed to Dr. Alex. Coventry, and is dated Salem, June 3d, 1820:

"My public employments in the war of our Revolution having callsed me to take my family to Philarlelphia, I remained there 
after its termination. During four years I lived in the country, and paid some attention to husbandry. One day when lean'ning to hold a plow (a good Pennsylvania plow of that day), the soil, rich and moist enough to be allhesive, I observed that the earth filled the hollow of the mould-board, and assumed a straight line from its fore end, near the point of the share, to its upper projeeting hind corner, and that it mainlained that same straight line. It then struek me that this straight line should exist in every mould-board and direet its eurvature. Four or five years afterwards I returned to Philadelphia, having been again called to public life. And, at a subsequent period, visiting Mr. Bordley, the Vice President of the Philadelphia Agrieultural Soeiety (of which I was a member, and its secretary at its first formation in 1785), he handed me a small model of a mould-board which Mr. Jeflerson had left with him. At the first glance I saw the straight line before mentioned governed its form, and asking Mr. Bordley's daughter, then at her needle, for a piece of thread, I stretehed it from the left lower fore part of the mould-board to its right upper overhanging fore eorner, and found it in a straight line, touching the mould-board in its whole length. 'Here,' said I to Mr. Bordley, " is the prineiple on which this mould-board is formed.'" * * * * "I have given this detail to explain the opinion I now express, that the straight line therein described is essential to the form of the mould-board of the least resistance. Around this line the currature is to be formed; and plaeing the lower edge or bottom of the mould-board on a level floor, if another straight line be laid transversely on the fore end or point of the mould-board, and moved regularly backward on its fitce in a plane perpendieular to the horizon, it will touch the monlc?board in its whole breadth, throughout its whole length, provided the curvature be eorrect. In a word, the eurvature will be a portion of a spiral serew. Take a large screw anger for an exemplitication. No earth ean be left on such a mould-board; for "rery sueceeding portion of earth which the plow raises pushes ofi that which is on the transterse straight line behind it : and the fitee of the mould-board consists-is mate up (mathematically speaking —of an infinite number of such transverse straight lines.

"One more olservation: The essential straight line indicates the slope of the wedge on which the furrow slice rises until it reaches that point in the line at which the transverse line is perpendicu- 
lan', after passing which the gradual overhanging of the mouldboincl pushes the furrow slice (supposing it to rest on its lower edge as a hinge) beyond the centre of gravity, and at length completely subverts it; or, in furmers' language, lays it upon its hack. The angle which the stright line should form with the sole of the plow is another material point to be discovered by experiments.

"In adjusting this mould-board to the plow, another point is to be determined-the extent of the angle which the essential stright line should form with the bar of the share or land sicte of the plow. The smaller this angle the less the resistance at entering the earth; but if the angle were to be very small, then the plow must have great length to obtain a proper breadth of furrow; and such great length would proportionally increase the quantity of fiction. Hence the conclusion, that keeping both these points in view, repeated experiments must decide where lies the just medium of breadth, of angle, and length of mouldboard."

The lines rumning from the front of the plow towards the back are now usually trausverse lines, but Mr. Pickering evidently applies this term to the lines rumning from the sole to the top of the plow.

The next patent granted was to Hezekiah Harris, of Kentucky,

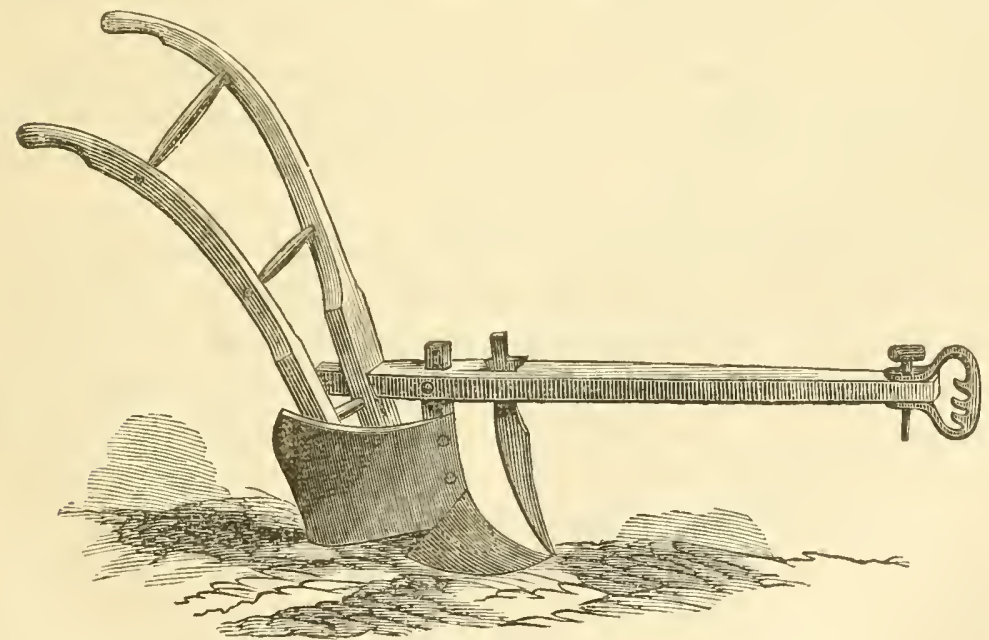

Fig. G2.

on the 24th of February, 1808, of which no record remains in the patent office, and of which we can learn nothing whatever. The next was to Richard B. Chenoweth, of Marylamd, a drawing of 
which is given in Fig. 62, and the following extract from the specification will give the idea of the inventor:

"There is attached to the upper side of the mould-board, which is of cast iron, a share which in its shape differs from any other now in practice, it being fastened on the upper side of the mould-board with screws, the point doubling over, but rumning even with the land side, which is also made of cast iron, and leaving a hollow under the mould-board so that small stones may pass withont interruption. The share is made of wrought iron with a steel edge weighing from four to eight pounds."

John Klay, of Maryland, received a patent for a plow dated January 11th, 1812.

Roswell Tousley, of Scipio, New York, received a plow patent on the same day; this man was subsequently a partner of Jethro Woods.

John Seltz, of Pemsylvania, received one February 8th, 1813.

Matthew Patrick, of New York, had a plow patented on the $2 d$ day of January, 1813.

Horace Pease, of Scipio, New York, received a patent for al plow August 28th, 1813.

Jethro Wood, of Scipio, New York, had a patent for a plow granted July 1st, 1814. He did not attach much value to this patent, and never attempted to introduce it extensively, as we are informed by his daughter's.

The next patents granted for plows were to John Swan, of Scipio, New York, on the 5th day of July, 1814; to J. Morgan and J. B. Harris, October 11th, 1814; to David Peacock, of New Jersey, May 29th, 1817.

Gideon Davis, of Maryland, received a patent for a plow May 26th, 1818. This plow is interesting, as it is the first attempt since Jefferson's day to construct the mould-board on mathenatical principles. The drawings will be found on Plate VI, and the following specification will show the ideas which the inventor sought to embody:

"The great desideratum to be attained in the box share or" shallow plow, is that it he so shaped and constructed as to detach the furrow slice from the solid ground, raise it up and turn it over, in the neatest and most uniform and effectual mamner, with the least possible labor, both to the plowman and the team, combining at the same time the advantages of being simple in its structure, strong and durible, easy to keep in repair, and cheap. 


\section{Plate VI.}

\section{DAVIS' PLOWS.}

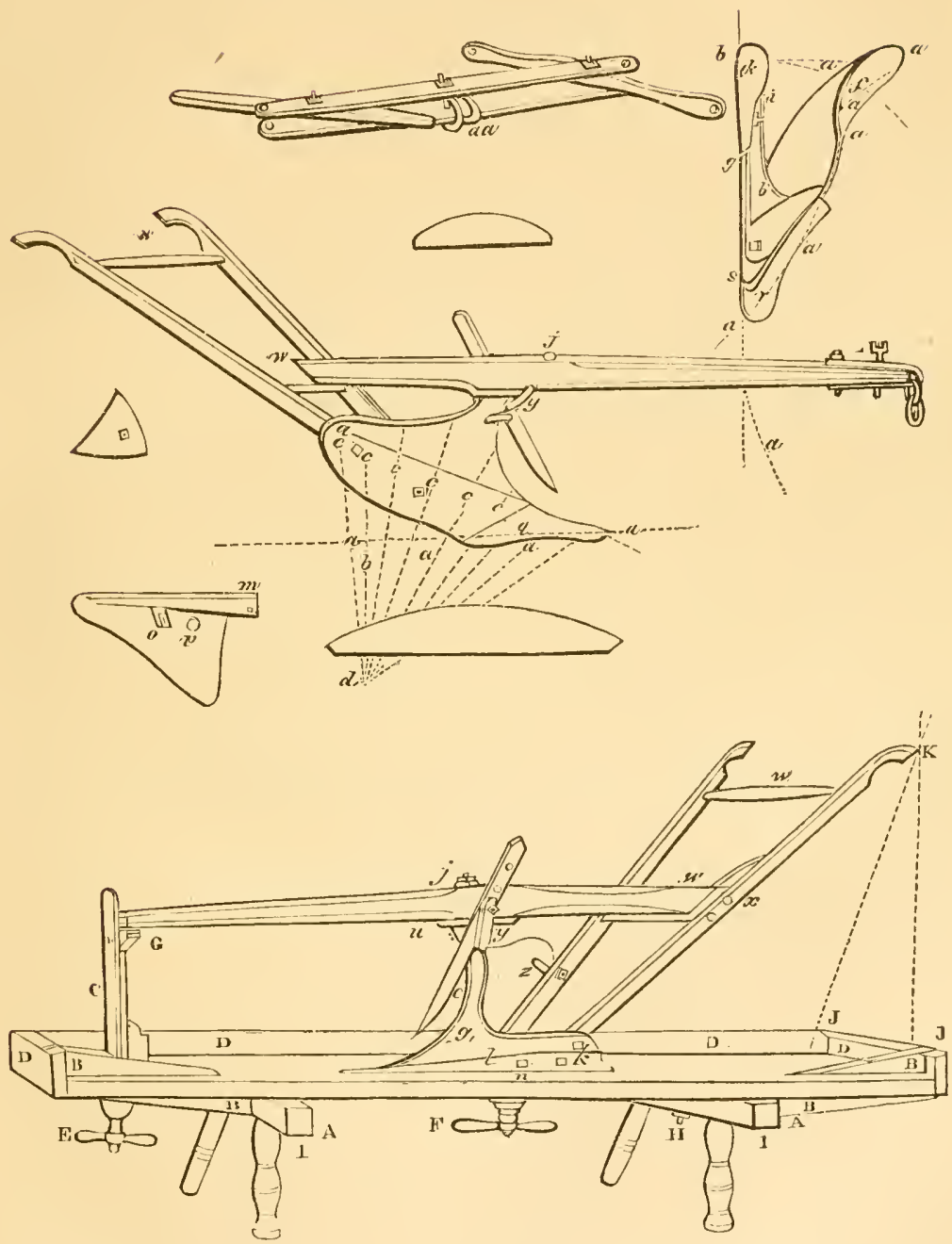



The mode of using, it is desirable, should be such as will cause the least trouble and ineonvenience to the plowman.

"With a view to combine as far" as practicalle these various ohjects, I begin by making the mould-board, land side, and standard (or width for the beam to rest on), all of cast iron, and in a solid piece; this is done in the manner that Charles Newbold, of New Jersey, made his improved plow, patented in the year 1797 , but with several alterations and improvements hereinafter particularly specified.

"First-Of the shape of the moulding part, or what is com monly ealled the face of the mould-board, the general principle heretofore concurred in by all scientific men who have turned their attention to this subject, is that as the furrow slice is detached from the solid ground, at a straight line, parallel to the surface, at such depth as may be required, that it should be raised up and turned over, so as to retain, as far as possible, the same flat shape. In order to accommodate the face of the mouldboard to this idea of raising the furrow slice up and turning it over, it has been so constructed as to form straight lines lengthwise, either horizontal or a little inclined, and also to correspond with another set of straight lines at right angles with the land side, or nearly so, commencing at the point touching the edge of the share and lower edge of the mould-board. These last mentioned straight lines, as they recede from the point of the commencement, gradually change from a horizontal to a perpendicular direction, and even pass beyond the perpendreular so fill as to give the proper over-jet behind. It has been thought that mould-boards so construeted would fit and embrace every part of the furrow slice in the operation of turning it over, not observing that the furrow slice must necessarily assume a convex form on the under side during the operation by which it is raised up and turned over.

"The truth is, however, that in raising and turning over the furrow slice it always aequires a convex form on the under side, or else it is broken into pieces and thrown over; as might therefore be anticipated, it will be found that all those mould-boards which are constructed on this principle wear through, in the operation of plowing, about midway, whilst the upper and lower edges are scarcely rubbed. It also necessarily results that plows of this description work hard and are of heavy draught, because the mould-board not being adapted to the convex form which the 
furrow slice is disposed to assume, lifts the furrow slice at a single point, and that in the middle instead of being equally applied throughout the entire operation.

"In order to meet and remedy the inconveniences arising fiom this form of structure, I form my mould-board into a different shape, and instead of working the moulding part or fice of the mould-board to straight lines, my improvement is to work it to circular or sphere lines. By repeated experiments I have ascertained that in one direction, viz.: from $a$, Plate VI, fig. 4, inclining to the back part, $d$, the circle or segment of the mould-board, to which the mould-board is wrought, should have about three times the radius of the smaller segments represented by the lines lettered $c c$, \&c., the former being thirty-six inches, the latter twelve inches. In order then to shape the moulding part, or the face of the mould-board, having obtained a suitable block, I begin by laying off the bottom (Fig. 3), and (Fig. 4) by circular or spheric lines at a $a$ a. If I intend to construct a plow of a proper size to ent and tum a twelve inch furrow, I strike this segment of a circle of thirty-six inches radius (Fig. 1), and at iwenty-four inches back from the point $c$ at right angles with the land side and twelve inches firom the land side; the circle will intersect the angle line; this circle is extended out from the land side; I then work the block to fit the same segment, inclined from $a$ (Fig. 4) at the point of the share, to $a$ at a perpendicular raised twelve inches from the horizon, with the circle extended in toward the land side; then having wrought to the shape of these two lines, I apply the circular part of the smaller segment (Fig. 2) and work the face of the mould-board, until that segment will have an equal bearing on all parts, corresponding with the cross lines c c $c$, de., which if produced would all terminate in a point at $d$, which is about thirty-six inches from the perpendicular, where the line $a$ a crosses the line $d b$; this being worked off uniformly, forms a section of an oxydromic or spiral curve, and when applied to practice is found to fit or embrace every part of the furrow slice fir more than any other shaped plow. The plow may be made larger or smaller, suited to deep or shallow plowing, by enlarging or diminishing the radii of the segments which it is wrought by. Believing that this mode of shisping the monlding part or face of the mould-board is an original invention of my own, not heretofore known or used, and that it is a most important improvement in the shape of the plow, I 
claim the exclusive privilege of making, usung and vending the silme.

"Second-Shape of the throat and hind part of the mouldhoard: The shape of the throat is exhibited in the accompanying drawing, fig. 4, fig. 5, Plate VI. I construct this part of my plow with a gentle curve from the top of the share entirely up) to the beam, which, at a suitable height for a plow designed to turn a furrow slice of about twelve inches in width, say about sixteen inches, will incline forward as it comes up to the beam to form a birth for it to rest on in an easy circular form. I dress it off also round as it ascends from the share, making it broader and broader as it approaches the beam. The object of this peculiar shape is to prevent brambles, long grass, \&c., from lapping so short as they would do if the front of the throat were sharp, and the inclination forward at the upper part of the throat forms a curve with the under side of the beam, so as to prevent anything in plowing to be jammed under the beam-the pressure below naturally forces the incumbrance up and forward. when it faces over and the plow cleans itself. This I consicler an improvement of great value in plowing in clover, long manure and the like. The head part of the mould-board, Figs. 3 and 4 , $f$, I dress off in a gentle curve from the end or wing of the share up to the hind colner of the mould-board. This shape I have ascertained to answer every purpose in turning over the furrow slice, and as it does not come down to the bottom of the furrow the plow works with much less friction, is lighter, cheaper and handsomer.

"Believing these shapes for" the throat or breast, and the hind part of the mould-hoard not to have been known or practiced before my application of it, and that they constitute valuable improvements in the construction of the plow, I claim tha exclusive right to use and dispose of them.

"Third-The structure of the land side with the mould-board and standard, or the fore and top part of the mould-board: Charles Newbold made his monld-board, land side and standard of one piece, and of cast iron. In connecting his land siclo to the mould-board, he made it nearly square and stout to give it strength. I make my land side thin and broad, g, Fig. 5, which gives more strength rertically, without so much weight. This form also makes it a guard, which prevents sods, dirt, \&c., from working in and clogrging that part of the plow. In order then 
to give additional strength to the land side sidewise, and to conneet it at a proper angle with the mould-board, I make a rib, $h$, Fig. 3, on the land side, about midway between the top and bottom, say about two and a half inches from the bottom. This rih is made broad where it joins the monld-board at $i$, and tapers as it goes back to the birth for the handle to fisten on, where it terminates at $i$, Fig. 3 , where I make a projection or jog, which cannot be represented in the drawing, to raise about half an inch for the end of the handle to rest against. This rest, or jog, sustains the pressure of the handle endwise, so that the screw bolt is only required to confine it to the side. C. Newbold made the standard of his plow to pass up through a mortise in the beam; mine extends only up to the beam; the beam is fastened on it with a strong iron serew bolt, which may be made either to pass up through the top of the standard in the front part of it and through the bean vertically, $j$, Fig. 5 , or to pass through the beam in an inclined direction, and containing the same inclination through the top of the standard, having on the inside a birth for the mut to work on, J, Fig. 4. There are plows in which the beam is fastened on the top of the standard with two bolts. The improvement which I claim to have invented consists, therefore, only in these particular modes of comnection. The adrantage of it consists in this-that the fastenings being made by a single bolt upon which the beam can turn, it enables me to adjust the landing of the plow by a simple operation in altering the position of the end of the beam, where it is united to the handle. This will be more particularly described when I speak of the stocking: of the plow.

"There have been, also, land sides heretofore constructed which were made thin and broad, but supported in a diflerent manner: My improvement, therefore, eonsists only in the mode of making the rib, the projection or jog in the inside of the land side, the form of the top of the standard or the fore and top part of the monld-board, which, being made to extend forward under the heam, equalizes the bearing of the beam. Thus a smaller piece of wood will be more sufficient to form a beam than if the fistenings to the handle and standard are brought nearer to each other.

"Fourth-The shoe: Charles Newbold made a bar of" wrought iron which he caused to extend back from the share to the end of the land side, below it, and fistened to it with a serew bolt passing up through the shoe and lind site. 
"Stephens, of New York, applied his shoe on the bottom of the land side of the plow, and fistened with a small screw bolt passing through both. Shoes constructed in this manner will only answer the purpose of protecting the bottom of the land side. The side, however, is equally exposed, and in time will wear" entirely off.' To obviate this inconvenience, I make a groove $\mathrm{Or}^{\text {' }}$ countersink in the side and lower edge of the land side of my nlow, which forms a birth for the shoe, and admits of the thickness, without any inconvenience, I make from its projecting out, R R, Figs. 3 and 5 ; the shoe extends round under the bottom of the land side and fastens on with one or more screw bolts.

"The improvement consists in so construeting and applying the shoe that it protects both the sides and the bottom of the land sicie. It may be made of wrought or east iron, or steel.

"Fifth-New mode of making, applying and using the share of the plow, whether formed of wrought or cast iron: If I apply the wrought iron share, I make it in the usual way by welding the wing on the land side (see Fig. 6), and fasten it to the cast iron part of the land side with a small screw bolt, $n$, Fig. 5. Then I fasten it to the mould-board by means of a projection made on the front and lower part of the mould-board, with an inclination forward, forming a dovetail or hook which I extend through the share. (See o, Fig. 6.) This mode will hold on the share very firmly, but as it is liable, being made of cast iron, to break off, in order to obviate this danger, I fasten the share to the mould-board with a strong screw bolt, having the head made to fit a tapering hole made in the mould-board, and passing down through the wing of the share, $p$, Fig. 6 , and drawn up tight with a serew nut. If it be a right-handed plow, this should be a left-handed screw, and if a left-hand plow, then a right-handed screw. This is somewhat the manner in which David Peacock, of New Jersey, fastened the share on his plow, patented in the year 1807, but with this difference: he put two screw boits and a false coulter through the wing of his share; therefore made it stationary, and without its being made fast to the cast iron part of the land side at all. But, in my mode of fastening the share on, by putting a piece of wood or leather between the wrought and cast iron land sides at $n$, Fig. 5 , the point of the share may be somewhat adjusted, and the bar always regulated to suit the shoe of the plow. The point and edge of the share is likewise of a different shape from any that lave here- 
tofore been made to my knowledge. Having remarked that the point of the slime is alwatys disposed to wear round, I make the point round at first. I also make it about twice as broad as usual, and of course much thinner. The edge of the share is likewise made rather concave or hollow, this being the shape to which it naturally wear's. In consequence of this they wear much more uniformly, will last longer and be less expensive.

"It is also a fact that the broad share or coulter point will enter or strike into the ground much better thin those of the ordinary construction, and, being much thinner, will retain their edge and work much longer without requiring repair.

"In using the wrought iron share, the point or fore and lower part of the mould-board, especially if the point of the share is suffered to wear off very short, is liable to wear away. To obviate this, I make a plate of wrought iron of suitable thickness, say one-fourth of an inch, Fig. 7, and shipe it to fit, or nearly nit, on the front and lower part of the monld-board, and fasten it on with the head of the main screw bolt, with which the share is fistened on, taking care to fit the lower edge down snug to the top of the share. This plate may be put on when needed, and renewed as required.

"If I apply a cast iron share, I make a birth or countersink on the lower and front part of the mould-board (see $q$, Fig. 4, and $r$, Fig. 3), on which I put my cast iron share, in the manner in which Richard B. Chenowith, of Baltimore, fitted the share on his plow, patented in the year 1808, but with the following alterations and improvements: He employed two small screw bolts to fisten his share on ; and to enable him to set the edge of the share deeper as it wore off, he made the holes in his monld-board of considerable length, and in such form that the share could, when required, be moved down or with the point and edge forward. Thus the point and erlge was extended, but the desired effect was not produeed. The point and edge would naturally wear to a bevel on the uncler side, and it was owing to this circumstance that it would not penetrate into the ground; not because it wanted more length. In my plow the share is fastened on with one screw bolt; more nay be used, but are unnecessary. Having the point made round, broad and much thinner than usual, with the edge rather hollow, it is thus accommodated to the shape into which it has a tendency to wear. When it is first put on, a small strip of wood or leather is inserted between the edge of the mould-bourd and the share. 
(See Fig. 3.) This strip may be about a fourth of an inch thick at or near the point of the mould-board, tapering to an edge at the other end, and about half or three-fourths of an inch wide. This strip should be made of such thickness as to set the point of the share level with the after part of the plow; and as the sul)stance of it is somewhat elastie, the tendeney is to diminish the sharpness of the stroke, which would be produced if the casting were to come together. The principal advantage, however, of this method of aftixing the share is that it affords an opportunity of adjusting the point and edge of the share, so that when the point and edge of the share have worn to a level on the under sicle, the piece of wood may be taken out and another inserted of ahout half the thickness, and then, again, if required, the whole maly be taken out. By this operation the point or edge is let down as much as is necessary each time. It, at the same time, inclines the point of the share to the land, which is as necessary as to set it deeper. When worn as long as it can be in this manner, strips of wood may be inserted between the upper edge of the share and the mould-board, which will adjust it still more, as was recommended by Richard B. Chenoweth in the use of his plow.

"In making my cast iron shares and shoes, if I use a metal which is not too high, I have one-half of the mould made of east iron and the other part of sand, in the usual way. The shares and shoes are thus rendered more uniform and less troublesome to mould, and consequently cheaper.

"In respect, therefore, to the share, whether of wrought or cast iron, I clain the shape of the point and edge as of ny invention, together with the modes of fastening the shares on the plow and adjusting them, the modes of moulding and casting shares and other shoes, either wholly in cast iron moulds or partly of cast iron and the resiclue of sand.

"Sixth-The manner of stocking or using the plow, heretofore the object of all constructors, has been, so far as I am aequainted, to make the beam immovably fast to the handle and to the standard, whatever may have been the particular mode of fistening adopted. In stoeking my plow the handle is made fast to the land side at $h$, Fig. 5; I then fit the beam on the top of the standard and on the inside or outside of the handle, so as to lay solid on one and fist anainst the other, $f$ and $t$, Figs. 4 and 5 . The beam is there fustencd on the standard with a strong serew 
bolt, either passing up through the front of the standard and the beam, as at $j$, Fig. 5 , or I pass a screw bolt down through both the beam and the top part of the standard, and fasten the neek of the screw on the inside of the mould-board, at $j$, Fig. 4 .

"Either of these modes will permit the beam to move on the top of the standard in the manner of a swivel, so as to turn the fore end of the beam to the right or left at pleasure, which $I$ consider an object of importance in the construction of a plow. The hind end of the beam is then fastened to the inside or outside of the handle, $w$, Figs. 4 and 5 . The other handle is fastened to the mould-board with two small serew bolts, and the two handles comnected by two rounds $u$, Figs, 4 and 5 . Thus framed, if it be wished to set a horse plow to work, after three horses abreast, I fit a block of wood in between the handle and the end of the beam of abont two inches thick. (See $x$, Fig. 5.) It then is necessary to put a brace from the screw bolt that fastens the beam to the handle and fasten it to the handle above with a small screw bolt, Fig. 5. Thus eonstructed, the plowman can raise the end of the beam by putting a bit of leather or wood between the top of the standard and the beam; if, on the contrary, he wishes to lower it, he can do so by diminishing the thicknesss of the block under the beam, or he may raise or lower the end of the beam where it rests against the handle. He may give the plow more or less land by adding to or diminishing the block between the handle and the end of the beam, or by loosening the upper serew that fastens the handle to the mould-board at $z$, and driving a wedge between the monld-board or the handle more land will be given, and be reversed. Thus the plow may be reatlily :njusted as convenience may require; and should the wood spring it can be set right withont difficulty or delay.

"The improvement, therefore, which I elaim to have invented in the stocking of the plow consists in enabling the plowman thus to adjust the stock at his pleasure, the introduction of the blocks between the beam and the standard and between the beam and the handle, the use of the wedge between the mould-board and the handle, and the particular modes of fastening the beam on the top of the standard and the side of the handle for the purpose of adjusting the plow so as to give more or less land or depth.

"Seventh-Of the conlter: If the locked coulter be applied, it is put in a rib on the point of the wrought iron share, much in the usual form, and passed through a mortise in the bean in the 
mode usually adopted. But having satisfied myself by experiments that it requires an increase of twenty-two per cent power of dranght more to urge the plow along, with such a coulter, than with a sword coulter properly fitted to it, my attention was directed principally to the latter.

"This I apply in a manner diflerent from any heretofore userl. Instead of putting it through a mortise in the beam, I apply my coulter to the side of the heam. (See $y$, Figs. 4 and 5.) My mode of doing it is as follows: Holes are made through the coultersliank, and a strong screw bolt passed through the beam and coulter; a strong strap of iron is fitted on the serew-bolt outside of the coulter, with a hook which is turned back of the coulter and tapped on the front of the throat of the plow. Thus fitted, if the coulter rests solidly against the standard and fair with the beam, when drawn tight to it with the screw, it cuts to great advantage. To operate more beneficially, the edge of the coulter should stand about five inches in front of the throat and about one inch to land.

"Lastly-The mode of using the plow: The ordinary mode of using the plow when drawn by horses or mules is to attach the team to the plow by means of double and single-trees, coupled with what is commonly called clips and open rings. A serious objection to this mode is, that the single-trees, being attached in this manner, are at liberty to dangle abont, so that they occasionally are caught in the ground and turned over, the chains become entangled in the legs of the animals, thus occasioning frequently much trouble and sometimes serious injury.

"My improvement consists in the application of the stiff double and single-trees (see Fig. 8), which are constructed by making the double-trees in two bars, so that the single-trees work between them. Thus, all the play is admitted which is needed, and the inconvenience pointed out entirely aroided. The mode in which the double-tree is attached to the plow is by means of a clevis which opens in the bow (see $a$ a, Fig. 8), which forms two blocks, admitting of being easily attached to or detached from the plow, perfectly safe, and by which the team can be placed farther from or nearer to the plow, quietly and without trouble.

"Date of patent, October 1st, 1825.

"Williaj Eldiotta, ?

"Alex. McIntire, $\}$ Witmesses."

"GIDEON DAVIS. 
We believe that Mr. Davis was the first to dispense with the perforation and consequently the weakening of the beam, in order to insert the coulter. His plan of attaching it to the side was imperfeet as compared with modern methods, but it was a step in the right direction.

The inventors of plows now multiply so rapidly that we shall caise to enumerate all the patents that were granted, and confine ourselves to those which involve new ideas, or those which have been remarkably popular. Zadock Harris, of Washington comnty, in the State of New York, received a patent on the 17 th day of Mareh, 1819, for an improvement in the plow, a figure of which is given.

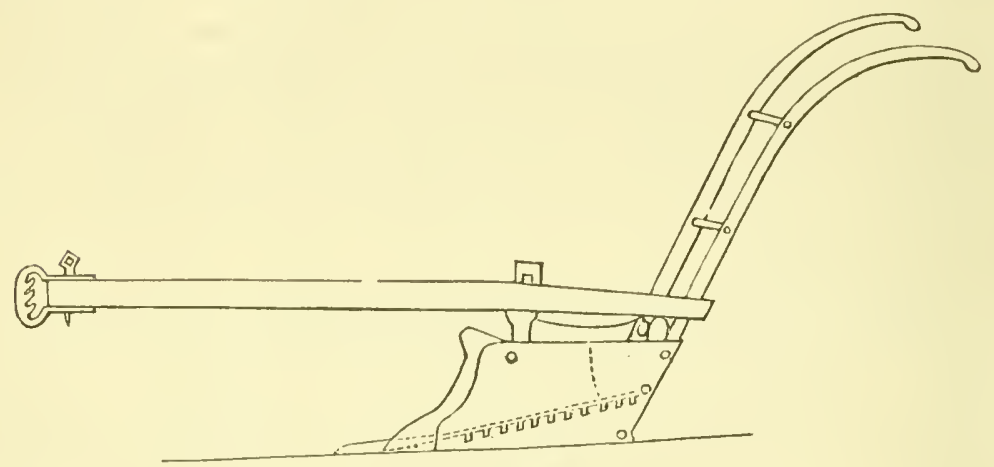

Fig. 63.

The following extracts from the specification will make the drawing intelligible:

"This plow is different from all other plows, inasmuch as the land side is composed of three plates which are fixed orer ench other, and the lower or under part of the plow is composed of two plates, with other pieces combined and comnected, as hereafter described.

"The first land side plate and the under plate are cast together, each in their proper direction or position, which is nearly at right angles.

"The lower part of the land side is so formed as to be of double the thickness of the upper part, so that the upper part maly receive the cutter which fits the sunken part and rests on the projecting thickness which forms an angle of aloout twelve degrees rising towards the back part of the plow.

"At the upper end of the said angular line there is a groove or cavity with a mumber of indents for the purpose of receiving 
the hooked part of the cutter, by which it may be extended at pleasure when the wearing of the entter requires it.

"The entter is a plate of steeled iron, formed to the shape of the plow in front and of a thickness so as to fili up the sunken part hefore described; the under side of the upper part of the cutter extends in a narrow form having a hook at the end, which bends downwards and catches in the indents before mentioned; when the last mentioned plate or cutter is in its place it earses the surface of the land side to be flush and even.

"Over the above described plates is placed another plate which may be called the shelter plate, as it receives all the wear of the land side; it extends the whole length of the plow, and covers the under structure; the front part partakes of the shape of the cutter and recedes a little from it; it is fastened either loy screws or bolts, which make the whole land side firm and secure.

"The plate of the under side of the plow, which is cast with the first plate of the land side, has on its upper surfice an indented groove and projects in front of the plow, and forms what is called a nose; this bar, as it wear's in plowing, may be extended and turned at pleasure. On the right liand side of the alove mentioned groove there is a rising ratchet or toothed edge, the indents of which prevent the under eutter from shifting its situation when in the act of plowing.

"The under cutter is formed of a proper shape to suit the under part of the plow, and is made either of wrought iron, steeled, or entirely of iron; the inner side is bent downwards for the purpose of catching in the ratchets or teeth before mentioned, when wanted to he brought forward, where it wears in plowing. Towalds the inner side of said eutter there is a long perforattion for the purpose of adnitting through it the shapes rising firom the cast plate, which fistens the cutter by a key.

"The mould-board is a separate piece, and made of cast iron, having proper staples or bolts in their proper situation for the purpose of tixing it by keys or otherwise; or it may be fixed by serews.

"This new construction of a plow may be adapted to any plow already in use, and the cutters maty be made either of steel, wrought iron or cast iron."

What is called the "under plate," in the specification, is a sort of shelf extending across the fore part of the plow from the land sirle plate to the mould-hoard; it is ahout one and a half inches 
above the sole of the land side, and two and a half inches on the mould-board side, so that it slopes towards the land side and towards the point. A flange is east on each side in which the bar runs which forms the point. The other parts of the plow are described with suffieient clearness in the speeification.

This is the first attempt that we have been able to find to meet a want which had been long and which is still felt, of guarding against the rapid wearing away of the point of the plow. This plow was once quite popular in Washington and the adjoining counties, but the difficulties in the use of the sliding point finally overcame the advantages arising from its use, and it finally disappeared from the market. The eases of the patent office are loaded with models showing a great variety of eontrivances for an independent sliding and reversible point. The best of these contrivances was probably that of Prouty \& Mears, of Boston; at all events, a greater number of these were sold, and they remained longer in use than any other; but at present the agricultural eommunity have almost all gone back to the point east on the share.

The use of two large wooden wheels rumning upon an axis, upon which the beam rested, is, as we have seen, a very old contrivanee; but the single wheel, running by suitable attachments under the fore part of the wheel, is a modern eontrivance of which it is generally believed Zadock Harris was the inventor. We are not sure of the fiuct, but the emrent of testimony is undoubtedly in his fivor. He first attached one of these wheels to one of his own plows in the summer of the year 1820 . It is eertain that he introduced their use into the northern part of New York.

On the first of September, 1819, Jethro Wood, of Scipio, N. Y., took out a patent for his improved plow. This eontained his most mature views upon the subject, and describes the pattern from which he never afterwards varied. Very large numbers of plows were made from patterns furnished by him, and even to this day there are many plows made in various parts of the eountry which depart very slightly from the prineiples established by him. If we are not mistaken, the plow known as the Livingston eounty is an example of this elass.

Jethro Wood was born, we believe, in Westchester county, New York, and in early life removed to Scipio, Canyuga county, in that part now known as the village of Anrora. There was a 
lirge number of the Society of Friends settled there, which probably induced him to select this location, he being a member of that society. There was much social visiting among them, and as they were all engaged in agricultural pursuits, this was naturally the leading subject of conversation at these gatherings. Roswell Towsley, Matthew Patrick, John Swanm, J. Morgan and J. B. Harris, all patentees of plows and all members of the Society of Friends, were also residents of Aurora. It was natural that daily association with men of this stamp should turn his mind to speculations upon the best form of the plow. He was not, as is generally supposed, a manuficturer of plows; we are assured upon the highest authority that he never made a plow in his life, he made the patterns only, and sold rights to manufacture them. Fig. 64 is an accurate copy of the figure drawn by him and deposited in the patent office as an illustration of his views of the best possible plan for the mould-board of a plow, and in comnection with the specifications which we give in a somewhat abridged form will, we trust, convey a clear idea to the mind of the reader of his views upon the subject.

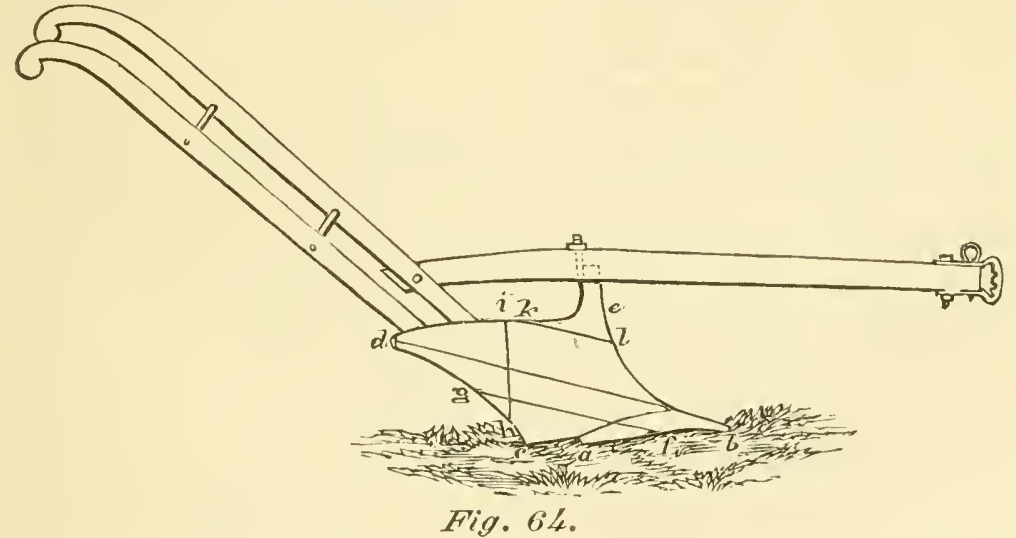

First Specification. - The mould-board: This may be termed a plane curvilinear figure, not defined nor described on any of the elementary books of geometry or mathematics, but an idea may be conceived of it thus: The land side of the plow measuring from the point of the mould-board, is two feet two inches long. It is a straight lined surfice from four to five and a half inches wide and half an inch thick. Of the twenty-six inches in length, eighteen inches belong to the part of the plow strictly called the land side, and eight inches to the mould-board. The part of the mould-board comprehended by this space of eight inches is very 
important, affording weight and strength and substance to the plow, enabling it both to sustain the cutting edge for separating and elevating the soil in swards, and likewise the standard for connecting the monld-board with the beam. The figure of the mould-board, as observed from the furrow side, is a sort of irregular pentagon or five sided plane, though curved, and inclined in a peculiar manner. Its two lower sides, $b$ and $a$, tonch the ground, or are intended to do so, while the three other sides, $c d$, $c e$ and $e b$, enter into the composition of the oblique or slanting mould-board overhanging behind, vertical, midway and projecting forward. The angle of the mould-board, as it departs from the foremost point of the land side, is about $42 \mathrm{deg}$., and the length of it, or in other words, the first side, $a b$, is eleven inches. 'The line of the next, or the second side, $a c$, is nearly but not exactly parallel with the before mentioned right lined land side, for it widens or direrges from the angle at which the first side, $a b$, and the second side, $a c$, join towirds its posterior or hindermos: point as much as one inch; henee the distance from the hindermost point of the mould-board at the angle of the second and third sides, $a c d$, directly across to the land side, is one inch more than it is from the angle of the first and second sides directly across. The length of the second side, $a c$, is eight inches. The next side, or what is here denominated the third side, $c d$, leaves the ground or furrow in a slanting direction, backward, and with an overhanging curve exceeding the perpendicular outwards from thence to six inches, accordiug to the size of the plow; the length of this third side is fourteen inches and one-half. The fourth side, $d e$, of the mould-board is horizontal, or nearly so; extending from the uppermost point of the third side to the fore part or pitch is eighteen inches. The fifth or last side, $e b$, descends or slopes from the last mentioned mark, spot or piteh to the place of beginning.

At the low and fore part of the mould-board, where it joins the land side, its length is thirteen inches. $* * *^{*} * *^{*} *$ The peculiar curve has been compared to a screw anger and to the prow of a ship, but neither of these similitudes conveys the fair and proper notion of the inventor. It has the following properties: A right line drawn by a chalked string, or by a straight ruler, diagonally or obliquely upwards and backwards from a point two and a half inches above the lip or extremity of the monld-board to the ande where the third and fourth sides 
of the montd-board jom, which is shown in the figure by the line b $d$, tonches the surfice the whole distance in an even and unifor'm applieation, and leaves no sinking or protuberance in any part of the distance, so, at a distance half way between the diagonal line just described and tha angle between the first and second sides, a line, $f g$, drawn parallel to the diagonal line already mentioned will receire the chalked string as on a uniform and even surfice. In like manner, if a point be taken one inch hehind the angle comnecting the sccond and third sides, and a perpendienlar, $h i$, be raised upon it, that perpendicular will coincide with the vertical portion of the mould-board in that place; or, in other words, if a plumb-line be let fall so as to reach a point one inch behind the last mentioned angle, then such plumb-line will hang parallel with the mould-board the whole way; the line of the mould-board there neither projecting nor receding, but being both a right line and a perpendicular line.

Morcover, if a right line be drawn from a point on the just described perpendicular, one inch or thereabouts above the upper margin of the fourth side, and from the point to which the said perpendicular, if continued, would reach, if the said J. Wood repeats a right line, $k l$, be drawn downwards and forwards, not exactly parallel to the diagonal herein already described, but so diverging from the same that it is one inch more distant or further apart at its termination on the fifth side of the mouldboard than at its origin or place of beginning, such line so beginning, continued and ended is a right line parallel to the mould-board along its whole course and direction, and the space over which it passes has no inequality thereabont.

If the mould-board be measured and proved vertically and obliquely by the saw in fashioning it, and by the rule in meeting it, and by the chalk line in determining it, the capital and distinguishing character of right lines extending on, over and along the peculiar curve which his mould-board describes is always and inseparably present.

Second Specification.-A cast iron standard for connecting the monld-board with the beam: It rises from the fore and upper part of the mould-board, being cast with it, and being a projection or continuation of the same from where the fourth and fifth sides meet. By a screw-bolt and nut properly adjusted above the top of the standard, and acting along its side, assisted, if need require, by a werlge for tightening or lonsening, the beam may he raised 
or lowered, and the mould-board, with its eutting edge, enabled to make a furrow of greater or smaller depth, as the plowman may desire; and a latch and key fixed to the beam, and capable of being turned into notches and grooves or depressions on one edge or narrow side of the standard, serves to keep the beam from settling or descending. By means of the screw-bolts, wedges, catches and keys, with their appropriate notches, teeth and joggles, the plow may be decpened or shallowed most exactly.

Third Specification-Claims the share.

Fourth Specification-Claims securing the handles to the mould board and land side of the plow by means of notehes, ears, loops or holders, cast with the land side and mould-board respectively; and serving to receive and contain the handles without the use of nuts and screws.

Fifth Specification-Claims an improvement in the method of adjusting the cast iron land side to the cast iron mould-board. Their junction is after the manner of tenon and mortise-are joggled or dovetailed together in the casting operation-so as to make them hold fast. The fore end of the tenon is additionally secured by a cast projection from the inside of the mouldboard, formed for its reception, and if any other tightening shonld be requisite, a wooden wedge well driven in will bind every part effectually without the assistance of screws.

Finally-He claims the right of varying the dimensions and proportions of his plow, and of its several sections and parts. A disclaimer of certain portions of these claims was entered February $24 \mathrm{th}, 1838$, and another disclaimer of certain other parts was entered on the 26th of May, 1838.

There can be no doubt that this plow became very popular among furmers, and did more to drive out the wretched and clumsy plows of the olden time than any other which had then been invented. As late as the year 1820, a writer in the Rhode Island American says that, in most parts of Massachusetts, the Old Colony plow, with ten-foot beam and four-foot land side, were still in use; and the Sutton plows, which he says "are not fit to plow any land that has sod on it; your furrows stand up like the ribs of a lean horse in the month of Mareh. A lazy plowman may sit on the beam and count every bout of his day's work. Besides, the great objection to all these plows is that they do not perform the work well, and that the expense is enormons for lacksmith work. Six of these plows cost me, on an average, last 
year, five dollars each to keep the shares and coulters it, for work, and the wear of the other parts could not be less than one dollar more-six dollar's per year for each plow." It was the merit of Wood that he was more successful than any of his predecessors in driving out the cumbrous forms of the plow above described, and in forming a taste for lighter, better and cheaper implements.

There were sold in the eity of New York of Wood's plows, in the year 1817, 1,550; in the year 1818, 1,600; in the year 1819, 3,600 . We are informed that the sale largely exceeded the last mentioned number in the year 1820 , but we camnot obtain the exact figures. These sales very largely cxceeded the sale of any other plow then in existence.

The first use that we have been able to ascertain that was made of the dynamometer in this State was at a trial of plows at Mount Vermon, New York, on the 20th of November, 1820. The width of the furrow was ten inches, but the depth is not stated. The power required by Henry Burden's plow was two and a half hundred weight; by George Woodward's, two and a half hundred weight; by John C. Stevens', three and three quarters hundred weight; by Jethro Wood's, three and a quarter hundred weight; and George Nixon's, three and a quarter hundred weight.

It is alleged that Mr. Wood not only made no profits by his efforts to improve the plow, but that he actually lost large sums by his enterprise. His daughters have repeatedly applied to Congress and to the State Legislature for compensation, but hitherto the application has been unheeded.*

It is evident that Mr. Wood had no claim as the inventor of a cast iron plow, because he had been anticipated in this by Newbold and by several others. He could not claim the vertical straiglit lines, as he had been anticipated in these by Jefferson and Small. He could not elaim the straight transverse line, $d b$, Fig. 64, for Col. Pickering had laid down this line long before him on theoretical grounds, and Jefferson, without any theory, had adopted it in practice. Mr. Wood's elaim must therefore rest on the straight lines $h f$ and $b l$, which, we believe, fairly belong to him.

In the year 1817, Mr. Edwin A. Stevens, of Hoboken, turned his attention to the plow. He had seen Newbold's plow, which first drew his attention to the subject. He made a mould-board

* Since writing this Report, the N. Y. State Legislature appropriated two thousand dollars to the heirs of Mr. Wood. 
according to his ideas of what was needed for good plowing, and then plowed with it in some very sharp sand which he found on the shore of Hoboken. Noting the parts which did not at nnce polish, he continued to change the twist of his mould-board, testing it constantly in this way until he found that it would polish all over and in all parts alike. He was then satisfied that he had the hest plow that was attainable, and had his castings made from this pattern. But he did a much more important service to plow makers and farmers by inventing the process of cold ehilling the base of the land side and the lower edge of the share, ignorant that the same thing had been done by Mr. Rimsom, in England. This discovery constitutes an era in the progress of the plow in this country. Mr. Stevens had a very good dynimometer with which he made miny experiments.

In the year 1819, Henry Burden, since so celebrated as the inventor of cut spikes and horse shoe machinery, was a young man who had just arrived in this country from scotland. He brought letters of introduction to the late Patroon, Gen. Stephen Van Rensselaer, who informed him that the plow in this country was still in a very imperfect condition, and advised him to turn his attention to its improvement. Mr. Burden acted on his advice, and constructed a plow which was a decided improvement upon all that had preceded it. It retained the principle of
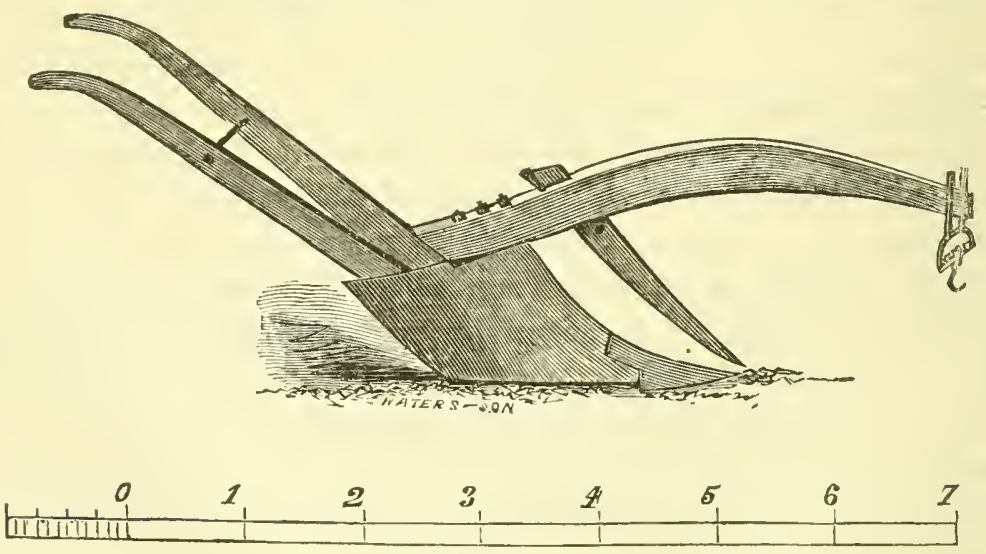

Fig. 65 .

vertical straight lines, but was quite unlike both Small's and Wilkie's. Many hundreds of them were sold, but as an opening was then made for Mr. Burden to enter into a much larger and more luerative business, he relinquished the manuficture of plows. A cut of the implement is given in Fig. 65. 
Mr. Burden never made a plow which exactly conformed to his own idcas of the true form, being restrained by the prejudices of the farmers, who required a longer and heavier plow than he deemed necessaly. In all the trials that were made with this plow in competition with others, it was found to do better work with less power than any other. It was all of iron exeept the beam and handles; its use extended as far as Richmond, in Vir. ginia.

Many other plows were patented and many were made and sold without being patented, which varied very little in their general principles, but which founded their elaims on public favor upon some very slight real or fancied improvements. As they soon went out of use it is unnecessary to deseribe them in detail.

David Hiteheoek, of New York, construeted a plow which he patented July 16, 1823, which was very popular, and continued to have a large sale for eight or ten years. These plows were of east iron, and were much shorter than those now in use. They were better aciapted for stubble than for sod plowing, though they did fair work on sod land-at least it was considered good in that day; they would not be as well approved at present. He made seven sizes. None of these plows would work well at a greater depth than five inches; the best work was done at four inches. It was largely used in New York, New Jersey and Canada, but most within a eirele of forty miles raciius, of which Woreester, Misss, was the centre.

About this period the Hingham self-holding plow beeame very popular in Norfolk and Plymouth eounties, in Massachusetts. It is the first attempt that has come to onr knowledge of a deliberate effort to make a self-holding plow, and for this reason we notice it, although it soon went out of use. It had an oblique beam, set strongly to land, on the forward part of which a strong iron axle was bolted transversely and at right angles to it; on the left end a small wheel ram on the grass, and on the right end a lurger wheel ran in the bottom of the furrow, which arrangement prevented it from eanting to either side. On this axle rises an areh, through which and through the axle a perpendicular shaft passes down near the bottom, having a drum, four inches in diameter and five inches long, which, rolling agalinst the edge of the slice being eut, gauges its width.

Mr. Joel Nourse, who is one of the most suecessful improvers of the plow of the present generation, having made and sold more 
approved plows than any other man in Amcriea, if not in the world, learned the blacksmith's trade of his father. When he was nineteen years old, his father gave him his freedom, and entered into partnership with him in the year 1827 . He forged the shares, coulters and other iron work for the old fashioned wooden mouldboard lock share plows of half a century ago. They employed an expert wheelwright to make the hard wood or oaken mouldboards and other wood work of these plows. This was in the town of Shrewsbury, Mass., six miles from Worcester. Mr. Nourse had a keen eye, a quick ear, and a dexterous hand. Always on the look-out for improvements, nothing in the action of the plow eseaped his observation. The shop was a frequent resort of farmers, whose conversation naturally run much on the form and construction of the implements which were heing manufactured under their eyes, and which, in the finished state, were all around them. Mr. Nourse carefully treasured up the hints which, from time to time, were dropperi around him, endeavoring constantly to realize them in practice. In this way the real theory of the plow began gradually to dawn upon him, and the constant improvements which be introduced caused a rapidly increasing demand for his work.

After his father's death he removed his establishment to Worcester, establishing himself there in a wider field of business Cast iron mould-boards were now getting into general use, though many furmers still were prejudiced against them, fearing that they would poison the land and increase the growth of weeds, and that they could not be relied on to stand the wear and tear of plowing.

A foundry, which was the first and the only one in New England, had been fitted up at Hartford, Conn., expressly for the easting of these plows. Mr. Nourse was acenstomed to go there in a two horse lumber wagon and buy a load of these cartings of the Jethro Wood and Hitcheock patterns, though there wats much the greater proportion of the latter. These he would bring io Worcester, and having fitted them with beams, handles and all other needful appliances, he sold them ont in a finished form. After he had been some time established in Worcester, his busi. ness increased so much that he took in Mr. Mason, his brother-inlaw, as partner, in the year 1837, and soon after this they admitted Mr. Ruggles, a brother of Judge Ruggles, of Maine, as a third partner, the name of the firm being Rugghles, Nourse \& Mason. 
The new firm began, in the year 1840, with making a series of plows of different sizes, jn strict aceordance with Mr. Jefler'son's principle; but these had but a very limited sale, as they were fonnd to be very deficient in turning qualities, though they answered very well in stubble land. On the fallure of this speculation, Mr. Nourse determined to remedy the difficulties which he found in existing plows, and apply to the new implements all the knowledge and skill which he had alcquiled in the conse of his experience. In order to accomplish this he took a sheet of thick lead and patiently cut and hammered upon it until he bromght it to a form which his judgment approred.

The plow thus made was distinguished from others chiefly in two respects. First, by the greater length of mould-board, and seeond, by a nearer approach to straight lines in a longitudinal direction. The most of the plows of that day had extremely short mould-boalds, and very few of them made any approach to straight lines. in any direction.

The Eagle plows, as compared with others in the market, were very long; they had more turn of mould-board at the rear end and a greater intensity of twist beyond the perpendicular. He was induced to pay particular attention to this point by the failure of the Jefferson plow to invert the furrow slice, but he found the unexpected result that, in accomplishing this object, he effected at the same time a much more complete pulverization.

The plow thus made from the lead pattern was the famous Eagle No. 2, and was finished in the year 1842. This plow retains its popularity to the present day, large numbers of them being still sold.

Finding this to be a very good and serviceable plow, he next made Eagle No. 20, and rapidly thereafter various other sizes of the Eagle were made, which are still popular, and are shipped to every part of the world where our commerce reaches.

From the year 1841 to 1861 the sale of these plows reached 25,000 annually.

The Eagle No. 2 was the ouly pattern of this series which was modeled in lead, the others being worked ont of the wood with more or less theory based on the Eagle No. 2 as the ground work.

In the year 1845, Governor Holbrook, of Vermont, began to aid Mr. Nourse in the plamning of his plows. The latter had never been able to devise any system that would make the straight 
lines come accurately, both vertically as well as longitudinally, but Governor Holbrook devised a system by which, if the longitudinal lines are carefully laid down upon the pattern, the vertical lines will be certain to eome right.

In $1841 \mathrm{Mr}$. Nourse went to Boston and opened a large ware house, the style of the firm being the same in both places. Some years later other parties were admitted into the firm, under the style of Ruggles, Nourse, Mason \& Co. The firm dissolved in 1855, all the old member's except Mr. Nourse retiring, and a new firm was formed under the style of Nourse, Mason \& Co. Thi: firm, under its various changes, have sold more plows than any other in the United States. Fig 66 represents Eagle No. 2.

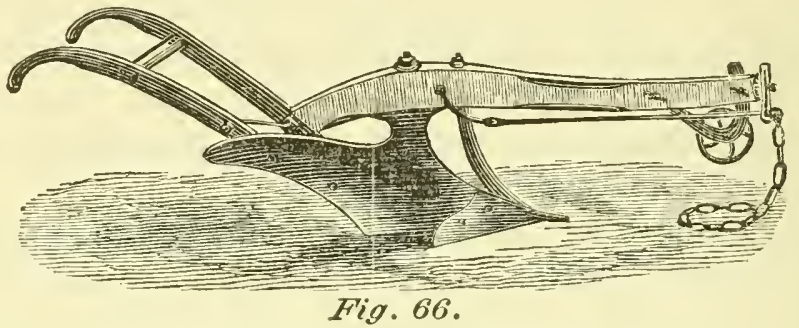

It is adapted to turn furrows from four to seven inches deep by twelve to fourteen inches wide. It was sometimes rigged with a common coulter for flat furrow plowing, and sometimes with a fin share, which adapts it for stubble plowing.

IVe insert, as a contribution to the history of the plow, the following letter, from Mr. J. Dutcher, of Durham, N. Y., addlessed to T. B. Wakeman, of New York:

"The history of the plow in America, for the last forty year's, has been so identified with that of my own, that in speaking of the plow I shall often have to say something about myself. I have always considered the plow the most useful and necessary implement that man has anything to do with, for this reason, I have bestowed upon it a great amount of time, labor and money.

"As early as the year 1806, when I was but a lad, I began to observe the difference in the constructions of the plow. At that time there were two kinds in use; one was called the Hog plow, which was said to be of Dutch origin, and another called the Bull plow, a Yankee invention. About this time I was learning the blacksmith trade, and had considerable to do with the plow, in constructing and making that part of it called the share. The Bull plow was the most estecmed; the other went out of use 
about the year 1809 or ' 10 . The cast plow, with wrought share, was known in and about Albany and adjoining counties. It is said to be Mr. Peacock's patent. But I considered all that I saw awkward and complieated, not simple enough for general use, but such as they were, I made and sold, like the other plow makers. In the year 1818 I heard that there was a new plow got up hy Jethro Wood, and as the plow was rather my hobby, I took the trouble of going some twenty miles or more to see it. But when I come to see and examine it I found it to be complicated, weak and short-lived, yet it was difierent from those heretofore usedcomposed of three parts, a mould-board, land side and share. The mould-board was too short and too full on the external surfice, and otherwise not properly shaped. Its entering wedge, or first part of the plow was too low and dicl not turn the furrow upon the edge in proportion to its entering the ground; in anything like quick speed the furrows were broken and deranged.

"The land side was too narrow, long, and too weak, and did not protect the front edge or part of the mould-board on the land side and was too straight on the lottom; the share was far from being right; it left the shin of the plow all unprotected. In April, 1819, I planned a plow which I supposed better adapted to do the work, as it afterwards proved itself to be. This plow I did not patent until 1832. Owing to the bad management in Washington I lost my first $\$ 30$. Not having my specification at hand, I will describe my improvement at that time, April 15, 1819. The mould-board was longer than any I had known. It was eoneave, with a corresponding shape. My land side I made twice as wide as Wood's-six to seven inches-and connected it to the mould-board by two wrought iron bolts. My share, in which consisted my greatest improvements, was constructed with a projecting piece called a shin share, so made as to supply with a new edge the shin of the plow as well as the wing. By this improvement, which has been adopted by all plow makers, the jolow was more durable by one-half. The making of the land side concave on the bottom, although about half an inch from the point to the heel of the plow, was a very simple but an important improvement. The mould-board back of the wing of the share did not tonch the ground by half an inch. The two improve. ments are quite necessary in rough and stony lands. Wherever my plow was introduced it superseded Mr. Wood's. The result was a proscention ly Mr. Wood for an infringement of his patent. 
He tried the second time, but was unsuceessful in both. About 1821 persons in different parts of the country got up plows. Among them were Mr. Tice, of Washington eounty, Mr. Wright, of Saratoga, Mr. Chamberling, of Dutchess, and several others in different parts of the Union. They all laid aside theirs and adopted my improvements. I found it impossible to protect myself from these eneroachments. Although my plow was made by all plowmakers, yet I did not eonsider it perfected. In 1823 I ascertained that my land side was not as durable as it ought to be. By not extending all the way outside to the share, it left part of the mould-board exposed to wear and could not be renewed without getting an entire new mould-board. To remedy this I extended the land side outside of the mould-board up to the share. Finding that the wrought standard I then used was not sufficiently strong and cheap, I, in 1823, extended the body of my cast mould-board up to the beam, securing the beam to the body of the plow by a wrought bolt from the centre of the land side and moukl-board perpendieular through the casting on which the beam rested, and through the beam, securing it with nut and screw. These have also been generally adopted. One more improvement remained to be made. In my letter to the Secretary of the Ameriean Institute, published in the journal of the Institute in 1837, I said that the mould-board, beam and handles of all the American plows were too short. I had been convinced of this years before. About 1838 I adopted these alterations. The plowmakers all followed suit. Owing to the imperfection of the patent law I had little encouragement to patent my list improvements. One clause in the patent law of 1836 , which declared that a patented article must not bear sale at the time of the issue of the patent, and that there must not be more than one year from the date of the improvement before the patent is taken out, deprived me of my rights to my improvements.

"My large size plow that takes a furrow seven inches deep by fomrteen wide, turns over six and three-quarter inches more at the top edge of the mould-board than at the bottom. From all that I have discovered in twenty-five years of observation and experimenting, I have not found one straight line that I could recommend on the running part of the plow. Although a plow will rum well in its perpendicular position if the land side is straight, yet it will run better if it be even one-eighth of an inch concave towards the land. In no case should it be rounding. 
"There are other points that should be kept in view, particularly the line of draft, compromised in the height of the horses' breast, and of the end of the beam and its length. I know plowmakers who are macquanted with this essential principle. When the land side is straght on the bottom from point to heel, the end of the beam must be one inch or more higher in order to make it enter, particularly in rough or hard land. This inch in the forward end of the beam places it thus much above the line of dranght. In drawing, the team pulls the bean down, causing the plow to run on the point, and cansing it to run unsteady, and, as farmers say, to root the ground. The lualf inch concave on the bottom will enable the plowmaker to fix the beam below the line of draught, which will make the plow run flat, and not rendering it liable to tip up behind when meeting with obstructions. This principle, as simple as it is, gave my plow a decided preference. The proper length of the beam is important, and often overlooked. Although smooth, mellow soil requires some variation in the plow from that designed for hard and stony land, yet for land in gencral two or three inches in the beam makes great difference in the ruming, throwing the end out of the line of draught. The length that I have found as generally best for an half inch concave is two feet two inches. I place my plow on a straight place, then measure the perpendicular from the point of the plow to the beam; then from this point two feet two inches to the end of the bean. For hard ground, two feet, and for mellow soil, two feet four inches are the extreme lengths.

"Owing to the ignorance and prejudice of farmers it has cost me more labor to introduce my plow than to make the improvements. These difticulties were aggravated by having my improvements pirated by almost every plowmaker in the country. The province of Congress is to give protection to the real inventor, not to convey his improvements to another. Every farmer has a right to his own field and its products; equally inalienable are the rights of inventors.

"My long experience in the construction and great familiarity with the use of the plow have led me to comprise the excellencies of the plow in seven essentiai points-naterials, strength, draught, expense of first construction, workmanship, yearly cxpenses and performance. A defieiency in one of these may make the plow comparatively worthless. 
"Mr. Wood lays it down as a scientific prineiple that the lines of draught of the mould-board should be as shown in A; that is,

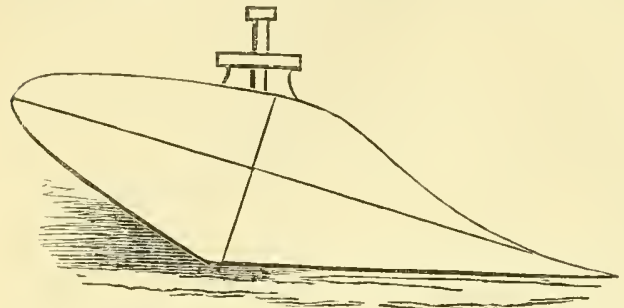

A beginning at the point of the share, draw a straight line to the upper edge to the mould-board behind, that the straight line should rest upon the external surfice of the mould-board all the way up to the upper edge of the mould-board behind. This, he sitys, is the line the furrow follows. Now I assert that this is not in accordance with the natural operations of the furrow as it rises and turns from its horizontal to its perpendieular and inclined position. Practical experience has shown me that the surfuce of the mould-board should be a curve as shown by a straight line drawn from the forward point on the lower side of the mould-board diagonally to the upper end. This line will be one ineh above the surface in the middle. Lines drawn at right angles in this line will be one-quarter of an inch above the surface. The iurrow will follow the eurved lines indieated in cut $B$.

"The time and money I have expended on the plow are equivalent to $\$ 5,000$. The advantages the public have derived ean be estimated by hundreds of thousands, while my returns have not ex-

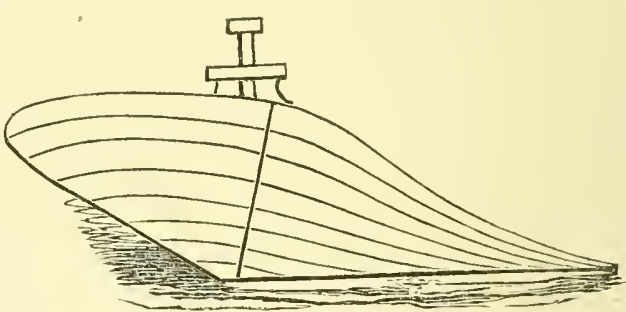

B eeeded $\$ 1,000$. Plowmakers have paid to Jethro Wood sums that should have come to me, the real inventor of the improvements. This was done in consequence of improper laws passed by Congress in his fitvor.

"In Mr. Jefferson's letter to Sir John Sinclair, in 1798, you will find Mr. Wood's mould-board deseribed. In Rimsom's History of Agricultural Implements, Johnson's Eneyclopedia of Agriculture, and in the English journals since 1800, you will see tbat Robert Ransom invented a east iron share as early as 1785 . He also invented the proeess of chilling the point of the share. A firmer in Suflolk, England, made, in 1790, cast Iand sides. Mr. Newbold, of Orange eounty, in this State, made east plows 



\section{Plate VII.}

IMCORMICK'S PLOW.
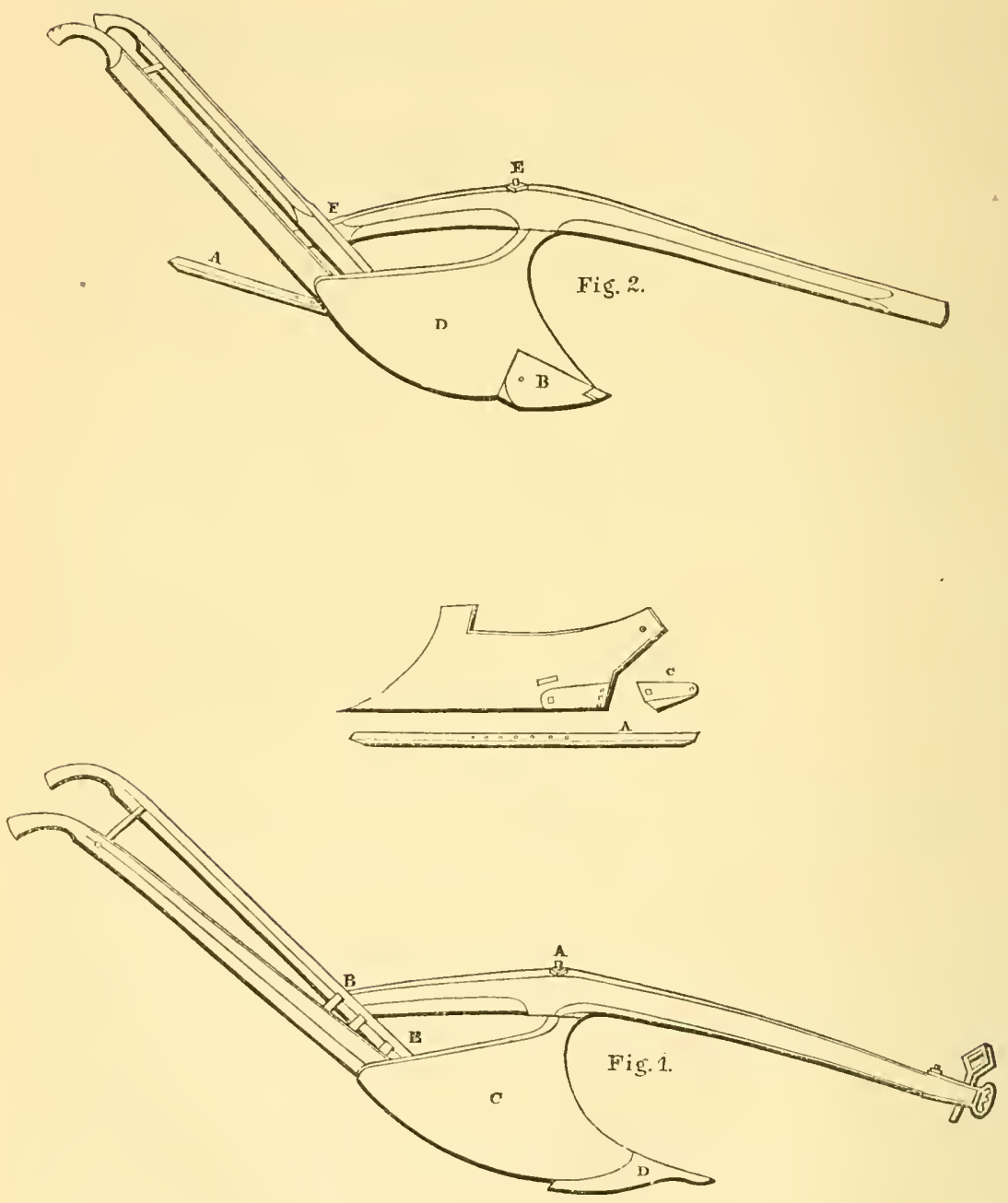
as early as 1790, and patented the invention in 1797. The patent, which I have seen, was signed by the elder John Adams. The casting of this plow went up through the beam like that of $\mathrm{J}$. Wood's. Mr. Peter T. Curtenius of this city had cast iron plows for sale in 1800. They were of three pieces-monld-board, land side and share.

"In 1814, Mr. Wood obtained a patent, again in 1819, and by special act of Congress procured a renewal of fourteen years, making thirty-three years in all. He now seeks another renewal!

"J. DUTCHER."

\section{McConmick's Plow.}

This plow was in great reputation and use. The only reason why we have not given a specification of it at large is, that having given Davis' and others at full length, it would take up too much room. There are, moreover, a great many points of resemblance between this and Davis'. A general reference, therefore, to the drawing of it is given in comnection with the following extracts from the original specification itself, which show that the improvements consist chiefly in the following particulars, viz. (See Plate VII):

First-In the shape of the bar and point, as well as the shoe or fender to be attached to a wrought or cast iron land side.

Second-In the face of the monld-board, and the method in which it is wrought; the front edge of the mould-board; the curve or projection over toward the land side; the method of making the hole for the brace or bolt through the neck from the hind part, or a ketch without a hole through; also, the keteh at the bottom of the mould-board to fusten the share on; the concave groove for the handle, and one hole for a bolt to fasten it, and the method of hardening the front edge and wearing of the mouldboard.

Third-In the method of fastening the wrought share to the cast land side and mould-board by ketehes and projections; the fender or shoe, the coneave groove in the land side for the handle to fit it; the structure of the fore part of the mould-board, for the cast share, and self sharpening and advancing point, the brace bar for the bar to rest on, and the method of fastening the bar or point, and its position upon an inclined plane, and the shape of the share.

Fourth-Putting the beam on the outside of the handle, the manuer in which they are fitted together, and fastening them witl. 
a staple and two serew muts; the adjusting of the bean on the top of the neck of the mould-board and fastening it with one end of the brace or screw bolt, both coming from the hind part and through the neek of the mould-board, with one serew, and raising and lowering the beam at the handle.

Fiftl-In the shape of the sword and front edge of the conlter and the method of fistening with the stirup.

Fig. 1. A-Beam bolt.

B-Fastening by a staple.

C-Mould-board.

D-Share.

E-Adjusting serew brace.
Fig. 2. A-Self sharpening point.

B-Share

C-Shoe or fender.

D-Mloukl-board.

E-Beam bolt, hooked at lower end.

F-Fastening by a staple.

\section{CHAP'TER V.}

\section{HISTORY OF AMERICAN PLOWS-CONTINUED.}

Mr. John Mears was born in 1795, and was brought up as a plowmaker. In 1831 he became aequainted with David Prouty, a practical farmer and country trader, with a mechanical turn of mind. Mr. Prouty called his attention to the Hitcheock plows, with which he had not previously been fumiliar. Finding them much better than any they had ever seen, David Prouty, his son Lorenzo and John Mears, formed a partnership for the purpose of making and selling these plows. They sold seven sizes of these, and at once found a very large demand for them.

Mr. Mears had a very active mind, and applied himself assiduously to the study of the plow. He had not long been engaged in this line of observation before he perceived the irregularity of motion which was produced by the oblique insertion of the beam, and he was not long in reasoning out the centre draught principle which we have deseribed in the chapter on "The Line of Draught in Plows," Chapter VIII. This has been one of the most important improvements made by American inventors of the plow, and is now almost miversally adopted by all plowmakers.

Their mould-board was formed by cutting a strip of sole leather to the width of the proposed furrey; one end of it was nailed to 
a flat surface, and the remainder was twisted over precisely as a furrow would be. The wooden pattern was then eut so as to coincide with the surface of the twisted leather. Prouty \& Mear's No. $5 \frac{1}{2}$ and No. 30 were formed in this way. They becime very celebrated, and large numbers of them were sold. The sales of this firm amounted to about five thousand annually, at an average price of eight dollars. Their self sharpening points were probably the best that were ever made. The first prize, at the great trial in Albany in the year 1850, was awarcled to these plows.

Messrs. Minor and Horton began to make what is known as the "Peekskill Plow" in the year 1835. Mr. Minor hild been an employee in the establishment for nine years. The first plow patterus made at Peekskill were by James H. Conklin, while an apprentice with Levi Carpenter in 1823. They were known as L. C. plows, and had two points to the share, a few of which are still in use. The next was made by Stephen Gregory, which was known as the Gregory plow; these were made in 1826. The next were made by the same J. H. Conklin, who had formed a copartnership with James WViley; these were made in 1827, and were called the Wiley \& Conklin plow. These suited the market well, and large numbers of them were sold of seven different sizes. Abont the same time Truman Minor, who was the superintendent of Seth Hait's foundry, made a set of patterns for four different kinds of plows. Shortly after this Mr. Hait died, when Frost Horton and Truman Minor formed a partnership as above stated, and having taken Mr. Hait's foundry, began the manufacture of the "Peckskill Plows," of nine different sizes. In the year 1855, Mr. Minor retired from the firm, and died in the year 1862. On his retirement the firm assumed the style of Horton, Depew \& Sons, which continued to manufacture the same kind of plows until 1864, when they sold out the business to J. B. Brown and I. L. Paulding, who formed a stock company known as the Peekskill Plow Company.

This company, since its first formation and under various names, lave made patterns for about ninety different forms of the warped surface which Mr. Minor originally devised. They have, during that period, made about one million sets of eastings, and it is estimated (though on umreliable data) that about half as many more have been made from patterns taken from these castings by others. 
Mr. Minor made a semi-eylinder of the length of the proposed plow, and of the same diameter as the wilth of the proposed furrow; the eylindrieal surface was divided in both directions by lines one inch apart. A line beginning at the left rear corner was traced diagonally through the corners of the squares to the right front corner; the line thus formed was applied from the point of the share to the rear upper wing of the mould-board, and the pattern was worked down until it accurately coincided with it; there is a series of straight lines also in this plow rumning from front to rear. Such is the description of the principles of the Peekskill plow given us in the year 1850 ly Mr. Minor. We wrote to Mr. Brown, of the Peekskill works, to know whether our recollections were correct. He replied as follows: "Your statement of the prineiples of Mr. Minor's plows expresses his ideas, as far as it goes, as well as they can be briefly expressed by words, but it seems to me to convey no idea of the helicoidal torsion which, being moderate, constitutes the 'easy lines' of Mr. Minor's plows."

The Peekskill plows have transverse straight lines, as we have before stated. The first or lowest of these in the No. 21 plow makes an angle of $21 \mathrm{deg}$. with the plane of the sole. The upper line is very nearly horizontal; the intermediate lines differ in the angle which they make with the plane of the sole by regulan gradations; if they are produced backward they would approximate to the form of a fan, but they do not radiate from a common centre. The lines running from the bottom to the top of the plow also vary in the angles which they make with the vertical line which in this plow is situated about five inehes in front of the extreme rear angle of the mould-board. The first of these lines forms an angle of about 40 deg. with the vertical, and they regularly increase as they approach the vertical. The length of this plow fiom the point to the extreme rear angle of the mould-board is thirty-five and a half inches; the length of feather fourteen and at half inches; distance from land side to the point of the feather, ten inches; length of land side twenty-seven inches; distance from sole to under side of the beam at the standard, fourteen inches. A figure of this plow is given in Transactions of the New York State Agricultural Society for 1850 , page sixty-one. There ean be no doubt of the great excellence of this plow; its chief defect is, that its curves are too regular, and therefore it fails in pulverizing 
power; but its draft is very easy. It won the second prize in the great trial at Albany in 1850, in fallows and in stiff sods.

It would be very improper to pass over the labors of the celebrated Daniel Webster, in a report on the history of plows. He invented in the year 1836 or 1837 , a plow for work twelve and fourteen inches deep, which is still in existence, the property of his life-long and highly esteemed friend, Peter Harvey. It is twelre feet long from the bridle to the tip of the handles; the land side is four feet long; the bar and share are forged together; the mould-board is of wood plated with straps of iron; breadth at the heel of the mould-board to land side, eighteen inches; the spread of the mould-board was twenty-seven inches; the lower edge of the beam was two feet four inches above the sole; width of share fifteen inches.

The history of this plow is so admirably stated in a letter from Gov. Holbrook, of Vermont, that we give it in his words. "I have certainly been faulty in recollection, in that I have not before now, given you an account of what I personally know of the eflorts of the late Daniel Webster, to improve the plow for deep thorough plowing. My memory was jogged in this regard by a question put to me in a letter received from a triend, yesterday, touching this matter; and, therefore, I now write to give you an account of Mr. Webster's great plow.

"You doubtless know that Mr. Webster was passionately fond of farming and rural life, of farm stock, and especially large, sleek, superb oxen, of which he always kept several yokes (as we say in Yankee phrase) or pairs for the work of the fium at Marshfield. IIe not only himself raised the best of large, lusty steers, which were closely matched and trained to the yoke, but not minfrequently he bought working oxen when opportunities offered for securing those which were well matehed, well trained, of large size and superior quality.

"In perfect accordance with his thoroughness in everything else, he believed in deep, thorough plowing, and that our farmers were quite too superficial in the tillage of the land. But at that early day there were no plows made that could turn a furrow of more than five or six inches deep. Therefore, he determined to make a plow himself that would give him the depth of furrow he desired in his farming, for a deeper furrow he must have, no matter, he said, if it was a foot deep.

"Accordingly, some thirty years ago or more, he set himself at 

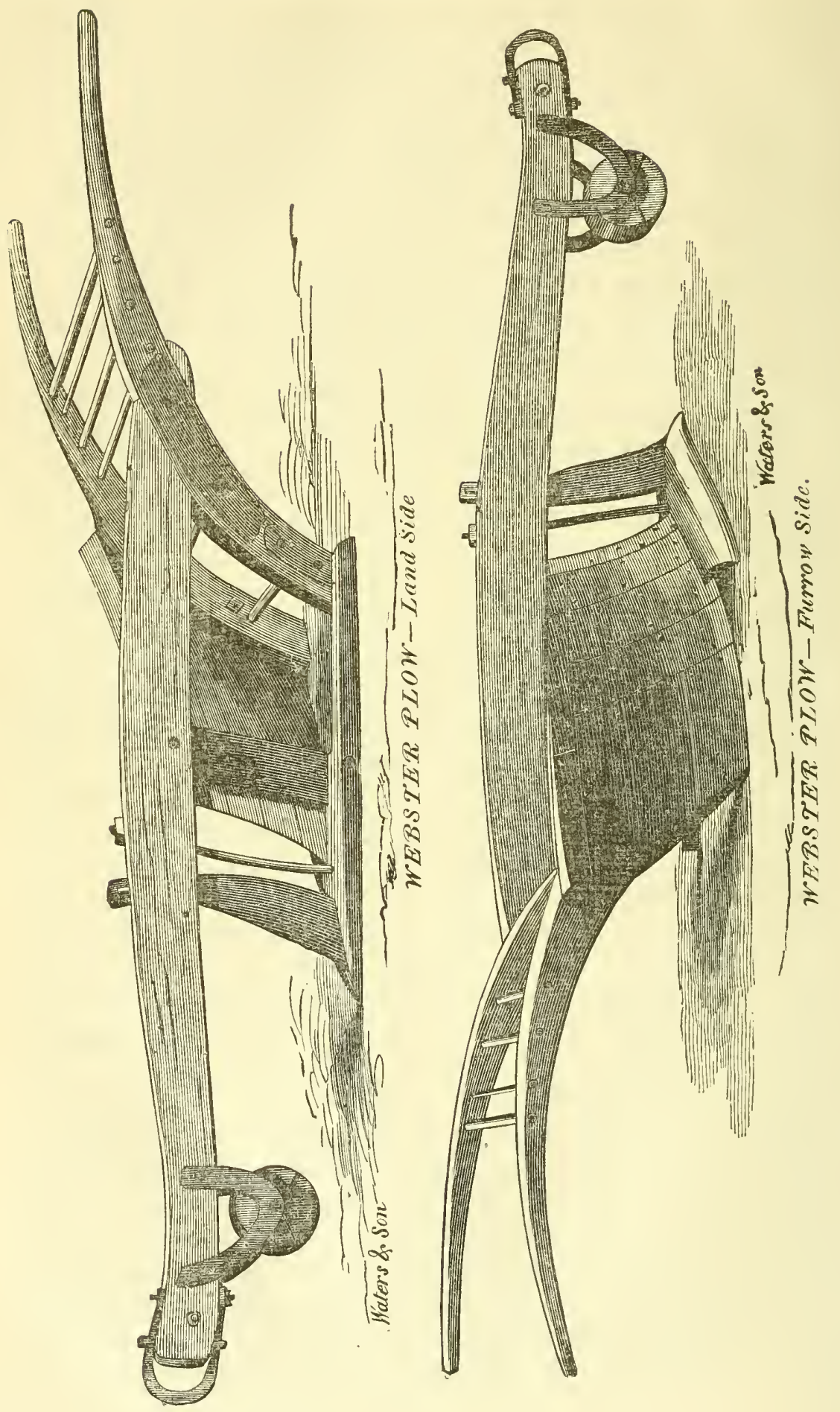

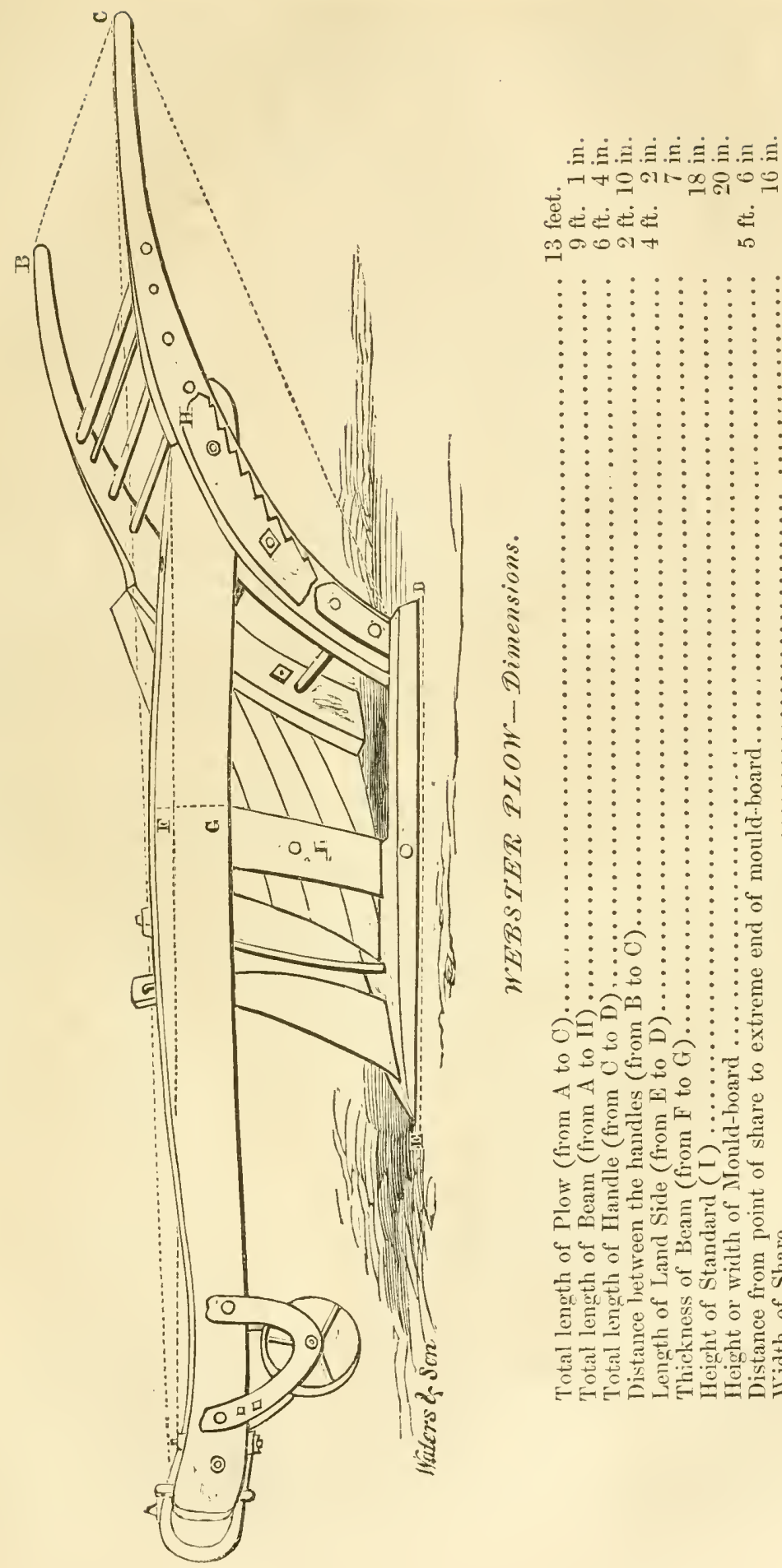

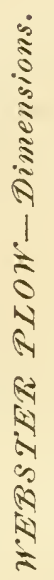

$: \div: \vdots: \vdots$

$:: \vdots:: \vdots:$ :

: $: 0 \vdots \vdots \vdots \vdots 0$

$\vdots \vdots:+0 \vdots \vdots \vdots$

ชิ

Оร

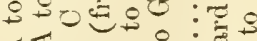

বद ज्ञ

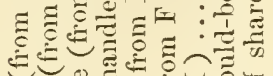

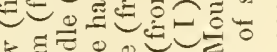

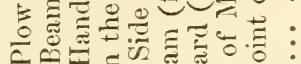

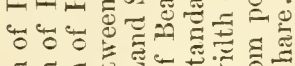

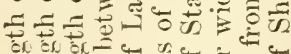
है $=0$ की 50

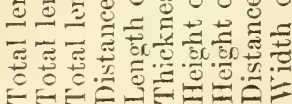


work to plan a large plow, and employed a wheelwright to make the wooden mould-board agreeably to his directions and under his daily personal supervision, and then a blacksmith was employed to cover the mould-hoard with straps of thin iron in the usual way of strapping wood mould-boards in those days, and to set the wrought iron and steel-edge share, and the lock-conlter, which passed up from the share through the beam, all agreeably to $\mathrm{Mr}$. Webster's directions. Then the wheel wright was direeted how to set the beam and handles. Everything must be done precisely as he directed as to landing of beam, pitch and landing of share, etc., and he felt as much interest and enthusiasm in the production of this plow as anybody could.

"The mould-board was immensely large and long, and was constructed substantially on Jefferson's principle of straight lines, but with such modifications and variations in form as Mr. Webster thought best, such as greater length, proportionately, and with more twist or overhang at the rear end, so as more surely to invert the sod in deep plowing. It was constructed to turn a furrow a foot deep and about two feet wide. The beam, of the toughest white oak, was long and of huge strength, sufficient for four yokes of his large oxen.

"When the plow was completed, ready for trial in the ground, Mr. Webster was the first man to hold it, and worked several hours with it, feeling greatly delighted with the capacity of his new plow for deep, thorough work.

"With this huge plow and a strong team the rough tillage lands at Marshfield, and such of the pastures as had beeome more or less covered with bushes and shrub oaks, small white birches, etc., were deeply plowed and thoroughly turned over and subdued. The bushes and shrubs were cut at the surface of the ground and eleared off the land, and the roots and stumps turned over by the plow.

"I visited Marshfield and Mr. Webster about twenty years ago, when he showed me this plow, explained how and why he got it up, and took me to see a field which had recently been cleared of bushes and shrubs and deeply plowed with this large plow. I remember his making a remark to me, substantially as follows: 'When I have hold of the handles of my big plow in such a field as this, with four yokes of oxen to pull it through, and hear the roots crack, and see the stumps all go under the furrow, out of sight, and observe the elean mellowed surfice of the plowed land, 
I feel more enthusiasm over my achievement than comes from my encomters in publie life at Washington.' 'That is the idea, and not fur from the language of his remark to me."

The following letter, received after Gov. Holbrook's gives Mr. Harvey's recollections of the history of the Webster plow:

"Boston, April 18th, 1868.

"My Dear Sir-I send you, by to-day's mail, the drawings of the Webster plow, together with a sketeh, which will give you the means of furnishing an aceurate description of its dimensions.

"This plow was manufictured in Mr. Webster's workshop on his furm at Marshfield; the model and plan of its eonstruction was entirely his own, and much of the work was performed by his own hand.

"He had, on his extensive farm at Marshfield, laying near to the sea (upland country), some eight or ten acres, more or less, on which there had been a growth of stunted oak, fit only for fire wood. This had been cut for this purpose; and an undergrowth of scraggy roots, spreading in every direction, had sprung up. It was useless for cultivation as it then was, the roots or stumps too small and too numerous to be removed with an ordinary stump puller, and too strong for any ordinary plow to grapple with. This plow was made to meet the difficulty, and sueceeded.

"I have seen the great man holding the plow, assisted by some six or eight farmers, with strong arms, while it was propelled by six pairs of oxen, tearing up roots and everything else that stood in its way, accomplishing a trimmph great in its way, as had been often performed by its maker in the many intellectual triumphs in the forum and senate, and apparently giving him quite as much delight.

"The plow proved a success, accomplishing all for which it was intended.

"It is probably the largest plow ever built on this continent. "Most respectfully, your's,

"PETER HARVEY."

A great number of inventions for subsidiary purposes are recorded in the Patent Office, having for their object some improvement in the elevis, the wheel, the share and various other subordinate parts; but the next really earnest attempt to improve the form of the plow was by James. Jacobs, whose patent is dated July 8th, 1834, and is represented in Fig. 67. 
The following extracts from his specification, will explain his ideas:

"The mould-board of cast iron, Fig. 67, from the extreme points of the length of the mould-board, from $a$ to $b$ a straight
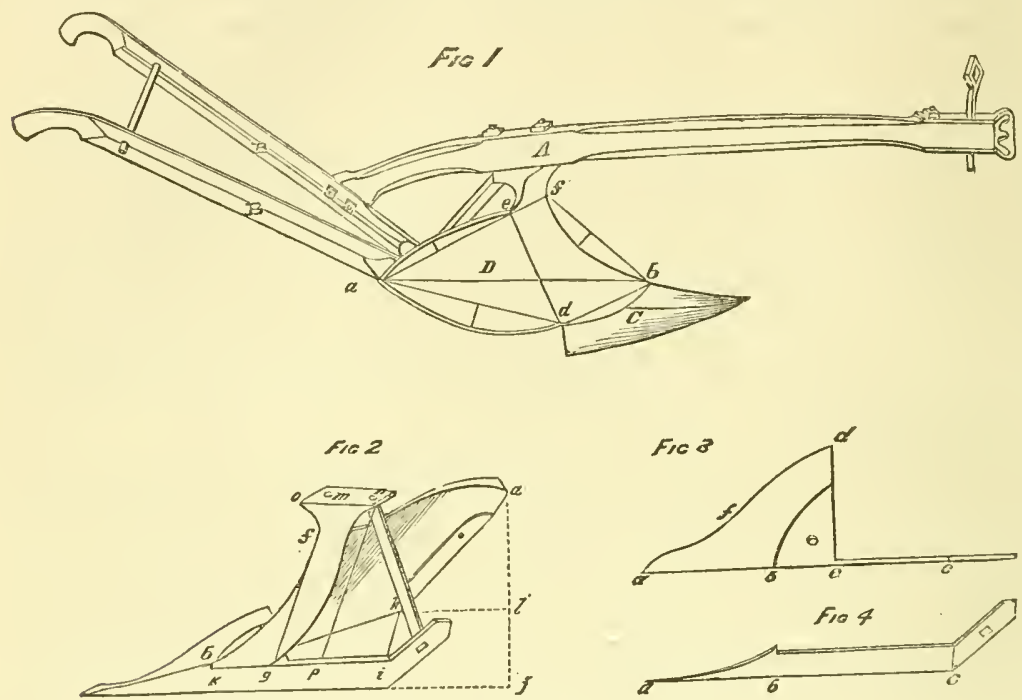

Fig. $6 \%$.

line is to be struck from one to the other of six inches and onceighth in length, and from the middle of this line a perpendiculitr is to be let fall to the surface of the mould-board, which will be five-sixteenths of an inch. A line is now to be struck from the point $c$, which is to be at the eommencement of the thin edge of the mould-board to the point $d$, placed at the shoulder on the uncier side, for the reception of the extreme edge of the back of the share of two and five-eighth inches in length. From the letter $d$ to $a$, a straight line is also to be struck of four and five-sixteenth inches in length; a perpendicular, let fall from the centre of this line to the surface of the mould-board, will be full three-cighth inch in length, and from said point $c$ to the hinder circular ed eve of the mould-board, seven-sixteenths of an inch. From the point $a$, to the point $f$, a line is drawn of four and seven-sixteenth inches in length, and a perpendicular raised from the centre of this line to the top of the circular part of the upper edge of the mould-board will be a full quarter of an inch in length. From the letter $f$ to the letter $b$ on the front edge of the mould-board a line is to be struck of two and three-quarter inches in length, and from the centre of this line a perpendicular let fall on the front 
edge of the mould-board will be five-sixteenths inch in lengtl. From the point $d$ to the point $b$ a line is to be struck of two and three-sixtcenth inches in length, and a perpendicular raised from the centre of this line to the thin edge of the mould-board will be one-quarter inch in length. The portion of the surfuce of the mould-board, contained between each point or extremity of these original straight lines struck as above directed, is to be shaped upon that segment or portion of a circle as will be between said point having the perpendicular for the height of the areh; the line $a b$ will be the only exception to the rule, and in this particular that three-quarters of the distance across from $a$ towards $b$ will be described on nearly a straight line, the extremity of the point being a little elevated.

"From the point $k$ to the point $g$ in Fig. 2, showing a left hand view of the mould-board, the line between these extremities or points will be of one and three-sixteenth inches in length, and another line from the point $f$ to $g$ will be two and a half inches in length; the point $k$ is to drop one-eighth of an inch below a horizontal line drawn from $g$ towards $b$. From the point $g$ to $b$ the length of the line will be one and three-sixteenths inch. From the point $h$ to I the length will be one and five-sixteenths of an inch. A perpendienlar is let fall from the point $a$ to the horizontal plane on which the flat part of the under side of the mould-board rests, designated by the point I, being that of the intersection, and another line at right angles with it, being continued from the point I till it intersects the line running along the face of the slice from $k$ to $g$, parallel with the bar, at the point $j$ gires a line struck from I to $j$ of three inches in length, which gives the correct width of the board behind from outside to outsicle. On the back of the inside of the mould-board a flat shoulder is formed of about two inches in length, inereasing in thickness of the mould-board towards the upper part to about double the width of the average thickness of the mould-board thronghout, and thereby presents a flat surface upon which the right handle is bolted. On the line $k g$, as a base, a perpendicular is to be raised through $f$ to the point $m g$ two and threequarter inches in height, and another parallel to it at one inch distant of two and nine-sixteenths of an inch in height. The distance from $m$ to $o$ will be a projection of one-quarter of an inch forwards. The curved line of the front edge of the slice continues its direction beyond $f$ about half the distance on to $m$, 
when it projects forward about one-quarter of an inch and is then moulded off to the point $o$, thereby leaving suffieient shoulder for the hole through which the front bolt is to be fastened. On the face of the mould-board, Fig. 1, the coneave surface $d$ to $e$ continues in the same slope to about two-thirds the distance above the neck over the line $f c$, where it projects forward in a eoneave sufficiently deep for the reception of the head of the front bolt terminating at the top under the beam in a sharp edge, having the corners rounded off. The back part of this head runs back about one-quarter of an inch beyond the curved line of the back part of the sliee, thereby leaving space for the insertion of a hole to be east for the reception of the end of the brace that extends from the heel of the bar to the said hole in the head. This form and arrangement present such a shaped mould or pattern as may be cast at one operation.

"Fig. 3 is a view of the share where a line from the point a to the point $c$ extends to two and four-eighths inches in length, and a line from $c$ to $b$ is of three and three-eighths inches in length, and the distance $c$ to $e$ is one and five-eighths inches along the bar. The width of the share from $e$ to $d$ is two and three-eighths inches, and the edge from heel to point is sharp throughout. That part between $a$ and $f$ extending in a circular from $d$ to $f$, and the remainder of the point from $f$ to $a$, is rounded at the extremity of said point. The depth at $c$, in Fig. 4, of the bar is to be three-eighths of an ineh, and at $e$ it is to be seven-eighths, and extending back to $b$ of the same depth, this share and bar is to be made of wrought iron. These proportions are reduced to one-fourth of a plow of full size, so that in construeting a mouldboard of the full size of my 'Smeller Plow' the proportions are to be increased aecordingly."

It will be observed that Mr. Jacobs' method is wholly empirieal, or, at least, if there is a prineiple involved in its construction, it is not obvious to us after a careful examination, and none is hinted at in the specification. It consists simply of lines drawn in eertain directions, and of speeified lengths in a plane and from given points in these lines, letting fall perpendiculars of given lengths, which are ordinates to the desired eurve at these points; the points of the curve being ascertained in this way, the remainder of the pattern is eut away so as to form a regular eurve with them.

The next attempt to apply mathematieal prineiples to the construction of the mould-board was made by Aaron Suith, of 
Bloomfield, Michigan, who obtained a patent May 10 th, 1844. This is the plow which first came into notice as the "Michigan plow" at the great trial by the New York State Agrieultural Society, at Albany, in 1850, and which, with some important modifieations, is now known as the sod and sub-soil plow, and is one of the best plows in existence for sod lands. A figure of this plow complete is given in the Society's Transactions for 1850. Figs. $69 a, 69 b, 69 c, 69 d, 69 e, 69 f, 68$ and 69 represent the plow in detail. Fig. 68 represents the sole; Fig. $69 f$ represents the sole of the share.

The following extracts from the specification will give an idea of the principles involved in its construction:

"Fig. 68 is a plan of the hind plow as I draw it on my workingboard when preparing to make a pattern. The numbers on the line $j j$, representing the land side, show the distance between the principal points of the varying outline of the mould-board as

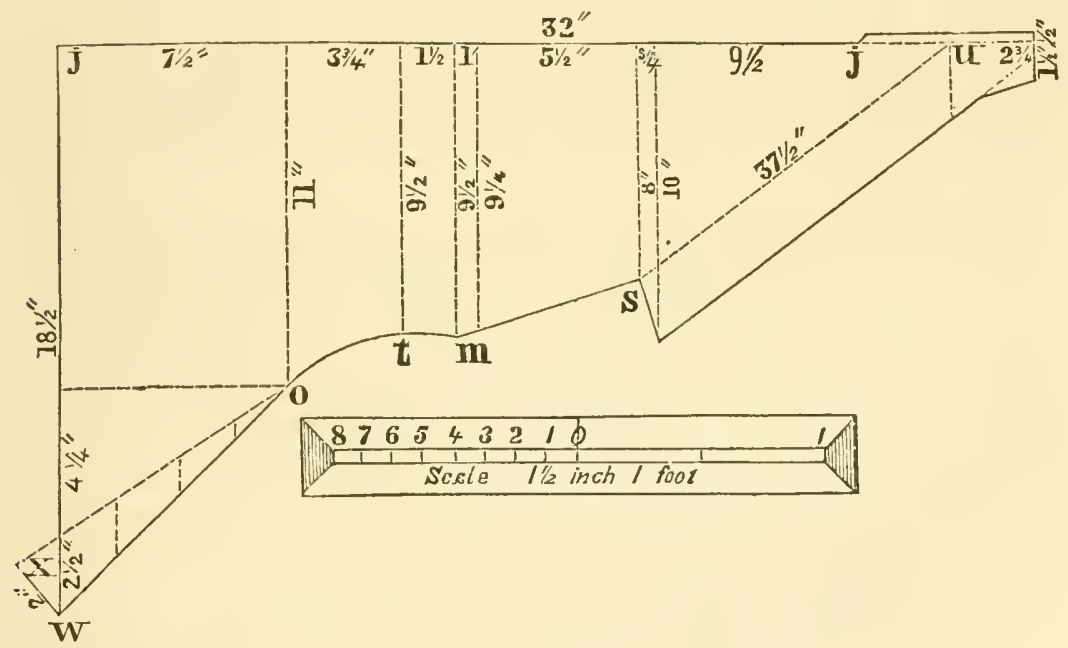

Fig. 68 .

maked by the dotted lines drawn at right angles to the land-side and terminating in those principal points. The distance from the fuce of the land side to these principal points are marked on these dotted lines.

"Fig. 69 is a right-hand or fice-view of the mould-board, with the share attached, showing the outline of its respective sides. The line $u l$ is erected perpendicularly from the point of the mouldboard. The measurements in the dotted lines, drawn horizontally from the perpendicular, give the outline of the head of the board, 
said measurements being taken at the respective distances markel on the perpendicular; the line $m n$ is drawn in the plane of the base of the mould-board. and the numbers from the perpendieulars drawn from the line give the outline of the lower side of the and of the board, and also of the top of it as fur as the lin': $o p$;

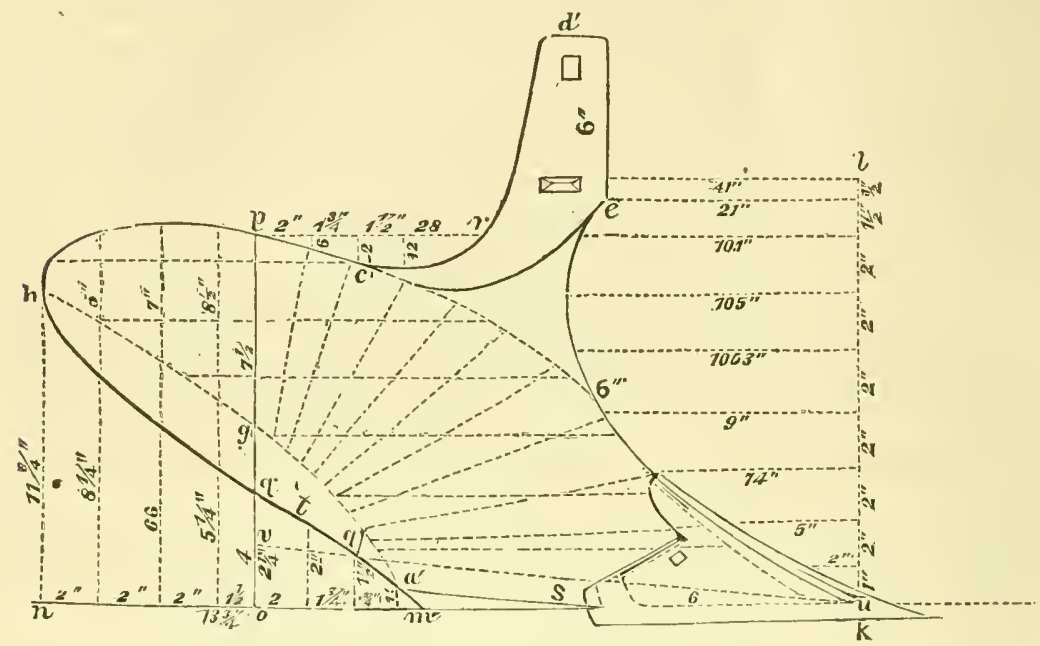

Fig. 69.

and the measurements from the line $p r$, drawn through the point $p$, parallel to the plane of the base of the board, gives its remaining outline to the sheath (generally called the standard). The line $n b^{\prime} c^{\prime} p$ is a guide line in forming the face of the board. The curve, $b c h$, may be determined bv the seale of one and a half inches to the foot, which is that to which the respective figures showing the parts in details are drawn. The face of the mouldboard was exactly perpendicular, and the line $o p$ from $q$ to $p$ is in it; $o p$ is also one of the guide lines in forming the face of the board. The rise of the line of the board from $a^{\prime}$ to $t^{\prime}$ is made at such a rate, compared with the spread of the board, as will exactly preserve through that distance the same width of the plow as at the heel, $a^{\prime}$. From $t^{\prime}$ to the perpendicular the rise is such that the increased width of the plow (Fig. 68) is to the distance as one to two and one quarter inches, and from the perpendicular to the end of the board these measurements are as one to one. The point, $t^{\prime}$, being where the action of the furrow slice, following that of the heel, $a^{\prime}$, commences, I make that a point through which to draw a line from the point of the monld-board, $u$, to the perpendicular. This line also lies in the surfuce of the board, and as 

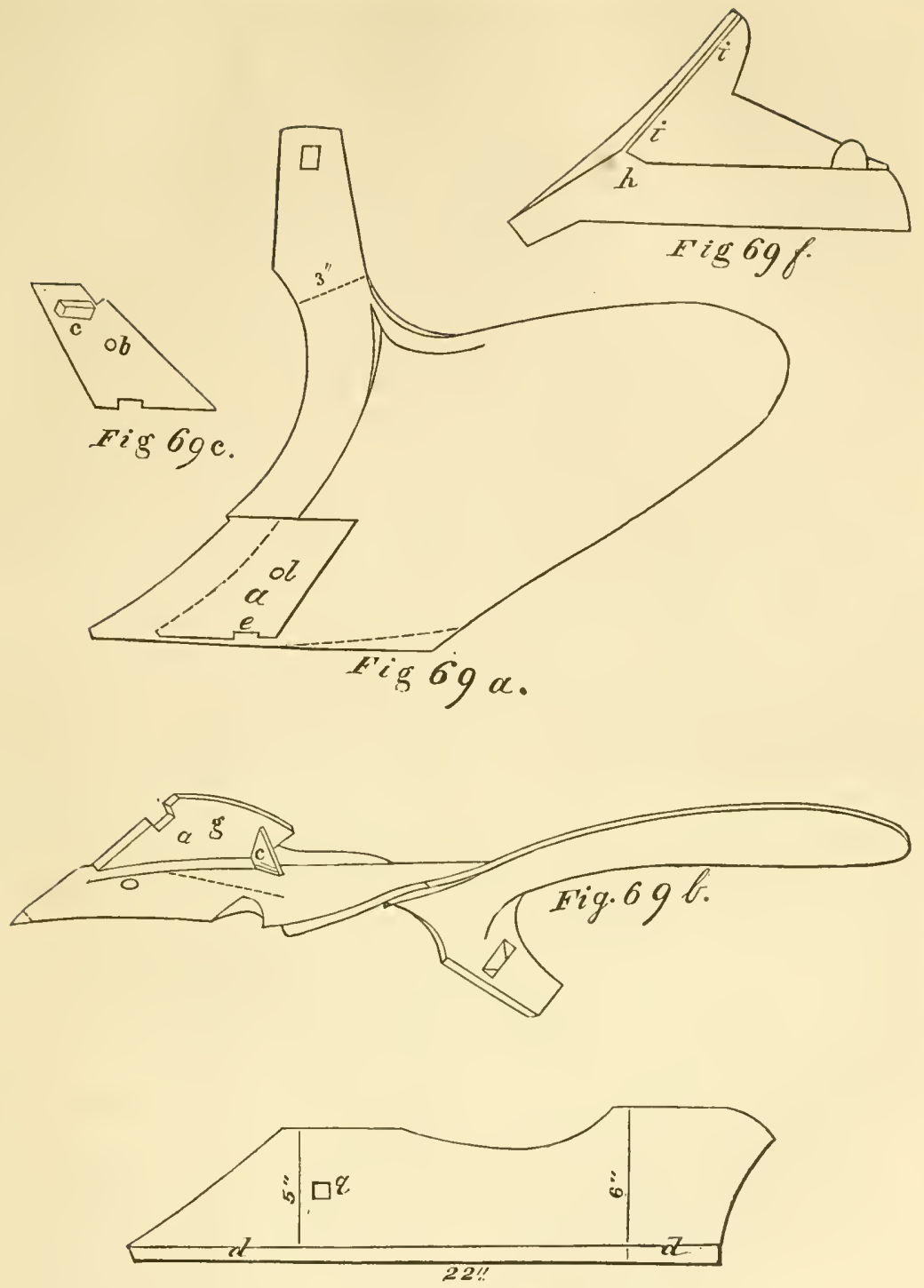

Fig. 69, d.

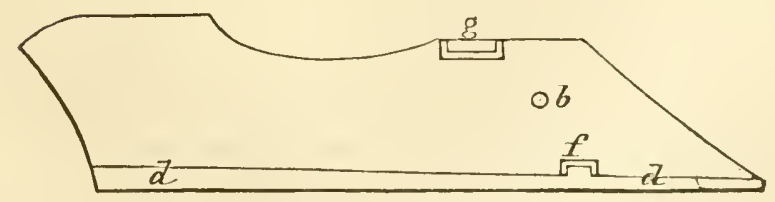

Fig. 69, e. 
a guide line. The lines $v p$ and $v u$, both being in the surtice of the board, the one where the furrow slice is nearly horizontal, and the other where it is perpendicular, the point, $v$, Fig. 69, I take as a radiating point to $u b^{\prime} c^{\prime} p$. A straight edge is to lie in each of these radiating lines so as to fit the actual mould-board.

"The same figure also exhibits another series of lines which lie in the surface of the board. These are parallel to the forward part of the base, $u s$, of the board, and tonch the curve, $u b c p$, and the perpendicular, o $p$. They are also fitted by a straight edge. The angle formed by the base of the land side and the line $u s$ is about $37 \frac{1}{2}$ degrees. The îriangular space, $a^{\prime} s m$, represents the heel of the mould-board, which is so formed as to cause it to lift or carry up the furrow slice to the top of that of the forward plow, which is from three to three and a half inches. The form of this part is shown in Fig. 69, $b i s$, which is an ent view of the heel, looking at it from the rear end of the plow. The line $a s$ is formed by the termination of the curving out of the mould-board as seen at $a^{\prime}$, Fig. $69, b i s$; the part $a^{\prime}$ in the same figure being a vertical continuation of the body of the mouldboard down to the sole, by which particular form this part is removed entirely out of the way of the furrow slice of the forward plow. The slice eut off by the fore plow may be about two and a half or three inches in thickness, and it is turned over by it into the furrow last mate.

"Fig. 9 is a left-hand view of the mould-board of the forward plow, separate from the share and land side. E, Fig. 12 is the share seen in place in Figs. 16 and 17.

"Fig. 14 is the plan of the length and width of this plow corresponding to Fig. 68 of the hind plow.

"Fig. 15 is a rigbt-hand view of the mould-board, share and coulter as combined for use.

"It will be seen on inspection that the curre of the mould. hoard forms an irregular conical figme, the larger end being direeted forward."

In Oetoher, 1839, Sammel Witherow, of Gettyshurg, and David Pierce, of Philadelphia, took ont a patent which was truly novel. We have not been able to ascertain that it ever got into general use, but it certainly seems worthy of a thorough trial. The following extract from the specitication will show the principle npon which it was founded very clearly:

"It is a principle resting "pon mathematical dem nstration that 
a eycloidal are is that which offer's the least resistance to a descending body, and it is hence deducible that an ascending body will pass up a cyeloidal curve with less resistance than "lp any other."

'This may he true, but we have never seen any such demonstration. It is undoubtedly true that a body will fall through at cycloidal are in less time than any other.

"The comstruction of our mould-boards is dependent on this principle. In forming then we employ the cycloidal curve in two ways, namely, to the formation of the concave of the mouldboard in the lines of ascent of the sward or furrow slice in the atet of plowing. The second application of the cycloidal curve is in the convex curve along the sole of the plow, constituting the part which enters and cuts the ground horizontally. In the accompanying drawing, Fig. 70 l'epresents a mould-board, A being

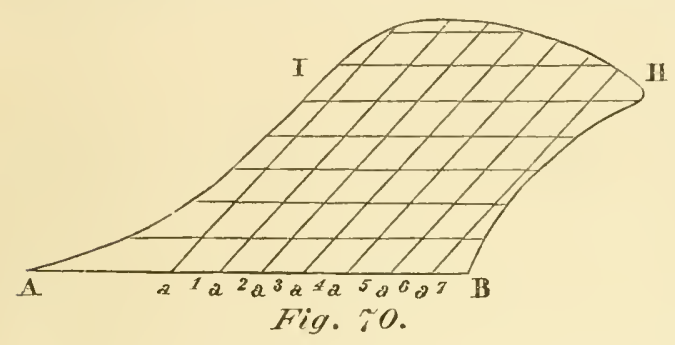
its point and B its heel; the line A B is that of the sole constituting the lower edge which cuts the furrow slice horizontally. This curve in a plow which has been essayed, and has been found to answer well, was generated by a circle of eighteen inches in diameter.

"In Fig. 71 the enrve C D E may represent the eycloid generated by the circle F. The point $\mathrm{D}$, which is that of least curvature, corresponds with the point A of the plow Fig. 70, the cycloidal line contimuing to the hind part or heel at B. It will, no doubt, be advantageous to

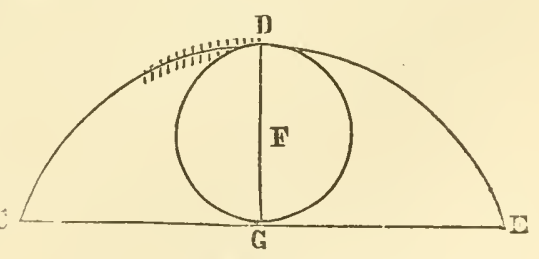

Fig. \%1. vary the curve according to the nature of the soil-a point to be determined by experience-but whatever variation may be found useful in this respect is still to be made in conformity with the principle upon which we proceed, namely, that of making it cycloidal. The line I II along the upper part of the mould-board and in a plane parallel to that of the plane of the line $A B$, we also make to fit the same cycloiclal gauge.

"In the plow that has been put in operation with a view of testing 
the principle, the lines of the ascent of the furrow slice which govern the concavity of the monld-board, were regulated by a cycloidal gauge made to a eurve generated by a circle of sixteen inches in diameter. Let C D G, Fig. 71, represent such a gauge, and the lines $a^{2} a^{3}, \& c .$, Fig. 70 , be assumed as those of the atscent of the furrow slice on the mould-board; in forming said board we 1) lace the gange in the direetion $a^{\prime}$ with the part $\mathrm{D}$, which is that of least eurvature at $a^{\prime}$, and thus proceed on until we arrive at the hinder part, B H, withdrawing or lowering the gange at its lower end at each suceessive application, so that a small portion of the least curved portion towards D, and a larger portion of that towards C shall touch the mould-board; these successive depressions may be indicated by the divisions at D upon the gauge. The degree in which the mould-board shall enrve and hang over at $\mathrm{H}$ for turning the furrow slice may be varied aceording to the judgment of the maker, the curvature being governed by the diameter of the generating cirele and the degree in which the gauge is depressed at every successive application of it.

"Having thus fully set forth the nature of our invention, and shown the manner in which we carry the same into operation, what we claim therein is the giving to our mould-board the segment of a cyeloid convexly on its face in a line leading from front to rear, and concavely in the lines of the ascent of the furrow slice."

\section{Remaris by the Inventors.}

"The main object is to pulverize the soil"-(they are the first who have made this arowal among inventors) — "and the only way in which this can be effected is by bending a furrow slice on a curved surface"-(this is the first allusion that we have met with to the influence of the shape of the surface in cracking the soil) "so formed that it shall also twist it somewhat in the mamner" of" the serew. Such a surface will be formed by taking a strip of iron and twisting it after the manner of a screw anger; and if there is given to this piece of iron a greater twist at one end than the other, cycloidal curves maty be therehy produced. Now as the curvature of the cycloidal mould-bourd generally inereases from the lowest to the highest point of ascent, it follows, necessarily, that the furrow slice, in passing along it, will be more and more bent as it aseends. By forming the fore part of the mouldboard by means of that point of the cycloidal galuge which has the least curvature and the hinder part hy that portion which hats 
the greatest, the bending of the furrow will continue and be increased as it passes horizontally ats well as in its ascent. By forming the lines of ascent cycloidal concavely and the horizontal lines eycloidal convexly, the twist in the monld-board will gradually inerease from the fore to the hinder part as the curves contract, which will operate very advantageously in pulverizing the soil. The convex eycloidal form given to the horizontal lines will cause the furrow slice to leare the mould-board in a direction well calculated to prevent it from falling off in segments. The adrantages possessed by this mould-lonard, as has been abundantly proved in practice, are, that it will seem light, and that it will turn the furrow slice over in a connected sheet well pulverized."

It has always been an object with inventors to diminish the friction of the land side. The first earnest attempt to realize this idea in practice was by T. D. Burrall, of Geneva, who claimed, on the 28th of Oetober, 1843, as follows:

"The nature of the invention consists in removing the sole of the land side, and placing an inclined wheel, denominated a shell wheel, between the land side and the mould-bourd, with its face in a line with the ent of the coulter. The land side enrves up from the point of the share and backward to the junction of the handle and beam. The beam is halved on the land side outward and the handle is affixed to the side of it, the whole being seenred by a serew bolt passing through them. This forms a seeure joint, without tenon and mortise, without materially weakening the beam or handles. This plow was earefully tested by the New York State Agricultural Society. At first it ran casier than the plows that were tried in competition with it, but after a little while it became choked, and then its draft was greater than the others. The judges of the society did not consider it an improvement, and we believe the public have pretty fully ratified their decision."

In the year 1839, Cyrus Alger, of Boston, reeeived a patent tor annealing cast iron plows, by which they were rendered malleahl(. so that the shape could be altered when desired, and then hardenes and tempered like steel. We are not informed whether this patent was ever brought into practical use, or whether it answered, in any tolerable degree, the purposes for which it was designed. If it really accomplished what it proposed to do, it would, in our judgment, be very important.

The next attempt at a mathematical monld-board was made by Mr. Simmel A. Knox, of Worcester, for many years the forman 
of Messrs. Ruggles, Nourse \& Mason. It is strietly geometrical in its construction, and it probably works with as little resistance as any plow that was ever made. It turns over the furrow very handsomely as well as evenly, and would secure the unlimited approbation of an English plowman; but its pulverizing power is somewhat deficient. and it therefore fails in what we consider one of the most important functions of a plow. A view of all the lines is given in Plate VIII. The patent for this method was granted in 1852 .

\section{Knox's Specification.}

"To enable any one skilled in the art of plow-making to form the mould-board of plows, according to my said invention, I will first describe the mode of determining the form of the surface of a pattern from which to mould and east the mould-board of a green-sward, flat-furrow plow intended for a twelve-inch furrow; and I will then indicate the ehanges necessary to the production of the required form for an old-ground plow, from which any skillful plowmaker will be enabled to make the necessary changess for plows of any other dimensions.

"For making the patter"n from which to cast the mould-board of a green-sward, flat-furrow plow, I first determine the proportions of the base by drawing a line, $A$, diagram Fig. 1, which represents the line of the land side, and at right angles to this I draw another line, $B \quad b$, on which I determine the breadth of the base of the plow from the line of the land side to the heel, $c$, of the mould-board, say twelve inches for a furrow of that breadth, and this I divide into inches. I then draw two lines, $D d$ and $E$ e, parallel with, and one on each side of, and at a distance of twelve inches from, the line $B b$. I then draw a diagonal line, $F f$, from the intersection of the line $D d$ and $A a$, passing through the line $B \quad b$ at $c$ (the heel of the intended mould-boalrd), and project the said line until it intersects the line $E$ at $e$, and the plane of this line, $F f$, perpendicular to the base, at the required height, to be hereafter specified, determines the inclination of the upper edge of the working surface of the interded mould-hoard to the vertical plane of the line $A$ a or land side. The distance of the point of the plow at $g$, from the line $B b$, is determined by multiplying the length of the diagonal line, $F f$, in inches, from the point where it intersects the lines $A$ a and $D d$ to the point of its intersection with the line $B$ b, by an equal number of inchus, and then dividing this product by the 


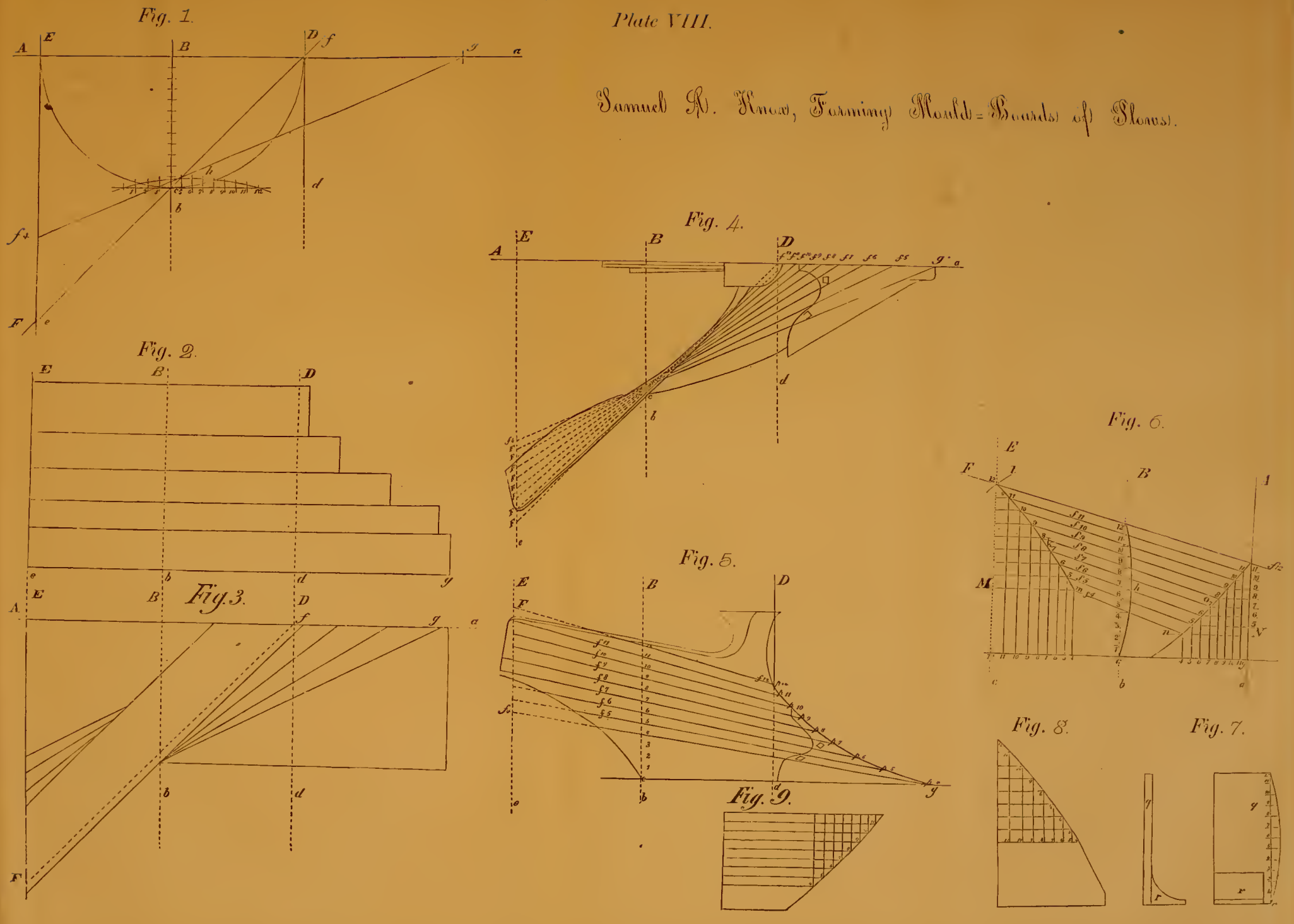



breadth of the intended plow at the heel, $c$, of the mould-hoard, saly twelve inches, the product of which will be twenty-four inches and one twelfth $\left(2+\frac{1}{12}\right)$, and add to this prodnct one-tenth thereof, which will make the distance of the point from the line $B$ b twenty-six inches and fifty-nine one hundred and twenticths $\left(\begin{array}{r}59 \\ 120\end{array}\right)$.

"Having determined the above proportions, I build up a block, represented at Figs. 2 and 3 , from which to form the pattern, and consisting of a series of flat blocks of wood, glued together to the requiled height in the usual mamner of preparing blocks for making plow patterns.

"The face, $A a$, of the said block is made perpendicular to the base and corresponds to the line $A$ a or land side of diagram Fig. 1; the end, $E$ e, presents a plane perpendicular to the base and at right angles to the face, $A$ a, and corresponding with the line $E$ e, of diagram Fig. 1, and the opposite end at $g$ is cut to the required length for the location of the point of the plow. On the under side or face of this block I transfer the two lines $B b$ and $D d$ and the diagonal line $F f$ from diagram Fig. 1, as represented in the dotted lines, Fig. 3. And I also mark on the face, $A$ a, and also on the opposite face of the said black lines, $B b$ and $D d$ to represent the planes of the said lines perpendicular to the base, as represented by dotted lines in Fig. 2.

"I divide the block into three imaginary divisions by three imaginary planes perpendicular to the base, and corresponding with the three lines $B b, D d$ and $E$ e, the first division being at the line $D d$, the second at the line $B b$, and passing through the heel of the intended monld-board, and the third at the line $E e$ : I then draw a diagram, Fig. 6, with a base line representing the base of the plow on which I erect a perpendicular line, 1 ; $a$ representing the land side or line $A \alpha$, diagram Fig. 1, and parallel therewith, and at a distance therefrom of equal to the breadih of the plow from the heel of the mould-board, in this case twelve inches, draw line $B$ corresponding with the line $B \quad$ on diagran Fig. 1, and from the base mak on the said lime twelve divisions: of one inch each, numbered from one to twelve. And I thin strike the are of a circle, $h$, on a radius of double the breadth of the intended plow at the heel of the mould-board, which in this case will be twenty-four inches, the said arc being macle to intersect the line $B b$ at the base and at the twelfth division from the base; and then draw lines parallel with the base through each of the points of the twolve divisions fo intersect or ent the said are, 
the said lines being indicated by the figures numbering the several divisions on the line $B b$. The are $h$ represents the concavity of the face of the intended mould-board at the second imaginary division. And the point of intersection of the said are $h$ with the base in the position of the heel of the mould-board and marked $c$, and the point of its intersection with the division line 12 determines the height of the line $F f$ of the upper edge of the working surface of the mould-board and perpendicularly over the heel of the mould-board.

"On the said diagram Fig. 6, I draw another line, $E$ e, parallel with the line $B \quad b$, and at a distance therefrom equal to the breadth of the plow at the heel of the monld-board, and in this case twelve inches. I then draw a straight line, $g f^{4}$, from the point of intersection of the line $A$ a with the base to the point of intersection of the division line 4 with the are $h$, and project it beyond the arc $h$. But it becomes necessary to determine the height, from the base, at which this line $g f^{4}$ will intersect the plane of the third division. This I obtain on Fig. 5, which represents the lines on the face of the mould-board when projected on a plane perpendicular to the base. On this figure I draw the three parallel lines $D d, B b, E$ e perpendicular to the base, and, as in the other figures, indicating the first, second and third divisions, as also the distance of the point $g$ of the plow from the second division. I transfer on the line $B b$ of this Fig. 5, from diagram Fig. 6, the several divisions numbered from one to twelve of the are $h$ of Fig. 6, and I then draw a straight line from the point $g$ through the division numbered 4 and project it to the line $E$ e, or plane of the third division, and this gives the inclination of the line $g f^{4}$ to the base, and hence the height of its intersection with the plane of the third division. And this height from the base I transfer to diagram Fig. 6, and draw through it a line $M / n$ parallel with the base until it intersects the line $g f^{4}$ on this diatgram Fig. 6, and from this point of intersection I deseribe the are of a cirle $l$ on a radius equal to the breadth of the plow at the heel of the mould-board, in this ease twelve inches; I then describe an arc of a circle, $k$, of a radius of four times the breath of the plow at the heel of the mould-board, and in this case forty-eight inches, making the said are pass through the points of intersection of the are $l$ with the line $E$, and the line $g f^{4}$ with the line $M r m$. This arc of a cirele, $k$, determines the concavity of the fares of the mombl-boand at the plame of the third division, 
and the point of its intersection with the line $E$ e determines the height of the upper edge of the working surface of the mouldboard from the base. And having thus obtained this height I transfer it on to the line $E$, Fig. 5, and from this height I draw the diagonal line $F f^{12}$ intersecting the division 12 on the line $B \sqcup$ twelve inches from the base, and project it to the front end of the plow. The inclination of this line to the base line gives the inclination of the upper edge of the working surface to the base of the plow, its inclination to the plane of the land side having been determined by the line $F^{\prime} f$ on diagram Fig. 1. The inclination of the line $g f^{4}$ to the plane of the base has already been determined, and to determine its inclination to the plane of the land side, I delineate on diagram Fig. 1 the are $h$ of Fig. 6 , so that the chord of the arc shall be parallel with the line $A$ a, and intersecting the line $B \quad b$ at the point $c$, or heel of the mouldboard, and so that the line of division 4 shall coincide with the line $B b$, the convexity of the are being towards the line $A a$, I then draw the diagonal line $g f^{4}$ from the point $g$ of the plow to the line $E e$, or third division, and intersecting the line $B U$ at the point of its intersection with the are $h$. The inclination of this line, $g f^{4}$, to the plane of the land side, so determined on diagram Fig. 1, I transfer to Fig. 4, which represents a plan view of the mould-board, with the lines projected on a horizontal plane, where it indicates the inclination of that part of the surface of the monld-board to the plane of the land side, along the entire length of the mould-board, the inclination thereof to the base having already been defined and represented in Fig. 5.

"Having, in the manner above described, defined and located the inclination of the surface of the monld-board to the plane of the base and the plane of the land side, along the stritight line $F f^{12}$ or npper edge of the working surfice, and along the straight edge, $g f^{4}$, from the point of the plow to the third division, it becomes necessary to define the form at certain distances between these two lines sufficiently near to each other that the workman may practically work down the whole surface of the mould-board. I have found that by lifting the form on the lines at distances of about an inch apart, that the workman can finish the residne of the surface with sufficient accuracy for all practical purposes; but, after the location of certain lines at this distance apart, by the same rules these divisions cin be multiplied to an indefinite extent. 
"Referring to diagram Fig. 6, the diagonal lines $F^{\prime} f^{12}$ and $g f^{4}$ will be found. On the line $E$ I I divide the space between the points of its intersection with the are, $k$, and the line $\lambda \mathrm{m}$ into eight equal parts, and from each of the points of division I draw lines parallel with the base to intersect the arc, $k$, and these points of intersection I mark from 4 to 12 , as the divisions are markerl on the are, $h$, of the seeond division; and I then draw diagonal lines, $f^{5}, f^{6}, f^{7}, f^{9}, f^{9}, f^{10}, f^{11}$, passing through points of the divisions correspondingly numbered on the are, $h$, of the second division, and on the are, $k$, of the third division, and project them until they intersect the first division. On Fig. 5, I measure the height from the base where the line $F f^{12}$ intersects the line $D d$ or plane of the first division, and transfer that distance or height on the line $A$ a or plane of the land side. In like manner, on Fig. 5, I measure the distance or height from the base where the line $g f^{4}$ intersects the line $D d$ or plane of the first division, and transfer that height on to the line $A$ a, of Fig. 6 , from the base, and draw a line, $N n$, parallel with the base until the said line intersects the diagonal line, $g f^{4}$, and this point of intersection will be found to be at the same distance from the line $A$ a, Fig. 1, as the point of its intersection of the said line $g f^{4}$ with the line $D d$ or plame of the first division is distant from the plane of the land side, so that these several points of intersection on these several figures prove each other. I then strike an are, $o$, of the same radius as the are $k$ (forty-eight inches), so that it shall interseet the point where the line $F f^{12}$ intersects the line $A$ a, and also the point where the line $N u$ intersects the diagonal line $q . f^{4}$; and the distance between the lines $F f^{12}$ and $N n$, where these lines cut the said line $A a$, I divide into eight equal parts, and from these divisions I draw lines parallel with the base, and these several lines will be found to eut the several diagonal lines, $f^{5}$ to $f^{11}$, inclusive, where they intersect the are $o$, which points of intersection on the said are, $o$, are numbered from 5 to 11 , as the corresponding divisions are marked on the ares, $h$ and $h$, of the second and third divisions.

"From the several points of intersection on the said an's o and $k$ of the first and third divisions, numbered from 4 to 12 inclusive, I draw lines perpendicular to the base, and eutting the said base lines; and the divisions thus obtained on the base line of Fig. 6 I then transfer to Fig. 4, transferring the divisions obtained from the are $o$ on to the line $D d$, or first division, and beginning with . . 
number 4, which will be found to coineide with the diagonal line $g f^{4}$ and ending with number 12 , which in both figures is the point of intersection of the diagonal line $F f^{12}$ with the line $A$ a or plane of the land side. And the divisions obtained from the are $k$ or third division, in like manner trausfer to the line $E$ e, or third division, on Fig. 4, measuring on loth figures from the lines $A a$, or plane of the land side, and the division number 4 will be found to coincide with the diagonal $g f^{4}$, and the division number 12 with the diagonal line $F f^{12}$ or upper edge of the working surface of the mould-board. From the several points of division thus transferred on the lines $D d$ and $E$ e of Fig. 4, except the two numbered 4 and 12 , on which the lines $F f^{12}$ and $g f^{4}$ were previously drawn, I draw straight lines diagonal to the plane of the land side, which lines are marked $F f^{5}$ to 11 inclusive. And where these several lines cut the lines $B b$, or plane of the second division, the distance of each from the line $A$ a, or plane of the land side, will be found, on measurement, to be equal to the distance of the correspondingly numbered divisions on the arc $h$ of the second division from the line $A a$ on diagram Fig. 6 . In this way the inclination which the surface of the mould-board makes to the plane of the land side along the several lines $g f^{4}$ to $F f^{12}$ is obtained, defined and proved, and it only remains to obtain, define and prove the inclination of the said surface to the hase of the plow along the said lines. This is done by transferring the divisions on the ares $o$ and $k$, as projected by lines parallel with the base, to the lines $A a$ and $E$ e. Those on the line $A a$ of Fig. 6, I transfer to the line $D d$ of Fig. 5 , measuring both figures from the base; and those on line $E$ e of Fig. 6 to the corresponding line $E e$ of Fig. 5, measuring both figures from the base. The surface of the mould-board having been defined at the first, second and third divisions, and along the several inclined lines from $g f^{4}$ to $F f^{12}$, the workman will be enabled to make the surface between conform properly to the surfice at these lines; but it will be obvious that the number of graduations on the are $h$ of the second division, instead of being made one inch apart, which I have found to be sufficient in practice, may be made als much less than an inch as the constructor may desire. As the form below the line $g f^{4}$ runs into the cutting edge of the share it is left to the judgment of the constructor to determine the form of that part, as also the form or extent of the surfice ahove the line of the upper working edpe of the mould-hoard and the 
extent of the wing back of the second division, as it may be cut short of, or extended back of the third division; as also with the amount to be cut away along the lower edge of the wing back of the heel of the mould-board.

"The drawings represent that form of the auxiliary parts which I prefer, but to which I do not wish to be understood as confining myself. The points where the several lines $g f^{4}$ to $F f^{12}$ intersect the vertical plane of the land side, and maked $p^{4}$ to $p^{12}$, in Fig. 5, will give the general configuration of the line of the forward cutting-edge, termed the shin of the plow. The mode of procedure which I have adopted for working out the block of wood to the form required for making a pattern is as follows: I make an instrument or gange, Fig. 7, consisting of a plate, $q$, on a base, $r$, at right angles therewith, and one edge of the plate, $q$, is cut to a form fitting the concavity or the are, $h$, Fig. 6 , when the base, $r$, of the said instrument is in the plane of the base of the said Fig. 6, and hence this curved edge will be the proper gauge to determine when the face of the block, Figs. 2 and 3 , is cut to the required concavity in the plane of the second division. I transfer on the face of the plate, $q$, of the said gauge up to the curved edge thereof, the gradnations or divisions of the are, $l$, Fig. 6. When the plane of the said gange is in the plame of the second division, $B b$, and the plane of its hase in the plane of the base of the block and the angle, $c$, at twelve inches from the face, $A a$, of the said block, or vertical plane of the land side, then the workman has obtained the required eoncavity of the face of the block in the plane of the second division, and marks thereon the divisions on the face of the gauge to locate the several divisions, numbered from 1 to 12 , of Fig. 6. I then make another gauge, Fig. 8, in like manner, with the curved edge thereof fitted to the concavity of the are 7 , Fig. 6 . While the base of the gange is in the plame of the base of Fig. 6, and on the face of this gauner, I transfer the graduations of the are $k$. I then cut into the fince of the block, in the direction of the plame of the thind division, until the curved edge of the said gange touches every part of the said surface, and its vertical edge, $E$ e, is at the same distance from the plane of the block which represents the land side, as the line $E$ e, Fig. 6 , is from the line $A$ a, of the said tignre, and the base of the gauge is in the plane of the base of the block. This determines the requisite concavity of the block in the plane of the third division, and at the required distince firom the land 
side, and I then transfer on the surfuce of the block the graduittions on the edge of the gange, numbered from 4 to 12 .

"I then make a third gauge, Fig. 9, in like manner as the other two, to correspond in every respect with the are 0 , Fig. 6 , as the other ganges were made to correspond with the ares $h$ and $h$. I cut and mark the surface of the block on the plane of the first division in the same manner as it was eut and marked by the other gauges in the plane of the second and third divisions, and bearing the same relation to the face of the bloek which represents the land sicle that the are $o$, on Fig. 6 , bears to the line $A a$ or plane of the land side. Having thus cut away the surface of the block to the required eoncavity in the plane of the first, second and third divisions, and marked and numbered thereon the several graduations to correspond with the graduations on the ares $o, h$ and $k$, of Fig. 6 , I then cut away the surface of the block in the direction of straight lines, so that a straight edge will touch along the entire length of the surface, passing through the graduations correspondingly numbered on the concavity at the three divisions, as shown on Figs. 4 and 5 by the lines $g f^{4}$ $F f^{5}$ to $F^{\prime} f^{12}$, inclusive, and then work off the remaining portions of the surface between and beyond these lines to a form which will correspond therewith."

Plows had previously been made approaching in some degree to a cylindrical form, but Mr. Joshua Gibbs, on the 15 th of August, 1854, patented a plow which strictly conformed to this principle, as will be seen by the following extracts from his specification:

"Fig. 72 is an elevation of my improved plow, showing the working side of the mould-board. Fig. - is the representation of the interior of a cylinder from which the mould-loard was made. Fig. - is a section of said cylinder. Fig. - the mouldboard as seen when looking at the forward end. Fig. - the limd side and parts connected with it. ****

"The working surface of the mould-board, A, consists of about one-quarter of the interior surface of a hollow cylinder, one end of which is represented in Fig. --, and a section of the interior in Fig. - - If the plow is intended to turn a furrow six inclues wide, a mould-board made from a cylinder of abont twelve inches bore is desirable; but if it is to turn a furrow twelve inches wide, the mould-board should be made from a cylinder with a bore of about two feet. As these plows hilve been found to work 
best when the length of the mould-board is from once and a half to twice the diameter of the bore of the cylinder from which the mould-board is made, and the form of its exterior edges about the same as represented in the drawing, the mould-board may he fastened to the other parts of the plow as may be convenient or desirable, taking into consideration the material from which it is made. The share is fitted to the lower edge of the mould-borrd, and its point is fitter to a recess in the heel of the coulter, C.

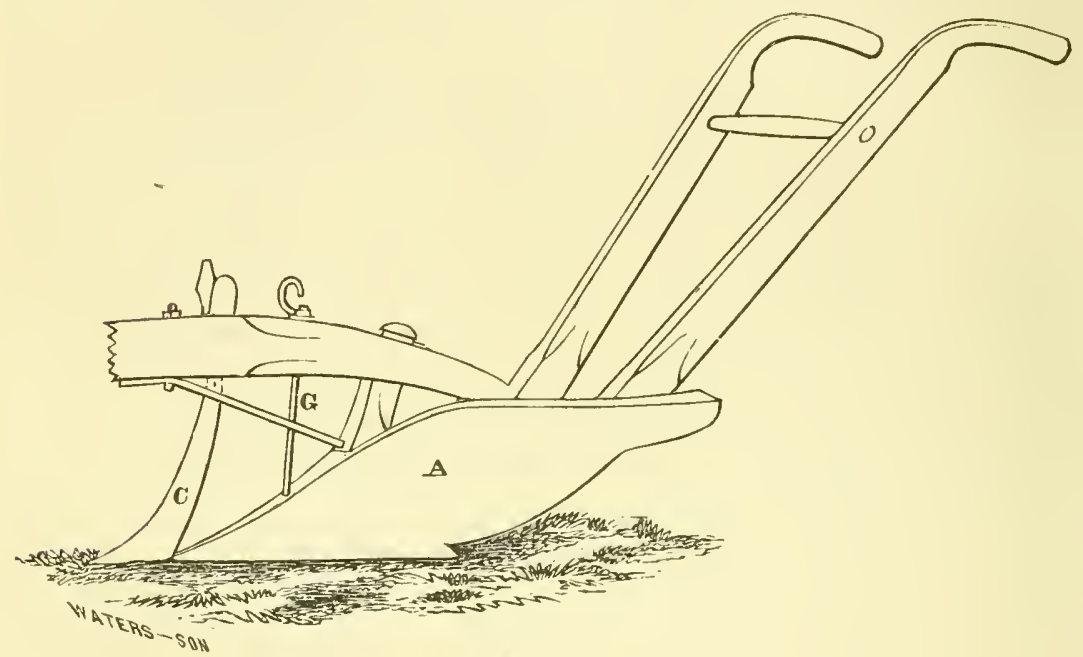

Fig. 72.

"It has been found that when the top of the land side was made parallel with the bottom, and a wooden standard fitted to it, with a shoulder fitted against the top edge of the land side, that the shoulder upon the wooden standard is soon worn off ans the wood wears away, so as to leave the plow defective and liable to get loose and shackling.

"To remedy this defect, and improve the plow in this respect. I make the top of the land side, D, opposite to the wooden standard, E, at an angle about as represented in the drawing, that is, higher towards the forward end of the plow, so that the iron land side shall protect the shoulder of the wooden standard, E, and prevent it from being worn off, so as to preserve a shoulder upon the standard, E, as long as there is any of the iron of the angle, $\mathrm{F}$, remains upon the land side to press against it, when the false coulter, or bolt, $\mathrm{G}$, is screwed up to hold the parts together." Claim-_ "making the working surface of the mould-board in the form of a hollow eylinder; the centre or axis of said cylinder 
being parallel or nearly parallel horizontally to the base of the mould-board or bottom of the plow substantially as deseribed."

In 1858, H. M. Platt invented a plow which was literally a serew-auger. It had wings, and a pair of broal wheels which turned an axis on which a mitre wheel was keyed, which played in a pinion upon the shaft of the auger, which drew the slice backward on to the wings, which rolled it over into position. We believe this has not been successful in practice.

M. L. Roberts, of Smithrille, Canada West, has no land side, but in place of it a wheel whose plane is at an angle of 45 degrees, and the mould-board consists of vertical rollers, the object of which is to diminish the frietion of plowing.

Chapman \& Barnum have also patented a device for diminishing the friction of the land side, which consists in substituting for the ordinary rear wing of the mould-board a revolving body what would be called a cone if its sides were bounded by straight lines. The sections, made vertically through the axis, are ares of circles. The small end of the cone is directed downward and the larger one upward. The lower end of the axis is inserted into a prolongation of the shoe, backward, the upper one being inserted in a bar, movable laterally, so as to increase or diminish the angle of the axis, at pleasure, with the plane of the sole.

We have not tried any of these friction expedients, but, from the best information we can obtain, they are illusory, and have never, so far, been practically successful.

In September, 1863, Mr. Mead, of New Haven, obtained a patent for a plow, the share and mould-board of which eonform exactly to the surface of a frustum of a cone, as shown in Fig. 73.

We have now passed in review all the expedients which have been devised within the period of four thousand years for the improvement of the plow. We do not flatter ourselves that we have seized on all the successive steps which have been made in the construction of this most important implement. If any attempt has been made to write a connected history of the plow hefore us, we have not been able to find it. We have traveled through a field hitherto unexplored, and it would indeed be wonderful if we should not miss some of the objects lying in our way.

It will be seen that the first idea of the plow was a crooked stick, of which various forms were in use. Then came the provision of an iron point to the plow. Up to this time the crooked 
sticks used were on the principle of the double mould-board; they threw off the earth on each side. The next step was to hew off one side of the stick, so as to throw out the earth only on one side, approximating to a single mould-board. Then the plow became a simple wedge, the land side being nearly parallel with the line of the plow's motion, the other moving the furrow slice to the right, but leaving the furrow standing on edge. Then the wedge was gradually twisted so as regularly to invert the furrow. Jefferson and Small diseovered the importanee of straight lines running from the sole to the top of the share and mould-board.

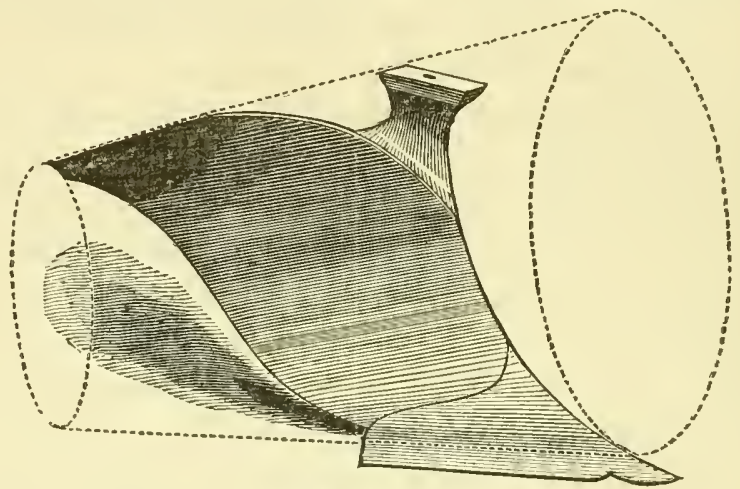

Fig. $\% 3$.

Colonel Pickering was the first to discover the importance of a straight line running from the front to the rear. Jethro Wood discovered that all the lines rumning from front to rear should be straight. Mr. Knox first diseovered a method of laying down all the lines of a plow on a plane surface. Mr. John Mears was the first to discover the importance of centre draft, and pointed out the practical means of attaining it by the inclination of the land side inward.

Aaron Smith was the first to adopt two plows to work well together, one of which threw two or three inches of the surface into the bottom of the preceding furrow, and the other covered it with the lower earth.

Finally, Governor Holbrook has invented a method by which plows of any size may be made symmetrically, either convex or concave, in such a way as to insure the complete pulverization of the soil.

We believe that we have been the first to announce that the great object in all plows is to form the curve in such a way as to make all the parts of the furrow slice to travel with different 
velocities in order to produce pulverization, but that these different velocities should be no greater than is required for the disintegration of the soil, in order to avoid an unnecessary expenditure of power.

In view of the fact that the plow has always been regarded as the basis of all civilization and all wealth, it may well excite astonishment that it should have required so many years to have made the few successive advances which we have just detailed.

We can only account for the apparent anomaly by remembering that very few of the gifted minds of successive generations have devoted their attention to the plow, and that until the present time there has been no elear and definite idea in the minds of inventors of the precise objects which they were seeking to accomplish.

We hope it will he found that the very careful and accurate trials with superior instruments made at Utica, will have the efieet of giving more definite ideas to the inventors of the country, and that the resnlt will be seen in a more rapid series of improvements in the plow in the next five years than has been accomplished in the preceding centuries.

Just as the manuseript is going into the hands of the printer we have received a panphlet giving a description of Dr. Grant's new invention of a plow for deep tillage.

We are heartily in sympathy with the objects which the Doctor has in view, but as we have never seen the plow nor its work we can give no intelligent opinion of our own as to his success in practically accomplishing those objects.

We give the drawings and description from the pamphlet as a part of the current history of the plow.

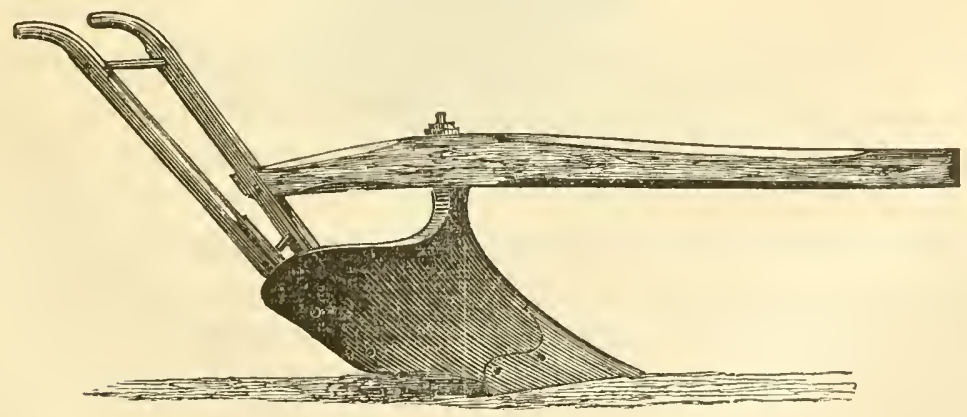

Fig. 1.

Fig. 1 represents the Iona turning plow, which has been fitted for receiving eertail: additions hy which it is transformed to ar 
implement of entirely new chatacter, and remlered eapalsle of very desirable preparation of the ground by deep working. The additions are very readily applied when the transformation is required, and as easily laid aside again when it is wanted for ordinary work without impairing in any degree its utility or convenience.

Fig. 2 represents the most important of the additions for the transformation to which all of the other's are accessory or sup-

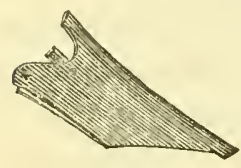
plemental. This consists chiefly of an inelined plane or share, either in one or more pieces, as cireumstances may determine. This arrangement has a corresponding land side, to which the

Fig. 2. original gives place in transiormation. There are two sizes of the inclined plane, designated as No. 1 and No. 2. The latter is able to raise its slice of subsoil from the greater depth. Each size of the inclined planes has a corresponding accessory part for rendering them more efticient for certain purposes that will be noted in the account of the operation of the implement. There are also two supplementary pieces for increasing the width of the mould-board at its upper edge, the wider of which is used for the deeper working.

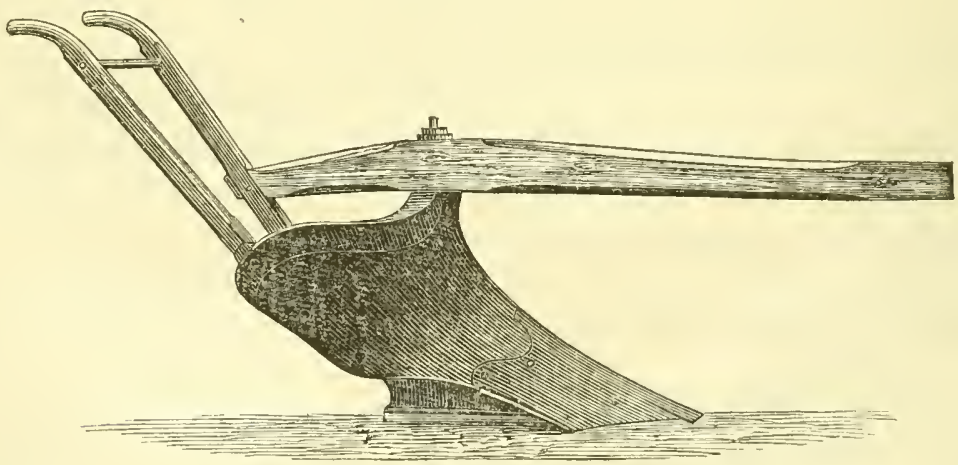

Fig. 3.

Fig. 3 represents the most simple form of the Transformed No. 1 , having the narrow supplemental plate and the No. 1 inelined plane without any of the accessories, all of which are important in fitting it for the variety of uses to which it is adapted. These are of the utmost simplicity in their manner of application, are (lurable in wear, and not liable to break or get out of repair. These plows perform easily and thoroughly the operation of trench plowing, that is often attemoted lout always with a very 
small measure of sucess) by driving large plows of the ordinary construction twice in the same furrow. The inclined plane performs thoroughly the work of a shovel or spade, and much more, taking up the subsoil cleanly from the bottom, leaving at level floor, finely pulverizing and mingling it with the fertile soil, but placing more of the surfice soil at and towards the bottom than toward the top, or vice versa, as may be desired, mingling manure also most intimately throughout, when that is used.

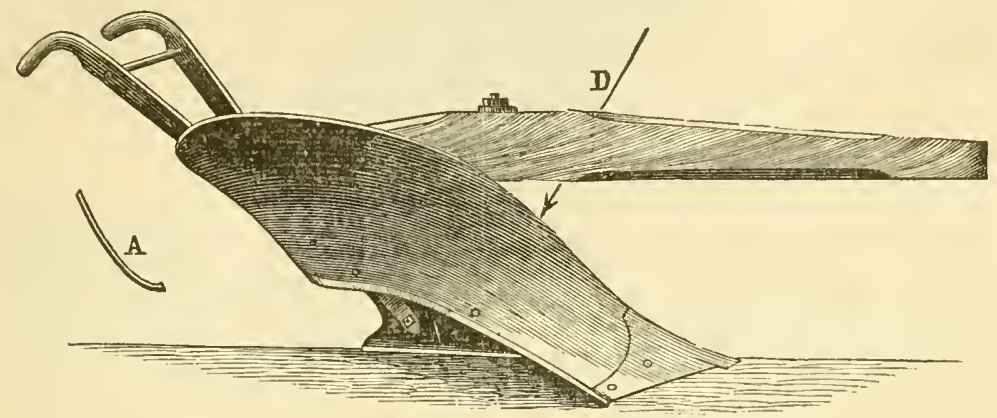

Fig. 4.

Fig. 4 represents Great Trench Plow No. 1. It cuts a furrow ten inches wide, and has good turning power for any thickness of slice not exceeding ten inches, and is calculated for any depth not greater than twenty inches. It is designed for heavy soils.

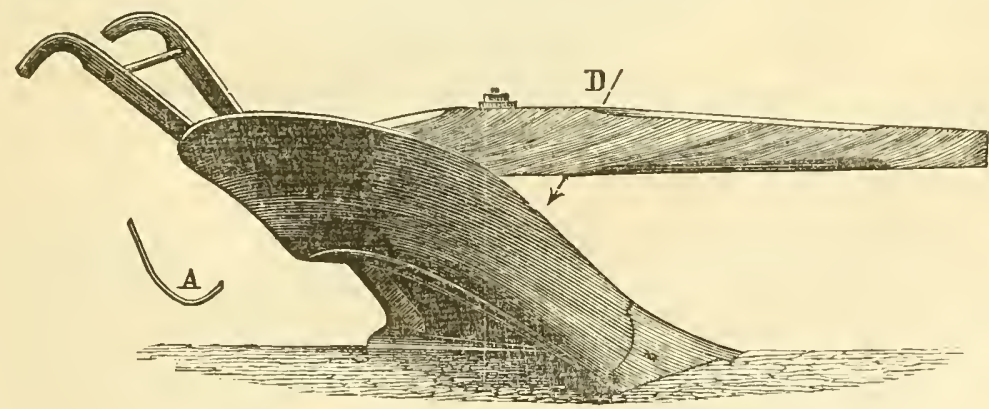

Fig. 5 .

Fig. 5 represents Great Trench Plow No. 2, which is designed for moderately adhesive loams, and for very friable sandy and gravelly soils, and will do the work well two feet deep, or any less that may be required.

Fig. 6 represents a great Trenching Plow that is constructed for working in loams or clays, but is prepared for the reception of appliances that adapt it for light loams or the most crumbly 
gravels. Its gauge is for less depth than the preceding, but by the assistance of the appliances it may be titted for a depth of twenty inches or more.

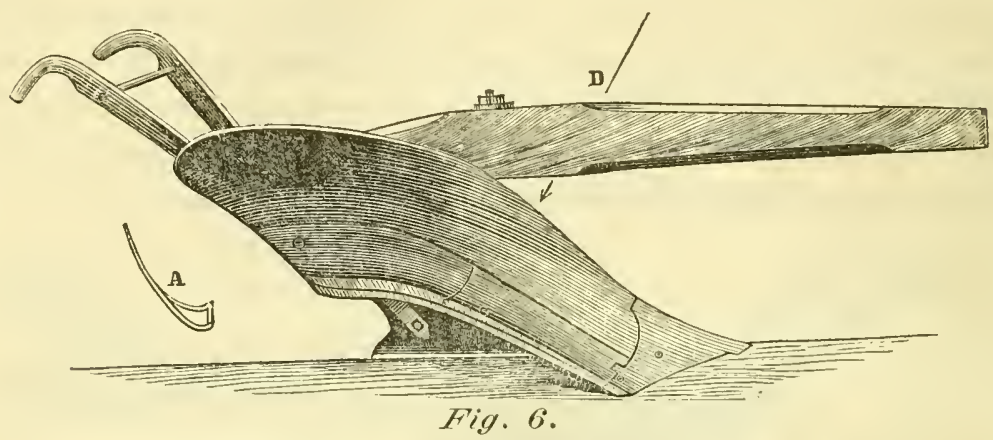

Fig. 7 represents a larger plow of tne same plan as the p:eceding, that by such accessions as are represented in the cut can be regulated for any kind of praticalsle soil and for any depth between sixteen and twenty-four inches.

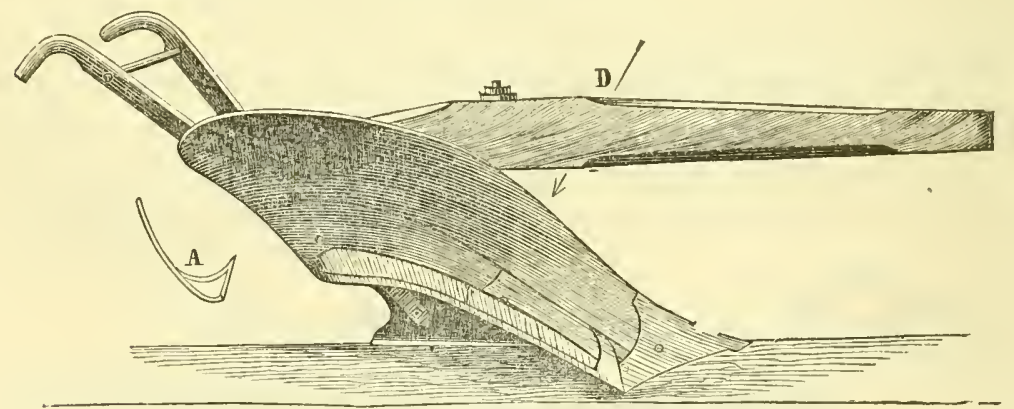

Fig. $\%$.

Deep working may be divided into two kinds that are effectual, and one ineffectual. The two effectual kinds may be designated by the terms half-trenching and trenching, or, for marked distinetion, thorouth-trenching. The former is often preparatory to the latter: Ineffectual deep-working is when tillage plows, going deeper thin their turning gange, simply raise the soil to let it fall back as if nearly undisturbed. Trenehing (or thorongh-trenehing) consists in reversing the two strata, that is, putting the upper fertile portion below, and lower unfertile portion above, the thickness of the latter being determined by the depth of working. For convenience, we designate these strati hy the terms soil and subsoil, as well as by the deseriptive terms fertile portion and 
unfertile portion, using them interehangeably, as may seem most convenient or applieable.

When pretty deep trenching is to be done, the labor of opening the first trench is considerably greater than that required for the

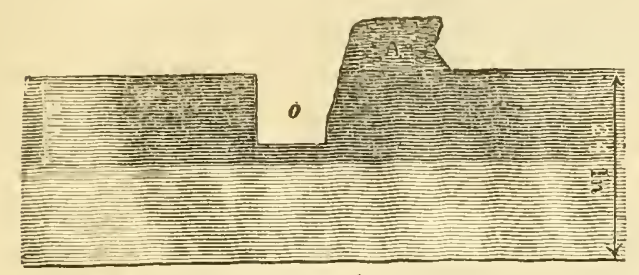

Fig. 1.

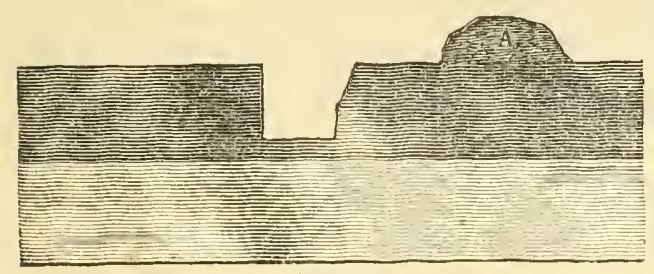

Fig. 2.

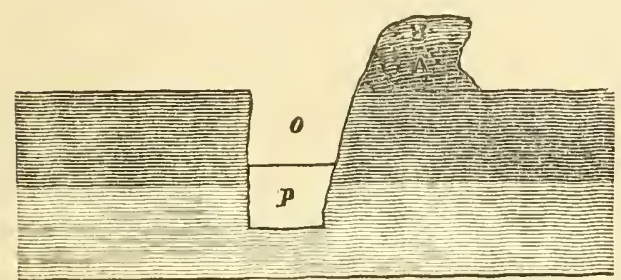

Fig. 3.

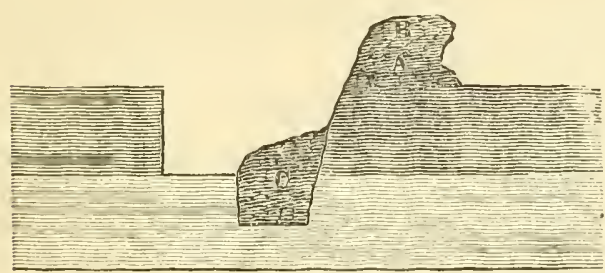

Fig. 4 .

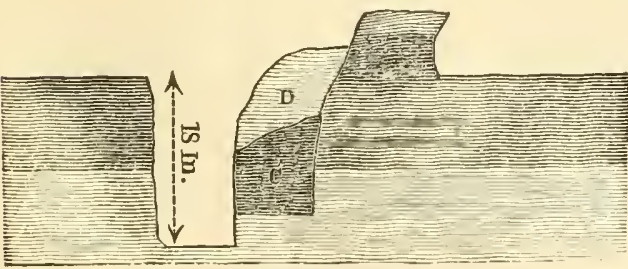

Fig. 5 . succeeding ones, whether performed with spade or plow, but particularly so with the latter. Fig. 1 represents a trench aloout nine inches deep, through which the turning and trench plows have each passed, and the raising capacity of the latter is nearly exhausted by the bank. By strenuous effort, six inches more of depth might be accomplished, but not very satisfactorily. To enable the plow to gain nearly the requisite depth in this first trench, the bank, A, must be removed to the position represented at A, Fig. 2. This may be partially done with a plow, but must be completed with spades or shovels, when the depth represented by $p$, Fig. 3, may be easily gained, but it will be difficult to go deeper in the trench with any of the plows here represented. The next proceeding in order is to turn over and throw down into the trench, $p$, a slice composed of the thickness of 


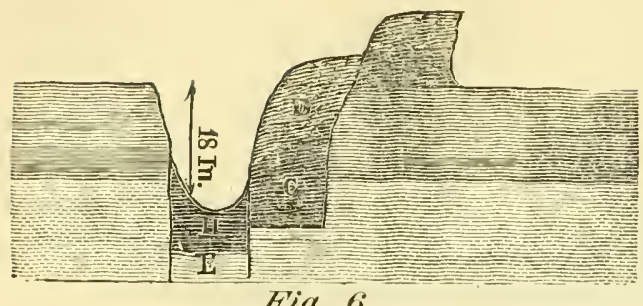

Fig. 6 .

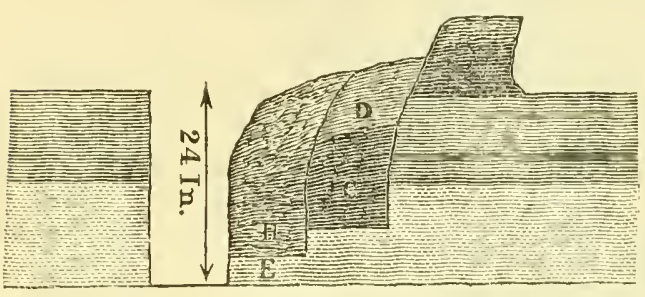

Fig. $\%$.

the fertile stracum, and as wide as the trench, as represented at $C$. The next step is to raise a slice of the subsoil of any thickness required, not making greater depth than twenty-one inches, as shown at D. The dart marked eighteen inches, by error, should be 21 . The representation in Fig. 5 is of work done in adhesive loam, and shows rather the working of the plow than the exact appearance of the trench, that never being quice so clear and square after the passage of the plow, as is here represented.

In very unadhesive, gravelly or sandy soils the appearance will be as represented in Fig. 6. Debris, as at $\mathrm{H}$, oceurs in gravels, consisting in part of the falling of the edge of the land side bank, and in part of the falling back of the subsoil slice. This is often in about the proportions required, and then only the passage of the transformed, with its peculiar grinding action is required to perfect the operation. If a larger admixture of the surface soil is required at the bottom of the trench, a small slice of it is easily thrown down by a small plow drawn by one horse before the passage of the transformed.

It is, of course, impossible to leave as clean a furrow as is represented in Fig. 7, as the ground from both sides will fall in and fill the furrow. It is rather intended to represent the actual working of the plow at the depth of two feet. These plows are worked with two pairs of strong oxen. 


\section{CHAPTER VI.}

\section{ON THE OBJECTS TO BE ACCOMPLISHED BY PLOWING.}

Before we can judge of the best form and arrangement of the flow, we must first clearly comprehend the objects sought to be acemplished by plowing land.

In general we may say that we seek in plowing land to cause it to yield a greater amount of erops; but this general answer is insufticient for our purpose. We want to know why plowing the land makes it more fertile before we are in a position to know which of the various forms of the plow is best adapted to promote the desired fertility.

If we find that two or more forms of the plow are equally adapted to improve the condition of the land, the question then arrises, which of them can be worked with the greatest econony? This question inrolves several elements. We are to inquire which of them can be worked with the least expenditure of animal power. It has been proved by the trials instituted by our own Society, by the Highland Society of Scotiand, and by the Royal Agricultural Society of England, that some forms of the plow can open a given sized furrow with thirty per cent less of power than others, or what is nearly the same thing, two horses will do as much as three. It is easy to understand that the farmer using the one will find farming a remunerative occupation, while the farmer that uses the other will carry on his business at a loss. Another question which must be answered under this head of inquiry is, which of the plows will wear the longest? It is well known that there are great differences in this respect, some listing five times as long as others. The points of many plows now in market will only last for a single day. Again, some plows can be advantageously worked by much less skillful workmen than others, and, of course, unskilled laborer's can always be oltained at a lower rate of compensation than the skilled classes. Finally, there are some plows which can be worked with far less labor by the operative, which is an advantage that no goou furmer will overlook. The plow which combines with the lowest price the greatest number of these advantages is clearly to be taken as the cheapest plow. 
Let us first endeavor to understund how the plow makes land more fertile. To accomplish this we mnst know what fertility is, and what causes it.

All plants whatever have their origin in a minute germ whose weight is exceedingly small compared with the weight of the fully developed plant. The germ has no creative power whatever; it ean only assimilate other matter with its own substance, and the whole of the extra weight of the mature plant consists of foreign matter which, by a curious but not unintelligible chemistry, the germ has assinilated with its own tissues and made a part of its own substance.

The substances thus assimilated are numerous, varying in different plants, but all derived originally from the rains and dews, from the atmosphere and the soil.

The compounds derived from air and water are called organic; those derived from the soil are called inorganic. Gum, sugar, and woody fibre are examples of the former; lime, potash, iron and saline matters are examples of the latter.

The amount of inorganie matter in plants varies from one to trelve per cent of their whole weight, aceording to their different natures; 100 pounds of wheat contains 1.18 pounds of ash or inorganie matter; 100 pounds of rye contains 1.04 pounds; 100 pounds of barley contains 2.35 pounds; 100 pounds of oats contains 2.58 pounds; 100 pounds of wheat straw contains 3.51 pounds of ash; 100 pounds of rye straw contains 2.79 pounds; 100 pounds of barley straw contains 5.24 pounds; 100 pounds of oat straw contains 5.74 pounds.

If we have an acre of land which yields us 1,500 pounds of wheat and 2,000 pounds of straw, it has taken from the soil about eighty-eight pounds of mineral matter.

An acre of land which bears a crop of oats, consisting of one ton of straw and forty bushels of grain, will abstract one hundred and fifty-six pounds of mineral matter from the soil.

The mineral matter ahsorbed by growing plants does not exist in the soil in unlimited quantities, but in definite quantities that can be exactly ascertained if we resort to the proper methods of inquiry. When we have ascertained the alssolute amount of mineral matters required by plants in the soil, if we divide the whole number of pounds of these matters in an acre of soil by eighty-eight, we shall know the exact number of erops of wheat that can be taken from an acre; and if we divide it by one hundred 
and fifty-six, we shall know the number of oat crops that can be taken.

When this number of crops has been taken from the soil, it is evident that its capacity for producing wheat or oats is exhausted. and can never be restored until the missing mineral is replaced from some foreign source.

In practice, however, the soil becomes incapable of yielding either wheat or oats long before the supply of mineral matter is exhausted. A wheat plant, for instance, may absolutely starve for want of ammonia in a soil which an exact chemical analysis shows to be superabundant in ammonia, or it may perish for lack of phosphate of lime in a soil replete with that substance; or it may be unable to procure a due supply of silicic acid from a soil consisting of pure sand.

Every farmer knows that if, after it appears to be exhausted of its mineral matter, the soil is allowed to rest, exposed to the action of frosts, rains, dews and sun-light, it will, after the lapse of a certain time, recover its fertility; the phosphate of lime, silicic acid and carbonate of potash, in which it seemed utterly deficient, have now been restored to it by the operation of its own internal processes, and not supplied to it from without.

Again, it is found that, on many kinds of land, very small crops are obtained at the first plowing; but that, at every successive plowing, the crop increases. It would seem from this that plants increased in magnitude just in proportion to the diminution of the supply of food.

An attentive examination of these apparent anomalies will lead us to a clear understanding of the causes of fertility in a soil.

First-Soils may contain a superabundance of mineral matters, though they are so unevenly distributed that a larger part of the soil is so deficient in them that it may be absolutely barren. Thus, if we measure off ten square feet at one corner of an acre, and cover it thickly with lime, the opposite corner of the are receives no benefit from the applieation; there is too much lime in one plat and none in the other. If the arable surfaces of the two soils are mixed together, both will be benefited and both will be more fertile. Or we may suppose that a soil deficient in phosphate of lime has a bone buried in it. After a certain time it will be found that some of the phosphate of lime and gelatine, with its included nitrogen, is dissolved, and the particles of earth in contact with the bone are saturated with the solution, and 
camnot take up any more. If we now remove the bone and bury it in unsaturated earth, another portion will be dissolved, and the soil contiguous to it will be saturated. We may thus, by successive removals and burials of the bone until it is wholly dissolved, render many times more soil fertile than if it had been left steadily in one place. 'There is no soil known through which the fertile matters are evenly diffused, and hence benefit must always result from mixing together the fertile and unfertile portions.

This is one of the objects sought to be accomplished by plowing land; it is because tlie spade accomplishes this more perfectly than any form of plow yet known to us, that so much larger crops can be obtained when that method of tillage is used.

Plows differ very widely in their power to mix soils together. Those which invert the furrow completely hardly mix it at all. Those which leave the furrow at an angle of $45 \mathrm{deg}$. mix it more intimately. Those which take a narrow furrow do it still more completely than those that take a broad one, and those that turn a furrow in two successive portions, as the sod and subsoil plow, intermingle the particles of the soil more perfectly than when it is turned in one mass.

It is obvious, from these considerations, that by bringing into contact with each other the particles of soil which had previously been separated, we increase its fertility, and therefore those kinds of plows which accomplish this object most perfectly, other things being equal, are to receive the preference.

Second-A very little reflection will satisfy a farmer that he may have abundant elements of fertility in his soil, yet he will derive no benefit from them, becanse they are locked up by aftinities which the rootlets of the plant cannot overcome. Thus, one ton of farm yard manure may be spread over a given area of soil, and one ton of coal spread over an equal contiguous area. The plants growing in the soil covered with'manure will be abundantly supplied with ammonia, while those growing in the soil coverert with the coal will receive none, and cease to grow in consesquence. If now we ascertain by analysis the amount of ammonia contained in each, we find that one ton of the former contains 17.4 pounds of ammonia, while a ton of the latter contains $47.0^{\circ}$ pounds, or nearly three times as much as the manure contained.

The important practical question, therefore, for the farmer to ask is, not how much plant nutriment is contained in his soil, but 
how much is there which is in such a physical and chemical condition as to be available by the rootlets of the growing plant.

As the success of the practical farmer depends almost entirely upon a knowledge of these principles, it will be necessary to give a brief explanation of them, especially as it is necessary to comprehend them, if we are to attain to clear understanding of the theory of the plow.

Mr. Wia filled several glass vases, furuished with stop-cocks at the bottom, with dry soils of various kinds; he then poured into each of them the drimage water from a barn yard loaded with stercoraceous and saline matters which, after it had filtered through the soils, was drawn off through the stop-eock. That which had passed through the stiffest clay came off limpid and apparently pure, the taste being almost like that of rain water; that which passed through a very sandy soil was but slightly changed in taste or appearance. The power of a soil to absorb the manmial matters seemed to depend upon the relative amount of aluminous matter contained in it, those having the greatest abundance absorbing most, those having the greatest amount of sand having the least. It was, however, established beyond a doubt that all soils had a peculiar power of absorbing manurial matters, which could not be separated by the action of water or by any other way than hy the absorbent action of the rootlets of a growing plant.

Dr. Velcker has followed up these investigations with great assicluity and success. He saturated various kinds of soils with a solntion of caustic ammonia, containing 23.24 grains of ammonia to the imperial gallon, and ascertained the amount of ammonia that was absorbed by each kind of soil. He thus found that 3,000 grains of a calcereous clay absorbed 2,758 grains of ammonia from 14,000 grains of the solution. From the same quantity a fertile loamy soil abstracted 2,604 grains; 3,000 grains of a stifi clay soil absorbed 2,262 grains of ammonia; 3,000 grains of a sterile sandy soil retained 3,228 grains of the solution; 3,000 grains of the soil of a rich pasture took up 1,728 grains of ammonia.

He next agitated these soils, which had heen saturated with ammonia water of the above mentioned strength, with a solution of ammonia, which was twice as strong ats the preceding, and found that they now, curiously enough, alsorbed very nearly 
equal portions of ammonia. Thus, the total amount of ammonia absorbed by 1,000 grains of soil was, in the case of the

1. Calcareous soil.................. 1.5193 grains of ammonia.

2. Fertile loamy soil $\ldots \ldots \ldots \ldots \ldots \ldots \ldots \ldots 1.5363$,

3. Clay soil..................... 1.1240 "

4. Sterile sandy soil............... 1.5220 "

5. Pasture land ................. " " "

Dr. Volcker next proceeded to verify these results by repenting the experiments in another form. He made four solutions of ammonia of varying degrees of strength, and used the same soila stiff calcareous clay-in all his experiments.

Per 1,000 grains.

Solution No. 1 contained 44.38 grains of ammonia per gallon, or.. .634

\begin{tabular}{|c|c|c|c|c|c|c|}
\hline No. 2 & "6 & 21.28 & “" & "6 & "، & .. .30t \\
\hline No. 3 & " & 1232 & " & "6 & "6 & .. .176 \\
\hline No. 4 & " & 6.16 & "6 & " & “ & .. .088 \\
\hline
\end{tabular}

The soil was saturated with each of these solutions, when it was found that 1,000 grains of the soil thus absorbed in

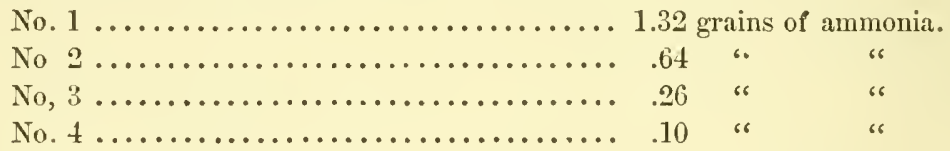

These experiments show conclusively that all soils have the power of absorbing ammonia from its solutions; that no soil can abstract all the ammonia from a solution; that all soils can take up a greater relative amount of ammonia from strong than from weak solutions of ammonia; hence a soil which had absorbed as much ammonia as it would from a weak solution took up a fresh quantity of ammonia when it was brought into contact with a stronger solution.

Dr. Valcker's experiments further showed that soils were equally disposed to appropriate ammonical salts as they were to alosorlb ammonia itself.

He next endeavored to ascertain how far the soils were disposed to part with the ammonia thus absorbed to the rain water which percolates through them. In order to accomplish this, a quarter of a pound of a soil, saturated with ammonia, was well shaken iu 7,000 grains of distilled water. It was allowed to settle for three days, when the elear liquor was carefully decanted, and the amount of water contained in it exactly ascertained. The soil thus washed was again shaken in a well stoppered bottle with 7,000 grains of fresh distilled water, and settled and decanted 
as before. This was repeated suven times successively, with the following results:

First washing, removed by 7,000 grains of water... .236 grs. ammonia.

\begin{tabular}{|c|c|c|c|c|c|c|c|c|}
\hline Second & 6 & 66 & 66 & 66 & 6 & $\ldots .642$ & 66 & 6 \\
\hline 'Third & 66 & 66 & 66 & 66 & 16 & ... .610 & 66 & 66 \\
\hline Fourth & " & ، & " & $6 s$ & 66 & ... .622 & "6 & c6 \\
\hline Fifth & 66 & 66 & 66 & 66 & \& & ... .120 & 66 & 6 \\
\hline Sixth & 66 & s6 & 66 & 66 & s & ... .193 & s & "6 \\
\hline Seventh & 66 & 66 & s & 66 & 66 & . . . 228 & 66 & 66 \\
\hline
\end{tabular}

Total......................... " "

Thus we see that after seven suceessive washings with 7,000 grains of water, or 49,000 grains of water in all, only 2.651 grains of ammonia was obtained firom a quarter of a pound of soil. It had previously absorbed 4.655 grains of ammonia, and there were therefore 2.004 grains left in it after this very thorough washing.

It is very clear from this experiment that the power of soils to remove ammonia from solutions is much greater than their property of yiclding it again to water.

Prof. Way discovered that soils not only possessed the power of separating ammonia, but likewise other bases from their solutions, and they held them after being so absorbed with very great tenacity. Thus, 100 grains of clay soil taken from the plastic clay formation in England absorbed 1.050 grains of potash from a solution of caustic potash containing one per cent of the alkaii. It is interesting to observe that the liquid was not in this case filtered through the soil, but only left in contact with the cold solution for twelve hours.

Prof. Way has further shown that soils have the ability to separate the alkaline bases from the acids with which they arc combined. He found that when saline solutions were slowly filtered through soils five or six inches deep, the liquids which passed through were deprived of their alkaline bases, as potash, soda, ammonia and magnesia, and only the acids were to be found in combination with some other base. Thus when muriate of ammonia was filtered through the soil the ammonia was removed, and a corresponding quantity of lime in combination with muriatic acid was found in the filtered liquid. In the same way sulphate of potash was deprived of its base, and the liquid collected gave sulphate of lime on analysis.

Prof. Liebig has attempted to show that this power of soils which enahles them thus to attraet manurial substances from their 
solutions is analogous to that by which charcoal separates coloring matters and odoriferous matters from their combinations. This is known to be partly mechanical and partly chemical. The chemical force, like that which causes the solution of substances in water, is very weak; it attracts substances to itself, but does not produce any change whatever upon the character of the substance. The coloring or the odorous matters are held in contact with the pores of the charcoal just as coloring matters adhere to the fibres of cotton or wool quite unchanged in their nature. Neither powdered pit coal nor the hard, glassy charcoal from sugar or blood have much power to attract coloring matters from their solutions, while porous blood or bone charcoal possesses this property in a very high degree, and among wood charcoals, those which have the greatest amount of capillary porosity.

It is just so with soils, those which have the greatest amount of capillary porosity will condense the greatest amount of manurial substances on their internal surfaces; will retain them longest against the adverse solvent action of water, and will give them out most readily to the rootlets of the growing plant. A mass of adhesive clay will absorb but a very slight amount of available manure, but if this same mass is rendered friable by mechanical processes its power of absorption is amazingly increased. In view of what has been stated, it is very clear that plowing land increases its fertility in one way by increasing its porosity by pulverization.

Again, many manurial substances exist in the soil which, being insoluble, exercise no action on the growth of plants, and contribute nothing to their nutrition; but by the slow, though regular action of the frosts and the rain, the air and the sunshine, these insoluble and refractory compounds are reduced to a soluble state, which are appropriated and held in deposit by the soil to the credit of the next cultivated crop. This routine explains the well known fict that soils, which have been cropped to the very verge of barrenness, will recover their fertility if allowed to remain long enough under the action of these climatic influences to saturate the soil with the necessary plant food which they have unlocked from their chemical combinations and given to the soil in a proper physical eondition.

These changes are brought about much more rapidly when certain mechanical changes of condition are wrought upon the soil. 
Carbonic acid is one of the most active of the agents employed in bringing the insoluble inorganic matter in the soil into that physical condition when they become available as plant food; in order that this acid may be formed, it is essential that tine carbonaceous matters in the soil should be brought into direct contact with the atmosphere from which they procure the oxygen necessary to convert them into carbonic acid.

So long as stagnant water remains in the soil, or so long as it is in a dense and very compact condition, it is impossible for the carbon in the soil to be converted into acid.

A supply of available phosphatic salts is essential for the growth of most cereal plants, but these salts often exist in great profusion in the soil without contributing in any way to the nutrition of plants, because they are in an insoluble condition. If now water charged with carbonic acid is allowed to circulate through the hard phosphatic nodules a portion of them will be dissolved by the acid and diffused by the water among the pores of the soil where they will be fixed in readiness for the demands of the growing plants. In this case we see another way that the fertility of the soil is increased by pulverization, because the air is admitted to the soil, which becomes the agent of converting the carbon existing in it into carbonic acid, which in its turn renders many snbstances which were previously useless very efficient in promoting the growth of plauts.

Mr. Way shows that the agents which exercise the greatest power in retaining manurial substances in physical combination with the soil are the double silicates, which we will endeavor to explain brictly, as their recent investigation has probably prevented a large proportion of the users of the plow from becoming fully acquainted with their properties.

If pure sand or powdered quartz be fused with lime, alumina ol some other alkali, they become chemically united, and are known as silicates. Thus, silica combined with potash is called silicate of potash; with ammonia, silicate of alumina, etc. These substances, under favorable circumstances, are very prone to unite together. Thus, silicate of alumina and silicate of lime are often found united together as one well marked substance having definite characters. These new compounds are called double silicates. They have the power, in a remarkable degree, of exchanging bases in a certain prescribed order. Thus, when the double silicate of alumina and sorla is digested with a solution of 
some lime salt, a new compound is formed, in which the soda is replaced by lime; in the same way the lime may be supplanted by magnesia, and the latter by potash.

It is very instruetive to observe that these successive replacements take place in a regular and unvarying order, which Prof. IVay has determined as follows: Soda, lime, magnesia, polash, ammonia.

Thus, in the double silicate of alumina and soda, the soda may be replaced by lime, the lime by magnesia, the magnesia by potash, and the potash by ammonia; but this cannot take place in the reverse order. Ammonia will dispossess any of the articles which precede it on the list; but none of these, either singly or in combination, has the power to dispossess ammonia. The value of these double silicates is in the order in which they are placed above. The double silicate of soda is less valuable than the double silicate of lime; the double silicate of lime is less valuable than the double silicate of magnesia; the double silicate of magnesia is less valuable than the double silicate of potash, and the latter is less valuable than the double silicate of ammonia. Thus we see the admirable provision of Divine Providence, that the more valuable compound shall always have the power of displacing the less valuable, while the inferior is restrained by impassible barriers from supplanting the superior compound.

When we learn that the formation and the transformation of these double silicates from a lower degree into a higher one is greatly promoted by a porons condition of the soil, we see an additional reason for the thorough pulverization of the soil by the plow.

The distance to which the roots of a plant will extend when there is no physical obstruction to their progress through the soil is far greater than is usually supposed by those who have not aetually witnessed their extension. We have seen the roots of Indian corm extending seven feet downward; the roots of lucerne will penetrate fiftcen feet; onjons will run downward three feet where the physical condition of the soil favors the extension of their range. It is olsvious that, as the nutritive matters in the soil camnot travel to the root, the latter must therefore go to the former; and the farther the root extends, the greater the amount of food which the plant ean obtain, and the greater must be its growth and nutritive capacity. The roots of plants always develop themselves in the direction of least resistance. If the roots of 
a plant have a hard, impervious soil on their right and a porous soil on their left, the roots will all be directed from the right to the left. The growth of roots takes place by the addition of new cells to their onter extremities. The newly added cell must therefore push the earth before it by a force somewhat greater than the cohesive force of the soil which it penetrates. The force required for this purpose exhausts the vital force of the plant. A thoroughly porous soil therefore relieves this exhaustion and economizes the vital force which is then directed to some other point. Plants differ greatly in their power of forcing their roots into the soil. Wheat and barley both radicate feebly and will hardly enter' a stiff soil, while buckwheat will penetrate it readily. The roots of quack grass (triticum repens) will force their way triumphantly through the stiffest elays, while the feebler roots of timothy (phleum pratense) will scarcely penetrate them at all.

Jethro Tull, to whom practical husbandry is so much indebted, ascertained the range of porous land required by each kind of plant in the following manner:

In the midst of hard, impervious land he dug a trench twenty yarls long, in the form of a truncated wedge, the transverse wiclth of the narrow end being two feet, and the broad end being twelve feet wide. In the fine, loose earth of this trapezoid he planted along the middle line, at distances of one yard apart, the plants whose root range he desired to ascertain. The plant one yard from the narrow end was smaller than that which was two yards from it, and this latter was smaller than that which was three yards distant. When he found the point where the plants ceased to enlarge and remained of the same size until that which was nearest to the widest end, he believed that he had the measure of the normal length of the root of that plant; thus when the trapezoid was planted with turnips each turnip was larger as it receded from the narrow end until the fifteenth, from thence to the twentieth the turnips were of equal size. Measuring laterally from the fifteenth turnip, he found that the range of loose soit wat four feet, which he therefore conclucled was the natural length of the turnip root.

When the first settlers of Ohio began to eultivate the rich valley of the Scioto, they subjected it to a very imperfect and shallow cultivation; two or three inches was the ntmost depth of the plowing, but such was the great natural fertility of the land that the erops of Indian corn averaged seventy bushols to the acre. 
Successive crops of corn have been ammally taken from the soil ever since, but the average product has rum down to about forty bushels to the acre. In the year 1862 a large field was plowed with the sod and subsoil plow to the full depth of eight inches. The result of this experiment was that the land produced one hundred and twenty bushels to the aere, while the skim plowed land contiguous to it yielded but forty bushels.

These facts show an additional answer to the question, "How does plowing increase the fertility of the soil ?" They tell us very clearly that it is by affording facilities to the extension of the roots, and thus extending the range of pasture for the plants.

The answers already given by no means exhanst the question. There are still many important uses of plowing which are yet undeseribed. The germination of seeds requires seclusion from light; they must therefore be placed beneath the surface. They also require the presence of atmospheric air; without it the radicle will not enter the soil nor the plumule protrude into the air; nor will the starehy matter's stored up in the cotyledons be transformed into sugar for the nourishment of the young plant. Pulverization of the soil is therefore essential, that the seeds may be regularly seeluded from the light; but in such a way that the air can penetrate very freely to them. These conditions are completely fulfilled when the land is properly plowed.

Stagnant water in the soil, by eutting off the access of air to the roots of plants, prevents their nutrition and consequently their growth. Deep plowing diminishes this evil by permitting the water to penetrate deeper into the ground.

Warmth of the surfice soil is essential to the growth of erops. When water lies upon the surface, it is taken up again into the air by evaporation, which causes the absorption of an immense amount of sensible heat which it renders latent. The cooling of surfaces by evaporation is made practically fimiliur to us whenever we wash our hands or wet our heads. Deep plowing and thorough pulverization, by permitting the water to sink into the ground, diminishes the amount of evaporation from the soil, and thus prevents the temperature of the surfice from being lowered.

The exhalation of moisture from plants into the air is very great. In the experiments very carefully made by Hales, he found that a sunflower three and a half feet high, with a superficial area of 5.616 square inches, perspired at the rate of from twenty to thirty ounees in twelye hours, or seventeen times more thin a man 
would do under similar circumstances. A vine with twelve square feet of foliage exhaled at the rate of five or six ounces a day. An acre of Inclian corn, having 1500 plants on an acre, would exhale about one ton of water in a day. If this moisture is supplied by the roots from the reservoirs of water in the ground as fast as it is exhaled, no mischief is done; on the contrary, the plant is benefited by the increased vital action which ensues. If, on the other hand, the supply from the ground is less than the amount evaporated, the plant withers and finally dies.

Every farmer is fumiliar with the curling of the corn leaves when the evaporation is most rapid under the fierce heats and the blue skies of midsummer, especially when the surface is baked hard. He also knows that the true antidote to this condition is a thorough pulverization of the soil. When this is effected, the stores of moisture in the depths of the earth are pumped up by the capillary attraction of the interstices of the soil, and the balance between supply and demand is once more restored.

Soil in a fincly divided state radiates heat much more rapidly than when its surface is hard and baked; it will therefore cool more rapidly. Dew is deposited in the clear nights most copionsly on those bodies which are relatively colder than the surrounding air. It follows from this, that when two contiguous acres of land are planted with an equal number of corn plants, they will both exhale the same amount of moisture from their leaves; but if the soil of one of the acres is thoroughly pulverized, and the other is hard baked, vastly more of the daily exhalation will be returned to the pulverized soil than to the hard one, on account of its superior ladiant powers. The pulverized soil will thus be supplied with water at the expense of the other.

No soil can produce maximnm crops of any kind where the food of the desired kind of plant is taken up and appropriated by weeds. It is therefore one of the prime objects of agriculture to destroy them, and at the same time to utilize them so as to make them restore to the desired plant that nutriment of which they have already robbed it. Other things being equal, that plow is best which most completely buries the weeds growing on the surface and secures their decomposition, so that the roots of the growing plant can avail themselves of the food stowed away in the cells of the weeds.

We hare now completed the task we proposed to ourselves, by showing all the objects which it is proposed to accomplish by the 
use of the plow in order that we may be enabled to ascertain what form of the plow is most likely to secure the ends which we have in view. 'They are:

First-To pulverize the soil with a view to promote those chemical transformations which will unlock the food of plants from its combinations with unassimilable elements and put it into such a physical condition as will make it accessible to the rootlets of the plant.

Second-To pulverize it with a view to facilitate the formation of the double silicates.

Third-That the roots may freely permeate the soil in all directions, thus increasing the range of their pasture.

rourth-To promote the germination of seeds.

Fifth-To get clear of stagnant water from the surfice.

Sixth-To prevent the refrigeration of the soil by evaporation. Serenth-To secure the return of the water evaporated by the plant in the form of dew.

Eiglith-To destroy the weeds in the soil.

Ninth-To utilize them and convert them into food for plants.

All plows known to us press downward upon the subsoil with a weight proportioned to the depth of the furrow slice and the density. This downward action combined with the sliding action of the shares has a necessary tendency to pack the subsoil and to polish the surfice. This effect is cumulative, and every successive plowing increases the evil until the bottom of the furrow becomes so dense that neither rain nor air nor the roots of plants can possibly penetrate beneath it. The spade avoids this difficulty. Hence, other things being equal, a plow which leaves the bottom of the furrow in the same state in which the spade leaves it would have a very decided preference.

Guided by the principles which we have now so fully explained, we have drawn up a series of practical directions which will be found inserted in the Programme, page 3, under the head of "Duties of Judges," which, if they have been fully carried out in the spirit in which they were devised, we believe will settle conclusively nearly all the questions in practical plowing which have heretofore been left undetermined.

We have not sought to give a complete and exhaustive enumeration of all the objects which the plow is designed to accomplish, such as the mellowing of the soil by frost and the destruction of insects, but only those which involve the peculiar form of the the plow and the principles of its eonstruction. 


\section{CHAPTER VII.}

ON SOME OF TIIE PRACTICAL QUESTIONS IN PLOWS AND PLOWING.

\section{PULVERIZATION.}

As stated in our chapter "On the objects to be accomplished by plowing," our convictions are strong that the primary object of the process is to mellow the ground by direct pulverization. We have never seen this stated as desirable in any of the English books or periodicals to which we have had access.* They all design to effect the pulverization of the soil "mediately by plowing, but they always expect to effect it immediately through the harrow. They must first turn over the soil, laying it in sharp and well defined ridges, mathematically parallel to each other. But this darling sharpuess of ridge camnot be obtained unless the slice is turned over with the least possible disturbance of the relations of its particles with each other; hence a structure which would effectually pulverize the soil and injure the sharpness of the erest would so offend the superstitious prejudices of English plowmen that not one could be sold in any of the markets of the kingdom.

This superstition was transmitted to America, and until very recently the lines of American plows have been formed on English principles. The importance of thorough pulverization was recognized hy American furmers at a much earlier period than it was in England; but as they had not thoroughly studied the relations of the lines of the plow to the comminution of the furrow slice, they were unable to realize their ideal of perfection in practice.

Let us suppose a series of sheets of pasteboard to be superimposed as at A, Fig. 74. It will be seen that the edges, $a b$, are in a straight line, at right angles to the line $c a$. If we now press a thumb on $d$, and, with the other hand, raise up the corners of the shects at $b$, the edges of the sheets will no longer be in a line at right angles with the line of the upper sheet, but the upper sheets will have advanced beyond the lower ones. Before the

\footnotetext{
*Perhaps we should except "Talpa" from this remark, but the author of that work dia not expeet to pulverize the soil by a plow, hut with some instrument which should throw out the earth like a woodchuck.
} 
flexure, the edge $b$, touched the dotted line at $e$; it is now separated from it by the space $b e$, and each successive sheet is seen to be in advance of the one beneath it. To produce this successive advanecment of the upper sheets, each must have moved over the surface of the other. Every plowman* knows that the furrow slice has a certain amount of elasticity, that is, the parts may be displaced to a certain extent, and then, on the removal of the displacing forces, they will return to their former position. This elasticity varies with the nature of soil. In some the slightest displacenent will cause a permanent disruption; in others it will stretch considerably before disruption takes place. The bending

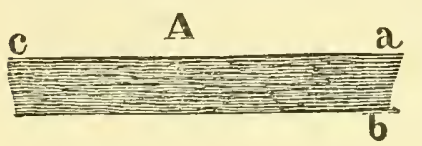

upward, as shown in the figure, is precisely what is done by the plow, the point of the plow being directly beneath $d$, and the point, $b$, resting on the

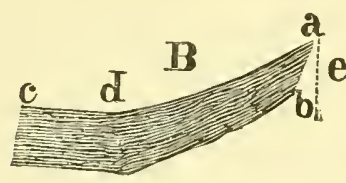
mould-board a little to the right of the shin. Let us suppese that the soil of the furrow slice, $B$ is the most elastic, and that the distance, $b e$, is just suffiFig. 74 . cient to overcome that elasticity, then it is evident that every soil whatever will be split horizontally into flakes at its lower edge by a plow having that elevation. We say at its lower edge because, as the upper edge does not move through a space equal to $b e$, and as that is the precise point where the elasticity of the slice is overcome, any less motion will fail to split the layers. It follows, from this reasoning, that every kind of soil should have a mould-hoard specially adapted to it, if we would obtain the greatest economy of power, because the more blunt is the entering wedge, the greater will be the draught; and it would be uneconomical to use an entering wedge sufficiently blunt to thake up a stiff clay for a light loam where a much more acute angle will suffice. Still, if economy of power is not an whject, a plow which will separate the most tenacious soils longitudinally will be sufficient for all soils that are less so.

Our object is, as we have said, to pulverize the soil; but splitting it longitudinally is not pulverizing it. To accomplish this object we must split it in other directions. Jethro Tull, as we have stated, invented a plow with four coulters, figured in Plate I, which made four vertical sections through the slice. This can

* Soe Tull's remarks, page 18. 
be better done by a proper twist. If the furrow slice is twisted with a force insufficient to overcome its cohesion it will assume the form (Fig. 75) represented in section at B. The radius, $a b$,

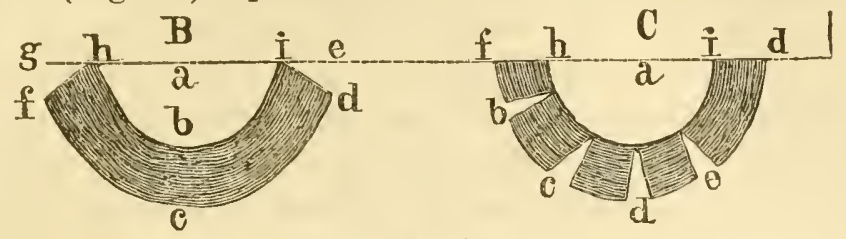

Fig. $\% 5$.

is shorter than $a c$, hence the arc at $b$ is smaller than that at $c$; but the lines before flexure were equal in length, therefore while the inner circle, $h b i$, forms a complete semicircle the outer line, $f c d$, falls short of being a semicircle by the distances $d e$ and $g f$, and the lines $d i$ and $f h$, which were before parallel with each other, now when bent into the curve form an acute angle. Suppose the twist is increased until the force of cohesion is overcome, the section now breaks asunder as at $b c d$, \&c., the fracture being greatest at the outer circle and growing smaller as it approaches the inner one; the edges $f h$ and $i d$ are again parallel, and are in fact in the same straight line. We have thus accomplished by a twist applied at the right point all and more than Tull accomplished by his four coulter's.

We have now, as shown in the furrow slice, Fig, 76, by a proper

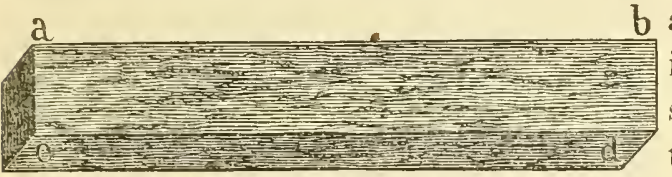

Fig. 76 .

b adjustment of the entering wedge of the plow, split it into layers on the face, $c d$, the fissures running through to the opposite face, and also by a proper arrangement of the twist we have split it on the face, $a b$, through to the bottom. These fissures are seen crossing each other at right angles on the end, $a c$.

By a proper adjustment of the wing of the mould-board we may break the slice in still another direction. Suppose the wing of the mould-board were to be turned at right angles to the direction of the ascending slice, as in Fig. 77. Then the ascending slice, $e d f c$, would be eompelled to change its direction from the line $e d$ to the line $a b$; but to accomplish this the particle of earth at $d$ would move through the are $b d$, while the particle at $f$ would only move round the centre. Now it is evident that since each particle in the dotted line $f d$ is moring 
with a different velocity the continuity of the line $f d$ will be broken, and a fracture will occur at the point $f$ represented by $b f d$, and it is also evident that every successive line of the slice $e d f$ c

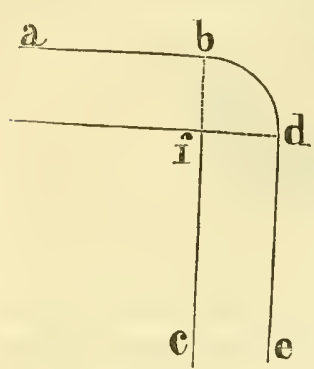

Fig. $\%$ \%

will be subject to a similar fracture on passing the point

$f$. It is, however, unnecessary to have so large a fracture; as the slightest fissure is all that is required, we may therefore very greatly diminish the angle of the wing with a great saving of

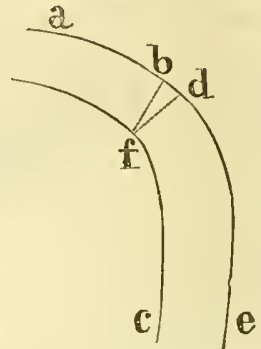

Fig. $\%$ S.

the power required, as at Fig. 78, where $b f d$, the angle of fricture, is seen to be very greatly reduced, although the actual pulverization is quite as well performed as it was with the much larger angle, $b f d$, in Fig. 77.

We have now, in addition to the longitudinal fissures shown in Fig. 74, on the sides, $a b$ and $c d$, another series of transverse fractures across the fice, $c d$, Figs. 75 and 77 , made by the lincis of the plow, which must necessarity break up the slice into fine particles, which will admit air and moisture, and facilitate the chemical transformations in the soil which we have shown to be so essential for the development of its latent fertility.

It is shown in the History of the Plow, which we have at-

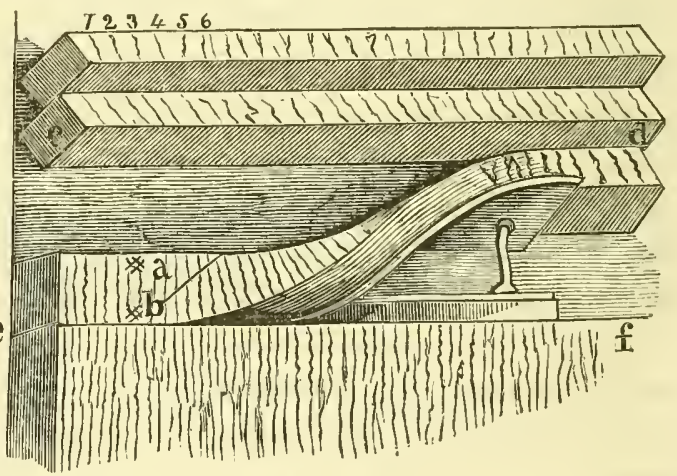

Fig. 79. tempted to sketeh, that the efforts of all the inventors who have applied their skill to the improvement of the moul 1 hoard, have been directed to the formation of a perfeetly curverl or twisted wedlge which should be entirely regular in its formation, that is, that the third line should depart from the plane of the seeond precisely as far as the second does from the plane of the first, and that the fourth shoukl depart from the third precisely as much as the third does from the seennd, and so on. This is especially true of the plows which are 
avowedly formed on mathematical principles, as Jefferson's, Stephens', Rham's and Knox's. Indeed, their object in invoking the aid of mathematical principles was to insure this perfect regularity in the twist of the mould-board.

If we are correct in the principles laid down above, the makers of plows have been in error with regard to the desirableness of a uniform twist in the mould-board. We grant that where economy of power is the sole olject, the twist must be regular and gentle; but where the primary object is to mellow the soil, then irregularity in the lines becomes indispensable.

We have shown that, in order to secure thorough pulverization, the surface of the monld-board must be adapted to fracture the slice in three several directions. It is therefore plain that there must be three points, at least, where the twist must be intensified so as to insure the desired result, and at these points, at least, the regularity of the curve must be inter'upted, so as to overcome the maximum elasticity of the soil.

The conclusion to which these views lead us is, that the best plow must have irregular lines of curvature to an extent which will insure the fracture of the furrow slice in three directions; but the irregularity should never be greater than will accomplish this result, as all excess will be a waste of power.

We have spoken repeatedly of the elasticity of the earth of which the furrow slice is composed, especially when its surface is covered with a tough sod. In order to measure the extent of this elasticity we inserted two wooden wedges, $a$ and $b$ (Fig. 79), at right angles to the land side of the furrow; when the plow, which was ruming twelve inches deep, came up with them at the zero line, the wedges ceased to be at right angles with the land side, but made an acute angle with it, and the wedge $a^{\prime}$ was seven inches in one instance in advance of the wedge $b^{\prime}$, and this was the measure of the elasticity of the slice, as the two wedges resumed their former relative positions when the furrow was completely turned over. There is considerable difficulty in making the experiment, as the slice is generally broken before it arrives at the zero line. We repeated it many times unsuccessfully. We found the stretch of the land side of the furrow twice to be six inches, and only once did it cohere until it was stretched sevell inches. 
ON THE DRAUGHT OF PLOWS.

In our inquiries respecting plows, their draught, or the power, which must be applied in order to enable them to perform the work required of them, is an element of the greatest interest, and our inquiries naturally resolve themselves into the following questions:

First-What power is required to plow a furrow of a given size with the same plow in soils differing in their cohesive properties?

Second-What is the power required to draw different plows through the same soil with furrows of equal size?

Third-What proportion of the power required by a plow is used by the sole? What by the land side? What by the share? What by the coulter? What by the monld-board?

Fourth-Does the wheel add to or diminish the dranght of the plow?

Fifth-Does increased speed produce an increase of traction, and if so, in what proportion?

It was our intention to have answered all these questions by varied and frequently repeated experiments, but when we were ready to enter upon this branch of the investigation, we found that the Express company, in consequence of a misunderstanding of their instructions, had shipped the dynamometer, and we were therefore unable to carry out our intentions. A few experiments were, however, made which we shall report in this connection. We would, however, in view of the great importance of the subject, strongly recommend to the Executive Committee of the Society to carry out these experiments next spring in the most thorough and satisfactory manner.

Such trials as have been made by various experimenters at different times and in various places which have come to our knowledge we have brought together here for the information of :hose who are interested in such subjects.

The most instruetive series of experiments on these points which have been made hitherto are those of Mr. Pusey, which are detailed in the first volume of the Jomnal of the Royal Agrieultural Society. The following experiments give some approximations to an answer to the first question, viz: "What power is required to plow a furrow of a given size, with the same plow, in soils differing in their cohesive properties?" Fergusson's swing plow, taking a furrow five inches deep and nine inches 
wide, showed a draught in a sandy loam of $266^{\circ}$ pounds; a loamy sand, 266 pounds; a moory soil, 322 pounds-increase, 21 per cent; a strong loam, 490 pounds-increase, 84 per cent; a blue clay, 700 pounds-increase, 163 per cent.

In our trials, Collins \& Co.'s steel plows, with a furrow twelve inches wide and twelve inches deep, showed a draught in an indurited clay soil, mixed with coarse gravel, of 613 pounds; an unctuous tough clay of 705 pounds, the increase being 15 per cent. Holbrook's plow, taking the same furrow, and in the same soil, showed a draught in clay and gravel of 615 pounds; unctuous elay of 671 .pounds; difference 9 per cent.

From these data it is obvious that the dranght of plows taken in different soils cannot be compared with each other since the difference in the power required to overcome their cohesion has, by actual trial been found to extend to one hundred and sixtythree per cent, and it is quite probable that future trials may disclose even wider differences than this.

In answer to our second question, "What is the power required to draw different plows through the same soil, with furrows of equal size, we have the following experiments by Mr. Pusey. The furrow was five inches by nine inches:

\begin{tabular}{|c|c|c|c|c|c|c|c|}
\hline \multirow[t]{2}{*}{ PLOWS. } & 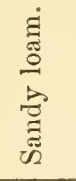 & $\begin{array}{l}\stackrel{\vec{\Xi}}{0} \\
\stackrel{9}{\Xi}\end{array}$ & 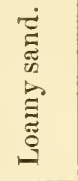 & 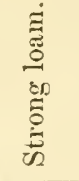 & $\begin{array}{l}\overline{0} \\
\overline{0} \\
\overrightarrow{0} \\
\overline{0}\end{array}$ & 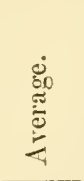 & 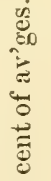 \\
\hline & lbs. & lbs. & lbs. & lbs. & libs. & lbs. & 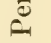 \\
\hline Fergusson' Scotch swing....... & 266 & 700 & 266 & 490 & 322 & 406 & 34 \\
\hline Clark's Scotch swing......... & 280 & 728 & 238 & 462 & 322 & 406 & 34 \\
\hline Hart's Berkshire one-wheel... & 196 & 602 & 168 & 322 & 224 & 201 & $\cdots$ \\
\hline Ransom's FF two-wheel..... & 196 & 602 & 182 & 462 & 196 & 329 & 9 \\
\hline Ransom's FF' swing.......... & 252 & 610 & 224 & 420 & 294 & 364 & 21 \\
\hline 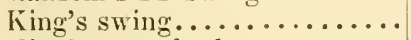 & 252 & 672 & 210 & 378 & 266 & 350 & 16 \\
\hline King's one-wheel ............ & 238 & 602 & 238 & 420 & 252 & 350 & 16 \\
\hline Rutland Ransom two-wheel... & 238 & 700 & 224 & 504 & 294 & 392 & 30 \\
\hline Oid Berkshire wheel plow..... & 322 & 728 & 294 & 504 & 350 & $4+1$ & 46 \\
\hline Holkham plow, two wheels... & 252 & & & & & & $\cdots$ \\
\hline Averages ... & 250 & 661 & 227 & 440 & 280 & $3 \pi I$ & 23 \\
\hline
\end{tabular}

We learn from this table that there is a difference between plows in the same soil, and with equal furrows of forty-six per cent in the extreme case of the Old Berkshire as compared with Hart's one wheel Berkshire, while the average difference in the dranght of nine plows was twenty-three per cent. 
The eolumn headed "Per cent of averages" is intended to show the excess per cent of the average draught of each plow in the five different soils over the draught of Hart's one wheel Berkshire, as for instance Ransom's F F two wheel plow required on an average in all the soils nine per cent more power than Hart's, \&c. In order to make this point still more intelligible, we have calculated the following table, showing the exeess of power per eent required for each plow over Hart's as shown in each kind of soil:

\begin{tabular}{|c|c|c|c|c|c|}
\hline PLOWTS. & 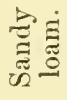 & 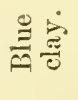 & 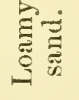 & 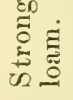 & 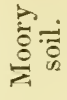 \\
\hline Hart's Berkshire one wheel ............ & 00 & 00 & 00 & 00 & $14 \frac{1}{3}$ \\
\hline Ransom's FF, two wheel .............. & 00 & 00 & $8 \frac{1}{3}$ & $43 \frac{1}{2}$ & 00 \\
\hline King's one wheel $\ldots \ldots \ldots \ldots \ldots \ldots \ldots \ldots$ & 21 & 00 & $41 \frac{3}{3}$ & $30 \frac{1}{2}$ & 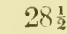 \\
\hline Rutland Ransom, two wheels ............ & 21 & 16 & $33 \frac{1}{3}$ & $56 \frac{1}{2}$ & $50^{\circ}$ \\
\hline Ferguson's Scotch Swing .............. & 36 & 16 & $58 \frac{1}{3}$ & 52 & $6+\frac{1}{3}$ \\
\hline Clark's Scotch Swing ................ & 43 & 21 & $41 \frac{2}{3}$ & $43 \frac{1}{2}$ & $64 \frac{1}{3}$ \\
\hline Ransom's Swing...$\ldots \ldots \ldots \ldots \ldots \ldots$ & 28 & $2 \frac{1}{3}$ & $33 \frac{1}{3}$ & $30 \frac{1}{2}$ & 50 \\
\hline King's Swing $\ldots \ldots \ldots \ldots \ldots \ldots \ldots \ldots \ldots$ & 28 & $11 \frac{1}{2}$ & 25 & $17 \frac{1}{3}$ & 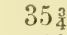 \\
\hline Old Berkshire wheel plow.............. & 64 & 21 & 75 & $56 \frac{1}{2}$ & $78 \frac{1}{2}$ \\
\hline Averages ... & 28 & $9 \frac{3}{4}$ & 35 & 37 & $23 \frac{1}{4}$ \\
\hline
\end{tabular}

This table will be found an exceedingly instructive one, which we urgently advise every firmer and plowmaker to study with profound attention. It shows that in a sandy loam the difference between the minimum draught (Hart's and Ransom's F F) and the maximum (old Berkshire) amounts to sixty-four per cent. Two horses would thus draw Hart's plow with much greater ease than three horses would draw the Old Berkshire. In the loamy sand the excess is still greater; the latter plow would require three and a half horses to do the work that the other would do with two. Alderman Mechi estimates the cost of keeping a horse in England for one year at $£ 39(\$ 195)$, and it is no less in this eountry. If this estimate is correet, a farmer would save at the rate of $\$ 292.50$ a year by using the lighter instead of the heavier plow. An examination of the other columns of per centages will show the saving which will be effected by the use of each. The table also shows how greatly the eeonomy of cultivation is affeeted by cohesive soils. The average dramght of all the plows in the sandy loam is 250 pounds, while the average draught in blue elay is 661 pounds; hence, while the furmer on the sandy loam is compelled to pay $\$ 195$ for his power, the firmer on the stiff clay must pay 4515 for cultirating the same area. 
The table also shows in a very striking manner how necessury it is that plows should be specially adapted to the soils in which they are intended to work. Thus Hart's plow works the easiest in all soils except the moory soil, in which Ransom's F F excells it by fourteen and one-third per cent, while in the strong loam Hill exceeds Riunsom by forty-three and a half per cent, and loany sand by eight and one-third per cent. Ransom's Rutland excels Furguson's Swing by fifteen per cent in sandy loam, while in strong loams Ferguson exceis Ransom by four and a half per cent. This question of the adaptation of plows to different soils and situations has been too much overlooked even by intelligent furmers, and it shows very clearly that the plow for "all kinds of work," which so many of them are looking and longing for, will never be devised by the ingenuity of man. If a farmer desires perfect work the plow to accomplish it must be made expressly for the soil and the conditions of the work, and if he uses any other kind he must pay the penalty in a waste of power and an imperfection in the work.

A series of experiments having for their object an answer to the question we are discussing, was made by Mr. J. C. Morton, and given in his Encyclopedia of Agriculture. The ground was a deep, silicious loam, above the quartoze conglomerate of the old red sandstone formation, and was of a uniform texture. The results of the dynamometer were taken with a self recording arrangement, and every care was taken to obtain perfectly correct results. The size of the furrow was in all cases six inches by nine inches.

\begin{tabular}{|c|c|c|}
\hline PLOWS. & Pounds. & Per cent. \\
\hline 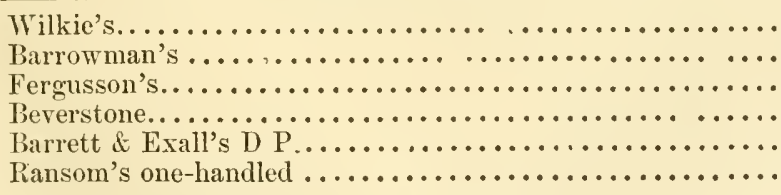 & $\begin{array}{c}581 \\
644 \\
560 \\
478 \\
567 \\
\ldots \ldots\end{array}$ & $\begin{array}{l}22 \\
35 \\
17 \\
00 \\
18 \\
\ldots \ldots\end{array}$ \\
\hline 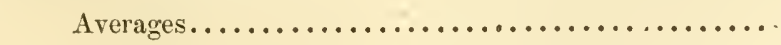 & 566 & 18 \\
\hline
\end{tabular}

In these experiments the same difference appears between the dranght of plows in the same soil and with a furrow of the same size, as was disclosed in Mr. Pusey's experiments, but it is not so great in amount, the draught of the heaviest exceeding that of the 
lightest by thirty-five per cent, and the average of the five by eighteen per cent.

The trials made by this Society in 1850 were on stubble land, the soil being a stiff loam inclining to clay, mingled with stones of various sizes, near Greenbush. The following table shows the difierences in the draught of the plows tried at that time:

\begin{tabular}{|c|c|c|}
\hline PLOWS. & Pounds. & Per cent. \\
\hline Wilkie's Scotch, A. Fleck .................. & 487 & 42 \\
\hline Subsoil and sod, French \& Smith ................. & 406 & 19 \\
\hline Washington Co., Iron Beam, D. Eddy \& Co ............. & 439 & 28 \\
\hline 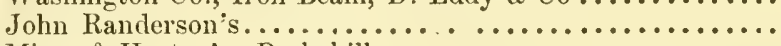 & 342 & 00 \\
\hline Miner \& Horton's, Peekskill..................... & 363 & 6 \\
\hline Starbuck \& Co., Trojan ....................... & 379 & 11 \\
\hline 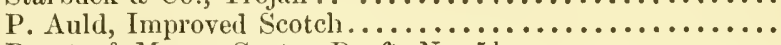 & 373 & 9 \\
\hline Prouty \& Mears, Centre Draft, No. $5 \frac{1}{2} \ldots \ldots \ldots \ldots \ldots \ldots \ldots$ & 383 & 12 \\
\hline Bosworth, Rich \& Co., Iron Beam, D............... & 425 & 24 \\
\hline R. R. Tench \& Co., Empire, A $3 \ldots \ldots \ldots \ldots \ldots \ldots \ldots \ldots$ & 456 & 33 \\
\hline H. L. Emery, Albany ....................... & 427 & 24 \\
\hline 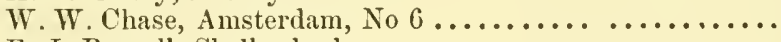 & 343 & $0^{\frac{1}{3}}$ \\
\hline E. J. Burrall, Shell-wheel......................... & 350 & 2 \\
\hline Prouty \& Mears, Connecticut Valley..... ............ & 525 & 53 \\
\hline Average.. & 407 & 19 \\
\hline
\end{tabular}

The furrow slice in the above trials was seven inches by ten inches.

In this series of experiments we find the difference between the heaviest and the lightest plow is equal to fifty-three per cent, and the difference between the lightest plow and the average draught of them all was nineteen per cent.

Summing up the results of the three sets of experiments, we have:

Mr. Pusey's Experiments-Maximum difference, $78 \frac{1}{2}$ per cent; average difference, $23 \frac{1}{4}$ per cent.

Mr. Morton's Experiments-Maximum difference, 35 per cent; average difference, 18 per cent.

New York State Agrieultural Society's Experiments-Maximum difference, 53 per cent; average difference, 19 per cont.

Average of the three experiments-Maximum difference, $55 \frac{1}{3}$ per cent; average difference, 20 per cent.

Which may be taken as the best answer that can yet be given to the second question.

The third question which we have proposed is, "What proportion of the power required by al plow is used by the sole? What 
by the land side? What by the share? What by the eoulter? What by the mould-boarcl?"

The first question is answered by Mr. Pusey's experiments, as follows:

\begin{tabular}{|c|c|c|}
\hline \multirow{2}{*}{ PLOWS. } & $\begin{array}{l}\text { Surface } \\
\text { draught. }\end{array}$ & $\begin{array}{l}\text { Weight } \\
\text { of plow }\end{array}$ \\
\hline & lbs. & lbs. \\
\hline 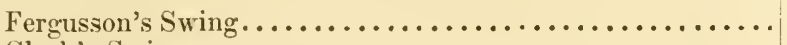 & 168 & 180 \\
\hline Clark's Swing $\ldots \ldots \ldots \ldots \ldots \ldots \ldots \ldots \ldots \ldots \ldots \ldots \ldots$ & 168 & 180 \\
\hline Hart's Wheel. . . & 42 & 168 \\
\hline 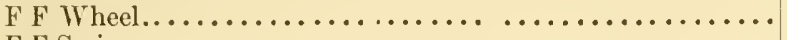 & 112 & 179 \\
\hline 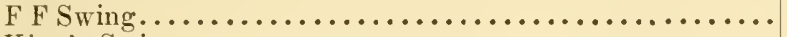 & 140 & 147 \\
\hline King's Swing. $\ldots \ldots \ldots \ldots \ldots \ldots \ldots \ldots \ldots \ldots \ldots \ldots \ldots$ & 112 & 112 \\
\hline 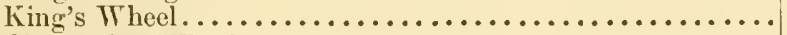 & 84 & 140 \\
\hline 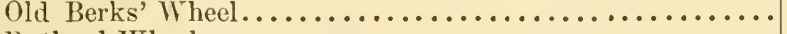 & 112 & ........ \\
\hline 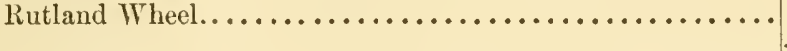 & 112 & 210 \\
\hline Average.... & 117 & 164 \\
\hline
\end{tabular}

The average draft of these plows working in strong loam, and with a furrow of five inches by nine inches, was, as we have seen, 440 pounds. Hence the ratio of the power consumed by the firetion of the sole to the whole power is as $1: 3.76$.

We have met with no experiments having for their object the determination of the friction of the land side separately from the other portions of the plow.

The only experiments known to us on the influence of the share on draught are those of Mr. Morton, which, although they do not give a complete answer to our question, are sufficient to show that this part of the plow exercises a very important influence upon the action of it. The draught of Ferguson's Swing plow, with a share ten inches wide, was 630 pounds, while the same plow, with a share six inches wide, drew only 560 pounds. In the former case the whole of the lower portion of the furrow was cut off; in the latter case four inches on the right side of the furrow were uneut, and were torn off by the wedge of the share and mould-board. The experiment shows that the cutting of these four inches and the increased friction of the wicler share increased the power required to the extent of twelve per cent.

The experiments of Mr. Stephens seemed to show that it required exactly the same power to draw a coulter through the ground as it did to draw the plow without a coulter; but this experiment needs rerification. 
According to Mr. Morton's experiments the whole draught of the plow is 476 pounds; the removal of the mould-board diminishes this only to 434 pounds; in other words, only ten per cent of the whole draught is caused by the turning of the furrow slice. The dranght of the plow running along the open furrow was 168 pounds, which, being subtracted from 434 pounds, the draught without the mould-board, leaves 266 pounds as the draught required for the cutting of the furrow slice. Should this division of the draught hold gencrally true, we may infer that the labor of plowing may be distributed as follows: Thirty-five per cent for the weight of the implement; fifty-five per cent to cutting of the furrow slice, and only ten per cent to the action.

This conclusion, if eorreet, will ehange the former current of opinion to a very great extent. Great labor has been expended upon the mould-board, upon the hypothesis that the draught depends to a very great extent upon its shape, but it will be seen that the share, the coulter, and the weight of the plow are fir more promising points for its improvement than the mouldboard.

The effeet of the friction of the sole upon the draught has been known to plowmakers for a long time, and many attempts have heen made to diminish it by the addition of a large wheel near the heel, in such a position that the plow nearly balances over it, and by the introduction of firction wheels on the land side. At the trial at Albany in $1850, \mathrm{Mr}$. Burrall exhibited a plow with one of these wheels. At first its draught was very light, though not as much so as some of the plows which were not furnished with this appliance, but after working some time the wheel becane clogged by the loose earth, and it then became decidedly heavier than those which were formed in the usual manner.

Another experiment which was tried by Mr. Pusey, with a view of determining the ratio of the draught to the depth of the plowing, may be usefully stated in this connection.

The experiment was made on a free, brown loamy sand of a good quality, without stone, gravel or elod, resting on a pure, yellow sand on the coral sag formation. The results are given in the following table: 


\begin{tabular}{|c|c|c|c|c|}
\hline PLOINS. & $\begin{array}{l}\text { Furrow, } \\
4 \text { by } 9 \text { in. }\end{array}$ & $\begin{array}{l}\text { Furrow, } \\
5 \text { by } 9 \text { in. }\end{array}$ & $\begin{array}{l}\text { Furrow, } \\
6 \text { by } 9 \text { in. }\end{array}$ & $\begin{array}{l}\text { Furrow, } \\
7 \text { by } 9 \text { in. }\end{array}$ \\
\hline Fergusson's Swing Plow............. & 252 & 266 & 266 & 308 \\
\hline Clark's Swing Plow.................. & 238 & 238 & 252 & 294 \\
\hline Ilart's One-wheeled................. & 154 & 168 & 224 & 252 \\
\hline F F (Ransom's) Two-wheeled .......... & 168 & 182 & 252 & 294 \\
\hline F F (Ransom's) Swing . . . . . . . . . . . . . & 224 & 224 & 252 & 294 \\
\hline King's Swing................. & 210 & 210 & 252 & 280 \\
\hline King's One-wheeled............ & 224 & 238 & 294 & 322 \\
\hline Rutland N L Two-wheeled.......... & 224 & 224 & 252 & 280 \\
\hline 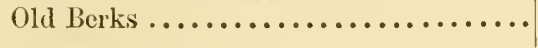 & 294 & 294 & 336 & 434 \\
\hline Average.......... & 221 & 227 & 264 & 306 \\
\hline
\end{tabular}

The increased average draught of the first inch is 2.71 per cent; of the second inch, 16.29 per cent, and of the third, 15.91 per cent. Average, 11.63 per cent.

Mr. Pusey made a second experiment to determine this point a few days afterwards upon a poor, moory soil, with Ferguson's Scotch plow, with the following results:

\begin{tabular}{|c|c|c|}
\hline \multicolumn{3}{|l|}{ Furrow, nine incles wide. } \\
\hline FURROW-Depth in inches. ' & $\begin{array}{l}\text { Draught } \\
\text { in ibs. }\end{array}$ & $\begin{array}{l}\text { Increase, } \\
\text { per cent. }\end{array}$ \\
\hline 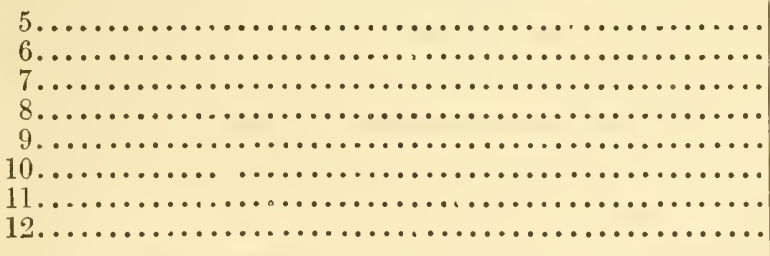 & $\begin{array}{l}322 \\
308 \\
350 \\
420 \\
434 \\
560 \\
700 \\
700\end{array}$ & $\begin{array}{r} \\
8.70 \\
20.00 \\
3.33 \\
29.03 \\
25.00 \\
\cdots \cdots\end{array}$ \\
\hline 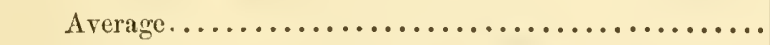 & 474 & 12.29 \\
\hline
\end{tabular}

The experiments on this point made by Mr. Morton are given in the following table:

\begin{tabular}{|c|c|c|c|c|c|}
\hline \multicolumn{6}{|c|}{ Furrov, nine inches wide. } \\
\hline FURROW. & Fergusson & Beverstone & Barrowman. & Barrett. & \multirow{2}{*}{$\begin{array}{l}\text { Average } \\
\text { pounds. }\end{array}$} \\
\hline Depth in inches. & Pounds. & Pounds. & Pounds. & Pounds. & \\
\hline 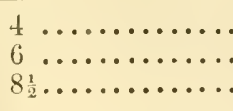 & $\begin{array}{l}462 \\
560 \\
840\end{array}$ & $\begin{array}{l}378 \\
476 \\
896\end{array}$ & $\begin{array}{l}574 \\
644 \\
854\end{array}$ & $\left|\begin{array}{c}354 \\
560 \\
\ldots \ldots \ldots\end{array}\right|$ & $\begin{array}{l}442 \\
560 \\
863\end{array}$ \\
\hline Average.... & 621 & 583 & 690 & 457 & 621 \\
\hline
\end{tabular}




\begin{tabular}{|c|c|c|c|}
\hline \multicolumn{4}{|l|}{ Increuse. } \\
\hline \multirow{2}{*}{ PLOWS. } & $\begin{array}{l}\text { Between } \\
4 \text { and } 6 \text { in. }\end{array}$ & $\begin{array}{c}\text { Between } \\
6 \text { and } 8 \frac{1}{2} \text { in. }\end{array}$ & \multirow{2}{*}{$\begin{array}{l}\text { Average } \\
\text { per cent. }\end{array}$} \\
\hline & Per cent. & Per cent. & \\
\hline \multirow{5}{*}{ 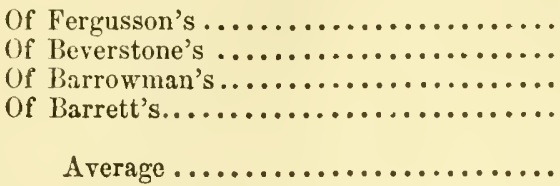 } & 21.21 & 50.00 & 35.50 \\
\hline & 25.92 & 88.23 & 57.07 \\
\hline & 12.19 & 32.61 & 22.40 \\
\hline & 58.18 & ........... & 58.18 \\
\hline & 29.37 & 56.94 & 43.31 \\
\hline
\end{tabular}

The average increase of power for each inch in depth of Ferguson's plow was 7.90 per cent, or 84 pounds; Beverstone's plow was 12.68 per cent, or 115 pounds; Barrowman's plow was 4.98 per cent, or 62 pounds; Barrett's plow was 12.92 per cent, or 103 pounds. Average, 9.62 per cent, or 91 pounds.

Our own experiments on this point were very meagre, on account of the mistake in sending off the dynamometer heretofore alluded to, but as the subject is of so much importance we give them here. The experiment was made in a very hard soil, with gravel indurated in the clay, and all the plowing was deeper than any previous plowing, so that in each case the plow went into soil which had never been disturbed before. The plow used was Holbrook's No. 100; furrow ten inches wide. At $8 \frac{1}{2}$ inches deep, 659 pounds; at $10 \frac{1}{2}$ inches deep, 753 pounds-increase, 94 pounds; at $12 \frac{1}{2}$ inches deep, 801 pounds-increase, 48 pounds. The average increase of power for each inch of depth in this case is 35 pounds, or 5.38 per cent.

We can most fully corroborate the correctness of Mr. Pusey's remark, that this is a very difficult experiment to make. It is hard to preserve the exact depth of one inch more or less; sometimes it will run up or down considerably more than an inch. Sometimes when plowing at a given depth the share will encounter a mass of roots which resist very greatly, while in plowing an inch deeper we do not encounter these obstacles, and the plow at that depth does not appear to draw as heavily as it did when plowing an inch shallower. Owing to these inequalities in the texture of the soil at different depths, we need not expect to meet with any very regular law of progression in the dranght in the indications of any particular table; but by having recourse to averages, the indications of a uniform law of increase begin to develop themselves sufficiently to assure us that when a sufficient 
number of experiments shall have been carefully made we may ascertain the law nearly enough for all practical purposes. The average increase of draught per inch in Mr. Pusey's experiments was 12.29 per cent. In Mr. Morton's experiments it was 9.62 per cent, and in our own experiments it was 5.38 per cent. The averige of all these is 9.09 , say in round numbers, ten per cent of increase in draught for each additional inch depth of furrow between the limits of four and twelve inches.

If this conclusion approximates to correctness it appears that the draught increases in proportion to the depth much less rapidly than has been heretofore supposed. Mr. Pusey says that it has been laid down in our books that the draught increases as the squares of the depth; that is to say, that if the dranght at four inches be 252 pounds, at seven inches it will be as 49 to 16 , or 756 pounds, whereas experiment shows that on an average it is only 308 pounds, or less than half that amount.

It must not be forgotten that both theory and experiment show that plows made expressly for deep tillage will work relatively lighter in a deep furrow than in a shallow one. Thus a plow made expressly for a four inch furrow compared with one made for a twelve inch furrow will work in the furrow it was designed for with much less dranght than a deep plow; but if the four inch plow is made to take a furrow ten inches deep, the plow designed for twelve inches will be found to require much less draught. This fact should never be lost sight of in trials of this kind.

We know of no experiments made with a view to determine the ratio of power required to turn over furrow slices of different breadths while the depth remains uniform.

There is another point upon which Mr. Pusey's experiments throw mueh light, and which led to conclusions very different from those which have been generally entertained. It has been generally supposed that the power required to draw a plow increased as the square of the velocity, but experiments show that this is not the case.

Mr. Pusey made repeated trials in order to settle this point under a great variety of circumstances. The first trial was in the moory ground mentioned in preceding tables, and with Clark's plow. The horses were made to walk as slowly as possible, and the draught was found to be 336 pounds in a five inch furrow. The horses were now urged forward at their highest rate of speed, 
and the draught was 350 pounds, which is only 14 pounds more than when they were walking slowly.

A seeond trial was had in an adhesive loam, in so bad a condition that the polished mould-board was completely enerusted with earth. Hart's plow was selected for the experiment, and one hundred and ten yards, or one-sixteenth of a mile, were aceurately measured off. At the first trial the horses traveled the distance in two minutes and forty seconds, being at the rate of one and a half miles in an hour. The dynamometer showed a draft of 322 pounds, the furrow being four inches by nine inches. At the second trial the distance was done in two minutes and twenty-five seconds, being at the rate of one and three-quarter miles in an hour. The furrow was of the same size, and the dranght was still 322 pounds as before. At the next trial the rate was one minute and forty seconds, which is at the rate of two and threequarter miles in an hour; the draft, from some canse, was reduced instead of being increased, and stood at 308 pounds. Finally the distance was accomplished in one minute and five seconds, or at the rate of three and a half miles in an hour. The draft was indeed increased, but the increase was only 14 pounds, which might very probably be due to an inereased tenacity of the soil.

The following table shows the time which would be required for plowing an acre, with a furrow nine inches wide, at the different rates of motion, exclusive of stoppages:

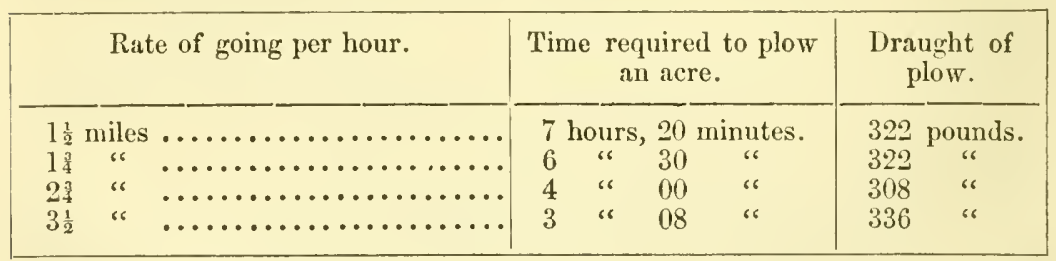

Mr. Morton's experiments were first with a speed equivalent to two and a half miles an hour. The furrow was four by nine inches, and the draught was 378 pounds. At five miles an hour the draught was 392 pounds. His experiments were made with a self recording dynamometer, in which the pencil described the extent of every oscillation. It is worthy of remark that these oscillations were very greatly increased at the higher rate of speed, ranging between the extremes of 210 and 644 pounds, while at the lower rate the oseillations ramged from 280 to 504 pounds. 
This result might have been reasonably expected, as when the plow strikes a stone or other obstruction the horses will naturally exert all their strength, and by so doing cause a wide sweep of oscillation.

We can say in conclusion that the results obtained upon this point by Messrs. Morton and Pusey are fully corroborated by our own observations. We could detect no difference between the draught at high or low speeds, except such as are within the limit usually allowed for errors of observation. In fact, the dynamometer sometimes showed a less draught at a high speed than it did at a low one.

This is quite in accordance with other experiments which have been made to ascertain the laws of friction, which show that it is entirely independent of velocity.

The resistance to the action of the plow is made up of the weight of the plow pressing upon the sole, with the superadded weight of the furrow slice; the friction of the land side against the earth; the friction of the furrow slice against the surface of the mould-board; the splitting action of the coulter, and the force required to lift up and turn over the furrow slice. It is only in this latter case that the real work performed is increased by the velocity, and this is so small a proportion of the whole force that it may be safely neglected in practice.

It will be seen at once by every farmer that the conclusion we have come to, in view of the experiments, is one of very great practical value. It shows, as Mr. Morton remarks, "the importance of employing dranght animals which naturally walk at a rapid pace. Such animals, with same effort, get through double the work of those of a more sluggish movement. With the same effort, and therefore at no greater expense to the farmer. The employment of active animals is obviously one of the most influential methods of diminishing the expense of horse labor."

In view of these experiments, Mr. Pusey remarks: "Here, then, it appears to me we have found the secret of the Scotch horse's superior performance as to quality of work done. Though they are stepping briskly along at a pace which enables them to work five-quarters of an acre in a day, while the dragging walk of the other horses carries them through three-quarters of an acre only in the same time. They feel the weight of the plow certainly not more than the others; perhaps even less. Let the horses be lively enough to face their work bollly, and step out 
well; they get, or rather their master gets, beyond the former three-quarters of an acre, two-quarters more plowed for nothing. It is true that the horses have to walk a greater distance in one case, but this camnot be of much consequence. In plowing an acre, with the furrow nine inches wide, the horse has to walk in the furrow eleven miles exactly. If, then, he plow three-quarters of an acre in a day, he has to walk eight and one-quarter miles only; if five-quarters, he must pass over thirteon and threequarters miles-but five and a half miles more than before. The increased rate of the animal's exertion has also, of course, a great effect upon the fatigue of its frame, where the difference is considerable. But I suppose that each animal has, in some degree, a natural pace, suited to its conformation, which is most easy to it, and that the quicker rate of two and three-quarters miles in the hour may be as natural to the Clydesdale horse as a more tardy walk to cart-horses of our heavy breeds. Still I do not wish to assert that, under all cireumstances, it is as easy for a horse to move quickly as slowly with a heavy draught. If he be overweighted, he will not have sufficient strength to spare for carrying on his own weight with ease, aud will naturally flag at his task.

"In order to move briskly, he ought, I suppose, to feel in some degree master of his work, and be able, if required, to draw something more than his actual load. I ought also to mention, after stating the superior exertions which the horse may be called on to make, that these Clydesdale horses of Lord Moreton's are not only fed in a superior mammer, but that their day's work is broken into two portions of time, between which they have rest, and either return home to be fed or are supplied by means of nose-hags, with corn, in the field. I believe that the practice of working horses for eight hours together not only adds to their fatigue, but that the absence of food for so long a time must be a much more severe privation to them (as to all animals feeding on grass and seeds only) than it is to the carniverous animals and to ourselves." 


\section{CHAPTER VIII.}

\section{ON THE LINE OF DRAUGHT OF PLOWS.}

In using a double mould-board plow it is very obvious that the line of draught will be in the direction of the middle line of such plow; that is, the resistance of the earth to the action of the mould-board on the right side of the beam tending to throw the heel of the plow to the left hand, will be exactly counterbalanced by the resistance of the earth on the left mould-board, tending to throw the heel to the right hand. These two faces being equal and contrary will therefore neutralize each other, and the plow will move steadily forward in the direct line of the draught.

This is not the case when the left side is cut off, as in our ordinary plows, and the whole of the work is done by the share and mould-board of the right side. Here the plow is acted on by a lever whose length is the brealth of the plow, the effect of which is to throw the heel of the plow against the land side, and therefore to throw the point away from land, thus constantly narrowing the breadth of the furrow. In order to obviate this tendency of the plow to run out, the English and Scotch plowmakers make their beams oblique to the plane of the land side, so that the forward extremity of the axis of the beam falls from an inch and a quarter to two inches to the right of the plane of the land side produced to that point. Although this obliquity of the beam effectually resists the tendency of the plow to run out, yet it introduces an element of unsteadiness into the motion of the plow which keeps the eye of the plowman continually upon the watch, and his hand continually in motion to rectify the aberration.

Messr's. Prouty \& Mears devised a much better plan for accomplishing this object, which has been since adopted by the greater number of our American plowmakers.

They considered that there was a plane passing lengthwise through the plow, which was so situated that the forces on each side of it would balance each other. Since the greatest amount of the force required to move the plow is employed in severing the furrow slice from the solid land, it follows that the plane will lie much nearer to the land side than to the furrow side of the plow. They accordingly found, from carefully repeated experi- 
ments, that in average soils and conditions that if the land side was made with seven degrees of obliquity to the perpendicular, or eighty-three degrees to the plane of the sole, the axis of the beam would lie in the plane passing through the centre of resistance. When the axis of the beam lies in this direction the plow moves forward without any tendeney to deviate from the line of motion either to the right hand or the left. T'his arrangement is illustrated in Fig, 80, in which a vertical section of the plow is

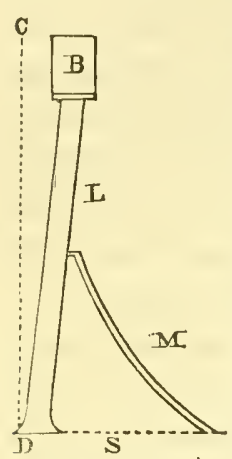
represented. The dotted line, $\mathrm{C} \mathrm{D}$, being the perpendicular to the plane of the sole, $\mathrm{S}$; the angle C D B is 7 deg.; L is the standard, and the lower part of it is the land side; M, section of mouldboard; $B$, section of the beam.

There is also a horizontal as well as a perpendicular plane of resistance. When the draught coincides with this plane there is no tendency in the plow to go deeper or shallower; if the draught is above it the point of the plow is drawn down-

Fig. 80. ward with a force proportioned to the height of the point of draught above this plane; if placed below it, the point of the plow will in like manner rise out of the ground, and these tendencies can only be counteracted by the plowman pressing on the handles of the plow in the former case, or lifting them by main force in the latter case.

Again, we have a third plane of resistance, which is vertical and transverse. The plow enters the unbroken earth by a single point, the transverse sections inereasing gradually in area until they attain to their maximum dimensions; but as the point enters and breaks the solid earth, the foree required does not increase nearly as fast as the sectional arca increases, hence the position of this plane raises from one to five inches behind the point of the plow, according to the consistency of the soil and the shape of the plow.

The point of resistance of the plow is therefore situated at the intersection of these three planes. If the line of draught passes through this point, the plow will, in the language of the plowman, "swim free;" and it is therefore a point of great practical importance to ascertain the locality of the point of resistance, and to have a ready means of adjustment by which the line of draught may be made to pass through it. 
In speaking of the proper angle of dranght, Mr. Stephens remirks ("Book of the Farm," page 286):

"The reasoning heretofore adopted on this branch of the theory of the plow seems to be grounded on the two fulluwing data: the height, on an average, of a horse's shoulder, or that point in his collar where the yoke is applied; and the length of. the draught chains that will give him ample freedom to walk. It falls out, fortunately, too, that the angle of elevation thus produced crosses the plane of the collar as it lies on the shoulders of the horse when in draught, nearly at right angles."

It may, however, be shown that the plow may be drawn at any angle from the horizontal nearly up to the perpendicular, if certain practical difficulties were removed, and that would require a continually diminishing force to draw it as the line of draught approaches to a horizontal direction, arriving at a minimum when it reaches that point. It is, however, impossible in practice to apply the force in this direction, as the line of draught would, in this case, pass through the solid earth of the furrow slice; but it is practicable to draw the plow at an angle of 12 degrees, which, as will be demonstrated, will require less dranght by fourteen pounds than would be required if the angle were 20 degrees, which may be considered as the average in the ordinary practice of plowing. A plow drawn at this low angle, viz., 12 degrees, would have its beam (if of the ordinary length) so low that the draught-bolt would be only ten inches above the base line; and this is not an impracticable height, though the traces might be required inconveniently long. On the same principle, the angle of draught might be elevated to 60 or 70 degrees, provided a motive power could be applied at such high angles. In this, as before, the beam and elevis would be in the straight line between the point of attachment at the collar and the centre of resistance. The whole plow, also, under this hypothesis, wonld require an almost indefinite increase of weight; and the power required to draw the plow, at an angle of 60 degrees, would be nearly twice that required in the horizontal direction, or $1 \frac{1}{1} \frac{6}{8}$ times that of the present practice, exclnsive of what might arise from increased weight. We may, therefore, conclude that to draw the plow at any angle higher than the present practice is impractieable, and, though rendered practicable, wonld still be highly inexpedient by reason of the disadvantage of incrersed force being thus rendered necessary, unless we ciun suppose that the application of 
steam or other inanimate power might require it. Neither would it be very expedient to adopt a lower angle, since it involves a a greater length of trace ehains, which at best would be rather cumbrous, and it would produce a saving of force of only 14 pounds on the draught of a pair of horses. Yet it is worthy of being borne in mind that, in all cases, there is some saving of labor to the horses, whenever they are, by any means, allowed to draw by a chain of increased length, provided the elevis of the plow is brought into the line of the draught, and the dranght ehains are not of such undue weight as to produce a sensible curvature; in other words, to insure the ehange of angle at the horse's shoulder due to the increased length of the draught chain."

This subject will be better understood when considered ili connection with Fig. 81 .

Let $a$ represent the body of the plow, $b$ the point of the beam, and $c$ the centre of resistance of the plow, which may be assumed at a . reight of two inches above the plane of the sole, $d e$, though it is liable to ehange within short limits. The average length of the draught chains or traces being ten feet,including evener, whiftle

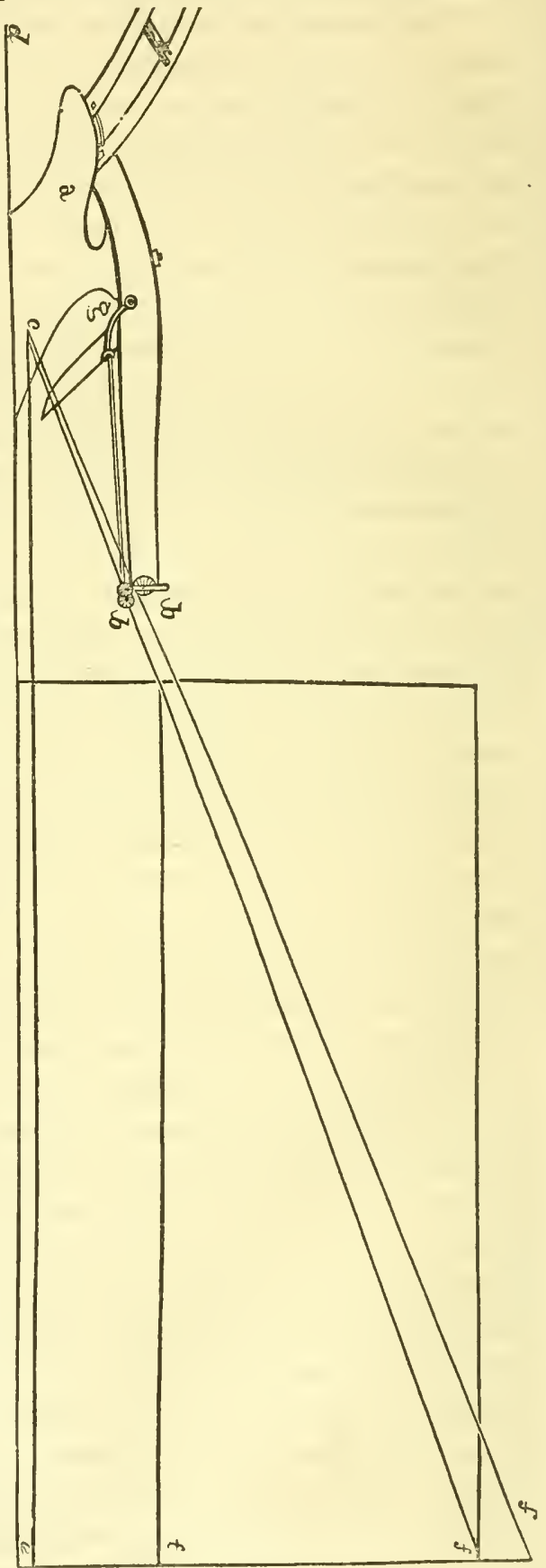

Fig. 81. 
trees, hooks, and all that intervenes between the clevis and the hor'se's shoulders. Let that distance be set off in the direction $b f$, and, the average heiglit of the horse's shoulders being four feet two inches, let the point $f$ be fixed at that height, above the hase line, $d e$. Draw the line $f c$, which is the direction of the line of draught, acting upon the centre of resistance, $c$; and if the plow is in proper temper it will coincide with the clevis; ecf heing the angle of draught and equal to 20 degrees. It will be easily perceived that, with the same horses and the same length of yoke, the angle, e c $f$, is invariable; and if the plow has a tendency to dip at the point of the share under this arrangement, it indicates that the draught-bolt, $b$, is too high in the bridle. Shifting the bolt one or two holes downwards will bring the plow to swim evenly upon its sole. On the other hand, if the plow has a tendency to raise at the point of the share, the indication from this is that the evener is too low in the clevis, and the rectification must be made by raising it one or two holes in the clevis.

Suppose, again, that a pair of taller horses were yoked in the plow, the traces, depth of furrow, and soil, and, by consequence, the point of resistance, $c$, remaining the same, we should then have the point $f$ raised to $f^{\prime}$. By drawing the line $f^{\prime} c$ we have $e c f^{\prime}$ as the angle of draught, which will now be 22 degrees; and in this new arrangement the draught-bolt is found to be below the line of dranght, $f^{\prime} c$; and if the traces were applied at $b$, in the direction of $f^{\prime} b$, the plow would have a tendency to rise at the point of the share by the action of that law of forces which obligês the line of draught to coincide with the line which passes through the centre of resistance; hence the draught-bolt, $b$, would be found to rise to $b$, which would raise the point of the share out of its proper direction. To rectify this, then, the dranghtbolt must be raised in the bridle by a space equal to $b b^{\prime}$, causing it to coincide with the true line of draught, which would again bring the plow to swim evenly on its sole.

Regarding the relative forces required to overcome the resistance of the plow when drawn at different angles of draught, we have first to consider the nature of the form of those parts through which the motive force is brought to bear upon the plow. It has been shown that the tendency of the motive force acts in a direct line from the shoulder of the animal of dranght to the centre of resistance; and, referring again to Fig. 81, were it not for considerations of convenience, a straight bar or beam lying in 
the direction $c b$, and attached firmly to the plow's body, anywhere between $c$ and $g$, would answer all the purposes of draught, perhaps better than the present beam. But the draught not being the end in view, but merely the means by which that end is accomplished, the former is made to subserve the latter; and as the beam, if placed in the direction $c b$, would obstruet the proper working of the plow, we are constrained to resort to another indirect action to arrive at the desired effect. This indirect action is accomplished through the medium of a system of rigid angular frame work, consisting of the beam and the body of the plow, or those parts of them comprehended between the points $b h c$, the beam being so connected to the body, $a h$, as to form a rigid mass. The effect of the motive force applied to this rigid system of parts at the point $b$, and in the direction $b f$, produces the same result as if $c b$ were firmly comnected by a bar in the position of the line $c b$, or as if that bar alone were employed, as in the case before supposed, and to the exclusion of the beam, $b h$.

Let us now proceed to examine the effect of the oblique draught on traction. The average draught of plows at the Albany trials in 1850, was 407 pounds, with a furrow seven inches by ten inches, when exerted in the direction $b f$. If now we take the value of the line $b f$ at 407 , a certain portion of the force will be exerted in direct traction, and another portion will be exerted in pulling the plow up from the ground in the direction $i f$, and the force of traction will be to the lifting force in the exact ratio of the line $i b$ to the line $i f$. The line $i f$ is 50 inches -16 inches $=34$ inches $:$ the line $b f$ is 120 inches; the line $i b$ is therefore 115 inches; and we therefore have 120 inches: 115 inches : : 407 pounds : 390 pounds $=$ the amount of direct dranght upon the plow exerted by the horses. In like manner the force lifting the plow upwards is found to be 114 pounds. The same result would follow if the beam were supported by a wheel under the point $b$; the wheel would then bear up the beam with the same force as that by which it was supposed to be suspended, viz.: 114 pounds. But to carry ont the supposition, let the dranght now found be applied at the point $c$; as the plow would then have no tendency to dip or rise, the force, $k b$, vanishes, leaving only the direct horizontal force, $i b$; hence, were it possible to apply the draught in a horizontal direetion from the point 
of resistance, the resistance of the plow would be 390 pounds instead of 407 pounds.

\section{THE WIIEEL.}

It is not difficult to show that, theoretically eonsidered, a wheel placed under the beam can in no case lessen the traction of the plow, as many plowmakers and plowmen have alleged.

Let us suppose that the line of draught is in the horizontal direction; it will therefore require that a support be placed beneath the beam to prevent its sinking too low, which support, in all modern plows, is given by a wheel. It has been shown that whether the plow be drawn in the ordinary direction of dranght, $b f$, in which one oblique propelling foree only is exerted, or with two antagonist forees, $b i$, in the horizontal direction, and the upholding foree, $b k$, in the vertieal, we find that in the latter the difference in favor of motive force is only one twenty-fourth of the usual resistance; but the upholding force is equal to two-sevenths, while none of these varrations has produced any change in the absolute resistance of the plow. The impelling foree is theoretieally less in the latter ease; but since the wheel has a load of 107 pounds to carry, we have to eonsider the effect of this load upon a small wheel, arising from frietion and the resistance it will encounter by sinking more or less into the subsoil.

Mr. Stephens has ascertained from experiment that the differenee of force required to draw a wheel twelve inches in dianeter, loaded is above described, and again when unloaded, over a tolerably firm soil, is equal to 22 pounds, a quantity exceeding one and a half times the amount of saving that would accrue by adopting this supposed horizontal draught with a wheel. Having thus found the amount of draught at two extremities of a scale, the one being the oblique draught, in eommon use, at an angle of 20 deg., the other dednced from this through the medium of the established principles of oblique forces, and the latter produeing a saving of one twenty-fourth of the motive force while it is encumbered with an additional resistance arising from the support or wheel. It necessarily follows that at all intermediate angles of dranght, or at any angle whatever where the principle of the parallelogram of forces finds place-and it will find place in all eases where wheels yielding any support are applied to the plow under the beam-there must necessarily be an increase in 
the amount of resistance to the motive force. The diagram, Fig. 82, will make this important matter still more intelligible.

Let $a$ be the point of resistance of a plow's body, $b$ the point of the beam, $c$ the position of the horses' shoulders, and $a d$ the horizontal line; then will $c a d$ be the angle of draught, equal

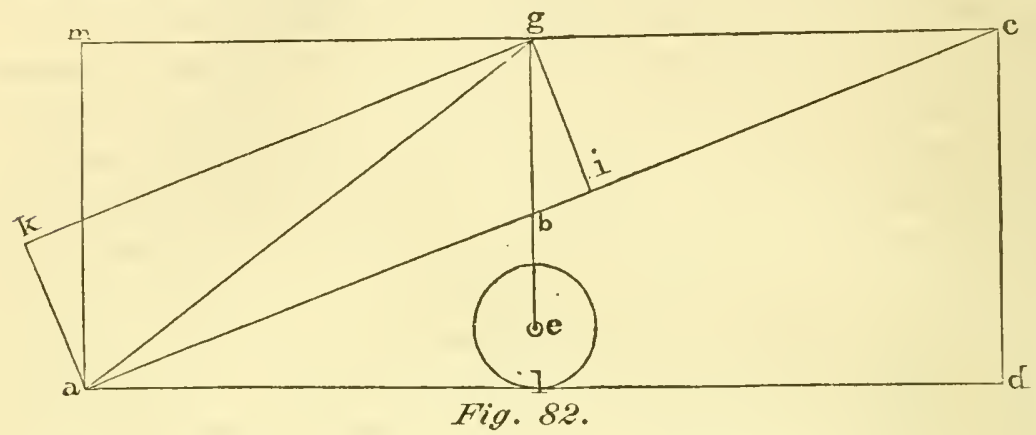

20 deg. Let the circle $e$ represent a wheel placed under the beam, which is supported by a stem or shears, here representer by the line $e b$. In this position the point of the beam, which is also the point of dranght, lies in the line of dranght; the wheel, therefore, bears no load, but is simply in place, and has no effect on the draught; the motive force, therefore, continues to be 407 pounds.

Suppose, now, the point of the beam to be raised to $g$, so that the line of draught, $g c$, may be horizontal; and since the line of draught lies now out of the original line, $a b c$, and has assumed that of $a g c, g$ being now supported on the produced stem, $e g$, of the wheel, draw $g i$ perpendicular to $a c$ and complete the parallelogram, $a i g k$; the side, $a i$, will still represent the original motive force of 407 pounds, but by the change of direction of the line of draught, the required force will now be represented by the diagonal, $a g$, of the parallelogram, equal to 425 pounds, and $g c$ is a continuation of this force in a horizontal direction. The draft is therefore increased by 18 pounds. Complete also the parallelogram, a $l \mathrm{~g} m$, and as the diagonal, a $g$-the line of draught last found-is equal to 425 pounds, the side, $l g$, of the parallelogram will represent the vertical pressure of the beam upon the wheel, $e$, equal to about 250 pounds, which, from Mr. Stephens' experiments, may be valued at 50 pounds of additional resistance, making the whole resistance to the motion 475 pounds, and being a total increase arising from the introduction of a wheel in this position of 68 pounds. Having here derived a maximum- 
no doubt an extreme case-and the usual angle of 20 deg. as a minimum, we can predicate that, at any angle intermediate to $l a b$ and $l a g$, the resistance can never be reduced to the minimum of 407 pounds. Hence it follows, as a corolliry, that wheels placed under the beam can never lessen the resistance of the plow; but, on the contrary, must in all cases increase the resistance to the motive force more or less, according to the degree of pressure that is brought to bear, and this will be proportional to the line of the angle in the resultant, $a g$, of the line of draught.

We have now finished the discussion of the wheel question on theoretical principles, deeming it best to introduce no disturbing questions to distract the attention of the reader until all that we had to say under that head was brought to a close.

We may now remark that our theoretical views are based upon a uniform motion, a uniform soil and a homogeneous texture, but such a coincidence of conditions is rarely met with in practice. Some portions of the soil are wet, while others are dry; some parts are hilly, and other's level; some parts are adhesive, and others are crumbling; some are stony, others full of roots. The instances are indeed rare where there is a perfect uniformity in the conditions which are essential to bring it into conformity with theory.

There are few questions connected with plowing which have been more energetically or more persistently disputed than that between wheel and swing plows. The Scotch plowmen have been especially pugnacious, loing battle for the swing plow with the utmost vehemence. The English plowmen have been equally certain that the wheel was essential to good plowing. While the Americans, thinking little about the matter and saying less, have instinctivcly adopted them.

The advocates of the swing plow claim the following alvantages.

First-It educates a better class of workmen. Almost any one, after the practice of one or two days, can use a wheel plow and do pretty good work. None but a first-class workman can make good work with a swing plow.

Second-Its depth can be regulated by the proper adjustment of the whiftle-trees in the clevis, or by increasing the length of the traces.

Third-The plowman can regulate the action of the point by bearing upon or lifting up the handles. 
Fourth-It is more simple in its construction and less in cost.

Fifth-It can be used across ridges, and under a much greater variety of circumstances than the wheel plow.

Sixth-It requires less power.

The advocates of wheel plows claim the following advantages for their favorite implement:

First-The plowing can be effected with more ease to the plowman.

Second-The work can be performed with much greater accuracy; the depth is more uniform and the sole is kept more level.

Third-Where very shallow or very deep plowing is required it can be better done with a wheel than with a skim plow, and also where the land is hard and stony.

Let us briefly consider these conflicting allegations:

First-It is doubtless true that a swing plow requires a more skillful plowman than a wheel plow, but this, in a country where skilled plowmen are so rare as they are in this, is an objection rather than an advantage. No one denies that a poor workman can do very much better work with a wheel plow than with a swing plow, and this, in our judgment, settles this point in their fitvor.

Second-The alleged capacity for adjustment is true, but it is equally true of the wheel plow.

Third-This allegation must also be admitted, but it is done at a great expense of friction upon the team, and of great labor to the plowman, which increases the wear of the plow. The use of the wheel obviates the necessity of all this, and therefore we think that in this respect wheels have the advantage.

Fourth-This must be admitted, but the advantage in this respect is so slight that it is scarcely worth taking into the account.

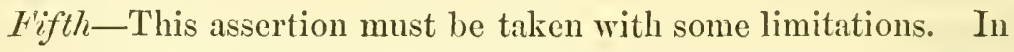
cases where the rock lies at varying depths, sometimes within three or four inches of the surface, at other's at a greater depth, in entting across dead fallows where the surface is rough, and hard clods interrupt the even action of the wheels, there can be no donbt that the swing plow would do best. In crossing steep ridges and furrows the action of the ascending wheel raises the share out of the furrow, while in descending it plunges deeper into the ridge. This, however, occurs only in extreme cases, and 
to a considerable degree the same effect attends the swing plow unless it is managed by plowmen more expert than are often found in England or even in Scotland, and of whom scarce a score could be found in the State of New York. On the other hand, in stony land, or where the soil is obstructed by roots, it must be confessed on all hands that a wheel is of the greatest advantage.

Sixth-The assertion that the wheel plow requires more power than the swing is completely disproved by the most accurate and frequently repeated experiments.

We have shown by geometrical reasoning that the wheel adds to the dranght of the plow when constantly pressed upon by the trim of the plow; but this ought never to be allowed, and will never occur in level and tolerably homogeneous soils, when the draught is properly adjusted. The pressure will only occur in coincidence with the occurrence of inequalities; but on the other hand, these inequalities must be overcome by the pressure of the plowman's hands, which, acting on a long lever, increases the friction in a greater degree than the wheel, and therefore augments the friction of the plow in a greater degree also.

Mr. Handley, in a paper which received the prize of the Royal Agricultural Society. details a series of experiments that he performed with a view to the determination of this question.

Two wheel plows were tried in connection with two swing plows. The average draught of the wheel plows was 288 pounds, while the average draught of the swing plows was 341 pounds, making an avertge difference of 53 pounds in fivor of the wheel plows.

Mr. Handley's experiments were performed at Ipswich, in 1838. The average weight of the wheel plows was 220 pounds; the average weight of the swing plows was 135 pounds. It was farther established at this trial that the draught of a plow is not increased in an equal ratio with its weight, for on loading one of the wheel plows with 112 pounds, or 51 per cent additional weight, the dranght was only increased 33 pounds, or 12 per cent.

These trials were repeated by Mr. Pusey in 1840, with the following results: The average draught of four swing plows, working a deep, strong loam, was 441 pounds, while that of the four wheel plows, working in the same soil, was 434 pounds. showing an average difference of 7 pounds in favor of the wheel plows in this kind of soil. In a brown loamy sand the average 
draught of the four swing plows was 245 pounds; that of the four wheel plows was 210 pounds, showing an average of 35 pounds in fivor of the wheel plows. In a blue clay soil the average draught of the four swing plows was 686 pounds; the average dranght of the four wheel plows was 630 pounds, showing a difference in favor of the wheel plows of 56 pounds. In a sandy loam the difference in favor of the wheel plows was 49 pounds. The average difference in these four trials, in as many different soils, was 37 pounds, or 10 per cent, in fuvor of the wheel plows.

Mr. Handley accounts for this superiority of wheel plows as follows:

"As regards the cause of the diminished force required by the wheel, compared with the swing plow, it appears to me to be principally, if not fully, explained by the more uniform horizontal motion communicated to the share and sole of the former through the regulating medium of the wheels at the fore part of the beam, which diminish the shocks arising from the continued vibrations of the implement when balanced between the hand of the plowman and the back and shoulders of the horse. It is not contended that wheels so situated act the part of lessening the friction between the sole and the soil; but they keep the rubbing part more truly to its depth, and maintain its horizontal action more correctly; whereas the horses affect a swing plow at every step by the irregularity of their proper movement, which has to be counteracted by the eflort of the man at the opposite encl. Thus conflicting forces are momentarily produced, and continual elevations and depressions of the point of the share take place, together with deviations from the flat position of the sole, which should be retained at right angles to the perpendicular; and to remedy which unskillful plowmen bear unequally on the stilts, which produces a lateral pressure lindwards, and eonsequently a great amount of friction along the whole of the left side plane of the plow. However small may be the efforts of the plowman to keep his plow 'swimming fuir', those efforts must be attended with increased resistance, and consequently with increased resist. ance to the horses."

It is not pretended that, in a wheel plow, none of these irregularities of motion exist; on the contrary, the dynamometer shows them to be very considerable, but less in legree than in the swing plow. The oscillations of the index of the dynamometer are, as 
unight be expected, very great when applied to a plow. The point of a plowshare may be readily supposed, at onc instant, to have burst a sod, which, opening and being laised upwards, offers for several inches but a trifling resistance to its progress; it again mects the obstacle, which is again overcome. It is similar with roots, stones and other varying impediments, and thus, at every step of the horse (whose motion is also a series of impulses), the draught, as exhibited by the dynamometer, is continually and largely varying.

These are effects arising from the nature of animal force and of the soil; they are necessarily common to both plows, but appear to be augmented in the swing, compared with the wheel plow, and sufficiently account for the diminished draught of the latter as shown in the experiments.

IVe think we have now shown that the claims of the advocates of swing plows are mostly invalid, while those of the friends of the wheel plow are shown to be founded in reason and experience, and the practice of American farmers is therefore fully justified.

Before leaving the subject we desire to quote a statement of Mr. Handley, which very strikingly illustrates the action of the plowman on the draught of the plow.

"In one of my trials I substituted for a first-rate plowman one who, though no novice, was decidedly his inferior, and who held the same plow for a bout, during which he exerted his best abilities, aware of the comparison about to be instituted, and yet the draught was in, his hands, increased six per cent, and I have no doubt, had he continued to hold the plow for an cutire day, it would have been considerably more. This man, though inferior to the other, possessed skill above the average of plowman usually employed. Had he held a plow with wheels there would probably have been no difference in the draught between the holding of the plow by himself and predecessor."

There is a considerable difference in the mode of making and attaching wheels to plows. The old fashioned high gallows frame may be seen in Plate I. This plan, though capable of being used by a good plowman so as to do good work, is so complex in the adjustment that in the hands of unskilled workmen they are apt to consume more power and to do less perfect work. 
A much better and simpler plan for a two wheeled plow is given in Plate V, in connection with the plows of Messrs. Ransome and

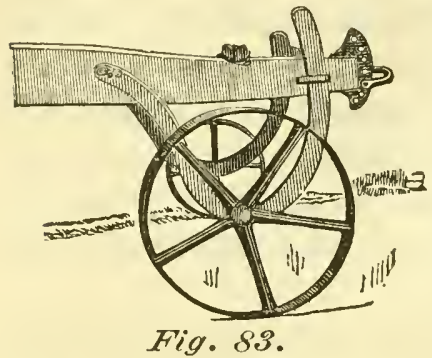

Howard. It is claimed by many that there is an advantage in the use of two wheels, as the land wheel acts as a lateral gange to the width of each furrow as well as to the depth, and therefore the uniformity of width, depth and angle of the furrow slice thus produced give a perfect form to the whole operation. The American form of the double wheel plow is given in Fig. 83 .

The usual form of the single wheel is shown on the side of

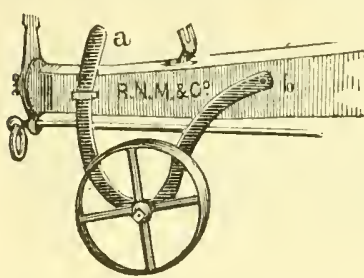

Fig. 84 the plow beam, in Fig. 84, and beneath it in Fig. 85. In either case the wheel frame is clasped to the beam in a manner that readily admits of raising or lowering the wheel to give the plow any desi-

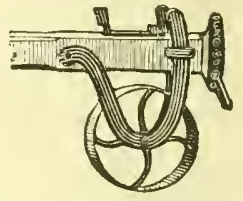

Fig. 85 . red depth of work; and when adjusted to a given point it is then made fast by tightening the clasp.

\section{THE COULTER.}

Fig. 86 shows the manner of inserting the coulter through a mortise in the beam. It is secured by a wedge; the beam is strengthened from splitting by a diagonal band passing round it. It is adjusted to the side of the beam, as shown

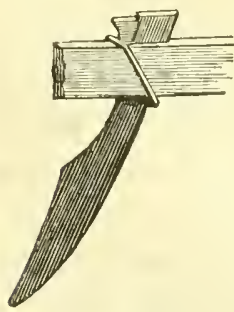

Fig. 86 .

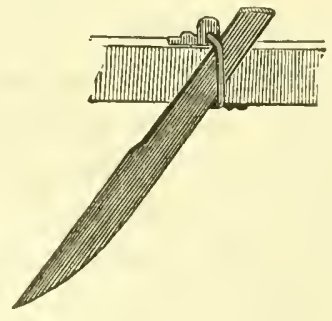

Fig. $\mathcal{S \%}$.

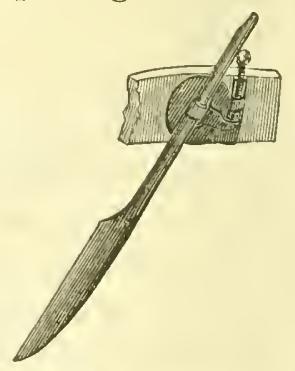

Fig. $\mathcal{S} 8$.

in Fig. 87, by a diagonal clamp, which supports the front of the coulter on the upper side, and the back on the lower side; the ends pass through holes in an iron plate, and are fastened securely by nuts.

Fig. 88 is a form of the coulter in which a circular plate, 
having a socket on its face, which secures the shank of the conlter; is made to revolve by the action of a screw, thus fnabling the plowman to set it at any desired angle.

The farorite plans for raising or lowering the coulter in England are given in Fig. 89, and also for changing its angle, which will be readily understood on inspection.
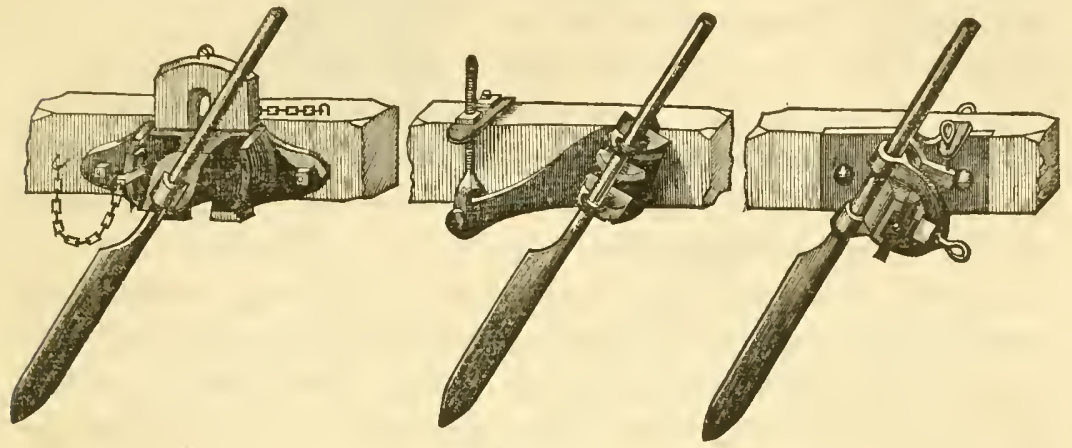

Fig. 89.

Fig. 90 represents the loek coulter, which is made of wrought iron, steel edged. It passes through the plow beam, and is made fast on top with a key, or with a nut and screw, and locks through the share and mould-board where they join together.

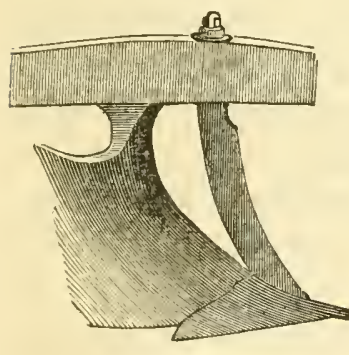

Fig. 90.

The adjustment is a very strong one, both for the coulter and the plow, and fits the implement for working among stones, stumps and roots, as the coulter cannot be turned out of place or broken by such obstacles. The revolving

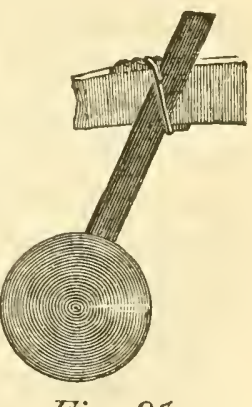

Fig. 91.

coulter is represented in Fig. 91. It consists of a steel plate, revolving on an axis, and having a stem which is clasped to the beam, as shown in the cut. In some cases the coulter is conveniently replaced by the fin share represented in Fig. 92. It is used for plowing sod lands infested with roots and stumps or stones, where the sward cutter camnot be used withont danger of getting bent or misplaced. It is also useful when plowing in stubble or coarse manure, serving to keep the plow from elngging at the standard. It separates the furrow slice from the unplowed land easier and more smoothly than it could be done by the breast of the plow. Nuch depends upon the form and size of 
the coulter and its adjustment. It should be made of iron, faced with steel, and of sufficient bulk to stand firmly in the position in which it is set for its work; not to bend either to the right hand or to the left. The most approved English coulters are about two and at half inches wide, and formed by the meeting of two curves, as in Fig. 89. The land side of the coulter should be flat, and the opposite side a gradual taper from the edge to the back. The thickness must be determined by the

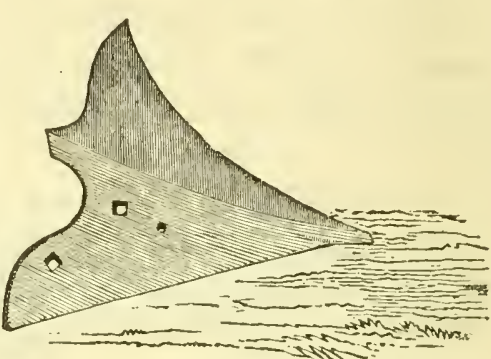

Fig. 92. strength of the work it has to perform. American coulters are generally made either straight edged, as in Fig. 87, or slightly curved backward from the point. When secured, as shown in Fig. 89 , it is kneed inwald, so as to adjust it to the plane of the land side.

Having now considered the various forms of the coulter, we pass on to a consideration of its function and its adjustment.

Mr. Stephens has asserted that the force required to draw a coulter seven inches deep in the earth requires no more power than it does to draw a plow making a furrow seven inches deep and ten inches wide, without a coulter. This experiment, we believe, stands alone, unsupported by the testimony of any other observer. We had desired to verify it at Utica, with every precantion to insure accuracy, but were prevented from doing so by the unexpected and untimely removal of the dynamometer from thence.

The subject being one of such great importance, we give Mr. Stephens' statements in his own words:

"On a subject which has of late attracted considerable attention, I was desirous of obtaining information from experiments alone on the actual implement; and, to attain this more fully, I determined on analyzing the resistance as far as possible. With this view, a plow was prepared whose coulter was deseended seven inches below the line of the sole, and fitted to stand at any required angle. This plow, with. its sole upon the surface of a two-year old lea, and the conlter alone in the soil, the bridle having been adjusted to make it swim without any undue tendeney, the foree required to draw this experimental instrument, as indieated by the dynamometer, was twenty-six imperial stones (350 
pounds), and no sensible difference was observed in a range of angles varying from 45 to 70 degrees. This coulter, having been removed, the plow was drawn along the surface of the field, when the plow indicated eight stones (112 pounds), the usual draught of a plow on the surface.

"Another well-trimmed plow was at work in the same ridge, taking a furrow ten by seven inches, and its draught was also 350 pounds. The furrow thus taken produced, of course, a slice of very rough plowmanship; and though it exhibited, by a negative, the essential use of the coulter-the clean cutting of the slice from the solid ground-the whole question of the operation and working effects of the coulter are thus placed in a very anomolous position."

If the experiment of Mr. Stephens is reliable, it would seem that the extreme care which plowmakers have taken to adjust the coulter accurately to the various parts of the plow is quite unnecessary, and that the reasons given for their respective plans rest upon a purely imaginary foundation.

Farmers having observed that a drawing cut requires less power to separate a solid body than a direct cut by pressure-as the saw cuts easier than the chisel--have imagined that they obtained such a drawing cut by giving a long rake to the coulter; but on looking elosely at the matter it will be seen that this gives no drawing action whatever to the cut of the coulter.

There is no upward and downward motion, no reciprocating action as when we draw a knife across a loaf of bread, but it is simply a cut effected by horizontal pressure operating through the whole length of the blade just as when the elge of a chisel is pressed into wood by the blow of a mallett. There is therefore no economy of power by inserting the conlter at a high angle with the sole, the resistance so far as the splitting of homogeneous earth is concerned is precisely the same whether the angle is 45 deg. or 80 deg.

Nevertheless, in practice, arising from other causes than the splitting of the earth, there are great advantages to be derived from a variation of the angle between $45 \mathrm{deg}$. and $85 \mathrm{deg}$., and incidentally there is a considerable saving of power.

Thus in plowing stubble land which is very foul the dry grass and butts of the straw would collect transversely on the edge of the coulter. In this case the draft is frequently increased by 150 pounds; by giving it it a long rake the stublble is shoved upward 
and the edge is kept elear. So when the ground is full of roots, when the conlter is set slanting the roots will slide upward, and the drawing action will cut them; whereas, if the conlter was set at 80 deg. it would draw them out. On the other hand, when used for plowing sod or clover the fiurrow will be much cleaner when the angle is 75 deg. or 80 deg., ats it will not press the griss and roots upwards before they can be cut through.

There is one rule pretty generally observed in relation to the coulter, both in Europe and A merica, which is that the land side face shall always be parallel to the plane of the land side of the plow.

Another rule pretty generally adopted is that at the point where the coulter meets the surface of the ground the edge should stand about one-quarter of an inch landward of the plane of the landside of the plow.

In the plows made by Prouty \& Mears, and those of some other makers, the reverse of this rule is adopted, the coulter being set inwards toward the mould-board about half an inch at the point where the conlter touches the surface, as shown in Fig. 93, and extending from thence landward so that the point of the coulter is vertical over the point of the share. This leaves a small triangle whose base is half an inch and whose altitude is the depth of the furrow to cut off by the shin of the

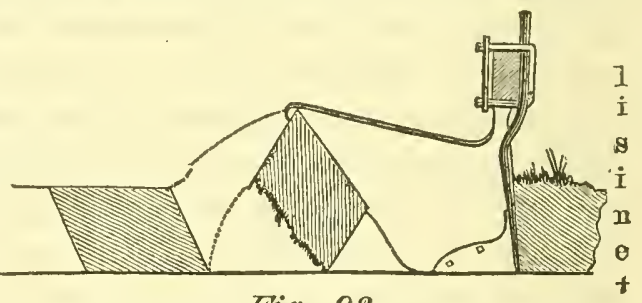

Fig. 93.

plow; this is converted into powder, which rolls over on the face of the furrow slice and covers the grass, which sometimes sticks up in the angle of the slice.

The vertical elevation of the point of the coulter above the plane of the sole is not well settled. In England it is generally put from one to two inches above, in America from three to four inches above it.

Then English and Scotch usually put the point of the coulter vertically over the point of the share, but in America it is placed mostly from two to four inches in advance of it.

We think there is no absolute rule which can be laid down upon these points. The nature of the soil to be plowed will influence the set of the coulter very considerably, and the determination of this part of the trimming of the plow may be safely left to the judgment of the plowman. 


\section{CHAP'TER IX}

OF THE MECHANICAL CONDITIONS OF TIIE PLOW.

In order to fulfill the indications described in the preceding pages, it is necessary to form the plow so that, in sandy land, or in light crumbly loams, the furrow shall be completely inverted, so that the surfice of the soil shall be laid upon the bottom, and that which was upon the bottom shall be turned upon the top.

In stiffer soils it is necessary to lap the furrows, so that the upper surfice shall form an angle of 45 degrees with the base, when the lower edge of the last plowed slice will lap over onethird of the preceding slice.

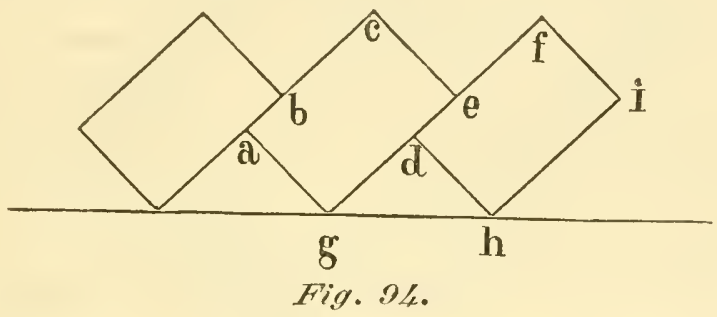

As will be seen on Fig. 94, where the lines $a c$ and $a f$ are nine inches long, and the lines $a g$ and $d, h$ are six inches long, and the lines $a b$ and $d e$ are each three inches long, or one-third of the length of the lines $a c$ and $d e$, which represent the breadth of the furrow. When the furrow slices are laid in this position, the line $b c$ is always equal to the line $c e$, and the line $e f$ to $f i$.

It may be shown by the following reasoning which we borrow from Mr. Stephens, that this position insures the exposure of the greatest possible surfice of earth to the atmosphere. It also elevates the maximum cubical mass of earth, and makes the deepest seed-bed when the angles are drawn off by the action of the harrow.

Let $a b$, Fig. 95, represent the breadth of a ten-inch furrow slice, and describe the semicircle, $a c b$, upon it as a diameter. From this well known property of the circle, that the angle in a semicircle is a right angle, every triangle formed upon the diameter as a base, will be right angled; and the only isosceles triangle that can he formed within it will be that which has, $c d$ 
equal $a b$, the breadth of the slice, which must always be equal to the distance between the apices of two contiguous furrows.

Complete the parallelogram, $a c d e$, which will represent the transverse section of a rectangular slice, whose breadth is ten inches, and whose two exposed fuces, $a c$ and $c b$, lie at angles of 45 degrees, and their breadth, as well as the area of the triangle, $a b c$, will be a maximum. In order to prove this, let a section of another slice be formed, whose exposed side, a $f$, shall be greater than the corresponding side, $a c$, of the former, and let this be taken at eight inches. From $f$, through the point $b$, draw

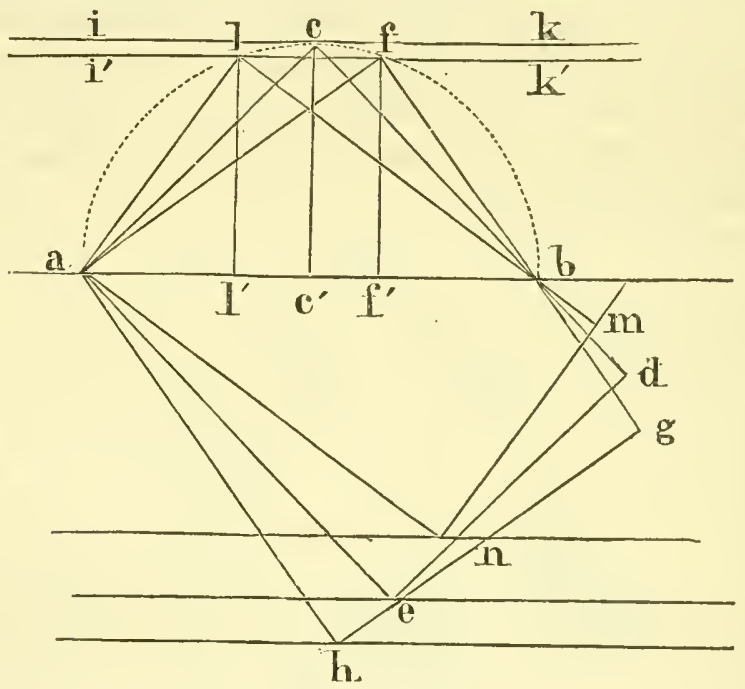

Fig. 95.

$f g$; then will $a f b$ be a right angle as before; $f g$, being also made equal to ten inches, complete the parallelogram, af $g h$, which will represent the transverse section of a rectangular slice ten inches by eight inches, occupying the same horizontal breadth as before, and whose exposed faces will be $a f$ and $f b$. Draw the line $i c k$ parallel to $a b$, and passing through the apex, $c$, of the triangle, $a c b$; and the line $i k$, also parallel to the line, $a b$, passing through the apex, $f$, of the triangle, $a f b$. Here the triangles, $a c b$ and $a f b$, stand on equal bases, $a b$; but the first lies between the parallels $a b$ and $i c k$, and the second between those of $a b$ and $i^{\prime} k^{\prime}$; the altitude, $f f^{\prime}$, therefore, of the triangle $a f b$ is less than the altitude, $c c^{\prime}$, of the triangle, $a c b$. And triangles on equal bases being proportioned to their altitudes, it follows that the triangle $a f b$ is less thim the triangle $a c b$, both 
in area and periphery. Suppose, again, a slice whose sides, $a l$, is less than the corresponding side, $a c$, and let it be six inches; from $l$ through the point $b$, as before, draw $l \mathrm{~m}$, and construct the parallelogram, a $l m n$. we-shall have a transverse section of a third slice of ten by six inches, whose exposed faces, $a l, l b$, occupy the same horizontal breadth as before. Here the triangle a $l b$ lies between the parallels $a b$ and $i^{\prime} k^{\prime}$, consequently to $a f b$, and less than $a c b$.

This simple geometrical demonstration as applicable to the slice may be corrohorated by the usual formula of the triangle. Thus the altitude of the triangle $a c b$ is $\frac{a b}{2}=5$ inches $=c c^{\prime}$, and the side $a c$ or $c b$ is $=\sqrt{a c^{2}}+c c^{2}$; or $a c$ and $c c$ being each equal to five inches, $a c$ or $c b$ will $=\sqrt{25+25}=7.071$ inches, which is the depth due to a slice of ten inches in breadth, and the sum of the two exposed faces will be $7 \cdot 071+2=14 \cdot 142$ inches.

In the triangle $a f b, a b=10$ inches, and $a f=8$ inches, then $a b^{2}-a f^{2}=f^{2} b^{2}$, and the $\sqrt{f b^{2}}=6$ inches. The three sides, therefore, of this triangle are ten, eight and six inches, and the altitude, $f f^{\prime}$, is easily found by the principles of similar triangles. Thus, in the similar triangles, $a f f^{\prime}, f b f^{\prime}, a b: a f$ $:: f b: f f^{\prime}$. The perpendicular $f f^{\prime}$ is therefore $=4 \cdot 8$ inches, hence the exposed surfices are as $14 \cdot 141: 14$, and the altitudes as 5 to $4 \cdot 8$.

Since it turns out that $a l$ is equal to $f b$, and $a b$ is common to both, it follows that $l b$ is equa! to $a f$ : and the periphery and altitude is also equal and less in all respects than the triangle $a c b$, and so of any other position or dimension.

By recurring to Fig. 94, it will be scen that when the furrow slices are laid at an angle of 45 degrees, a triangular drain, $g d h$, is left under each furrow. This not only drains off the surface water, but allows the air to entcr freely beneath the surface, which, in conformity with what has been said in the preceding section, is of very great advantage, and strongly recommends the adoption of this mode of plowing in stiff and retentive soils.

It will follow, from what has been stated, that the proportion of the depth to the width must always be in the ratio of 2 to 3 . Six inches deep and nine inches broad, or seven inches by ten, are the most usual proportions.

Fig. 96 illustrates the action of the plow in this style of plowing; $a b$ is the exterior edge of the slice which is being turned; $e f$ is the edge along which the land side of the plow has just 
passed; $c d$ is the inner edge of the slice; $g h$ is the sole of the furrows, and $i k, l \mathrm{~m}$ are slices which have been previously turned over.

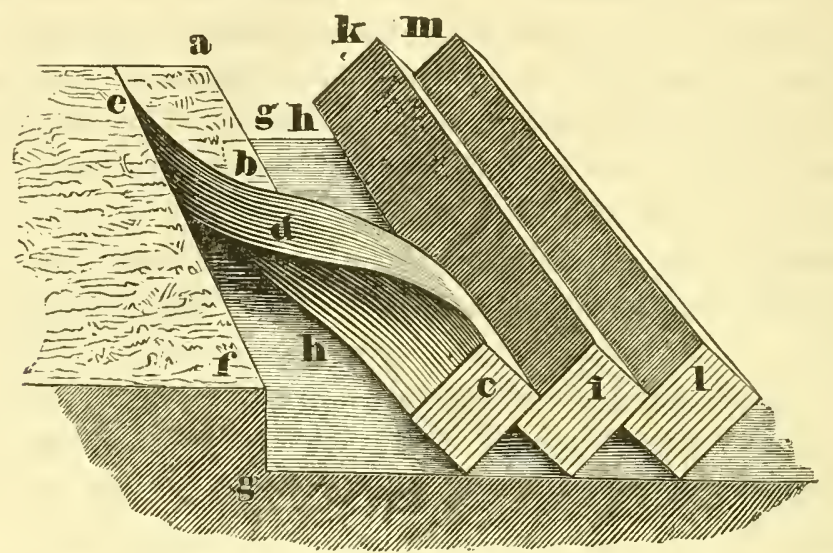

Fig. 96 .

The exact mechanism of the rotation of the slice is clearly illustrated in Fig. 97. Let $a b c d$ represent the transverse section of a furrow slice nine inches wide and six inches deep, which it is proposed to raise. The point of the plow enters at the point $d$; as nothing is cut or broken before it, it must necessarily take a greater strain and sustain a greater amount of abrasion than any other portion of the implement. The entrance of the point gives an upward tension to the slice, which facilitates the action of the

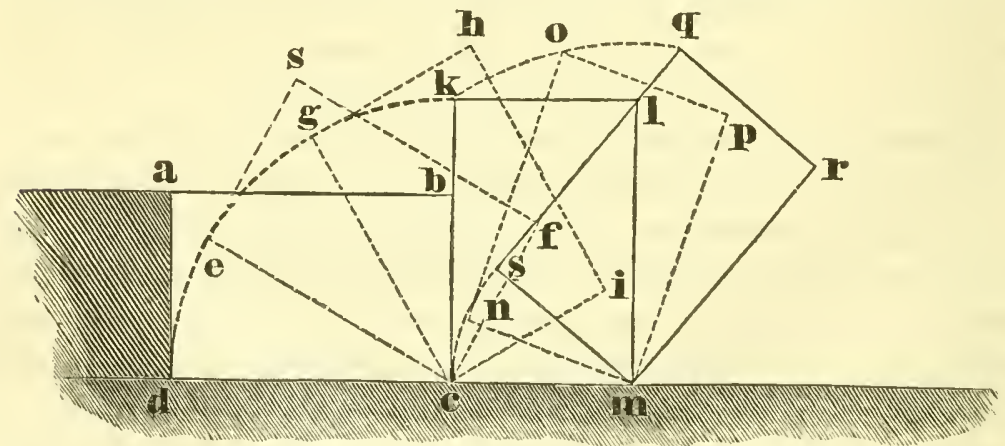

Fig. $9 \%$.

horizontally cutting edge of the feather, which severs the slice at the bottom from the sole, $d c$, as it advances forward; at the same time the slice is raised from its centre, $c$, and the outer and under corners traverses the are of a circle, $d$ eg $k$. The parallelogram, c e $s f$, shows the position of the slice when the point $d$ has been 
vertically elevated four inches to the point $e$. At the point $g$ it has been vertically elevated eight inches, and the position of the slice is shown in the parallelogram $c g h i$. When the point $d$ has been laised through an entire quadrant, the line $d c$ is represented by $k c$, and the line $b c$ by $c m$. The vertical line of the mould-board in contact with the line $k c$ is called the zero line, and the point touched by the angle at $k$ is called the zero point. This point is of importance, as from it all measurements of plows are usually male. $\mathrm{U}_{\mathrm{p}}$ to this time the slice has turned on the centre $c$, but on its further passage to the positions o $p n m$ and $q r m s$, the centre of rotation is the point $m$, until it attains to an angle of 45 degrees, when the slice rests upon the edge of the preceding furrow. If the whole sole of the slice were to be severed by the share, it is clear that it would be very difficult, if not impossible, to lay the slice accurately. The plow would act as a simple wedge, pushing the slice over to the furrow side from the land side; it would not coincide with the twist of the mouldboard, and therefore the transverse eracks which it receives, and which is so essential to its pulverization, would not be communicated to it; it would frequently leave it in a vertical position, and sometimes, especially on side-hills, the furrow would fall back into its old position. To prevent this, the rear angle of the feather should never be further from the plane of the land side than from one-half to three-quarters of the breadth of the furrow, that is, if the furrow is ten inches wide, the rear angle of the feather should be from five to seven and one-half inches from the plane of the land side, measuring across the sole of the plow by the shortest line between them. The strip thus left unsevered on the furrow side holds the furrow to its place and forms a sort of hinge upon which it turus.

We have hitherto confined our attention exclusively to furrow slices whose transverse sections are rectangles; but many plowmakers and plowmen insist that a crested furrow, whose transverse section is a trapezoid, is better than the rectangular furrow because it forms a deeper seed-bed. This form is produced when the rear angle of the feather lies in a plane from one inch to an inch and a quarter higher than the plane of the point.

Fig. 98 shows that those who claim a better seed-bed for a trapezoidal furrow are mistaken. A series of triangles, $f g f^{\prime}$ and $f^{\prime} g^{\prime} f^{\prime \prime}$, etc., are left undisturbed at the bottom of the furrow, which are effectually cut up by a plow turning a rectangular 
furrow slice. Again, the side $a b$ being nine inches, and the side $c d$ a fraction longer; the side $b d$ six inehes, and the side $a c$ four and a half inches, it is evident that less loose earth is provided for the seed-bed by a trapezoidal stice than a rectangular one by the triangle, $d e c$, which varies from one-seventh to one-tenth of the entire scetion, according to the elevation of the rear angle of the feather.

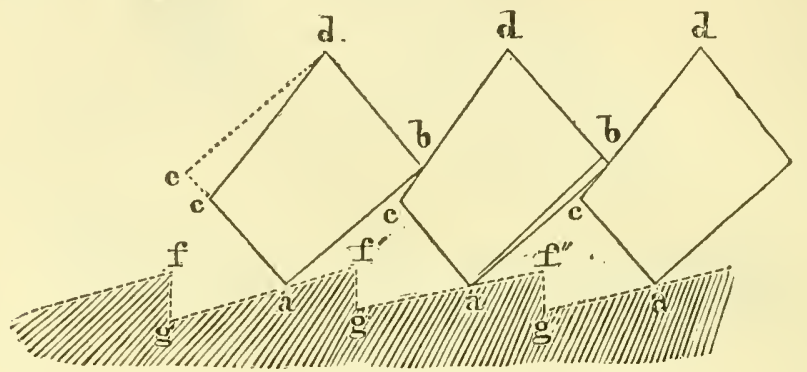

Fig. 98.

The practical rule proposed by $\mathrm{Mr}$. Stephens for the formation of the sole of the plow, with reference to the formation of rectangular furrow slices, is that the height of the shield-the surface of the share-on the land side, opposite to the rear angle of the feather, be two and a half inches above the line of the sole shoe; that the share be one-half an inch below the line of the sole shoe, and not exceeding one-half an inch to landward of the land side plane; and that no part of the edge of the feather should be more than three-eighths of an inch above the plane of the sole shoe, that plane being always understood to be at right angles to the land side plane.

Another style of plowing, known as sod and subsoil plowing, which was introduced into this country about the year 1850, has worked its way very largely into public favor, and is probably destined to receive a still greater popularity as time continues to reveal its merits.

Fig. 99 shows the manner in which the work is performed. A skim plow is attached to the fore part of the beam, by elamps, which turns over from two to three inches, $a$, of the sod, depositing it, with the grass downward, on the sole of the preceding furrow, c. A larger plow, attached to the rear of the beam, follows and turns over the rest of the furrow, $b$, depositing it, in a finely pulverized condition, on the top of the first or sod furrow. In this way the grass and weeds on the surfice are effectually buried, 
and are placed in a position to nourish the roots of the crop at the precise period when nourishment is most needed for maturing the crop. This kind of plowing prepares sod-ground for corn in the best possible manner.

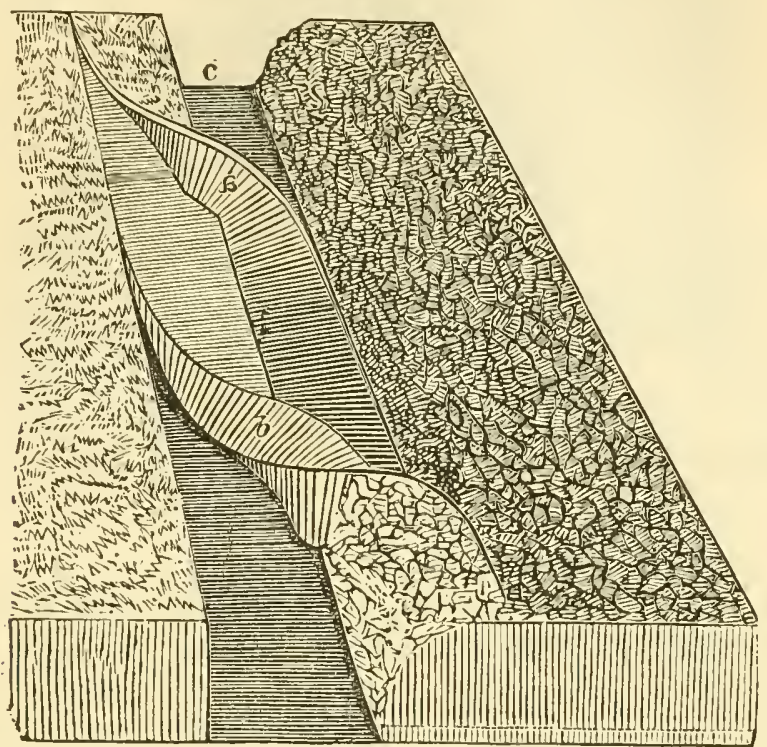

Fig. 99.

For land which is too bushy or too rooty with wild or swamp grasses, or where ic is so sandy or mellow that pulverization is not an object, a third style of plowing is adopted which requires a special form of the plow.

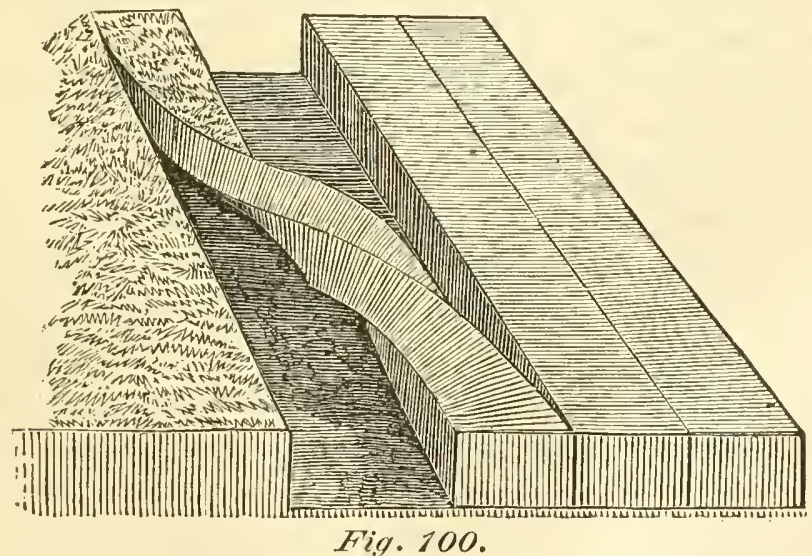

The action and movement of the furrow slice for fat furrow sod plowing is shown in Fig. 100, and requires no other explanation. 
The fourth kind of plowing is in stubble or old land, and is generally called stubble plowing. Fig. 101 represents this style

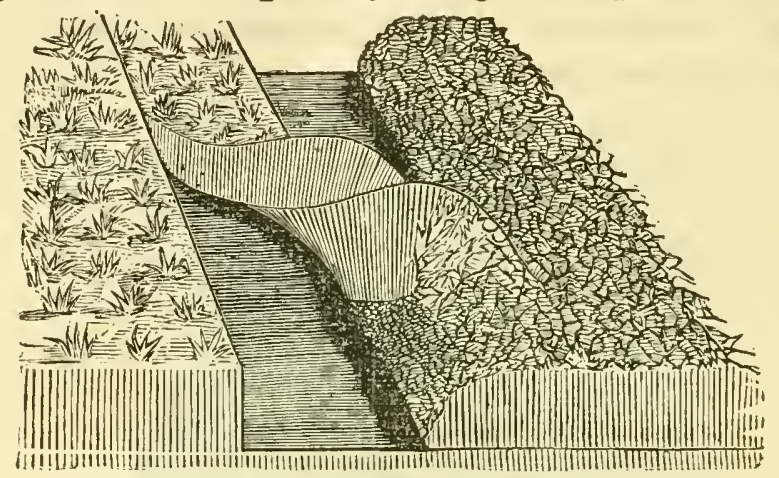

Fig. 101.

of plowing. The twist of the furrow is more sharp and decided than in sod plowing, as the soil is less compact, and can be pulverized with less expenditure of power.

Many side-hills which are fertile, are yet so steep that a furrow cannot be turned up hill, and must therefore be turned down hill. This requires a plow which shall permit the share and mouldboard to swing alternately to the right and left of the land side.

Since mowing machines have been nsed as a substitute for the scythe, a demand has arisen for a more level culture, dispensing with open furrows and every other form of surface obstruction. The swivel plow being adapted to meet this want, its use has been greatly extended, and few farmers now feel that they can dispense with them.

There are other kinds of plows, but these five are sufficient for the cultivation of the land, and no good farmer can afford to dispense with them.

Mr. Holbrook has made an effort to dispense with so great a number by adapting to his sod plows a mould-board for stubble plowing, and a skim plow, when desired, for sod and subsoil plowing; and he has thus undoubtedly greatly increased the range of usefulness of each plow. Still it is impossible to ignore the fact that each plow can only do perfect work when taking the exact depth and width of furrow for which it was designed, and in exact proportion to its recession from this standard does it depart from perfect work. Such being the fact, we hope to see a very considerable increase in the number of plows owned by each firmer, which will enable them to do much better work in 
all positions, and to grow a much larger crop upon an acre than they have ever done before.

Before entering upon a consideration of the parts of a plow in detail, it is desirable to define those parts with accuracy, so that all ambiguity and misapprehension mat be avoided

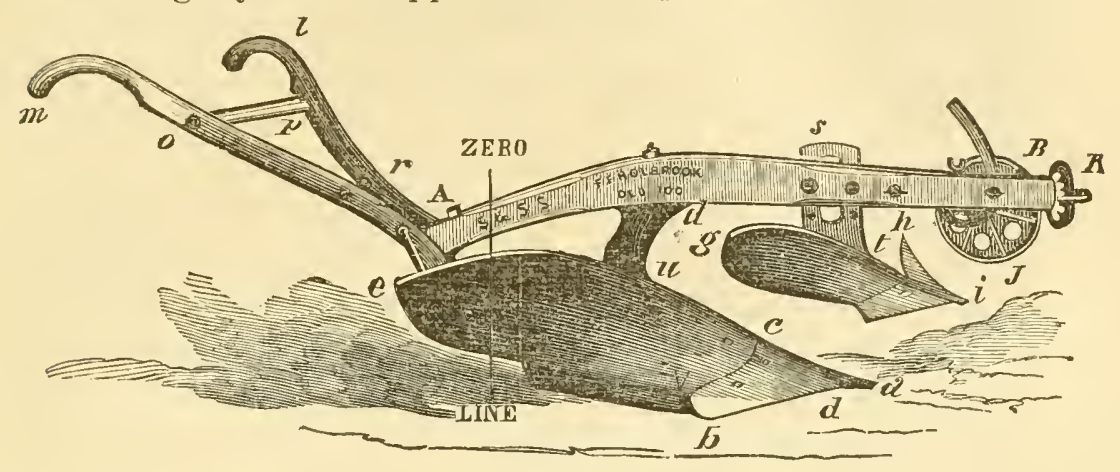

Fig. 102.

Fig. 102 represents Mr. Holbrook's Sod and Subsoil Plow. A B is the beam; $g i$ the skim plow; $s t$ its standard; $l l i$ its fin coulter; $j$ the wheel; $k$ the bridle; $a$ the point of the plow; $a c b$ the share; $b a^{\prime}$ the feather; $b$ the rear angle of the feather; $a^{\prime}$ the front angle of the feather; $e u c v$ the mould-board; $f v$ the sole of the mould-board. The portion of the mould-board in contact with the furrow slice, at the instant that it assumes the vertical position, is called the zero line, and is marked on the figure. The portion of the mould-board in the rear of this zero line is called the wing of the mould-board; $d u$ is the standard; $u c a$ the line where the portion of the mould-board in frout of the standard, which coincides with the land side, is called the shin. The curved portion of the plow, included in $u v$ a, is the breast. The furrow side of the share is denominated the shield. The side of the figure towards the eye is the furrow side, and the opposite one is called the land side; $m$ and $l$ are the stilts or handles; $o p$ and $q r$ are the handle braces.

ON THE VARIOUS MEANS OF HOOKING TEAMS TO THE PLOW.

This is done by swing or swingle trees and bars, as they are called by some, or whiftle trees and eveners, as they are called by others. The length of the evener is generally three and a half feet; the length of the whiflle tree, between the hooks of the traces, is three feet, but these lengths are often considerably raised in order to meet special conditions. 
The stran upon a whifle tree when used in plowing is analogons to that of a beam supported at both its ends and sustaining a loan in the middle. The rule for estimating their strength is therefore the same in each case; aud we know that the strength of heams is proportional to their breadths multiplied into the square of their depths and divided by their lengths. It is to be understood that the depth here expressed is that dimension of the whiffle tree which lies in the direction of the strain. It is used to express what the fiumer would eall the lreallh of the whithle tree. Suppose a whithle tree three feet long between the trace hooks; its depth three inches, and its hreanth one and a half inches, according to the rule given ahove, we lave $\frac{1.5 \times 3^{2}}{3}=4.5$, which, multiplied by the constant 11 mber 660 for oak, and 740 for ash, gives, in the one case, 2,970 pounds, and in the other 3,330 pounds, as the force that would break the whifile tree. The sime rule is applicable to the evener. 'The strength, thus found, is applicable only to the centre of the whithle trees and evener, for it is obvions that the strain at the extremities is only half that at the centre. The ends may, therefore, be mueh less in depth than the centre, with perfect safety.

Wooden whifile trees ought always to be fitted with clasp and eye mounting of the best wrought iron, from two to two and a half inches broad, alont three-sixteenths of an inch thick in the middle parts, and worked ofl to a thin edge at the sides. The part forming the eye may range fiom one-half inch diameter in the centre eye of the large tree to three-eighths inch in the end clasps of the small trees; and they are applied to the wood in a hot state, which, by cooling, embraces the wood very firmly.

On the evener, the middle clasp has usually a ring or link welded into it, by which it is attached to the hook of the plow bridle. The two end elasps have their eyes on the opposite edge of the whiffle trees, with sufficient opening in the eyes to receive the $(S)$ hooks of the whiftle trees and evener.

The mode of attaching two horses to a plow is so well understood by farmer's that it is unnecessary to occupy any space in describing it.

Figg. 103 gives Mr. Stephens' mode of yoking three horses to the plow, which works very well in practice. In this figure, $a$ is bridle of the plow; $b$ the evener, five feet in length and of strength proportioned to the draught of three horses; a d and $e$ are the three whittle trees. The traces, though broken off in the 
figure at $f g$, are to be understood as extending forward to the shoulder's of the hor'ses. Between the evener and the whithe trees the compensating apparatus is placed, as seen in the figure, consisting of three lever's, usuilly constructed of iron. Two of these, $h i$ and $h i$, are levers of the first order, but with unequal arms; the fulcrum, $k$, being fixed at one-third of the entire length

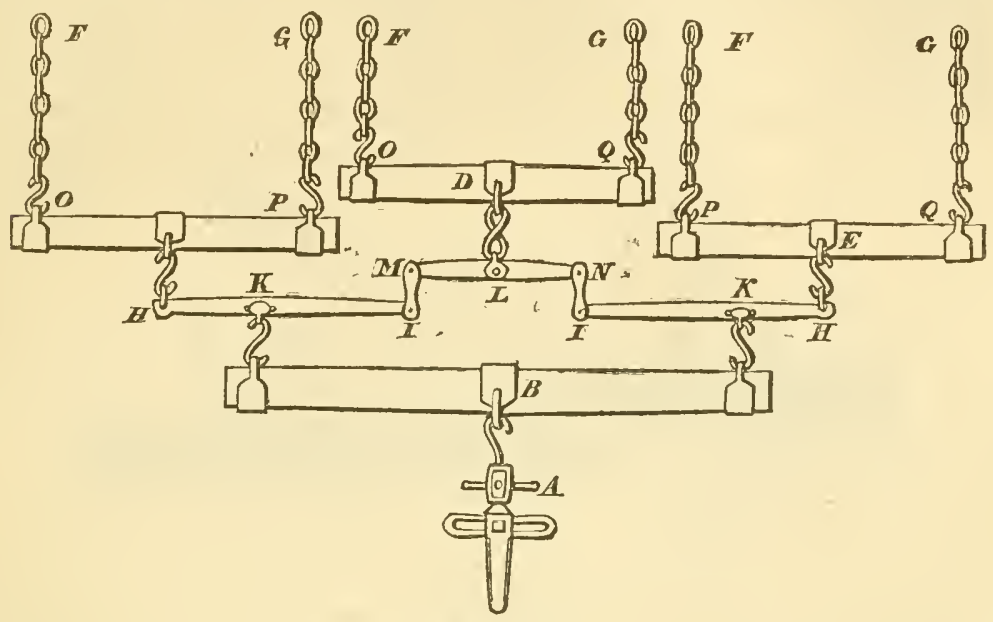

Fig. 103.

from the outward end of each. The arms of these levers are, therefore, in the proportion of two to one, and the entire length of each between the points of attachment is twenty-seven inches. A comecting lever, $l$, of equal arms, and twenty inches in length, is jointed to the longer arms, $i i$, of the former, by means of the double short links, $m n$. The two levers, $h i, h i$, are hooked by means of their shackles at $k$ to the evener, $b$. From the mechanical arrangement of these levers, if the whole resistance at $a$ be taken at 600 pounds, $k$ and $k$ will each require an exertion of 300 pounds to overcome the resistance. But these two forces fall to be subdivided in the proportion of the arms of the levers $h i$; two-thirds of each, or 200 pounds, being allotted to the arms, $h$, and the remaining one-third, 100 pounds, to the arms, $i$, which hrings the system to an equilibrium. The two forces, $i \quad i$, being conjoined by means of the connecting lever's $m n$, their union produces a force of 200 pounds, thus equalizing the three ultimate forces, $l l l l$, to 200 pounds each, and these three combined are equal to the whole resistance, $a$; and the three horses that are yoked to the whiffle trees, $c d e$, are subjected to equal exertion, 
whatever may be the amount of resistance at $a$, which has to be overcome.

The method of attaching three horses to the plow, most usual in the State of New York, is shown in Fig. 104. In this ease the length of the whiffle trees is twenty-four inches; the secondary evener is thirty inches, and the principal evener is forty-five inches; in each case measuring between the draft-hooks. This brings the horses very near together, but they cannot much exceed this length if one of the horses walks in the furrow. In

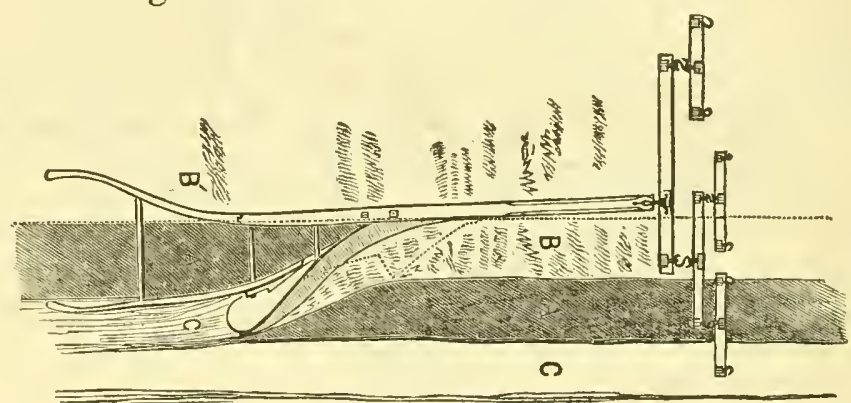

Fig. 104.

case the two horses are on the right hand and the one horse on the left, the clasp-ring or hook which is attached to the plow must be placed exactly at one-third of the distance between the two hooks at each end of the principal evener, that is, fifteen inches from the right hook; if the two horses are placed at the left hand, then the distance must be reversed. In this case, as before, each horse will pull exactly one-third of the load, for, as the left-hand lever is just twice as long as the right-hand lever, this last will take just twice as much power to draw it. If the total draught of the plow is 600 pounds, the left horse will pull one-third of it (200 pounds) and the two right-hand horses will pull 400 pounds; the secondary evener being a lever having equal arms, the load on each horse will be just half that amount-200 pounds. If the nigh horse is heavier and stronger than the other two, it will be still more convenient, as the long side of the evener may then be somewhat shortened so as to enable the horse to walk more easily in the furrow.

When it is desired to attach four horses to the plow, it is usually done by placing them two-ind-two, one pair before the other, the evener of the forward pair being connected with the evener of the hinder pair by a long-chain called a soam-chaiu. The horses next to the plow are comected hy a nock-yoke, through 
the ring of which the neck-yoke runs. It is an objection to this method, that both teams are not obliged to do their fair equal share of the work.

The plan recommended by Mr. Stephens obviates this difficulty, and compels each horse to take his proper proportion of the load.

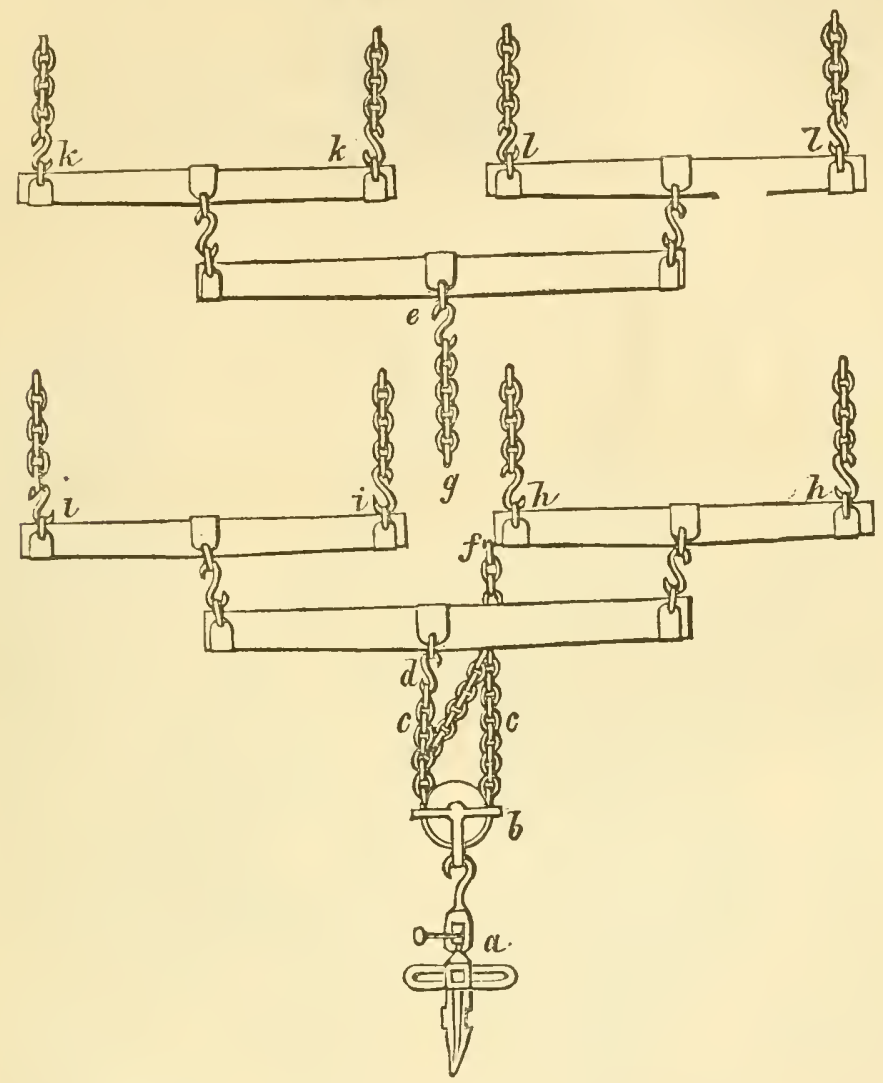

Fig. 105.

It is represented in Fig. 105, where $a$ is the bridle of the plow, with its swivel hook. A pully, $b$, of cast iron, six inches in diameter, mounted in an iron frame, of which an edge view is given in $m$, is attached to the hook of the bridle. A link-chain, $c$, is rove through the frame of the pulley, and to one end of it the short end is hooked; the evener, $d$, is hooked to a set of whiffle trees for the plow horses. The other end of the chain passes forward to a sufficient distance to allow the leading horses room to work, and to it is hooked the second evener at $e$, for the leader's. In the figure, a part of the chain, from $f$ to $q$, is broken off; but the full length is about eleven feet. In this arrangement the 
trace-chains of the nigh-side hind horse are hooked to the whiffle trees at $h h$, and those of the off-side horse at $i i$; the learler's being at $k$ and $l l$ respectively. In this arrangement the balance of the forces is perfectly preserved; for the hind horses and the leaders, as they pull at opposing ends of the chain passing round a pulley, which must inevitably be always in equilibrium, each pair of horses has an equal share of the dranght; and, from the principles of the evener and whifle trees, through which each pair acts, the individual horses must have an equally perfect division of the labor, unless this equilibrium has been removed for the purpose of easing a weaker horse. In order to prevent either the hind horses or the leaders from slipping too much ahead, it is common to apply a light check-chain, $o$, of about fifteen inches long, connecting the two parts of the main chains, so as to allow only a short oscillation round the pulley, which is limited by the check chain. When this is adopted, care should be taken never to allow the check-chain to remain upon the stretch; for if it does so, the advantage of equalization is lost, and it becomes no better than a simple soam-chain. In all case's of using a chain, that part of it which passes forward between the hind horses must be borne up by means of a neck-yoke or other attachments to their back-bands or collars.

\section{ADJUSTMENTS FOR PLOWING UNDER WEEDS AND STUBBLE.}

Those who have plowed land infested with long weeds, bushes and tall corn stubble, well know how difficult it is to make good work and bring the surface growth beneath the plowed ground. Fig. 106 shows a ready and effective means of accomplishing this object. This plan consists of a log-chain, or large tarred rope, having one end attached to the outer end of the whiflle tree of the off-side horse, and the other end hitched round the beam of the plow, near the standird, as represented by the Fig. 106. The chain should always be only long enough to draw the tops of whatever is being plowed in along in the furrow, just in time io allow the furrow slice, when turning, to fall on it. If the chaiu is a few inches too long, the furrow slice will fall upon it, and be broken and displaced as the chain draws out. Take a "rolling hitch" around the beam of the plow, and then adjust the length of the chain until the bight of it will remain on the turning furrow slice, only two or three inches forward of the point where it comes to rest. This will draw the tops of weeds, grass, Canada 

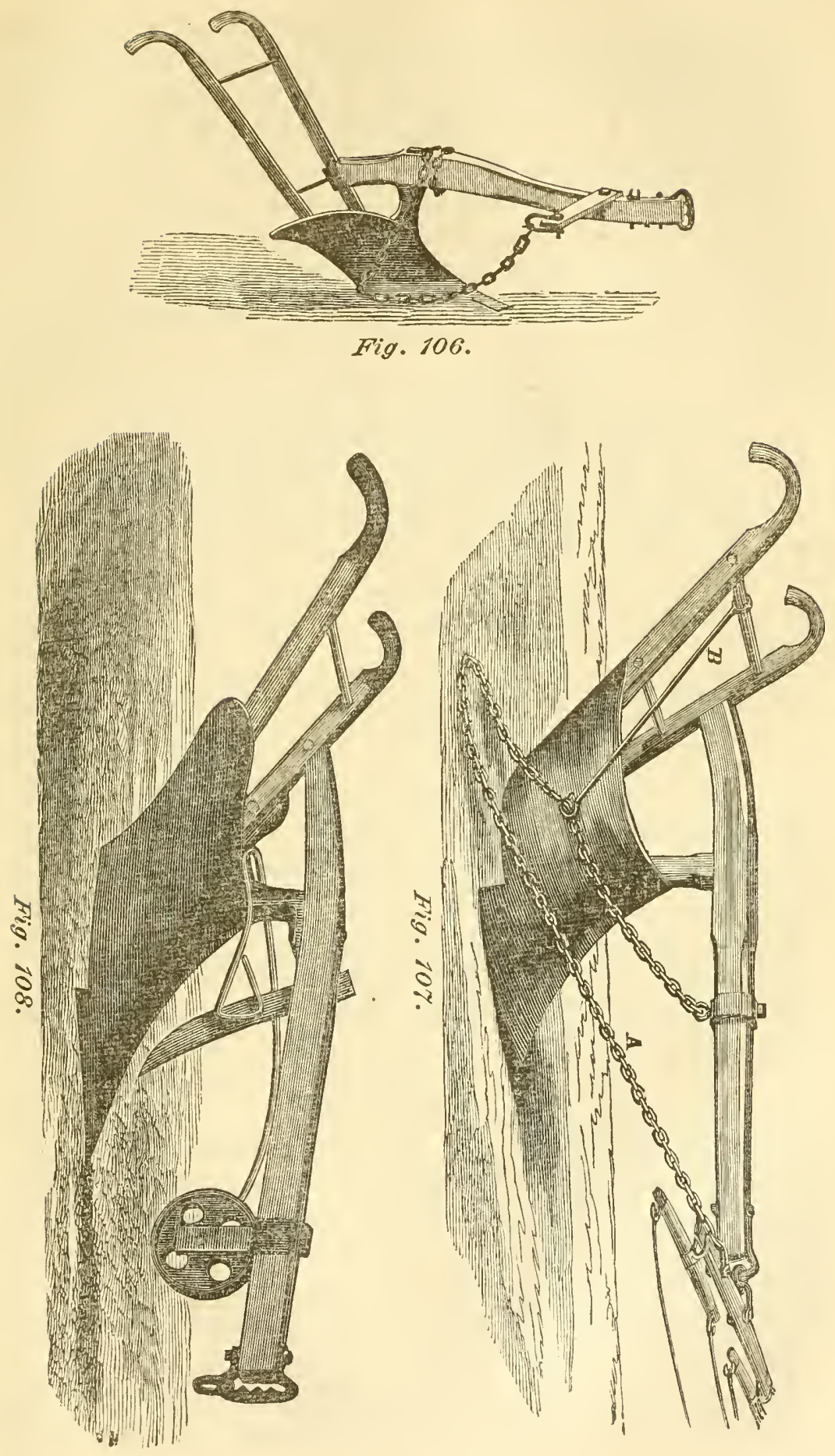
thistles, and corn-stalks, completely beneath the falling eartin; whereas, without such a contrivance, the tops would extend above ground, and if not already matured, would continue to grow, sometimes quite as well as if they had not been plowed in. Sometimes weeds and corn-stalks are first mowed close to the ground, and hauled into the furrows, as the plowing is in progress. But, in this practice, the green material is not distributed as evenly as it is when plowed in without being mowed. A piece of halfinch round iron, bent in the form of a letter $U$ is used instead of a chain for drawing under red elover or other crops. But, as a chain is more flexible than an iron bow, it has been found more convenient. When the plow is drawn by oxen, the chain is attached to a stick about twenty inches long, bolted to the upper side of the beam, as shown by the preceding engraving. If hitched to the forward end of the plow beam, the chain will not always run far enough to the right side of the furrow to draw in the tops of all the stalks. However, if the chain is adjusted correctly as to length, the work can be performed quite satisfuctorily.

Plowmen experience some diffieulty in keeping the bight of the chain back in its proper place on the turning furrow slice. For this reason they are not able to draw everything under the slices, as is desirable. To obviate this difficulty, J. \& A. Kilmer have invented the arrangement shown in Fig. 107. The attachment in question is merely a chain, A, conmected to the plow beam and the doubie whiffle tree, and provided with a rod, B, which is called a "regulator" by the inventor. This regulator" makes a bight or loop in the chain, so that the matter desired to plow under is caught by it and diverted toward the furrow, into which it is thrown and covered.

\section{DEVICES FOR CLEARING THE COULTER.}

In using the ordinary plow, especially on stubble fields, or in heavy grass land, the angle between the conlter and beam firequently becomes choked to such an extent as to raise the share from its proper depth, and necessitate stopping the team and removing the obstacle by hand. In the accompanying engraving there is represented a very simple contrivance designed to remedy this difficulty. (See Fig. 108.)

In the guide wheel is placed a stud or pin which forms a crank, and to this pin is pivoted the end of a rod of iron, which is earried 
along under the beam and around the lug of the share to the coulter, as seen in the engraving. As the guide wheel rotates a reciprocating with a vertical motion is given to this vibrating rod, so that as the rod advances to the front of the coulter edge it pushes the stubble from the blade and throws it down into the furrow.

\section{LEFT IIAND PLOWS.}

In some parts of the country left hand plows are very much in vogue. The team is generally driven with a single line. In Fig. 109 we give an illustration of the mode of driving.

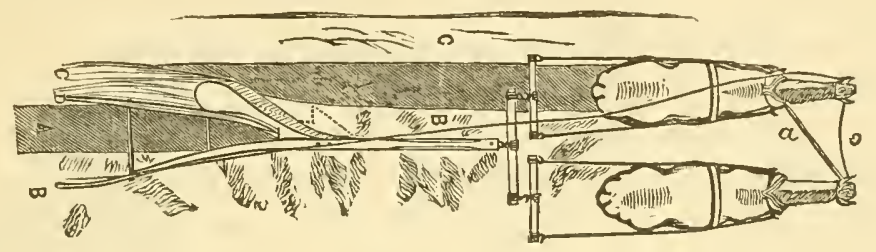

Fig. 109.

In this case the nigh horse walks in the furrow, and the single line is attached to his bridle. The off horse is guided by a "jockey stick," $a$, from the hames ring of the nigh horse, and by strap $c$ between their heads.

\section{PLOWING GROUNDS WITHOUT DEAD FURROWS.}

It is sometimes very desirable to do this; we therefore give the annexed method of accomplishing it, taken from the "American Agriculturalist."

\section{PLOWING GROUND WITHOUT DEAD FURROWS.}

Dead furrows are a nuisance, especially where hoed crops are cultivated; and when land is stocked down for meadows, deep dead furrows make an uneven surface for the mowers and horserakes to work over. When a field is plowed in lands beginning on the outside, turning all the furrows outward, and finishing the plowing in the middle of the field, there will be a dead furrow from every corner to the middle dead furrow of each land, and a strip of ground eight or ten feet wide on

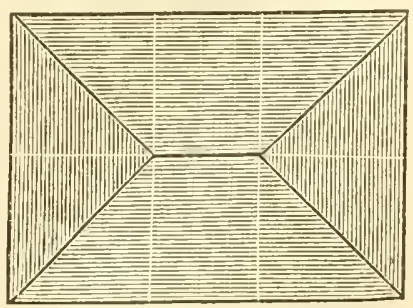

Fig. 1. one side of every dead furrow will be trodden down firmly by the teams when furning around. Plowing a field without dead fur- 


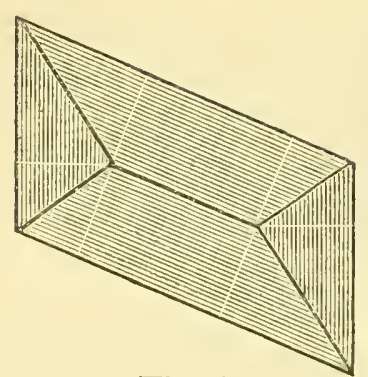

Fig. 2.

rows is simply commeneing at the midale and turning the furrow slices all inward. If the plowing be done with a riglit hand plow the teams will "gee around," always tmining on the mplowed gromd. When a field is plowed in this mamner there are no ridges or dead furrows, and the surfice is even, so that the operation of any machine is never hindered. When sod ground is plowed in lands there is always a strip of ground beneath the first two furrow slices at every ridge that is not broken up. This is to a great extent avoided when the whole field is plowed as one land, and may be entirely avoided if back-furrowed. The accompanying diagrams will show how to plow a square field, or one of irregular boundary, commeneing in the middle and finishing at the outsides. Fig. 1

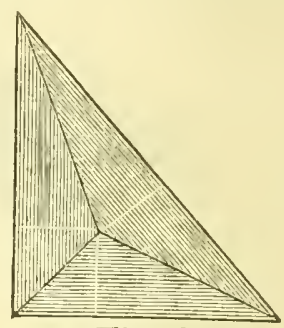

Fig. 3. shows a rectangular field. The plowman finds a point equally distant from three sides, measuring of conrse at right angles to the sides, and sets a stake. Then he finds the point equally dis.

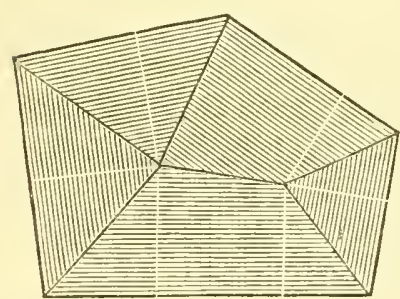

Fig. 4 . tant from the three sides at the of her end, and sets another stake. From these two stakes to the eorners of the field he turus two furrow slices together, and then plows the field, heing guided by them, and oceasionally measming to the ontside to see if he is keeping his furrows of equal width at setting in and muning out, and on each side. In Fig. 2, a four sided lot, where the angles are not right angles, precisely the same rule is followed. In the case of the triangular field, the plowman begins hy plowing about a single point, which, though awkward at first, may be execnted with ease after a few trials. In the ease of the irregular five sided lot, represented by Fig. 4, it is a littie more difficult to start exactly right, but the ruling gives a cleall idea of how the furrows run, and it is always well to pace ofi frequently to the outside of the lot-or rather from the funce starting at right angles to it--to be sure that the portion remaining unplowed on each side, and at each end of each side, reminims always of a corresponding with as the plowing progresses. 


\section{CHAPTER X.}

\section{REPOR'T OF THE JUDGES}

APPOLNTED BY TIIE STATE AGRICULTURAL SOCIETY OF NEW YORK TO EXAMLNE PLOWS, CULTIYATORS AND HARROWS.

IISTORY OF THE TRIAL.

The Society has for several years had it in contemplation to make a thorough trial of the various agricultural implements used for preparing the land for the growtl of crops; for putting in the seed; for the distribution of manures, and for severing the crops from the soil, as well as preparing them for market.

Nuch delay oceurred in prosecuting this design from its inability to procure instruments of sufficient accuracy for determining the actual results obtained in a satisfictory manner. Thesedifficulties were finally overcome, and instruments were invented and manufactured for the purpose, mainly by Mr. Henry Waterman, of Hudson, the Consulting Engineer of the Society.

It was at first proposed to make a trial of all the implements in a single year, but it was soon found that this would involve so large an amount of habor, and occupy so much time, that it would be impossible to procure a board of judges who could spare the time from their own private pursuits to do justice to the work assigned to them.

It was, therefore, resolved to hold a trial of the implements for severing the crops from the ground and for preparing them for market in the year 1866, at Auburn, and the trial of plows, harrows and cultivators was fixed for the month of May, 1867.

Extensive correspondence was had with the leading manufacturers of these implements, after which the executive committee prepared a programme, which is given below, and appointed the following gentlemen to act as judges at the trial, viz:

John Stanton Goulo, of Hudson, N. Y., Chairman; Prof. Benjamin Pierick, Cambridge, Milss.; Hon. Elisha R. Potter, Kingston, R. I.; Sanford Howald, Lansing, Michigan; Henry Watermax, Hudson, N. Y.; Prerer Crispeld, Jr., Kingston, N. Y.; George Geddes, Syracuse, N. Y.; Abrainan B. Conger, Waldberg, Rockland county, N. Y.; Joseru McGraw, Jr., Dryden, N. Y.; B. P. Jolnson, Alhany, N. Y. 


\section{NEW YORK STATE AGRICULTURAL SOCIETY.}

\section{Second National Trial of Plows and Other Implements. 1867} PROGRAMME FOR PLOWS.

The New York State Agricultural Society respectfully invite the makers of plows in any State of the Union, in Canada, and in Europe, to compete in the following enumeration of classes for the prizes annexed to each class:

A gold medal is offered by the New York State Agricultural Society for the best plow in each of the following classes:

Cuass I.-A sod plow for stiff soils.

Class II.-A plow for stubble land in stiff soils.

CLass III.-A sod plow for sandy soils and light loams.

CLass IV.-A plow for stubble land, which will cut a furrow twelve inches deep, with three horses, which will raise the lowest soil to the surface of the furrow. For a plow which will turn a furrow of this kind not less than five inches wide, the Society offers as a prize its large gold medal.

Class V.-A Michigan sod and trench plow.

Class VI.-A subsoil plow in connection with an ordinary plow.

Class VII.-A ditching plow for opening drains.

Class VIII.-A machine for excarating ditches for under-draining.

CLASS IX.-A steel plow for alluvial and unctuous lands.

Class X.-A swing or side-hill plow.

\section{ENTRIES.}

$\$ 1$. Competitors must enter their plows at the Secretary's office, Albany, at least two weeks before the time fixed for the commencement of the trial. This rule will be rigidly enforced, as it will otherwise be impossible to provide lots for the trial.

$\S 2$. At the time of making the entry each competitor will be required to file a statement showing, first, the price of the plow; second, its weight; third, the rule or the formation of the mould-board; fourth, a statement of the valuable points claimed by the exhibitor.

$\S 3$.

$\S 4$. Each plow will be numbered in the order of its entry. A card showing legibly this number and the number of its class must be affixed to each plow. If it is lost or the numbers be obliterated, new cards will be furnished by the Secretary. No judge will make any record respecting any plow unless this card is upon it. Without a strict adherence to this rule it will be impossible for the judges to keep their notes correctly.

$\$ 5$. Every plow entered will be charged with a fee of twenty dollars.

$\S 6$. As soon as the time for making the entries has expired, the Secretary will cause them to be printed. A complete list of the entries, with the numbers and the statements required to be made, will be placed in the hands of each of the judges.

\section{DUties of OfFicers.}

The Officers of the Society will,

$\S 1$. Stake off a sufficient number of plots, each containing a quarter of an acre. A space two feet wide will be left between each plot.

$\S 2$. The stakes will be $2 \frac{1}{2}$ feet long by $2 \frac{x}{2}$ inches wide. The plots will be numbered from No. 1 upward. 'There will be four stakes to each lot, each of the four 
will bear the same number. The number of all the stakes will face inward toward the lot which they designate. The stakes will be rounded at one end and sharpened at the other.

$\S 3$. Eight poles will be provided, each eight feet long, they will be painted white downward two feet below the top, a black ring six inches wide will be painted in the middle of the whole field. Two swivel hooks.

Two hooks with their ends bent on opposite sides of the shank. Four ganges to show the breadth of the furrow. One for ascertaining its deptl. One dynamometer. Onc platform scale of sufficient size for weighing plows. One tape line 200 feet long. Onc tape line eight feet long for each member of the descriptive committee. A two-foot carpenter's square. A bevel rule. A spirit level, and a blank book and pencil for each judge.

§. They will procure a sufficient number of active and faithful policemen to keep all intruders from the plow ground, and to preserve order at the trial. A tent sufficiently large to shelter all the judges. A team for the special dynamometer trials, and a lumber wagon.

\section{Duties of Competitors.}

$\S 1$. Each competitor will furnish his own team and plowman. In the special dynamometer trials the team to be furnished by the Society.

$\S 2$. They will provide themselves with wrenches and other tools for taking the plows apart when necessary.

$\S 3$. The plots will be plowed in the order of their numbers. All competitors not ready for work when called on may be ruled out by the judges.

\section{Duties of Judges.}

$\S 1$. The chairman of the Board of Judges will, on the first day of the trial, distribute the plots of ground by lot among the competitors.

$\S 2$. The judges will commence operations each morning at eight o'clock, lunch at half past $t$ welve o'clock, and finish at half past five $o^{\prime}$ clock. They are particularly requested to look over their minutes every evening, and if their notes are imperfect to remedy the deficiency as early as possible.

$\S 3$. Before entering upon his duties, each judge shall subscribe a written declaration that he is not directly or indirectly interested in the sale of any plow.

$\S 4$. The following will be examined as the most important points of the plow:

1. Pulverizing power.

2. Non-liability to choke in stubble.

3. Lightness of draught, considered in connection with pulverizing power.

4. Ease of holding.

5. Durability.

6. Cheapness.

7. Excellence of mechanical work.

8. Excellence of material.

9. Thorough inversion and burial of weeds.

10. Even distribution of wear.

11. Regularity or trueness of turning and carrying the furrow slice on sod.

$\S 5$. Lightness of draught alone, except in sandy lands, will not be esteemed a great merit. The plow which pulverizes the soil most, with the least draft, will have the preference.

$\S 6$. The Society desire to encourage an increased depth of plowing in the State. Those plows, therefore, that are able to turn a furrow in a satisfactory manner, 
so that the depth shall bear the greatest proportion to the width, will have the preference. The furrow will be laid as nearly as possible at an angle of forty-five degrees.

$\S 7$. The judges will be subdivided into committees, as follows.

(a) A Dynamometer Committee.

(b) A Description Committec.

(c) A Weight and Price Committee.

(d) A Time Committee.

(e) $\Lambda$ Committee on Quality, Material and Mechanical Structure.

Each judge will form an opinion upon each point of the work of the plows and record it in his note book.

$\S 8$. The point of each plow will be detached before it begins to work and accnrately weighed by the Weight and Price Committee. It will be weighed again as soon as its work is finished. It will be decmed a point of great merit in the plow that shows the least abrasion.

$\S 9$. Not more than four plows shall be at work at any one time, and one judge shall be assigned by the chairman to each plow. It shall be the duty of the judge so assigned to observe the action and work of the plow during the whole time that it is in operation. He will note the exact time occupied in plowing. If there are any stoppages he will note the exact time of the stoppage, and state exactly the cause of it. He will measure and record the length and breadth o each urrow slice three times on each furrow, the arerage of these to be taken as its true size.

$\S 10$. The dynamometer will be applied on two furrows, viz., going and returning on each lot. The length and depth of the furrow slice shall be measured six times on each furrow, when the dynamometer is applierl. The judge in charge will also observe whether the sole of the plow is kept in a horizontal position; if it departs from this at any time it is to be noted; the instrument $\mathrm{No} .2$ will enable him to measure the amount of departure.

$\S 11$. In addition to the dynamometer trials on the respective lots, additional trials shall be made under the direction of the judges in some level field. Each plow shall plow one furrow without, and the next with the dymamometer attached, and so on until all have been tried. If desired, the judges may then try the draught by a windlass and hand power.

$\$ 12$. After all of the plowing is finished, the judges will carefully and critically examine each lot. They will designate the different qualities of plowing by the numbers one up to ten. Ten indicates the best plowing, one the worst, and the other numbers the intervening degrees of merit. As the examination proceels each judge will place in the book opposite to the number of the lot the number which, in his judgment, indicates the excellence of the plowing. The judges will then assemble privately, when the chairman will inquire of each judge successively what number indicating excellence he has affixed to No. 1. The chairman will record such numbers opposite to No. 1. He will then ask for the marks of each judge for lot No. 2, and so on until the merit marks of all the judges are ascertained and recorded. The plow used on the lot to which a majority of the judges assign the highest marks of merit shall have the preference for "excellence of work."

$\S 13$. The records of the dynamometer trials shall then be examined by the judges, and if they find that there is any very striking discrepancy between the clifferent kinds of trial above mentioned they may cause the plows in which such discrepancy exists to be tried over until they are fully satisfied with respect to 
the draft of each. They will then determine the best plow for lightness of dranght, which determination shall be recorded by the chairman.

$\$ 14$. The plows shall then be examined with regard to wear, those being deemed best where the wear is most evenly distributed. The plows having the greatest number of votes shall be decmed the best in point of durability.

$\$ 15$. The plows shall then le minutely examined with reference to the material of which they are composed (the quality of the wood and iron), and the best in this respect shall be recorded as "made of the best material."

The plow having the greatest number of suffrages sha!l be deemed the best for mechanical construction."

$\$ 16$. Exhibitors will be reqnired to present an ingot, cast in an iron mould, of the iron used in making the plow, at least one and a half inches thick. There must be an affidarit stating the furnace from which they obtain their pig-iron, and if more than one kind is used, the proportions of each kind used, and that the ingot is a fair sample of iron used in the plows.

$\S 17$. The judges will closely observe the furrow slice in the act of being turned and see if that action tends to open or compress it; they will also observe the force required to press the end of a stick into the furrow. If practicable the jul res will not determine on the question of pulverization until they have had an opportunity of seeing the time that elapses before each lot dries after a fall of rain, and the growth of crops on each.

$\S 18$. The plow which is finally determined to have the greatest number of good points shall be awarded the first prize as the best plow.

$\S 19$. The judges shall in no case consult with each other or express opinions in presence of competitors.

$\$ 20$. No person except judges and officers shall be permitted by the police to enter upon the plowed grounds.

$\S 21$. The judges will cause comparative experiments to be made to ascertain the influence of the coulter on draught; they will investigate experimentally the best angle for its insertion, and also the most advantageous depth for it.

5 22. They will inquire into the effect of the wheel on draught.

$\$ 23$. They will ascertain the influence of speed upon the draught of the plow.

$\S 24$. They will ascertain the effect of long and short beams.

$\S 25$. They will investigate the influence of weight on plows.

$\S 26$. They will ascertain the rate which the several parts of the plow consume power, as compared with the total draft, $i$. $e$. what proportion of the power is consumed in turning the furrow over? What proportion for overcoming the cohesion of the earth on the land side? On the bottom? How much of friction?

\section{Miscellaneous Regulations.}

$\S 1$. The plows for competition must be exactly as they are sold to the farmers, except that each competitor will be allowed to scour the working parts.

$\$ 2$. Provision will be made by the Society for conveying the judges to and from the trial grounds. Lunch will also be provided for them.

§ 3. Notice will be given of the time and place of holding the trial as soon as it is determined on.

\section{PROGRAMME FOR HARROWS.}

$\S 1$. Thero will be but one class of these machines. A premium of a medal is offered for the best harrow.

§ 2. The generai rules for the trial of plows will be followed in the trial of harrows, as far as they are applicable. 
§3. Harrows will be tried next in order after the trial of plows.

$\S 4$. The points to be determined respecting them are as follows:

1. Which combines strength with lightness in the highest degree?

2. Which combines the best materials with the best workmanship?

3. Which combines the greatest pulverizing power with the least draft?

4. Which is managed in the field with the greatest facility?

5. Which is least liable to clog in working?

6. Which works the most rapidly?

Persons desiring to enter articles for exhibition only will be permitted to do so on payment of five dollars.

\section{PROGRAMME FOR CULTIVATORS.}

The Society offer the following premiums for cultivators :

Class I.

For corn and root crops, best one-horse cultivator to cultivate one row, a gold medal.

For best two-horse cultivator for cultivating two rows, a gold medal.

\section{Class II.}

For mellowing soil and killing weeds, best cultivator on wheels, with device for raising and lowering the frame that holds the teeth, so as to regulate the depth of cultivation and to make the machine portable, a gold medal.

Best cultivator having handles to guide it, and with or without small wheels to regulate the depth of the cultivator, a gold medal.

The judges will carefully observe and express their opinion on each of the following points :

1. Thoroughness and depth of pulverization. It is desirable the instrument should work deep or shallow, as may be desired by the operator.

2. Adaptation to a variety of soil, such as sandy, stony, clayey, etc.

3. Facility of control by the driver; this includes steerage, turning corners, raising or lowering one or the other of the parts at the pleasure of the driver.

4. Comfort and convenience of the driver; this also includes his ability to see the rows distiuctly.

5. Portability and convenience for storage.

6. Ability to resist clogging, not only by grass, roots, and other ligneous matters, but in damp soils .

7. Adaptation to side hills and uneven surfaces.

8. Adaptation to the greatest variety of purposes.

9. Durability.

10. Cheapness.

The instrument having the greatest number of merits and the fewest defects will be entitled to the prize. If, however, an instrument has many advantages, if it has one defect of great magnitude, it must be rejected.

The same implement may compete in both classes if desired, but it will pay a separate entry fee for each class.

The trial of cultivators will follow immediately after the trial of harrows.

Place of Trial-Near Utica, N. Y.

Time of Beginning-Tuesday, May 7th, 1867.

The judges will meet at Baggs' Hotel on Saturday, May 4th. 
The President, Secretary, Consulting Engineer, and Chairman of the Bostrd of Judges, will assemble at Baggs' Hotel on 'Tuesday, April 30 th, and will make all needful arrangements for the preparation of the ground and the reception of implements.

State Agricultural Rooms, Albany, N. Y.

B. P. JOHNSON, Secrelary.

The judges and competitors were all assembled at Utica on the 7th of May, as appointed in the programme. The grounds were all staked on the farm of Mr. John Butterfield, who had generously offered it, with all needful facilities, to the Society; and every preparation was completed, but it had rained nearly every day for a week previous, the ground was thoroughly saturated with moisture, and it continued to rain for ten consecutive days after the 7 th, the day appointed for the commencement of the trial. The land was, in consequence, like a mortar-bed, and was utterly unfit for a trial which would be satisfactory either to the Society or the competitor's.

It was therefore resolved, after conference with all parties, and with their entire assent, to adjourn the trial until the 10th day of September, to be held at the same place.

At that time, the parties having reassembled, the trial was had in conformity with the programme. The following is the list of entries:

\section{PLOWS.}

Class I.

No. 16............ F. F. Holbrook........... Boston.

Class II.

No. $17 \ldots \ldots \ldots \ldots \ldots$........ Holbrook............ Boston.

No. 12.......... Collins \& Co............ New Tork.

Class III.

No. 1 ........... A. L. Brearley \& Co........ Trenton, N. J.

No. 18............ F. F. Holbrook........... Boston.

Class IV.

No. $19 \ldots \ldots \ldots \ldots \ldots$..... F. Holbrook........... Boston.

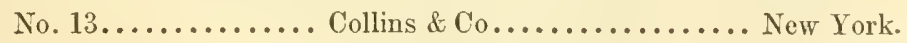

Class V.

No. $20 \ldots \ldots \ldots \ldots$..... F. F. Holbrook........... Boston.

Class VI.

No. 6 ........... R. J. Wheatley.......... Du Quoin.

Class VII.

No. 5............. P. Routt.............. Somerset, Va.

Class VIII.

No. $23 . \ldots \ldots \ldots \ldots$..... Heath............. Fowlerville, N. Y.

CLASS IX.

No. 14........... Collins \& Co............ New York. 


\section{CIJASS X.}

No. $21 \ldots \ldots \ldots \ldots$. F. F. Holbrook............ Boston.

No. $27 \ldots \ldots \ldots \ldots$........ D. Burch............ Sherburne, N. Y.

On an examination of the preceding list of entries, it will be observed that the plows entered by F. F. Holbrook are more numerous than those of any other contributor, and that in fact they are represented in nearly every class. These plows are all constructed on a plan invented by Governor F. Holbrook, of Vermont, and now a professor of Agriculture in Cornell University.

We were instructed in the most minute details of this plow by Gov. Holbrook, and the trials at Utica and subsequently at Brattleboro showed rery clearly the inflnence of the warped surfice which is generated by his method upon the texture of the soil.

Governor Holbrook is as yet umprotected by a patent on his method, and we are therefore most reluctantly compelled to withhold a description of it, but we have no hesitation in saying that it is the best system for generating the true curves of the mould-board that has been brought to om knowledge. This method is applicable to the most diversified forms of the plow, to long or short, to broad or narrow, to high or low, no matter what the form may be, this method will impress a family likeness upon them all; there will be straight lines in each running from the front to the rear, and from the sole to the upper parts of the share and mould-board. None of these lines will be parallel to each other, nor will either of them be radii from a common centre. The angle formed by any two of them will be unlike the angle formed by any other two; a change in the angle formed by any of the transverse lines will produee a eorresponding ehange in the vertical lines, and there will always, in every form of the plow, be a reciprocal relation between the transverse and vertical lines. Plows made upon this plan may appear to the eye to be as widely different as it is possible to make them, and yet, on the application of the straight-edge and protractor it will be found that they agree precisely in their fundamental character. The surface of the mould-board is always such that the different parts of the furrow slice will move over it with unequal velocities.

\section{Class I.--Sod Plows for Stiff Solls.}

The only entry in this class was by F. F. Holbrook of his Lilp Furrow Sod plow for stiff soils (No. 65). Weight, 130 pounds. Price, \$20.

The soil was of a stiff, clayey consistency, and running at six 
inches below the surfice into a mixture of blue clay and grarcl: it was in a very dry state, and had never been previously plowed to a greater depth than five inches. The sole of the plow during the entire trial run in soil which had never before been stirred with the plow. The furrow slice was ten inches by seven inches. The actual draught was 472 pounds; the draught as estimated for each cubic foot turned over, 972 pounds. It worked exceedingly well, pulverizing the ground thoroughly, holds very easily and keeps well in the ground, and has a remarkable power of seif-adaptation to the furrow slice.* We ascertained by trial that this plow may be made to do very good work in a furrow eight inches deep and twelve inches wide, or by changing the cutters it will make good flat furrow plowing.

Inasmuch as there was no competition in this class, we should have deemed it our duty to have withheld the gold medal if we had the slightest doulst that it was fully merited, but we have no doubt whatever upon that subject. The material which enters into its composition is of the very best quality. the workmanship is excellent, it is strong and durable, the draught is light, and it has every quality of a good plow in a very eminent degree. We therefore unanimously award a gold medal for this plow in this cliss. The annexed cut is a ve:y good representation of it. (Fig. 110.)

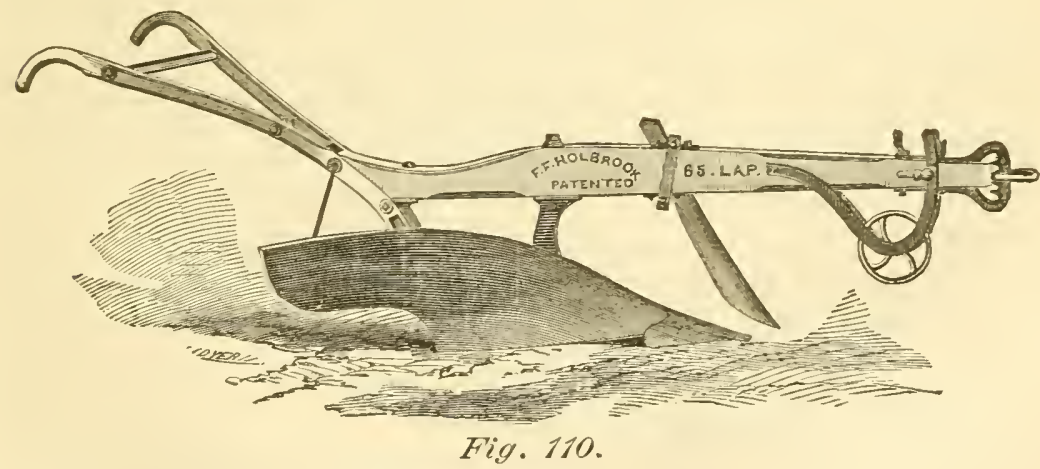

Class II.-For Stubrle Laxds in Stiff Solls.

The entries in this class were:

F. F. Holbrook's No. 66. Weight, 118 pounds. Pi ice, \$1?. size of furrow slice, ten inches wide, seven inches dcep.

* In view of the extrems tenacity of the ground this shows an exceedingly light draught. 
Collins \& Co.'s B 14. Weight, 98 pounds. Price, \$25. Size of furrow slice, thirteen inches wide, seven inches deep.

The lot of land on which the trial was had sloped downwards towards the north. It may be described as a stiff clay loam which is underlaid from four to five inches below the surface with a gravelly stratum, consisting of stones varying in size from it hen's egg to a cherry, impacted in a stiff clay. It had never been plowed deeper than five inches. The plows, therefore, had to work in two inches of soil which had never been stirred before. The land had been saturated with water in the early part of the season, and in the latter part it had been baked by the fieree summer sun until it was almost as hard as a brickbat. A luxuriant coat of vegetation had sprung np under these influences, consisting of smart-weed (Polygonum acre), mild water pepper ( $P$. hydropiperoides), mullein (I erbascum Thapsus), Indian tobaceo (Lobelia inflatu); several Aster's, chiefly $A$ corymbosus and $A$ cordifolius, heal-all (Brunella vulgaris), red-top (Agrostis vulgaris), quack (Triticum repens), Fescue grass (Festuca elatior), hairy panic grass (Panicum capillare)-this was very abundant--seouring rush (Equisitum arvense), fox-tail (Setariaglanca), three or four species of sedge, thistles (Cirsium Lanceolatum and Carvense), golden rod (Solidago Ohioensis?) yarrow (Achillea Millefolium), fled clover ('T'rifolium pratense), white clover (Trifolium repens), reabane (Erigeron Philadelphicun), daisy fleabane (Estrigosum), shepherd's purse (Capsella Bensa pastoris), dandelion (Taraxicum Densleonis), bhe vervein (I'ert,ena hastata), water hoarhound (Lycopus sinuatus), sunflower (Helianthus strumosus). Some of these plants grew together in patches, while other's were found seattered in all parts of the lot. Besides these plants there wats the stubble of the preceding year, which had been cut pretty high. Take it altogether it was one of the most diflicult fields to plow that could be well imagined. The plowing was executed in furrows rumning north and south; at abont one-third of the length of the furrow a line rumning east and west divided the lands into parts differing essentially in their physieal characters. The lower or northern end of the land was more unctuous and athesive, of a yellow color, and having fewer stones than the upper or southern portion. It appeared to the eye to be more easy to plow than the upper part, hut in every furrow the dynamometer showed a greater degree of resistance. 
The amexed Fig., 111, represents Mr. Holbrook's plow No. 66. The next ents, Figs. 112 and 113, represent views of the Collinsville plow in competition in this class, and the separate pieces which compose it.

The trials were made on lands one-quarter of an acre in extent. After a very careful examination and comparison, the judges decided upon the several points as follows:

First-Pulverizing power: One-half the judges were of opinion that Holbrook's plow pulverized the soil more effectually than the other. The other half were of opinion that the Collins plow had pulverized the land quite as well as the Holbrook plow. No decision was had upon this point.

Second--Non liability to choke in stubble: The judges were unanimously of opinion that Holbrook's was superior in this respect.

Third-Lightness of draught: The following is the record upon this point:

Holbrook's No. 66.

\begin{tabular}{|c|c|c|c|c|}
\hline \multirow{2}{*}{$\begin{array}{c}\text { Width of furrow, } 10 \text { inches. } \\
\text { Depth of furrow, } 7 \text { inches. }\end{array}$} & \multicolumn{2}{|c|}{ READING OF THE DYNAMOMETER. } \\
\cline { 2 - 5 } & DISTANCE IN YARDS. & $\begin{array}{r}\text { HALF POWER IN POUND } \\
\text { YARD8. }\end{array}$ \\
\cline { 2 - 5 } & Ist furrow. 2d furrow. & 1st furrow. 2d furrow. \\
\hline In hardest soil down hill...... & 88 & 94 & 16,000 & 17,600 \\
In hardest soil up hill........ & 81 & 102 & 14,700 & 18,300 \\
Iu loosest soil down hill...... & 78 & 78 & 12,400 & 11,450 \\
In loosest soil up hill.......... & 92 & 70 & 12,300 & 9,400 \\
\hline
\end{tabular}

Collins' Plow B 14.

\begin{tabular}{|c|c|c|c|c|}
\hline \multirow{3}{*}{$\begin{array}{l}\text { Depth of furrow same as the } \\
\text { preceding. } \\
\text { Width of furrow, } 13 \text { inches. }\end{array}$} & \multicolumn{4}{|c|}{ READING OF THE DYNAMOMETER. } \\
\hline & \multicolumn{2}{|c|}{ DISTANCE IN YARDS. } & \multicolumn{2}{|c|}{$\begin{array}{c}\text { HALF POWER IN POUND } \\
\text { YARDS. }\end{array}$} \\
\hline & 1st furrow. & $2 d$ furrow. & 1st furrow. & $2 d$ furrow. \\
\hline In hardest soil down hill... . . & 109 & 125 & 22,400 & 25,500 \\
\hline In hardest soil up hill........ & 119 & 119 & 23,000 & 24,500 \\
\hline In loosest soil down bill...... & 44 & 48 & 9,100 & 9,450 \\
\hline In loosest soil up hill.......... & 53 & 53 & 10,300 & 10,900 \\
\hline
\end{tabular}



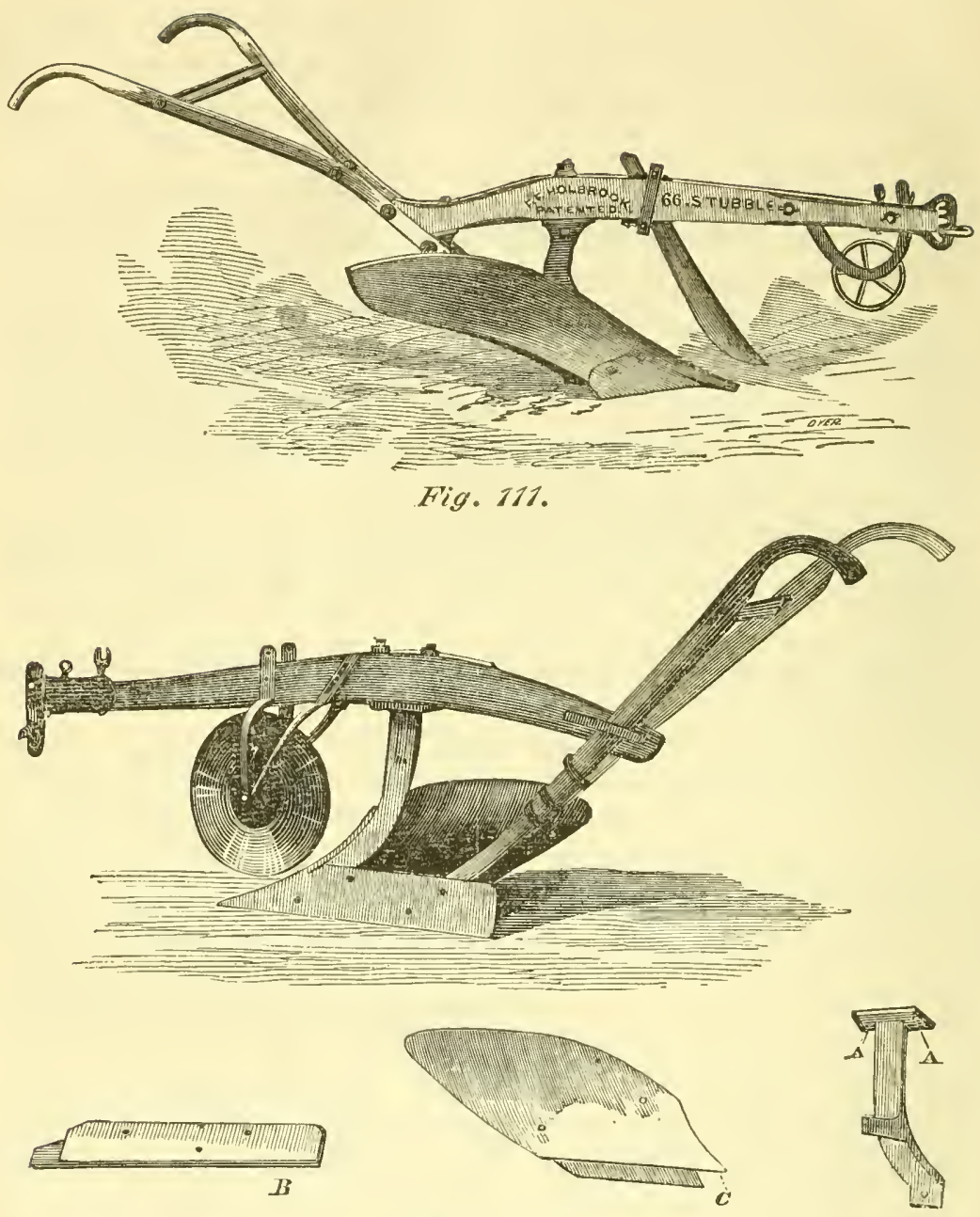

Fig. 172.

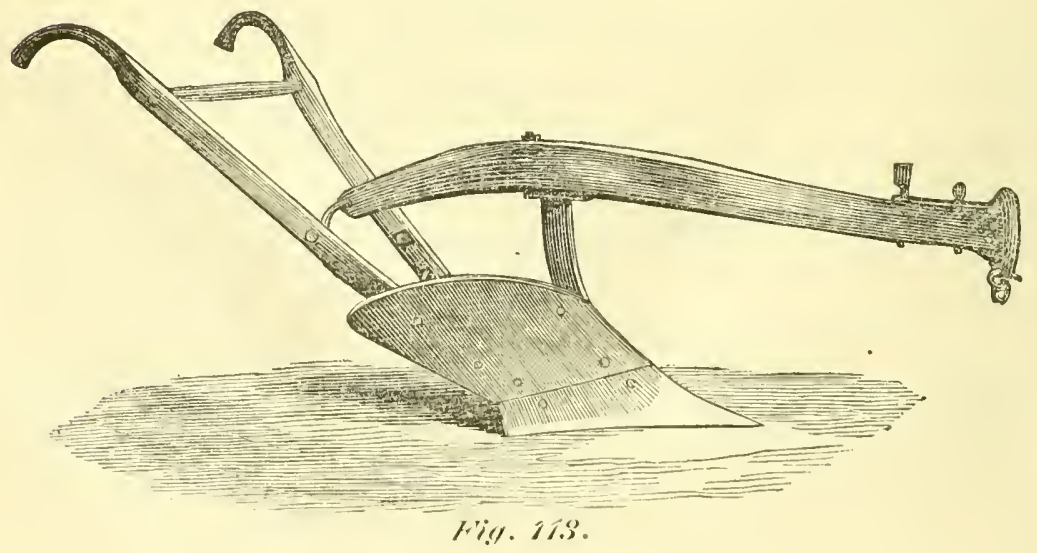


It will be understood that the "hardest soil" of the talle is the southern or upper end of the lot, while the "loosest soil" is the northern or lower end of the lot. The "hardest soil" is the gravelly portion, the "loosest soil" is the tenacious portion.

The following table is deduced from the preceding, and shows the average number of pounds required to draw the plow through each yard of the whole furrow:

\begin{tabular}{|c|c|c|c|c|c|c|}
\hline & \multicolumn{3}{|c|}{ HOLBROOK. } & \multicolumn{3}{|c|}{ COLLINS. } \\
\hline & \multicolumn{3}{|c|}{ FURROW 6 BY 10 INCHES. } & \multicolumn{3}{|c|}{ FURROW 7 BY 13 INCHES. } \\
\hline & $\begin{array}{c}\text { lst } \\
\text { furrow. }\end{array}$ & $\begin{array}{c}2 \mathrm{~d} \\
\text { furrow. }\end{array}$ & $\begin{array}{l}\text { Mean } \\
\text { of both. }\end{array}$ & $\begin{array}{c}1 \text { st } \\
\text { furrow. }\end{array}$ & $\begin{array}{l}2 d \\
\text { furrow. }\end{array}$ & $\begin{array}{l}\text { Mean } \\
\text { of both. }\end{array}$ \\
\hline In hardest soil down hill... & 364 & 375 & 369 & 411 & 409 & 410 \\
\hline In hardest soil up hill..... & 363 & 359 & 361 & 391 & 412 & 401 \\
\hline In loosest soil down hill... & 318 & 294 & 306 & 414 & 394 & 404 \\
\hline In loosest soil up hill...... & 289 & 269 & 279 & 389 & 411 & 400 \\
\hline $\begin{array}{l}\text { Average of work up and } \\
\text { down hill, in hard soil... }\end{array}$ & 363 & 367 & 365 & 401 & 410 & 405 \\
\hline $\begin{array}{l}\text { Average of work up and } \\
\text { down hill, in soft soil.... }\end{array}$ & 303 & 281 & 292 & 401 & 402 & 401 \\
\hline Average of all the trials.... & 333 & 324 & 328 & 401 & 406 & 403 \\
\hline
\end{tabular}

These numbers are reduced to the power required for each cubic foot of earth by dividing the actual area of a cross section in inches, and multiplying by 144 square inches, which gives the following table:

\begin{tabular}{|c|c|c|c|c|c|c|}
\hline & \multicolumn{3}{|c|}{ HOLBROOK. } & \multicolumn{3}{|c|}{ COLLINS. } \\
\hline & $\begin{array}{l}\text { 1st } \\
\text { furrow. }\end{array}$ & $\begin{array}{c}2 \mathrm{~d} \\
\text { furrow. }\end{array}$ & $\begin{array}{l}\text { Mean } \\
\text { of both. }\end{array}$ & $\begin{array}{c}1 \text { st } \\
\text { furrow. }\end{array}$ & $\begin{array}{c}2 \mathrm{~d} \\
\text { furrow }\end{array}$ & $\begin{array}{l}\text { Mean } \\
\text { of both. }\end{array}$ \\
\hline In hardest scil down hill... & 768 & 770 & 769 & 650 & 646 & 648 \\
\hline In hardest soil uw hill..... & 747 & 738 & 742 & 612 & 652 & 632 \\
\hline In loosest soil down hill... & 654 & 604 & 629 & 655 & 623 & 639 \\
\hline In loosest soil up hill...... & 550 & 552 & 551 & 615 & $65 \mathrm{l}$ & 633 \\
\hline $\begin{array}{l}\text { Arerage of work up and } \\
\text { down hill, in hard soil... }\end{array}$ & 757 & 754 & 755 & 631 & 649 & 640 \\
\hline $\begin{array}{l}\text { Average of work up and } \\
\text { down hill, in soft soil.... }\end{array}$ & 602 & 578 & 590 & 635 & 637 & 636 \\
\hline Arerage of all the trials... & 679 & 666 & 672 & 633 & 643 & 638 \\
\hline
\end{tabular}

On comparing these two tables it will be seen that they give difierent results. The mean average result of all the trials as 
indicated in the first table for Holbrook's plow is 328 pounds. The mean result for Collins' plow is 403 pounds, making a difference of 75 pounds in favor of Holbrook's.

The mean average result according to the second table for Holbrook's plow is 672 pounds, and for Collins' 638 pounds, making a difference of 34 pounds in favor of Collins.

Before the dynamometer was applied it was the opinion of several of the judges who consulted on the sulject that as the soil on the lower or southern end of the lot was the most homogeneous that the indications of the dyuamometer while passing through it would give the best indications of the relative power consumed by each plow, and it was aceordingly resolved to make separate observations upon it.

On comparing the power consumed by each plow while passing through the more homogeneons portion of the furrow it will be seen that the average draught of Holbrook's plow was 590 pounds, while the average draught of Collins' was 636 pounds, showing a difference in fiuvor of Holbrook's of 46 pounds.

\section{SUMIMARY.}

By the first table Holbrook has the advantage by 75 pounds. By the second table, in "loosest soil," IIolbrook excels by 46 pounds. By the second table, the general average, Collins excels by 34 pounds.

The question to be determined is, which of the plows is of the easiest draft?

From the indications of the first table it would seem that the Holbrook plow has the preference, but Collins' plow turned over twenty-one square inches more than Holbrook's and hence appears to do more work with less power. It appears from the experiments of Mr. Morton that only ten per cent of the power required for plowing is expended in turning over the sod, while the remaining ninety per cent is absorbed by friction and by the clearage of the soil. If this statement of. Mr. Morton's is correct, then it would be incorrect to assume that the power required is in proportion to the square inches in the furrow slice, and therefore the iudications of the second table would not be correct.

A majority of the julges therefore decided that the Holbrook plow had the lightest draught, and they were confirmed in this conclusion by the fact that in the homogeneous soil even by the second table the Holbrook plow wis shown to be the lightest. 
Fourth-Ease of holding: Unanimously decided in favor of Holbrook's plow.

Fifth-Durability: Unanimonsly decided in favor of Collins' plow.

Sixth-Cheapness: Decided in fivor of Holbrook.

Seventh-Excellence of mechanical work: Decided to be both equal.

Eighth-Excellence of material: Decided in favor of Collins.

Vintle-Thorough inversion and burial of weeds: Unanimously decided in favor of Collins.

Tenth-Even distribution of wear: No difference of wear.

Eleventh-Regularity or trueness of turning: Decided unanimously in favor of Holbrook's.

The preference was given to Holhrook's plow on the second, third, fourth, sixth and eleventh points, being five points in all. The preference was given to Collins on the fifth, eighth and ninth points, being three points in all, and were decided to be equal on the first, seventh and tenth points, being three points in all.

As the Holbrook has the greatest number of points of excellence, and as it is not objectionable in any point, and as the points in which it excels are the most important ones, the judges agree to award it the gold medal.

\section{Class III.}

Entries were made in this class by A. L. Brearley \& Co., Trenton, N. J., and F. F. Holbrook, Boston.

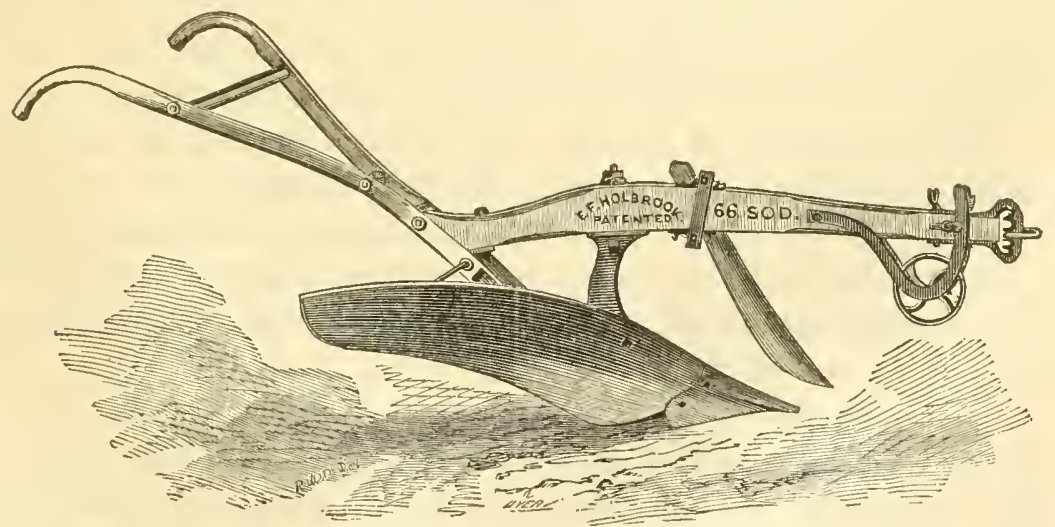

Holbrook-GG, sod.

No ground, after diligent search, being found in the vicinity of Utica suitable in all respects for' a trial of them, the proprietors very politely waived their admitted right to a trial elsewhere, and no trial or award in this class was made. 


\section{Class IV.}

The State Agricultural Society of New York has long been deeply impressed with the conviction that no one thing was more essential for the enhancement of the profits of agriculture than a deeper and more perfect tillage, and that no one cause was more operative in. causing the diminution of several of our most important crops per acre than shallow plowing. In some counties the produce per acre is increasing, in others it is diminishing. In the former the plow runs deeper every year, in the latter it merely skims the surface. In these counties the plow rarely runs deeper than three inches. In some of our best counties the plowing is done as deep as eight or ten inches, but the average depth of plowing over the whole area of the State does not exceed four and a half inches.

It is true that in some sections the surface soil is underlaid by a subsoil which, when first brought to the surface in large quantities, is injurious to vegetation; but there are very few subsoils in the State that are so bad that if plowed in the fall, and one inch of them is brought to the surface where it can be exposed to the ameliorating influence of the atmosphere and the winter frosts they will not perceptibly increase the crop. * If this process is resorted to every other year, almost any soil may be deepened in sixteen year's from four inches to twelve inches, thus trebling the range of pasture for the roots of plants, and doubling if not trebling the amount of the crop.

This is not the language of theory, but of sober and often repeated experiments male in every section of the State.

We might write a volume filled with experiments carefully made by weight and measure to illustrate the importance of deep plowing, but we content ourselves with a statement submitted to us by an eminent agriculturalist and statesman whose name would be a sufficient guarantee for its correctness in any part of the United States, which is as follows:

"Some two or three weeks since I visited a furm near here which a young man bought six years ago who used to work for me. When he bought this place it had a barn on it 30 by 40 feet, and it held the entire crop that the farm was capable of producing. He built a barn the first year 100 feet long by 40 feet wide and 20 foot posts, and stabling all below this. This 
fall his barns are nearly full; ten or twelve tons more of straw or hay would entirely fill them. He has between 800 and 900 lushels of corn, 550 bushels of oats, some rye and buckwheat, potatoes, and 500 bushels of carrots. 'The farm had been shallow tilled for sixty or seventy years, closely cropped, and the manuring was not liberal. He commenced with some twelve or fifteen acres of sod, plowing it in November nine inches deep, manuring it the next spring with twenty-five two-horse loads per acre, and cross plowing it about four inches deep, and planting with corn, de. The seeond year the field was stocked to grass with at grain erop, and another field of twelve or fifteen acres of sod taken up and managed like the first. In this way he has gone on from year to year, until now he has plowed all the plowable portion of his firm nine inches deep, which is nearly twice as deep as it had ever before been worked. Next year he commences to go over the same ground again in a similar way. excepting that the plowing will invariably be from two to three inches deeper than before."

Entertaining these views the Society determined to avail itself of this trial in order to turn the attention of the farmers of the State to the importance of deeper plowing than they have been accustomed to, and to furnish them, if possible, with better facilities for accomplishing it than they had hitherto enjoyed.

It therefore offered its highest prize-the large gold medalfor "a plow for stulbble land which will eut a furrow twelve inches deep, with three horses, which will raise the lowest soil to the surface of the furrow, and which will not be less than five inches wide."

It knew when it made the offer that a furrow tu:ned so as to lie at an angle of forty-five degrees atter reversal must have its depth in the ratio of its breadth as two to three, but it refused to assume any limit to the ingennity of American engineers and mechanics, and sent out its ofler to the world hoping rather than expecting that it would be successfully competed for.

Two plows were entered for this premium, both of them of a very superior character, and both doing the work which was called for.

The trial was in the same field in which Class No. II was tried, and the description of the soil given under that class will answer for this, only as the plowing was so much deeper in Class IV the difficulties arising from the impacted gravel were greatly exag- 
gerated. It may be that worse land to plow can be found, but none of the judges has ever seen worse.

The plow entered by Collins \& Co., Hartford, Comn., was a steel plow known as C 3 . Weight, 95 pounds. Price, $\$ 25$.

The plow entered by F. F. Holbrook was a cast iron plow, known as Plow. No. 69. Weight, 139 pounds. Price, $\$ 24$.

This plow is furnished with two mould-boards (as is the ease with all Mr. Holbrook's plows), one of which is used for sod, the other for stubble plowing; one of them may be detached and be replaced by the other in a very short time by any plowman.

The judgment on each point was as follows:

First-Pulverizing power: Unanimously decided in favor of Holbrook's.

Second-Non liability to choke in stubble: Unanimously decided in favor of Holbrook's.

Third-Lightness of draught in connection with pulverizing power: The following tables show the results for

Holbrook's No. 69:

\begin{tabular}{|c|c|c|c|c|}
\hline \multirow{3}{*}{$\begin{array}{l}\text { Size of furrow turned, } 12 \text { inches } \\
\text { wide and } 12 \text { inches deep. }\end{array}$} & \multicolumn{4}{|c|}{ READING OF THE DYNAMOMETER. } \\
\hline & \multicolumn{2}{|c|}{ DISTANCE IN YARDS. } & \multicolumn{2}{|c|}{$\begin{array}{c}\text { IALF POWER IN POUND } \\
\text { YARDS. }\end{array}$} \\
\hline & 1st furrow. & $2 \mathrm{~d}$ furrow. & 1st furrow. & $2 \mathrm{~d}$ furrow. \\
\hline In hardest soil down hill.... & $113 \frac{1}{2}$ & 117 & 33,300 & 35,700 \\
\hline In hardest soil up hill ........ & 126 & 116 & 41,200 & 35,400 \\
\hline In easiest soil down hill....... & $57 \frac{1}{2}$ & 57 & 19,800 & 19,550 \\
\hline In easiest soil up hill......... & $47^{2}$ & 54 & 16,700 & 16,800 \\
\hline
\end{tabular}

Collins \& Co.'s $C 3$.

\begin{tabular}{|c|c|c|c|c|}
\hline \multirow{3}{*}{$\begin{array}{l}\text { Size of furrow turned, } 12 \text { inches } \\
\text { wide and } 12 \text { inches deep. }\end{array}$} & \multicolumn{4}{|c|}{ READING OF THE DYNAMOMETER. } \\
\hline & \multicolumn{2}{|c|}{ DISTANCE IN YARDS. } & \multicolumn{2}{|c|}{$\begin{array}{l}\text { IALF POWER IN POUND } \\
\text { YARDS. }\end{array}$} \\
\hline & Ist furrow. & $2 d$ furrow. & 1st furrow & $2 \mathrm{~d}$ furrow. \\
\hline $\begin{array}{l}\text { In hardest soil down hill...... } \\
\text { In hardest soil up hill......... } \\
\text { in easiest soil down hill....... } \\
\text { In easiest soil up hill } \ldots \ldots \ldots \text {. }\end{array}$ & $\begin{array}{l}70 \\
76 \frac{1}{2} \\
85 \\
98\end{array}$ & $\begin{array}{r}101 \frac{1}{2} \\
84 \frac{1}{2} \\
64 \frac{1}{2} \\
88 \frac{1}{2}\end{array}$ & $\begin{array}{l}25,900 \\
22,000 \\
33,155 \\
27,700\end{array}$ & $\begin{array}{l}31,800 \\
25,750 \\
28,000 \\
29,150\end{array}$ \\
\hline
\end{tabular}


The following table is computed from the preceding one, and shows how many pounds were required to draw each plow through each yard in each furrow. For example, if a rope hat been attached to the bridle of Collins' plow and passed over a pulley, it would require a weight of 740 pounds, acting by its own gravity, to pull it one yard of the hardest soil down hill in the first furrow, and 617 pounds in the second furrow:

\begin{tabular}{|c|c|c|c|c|c|c|}
\hline & \multicolumn{3}{|c|}{ COLLINS \& CO. } & \multicolumn{3}{|c|}{ HOLBROOK. } \\
\hline & $\begin{array}{l}\text { 1st } \\
\text { furrow }\end{array}$ & $\begin{array}{c}2 \mathrm{~d} \\
\text { furrow. }\end{array}$ & $\begin{array}{l}\text { Aver- } \\
\text { age. }\end{array}$ & $\begin{array}{l}\text { 1st } \\
\text { furrow }\end{array}$ & $\begin{array}{c}2 d \\
\text { furrow }\end{array}$ & $\begin{array}{l}\text { Aver- } \\
\text { age. }\end{array}$ \\
\hline $\begin{array}{l}\text { In hardest soil down hill... } \\
\text { In hardest soil up hill..... }\end{array}$ & $\begin{array}{l}740 \\
577\end{array}$ & $\begin{array}{l}617 \\
609\end{array}$ & $\begin{array}{l}678 \\
593\end{array}$ & $\begin{array}{l}587 \\
654\end{array}$ & $\begin{array}{l}610 \\
610\end{array}$ & $\begin{array}{l}598 \\
632\end{array}$ \\
\hline Arerage............. & 658 & 613 & 635 & 620 & 610 & 615 \\
\hline $\begin{array}{l}\text { In easiest soil down hill.... } \\
\text { In easiest soil up hill ..... }\end{array}$ & $\begin{array}{l}780 \\
565\end{array}$ & $\begin{array}{l}752 \\
659\end{array}$ & $\begin{array}{l}766 \\
612\end{array}$ & $\begin{array}{l}666 \\
711\end{array}$ & $\begin{array}{l}686 \\
622\end{array}$ & $\begin{array}{l}676 \\
666\end{array}$ \\
\hline Average............. & 672 & 705 & 689 & 688 & 654 & 671 \\
\hline 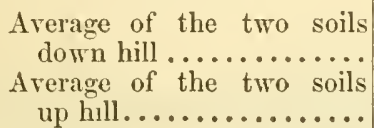 & 671 & 684 & 722 & 626 & 648 & 637 \\
\hline Average............. & 665 & 659 & 662 & 654 & 632 & 643 \\
\hline
\end{tabular}

On examining the tables it will be seen that the average power required to pull the Collins plow in the hardest soil was 20 pounds more than that required to pull the Holbrook plow; in the easiest it required 18 pounds more; the average of all the pulls was 19 pounds more.

This fully establishes the fact that the Holbrook plow has the lightest draught.

N. B.- It will be observed that the above table also represents the power required to turn each cubic foot of earth, because the area of the cross section is just a square foot.

Fourth-Ease of holding: Decided in favor of Holbrook's.

Fifth-Durability: Decided in favor of Collins'.

Sixth-Cheapness: Decided in favor of Holbrook's.

Seventh-Excellence of mechanical work: Adjudged equal.

Eighth-Excellence of material: Decided in favor of Collins'.

Ninth-Thorough inversion and burial of weeds: Decided in favor of Holbrook's. 
Tenth-Even distribution of wear: The difference in this lespect was very slight, but while every part of Holbrook's monid-board was evenly polished, there were a few points in Collins' which had evidently less rubbed. Slight as the difference was, there was a difference, and we were therefere compelled to decide this point in Holbrook's favor.

Eleventh--Regularity or trueness of turning: Decided in fivor of Holbrook's.

\section{SUMIIARY.}

The first, second, third, fourth, sixth, ninth, tenth and eleventh points, eight points in all, were decided in fivor of Holbrook's plow. The fifth and eighth points were decided in favor of Collins' plow, and they were adjudged to be equal on the seventh.

The judges therefore decided that Holbrook's plow was the best one, and as it fully met the requisitions of the Society, they adjudged to it the Larae Gold Medal.

The ammexed cut, Fig. 114, gives a tolerably clear idea of the appearance of Holbrook's prize plow No. 69.

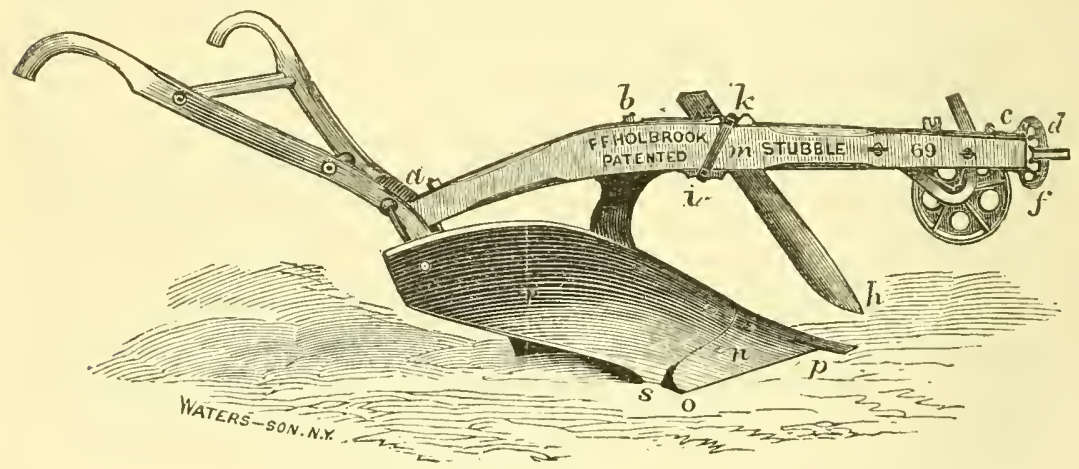

Fig. 114.

It will be observed that it enters the ground with a very low inclined plane, rises by an easy curve which elevates the slice into the air, and then by a succession of sharp twists in different directions it cracks the slice, and if it is in a tolerably dhy condition reduces it to powder.

The Society called for a plow "which will raise the lowest soil to the surface of the furrow." This was done by this plow at Utica to the very letter of the requirement, but as we desire that the public may exactly understand the whole case, we must state that owing to the extreme dryness of the soil and its minute pulverization, the lowest soil, after being lifted to the top of the 
furrow, fell back again into the furrow channel to some extent. We did not consider this an objection, as it promotes that mixing of the soil which we have shown to produce such good effects; but it is proper to add that we saw this plow work subsequently in the soil of the Connecticut valley, where there was more moisture in the soil, and there, nome of the soil fell back into the firlrow channel, but the furrow, twelve inches deep, was turned over as handsomely as could be desired and remained just as it was first laid

'The adhesive character of the soil in this valley cnabled us to study the action of the twist of the plow to great advantage. IVe could see the horizontal laminations and the vertical and transverse eracks just as they were produced by the various curved lines on the surface of the mould-board, opening the whole interior of the furrow slice to the air.

We are aware that we shall shock the prejudices of all farmers by the assertion, but we camnot refrain from expressing our deliberate conviction that this plow put the land at Utica in a better condition for a crop than it could possibly have been put by the spade. We have seen very active laborers who have spaded sixteen square rods of earth a day to a depth of seven inches, but the average day's work does not exceed ten square rods a day. One man and three horses will plow two hundred and forty rods a day; or, in other words, three horses will do the work of twenty-three men, and in addition will stir it five inches deeper and leave it in a mellower condition. There can be no question, therefore, of the great value of this plow. Its performances astonished every one who saw it operate. A portion of the land plowed was the site of an ancient brick yard, containing a thick stratum of angular fiagments of burned brick tightly imbedded in an indurated bed of blue elay, yet the plow passed through it without stopping, and eompletely pulverized every part of its immense furrow slice of twelve inches square. In two or three instances the plow was arrested suddenly by large boulders deeply impacted in the soil, but no part gave way in the least, even when subjected to this sudden strain. This, in our opinion, is a conclusive test of the great strength of this plow, and of the judicious distribution of the material which enters into its composition to resist the strains and shocks which it has to eneounter.

After a most careful and thorough examination of all the separate parts of this plow, considered individually and in combinal 
tion, havmg applied all the tests known to us, and having seen it work in a variety of soils, and under very diversified circumstances, we are compelled to record our deliberate opinion that this plow is one of the most valuable contributions that the mechanic arts have ever made to agricultmre, and that its wide diffusion through the State of New York will add immensely to the profits of agriculture by greatly increasing the fertility of land at a very small cost.

We subjoin a full and minute description of the plow and its constituent parts.

\section{Description of F. F. Holbrook's Plow No. 69-Class IV,} EnTRY No. 19.

There is a point in every monld-board which coincides with the edge of the slice at the instant that it assumes the perpendicular position, and which is vertically above the sole of the plow, the exact breadth of the furrow. This is called the zero point, and a vertical line drawn through it and produced to the sole is the zero line. In measuring this and all other plows described in this report, we have dropped a plumb line to the plane of the sole and measured in a straight line backward and forward to the point from the zero line thus ascertained.

From the zero point to the tip of the handle $\ldots \ldots \ldots \ldots \ldots \ldots \ldots .41_{4}^{\frac{1}{4}}$

From the zero point to the second cross-brace............... $27 \frac{1}{4}$

From the zero point to the first cross-brace $\ldots \ldots \ldots \ldots \ldots \ldots \ldots 16 \ldots \ldots$

From the zero point to top of flanch where the handles are secured.... $11 \frac{1}{2}$

From the zero point to bottom of handles................. 7

From the zero point to rear edge of mould-board............. $3 \frac{1}{4}$

All the above measurements are rear; the rest are in front of the zero point.

From the zero point to heel of land side $\ldots \ldots . . .13$

From the zero point to centre of standard.........................

From the zero point to rear end of sole of share $\ldots \ldots \ldots \ldots \ldots \ldots \ldots 15$

From the zero point to front of standard................. $16 \frac{1}{4}$

From the zero point to rear edge of coulter at top of bcam........ 221

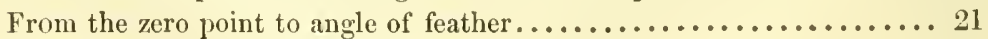

From the zero point to front edge of coulter at top of beam ........ $25 \frac{1}{4}$

From the zero point to fore end of feather................. $31 \frac{1}{2}$

From the zero point to point of share................... $33 \frac{1}{4}$

From the zero point to point of coulter .................... 35

From the zero point to centre of wheel ................... $43 \frac{1}{2}$

From the zero point to fore end of beam ................... 51 ?

From the zero point to centre of holes in bridle............. $52 \frac{1}{2}$ 
The whole length of the implement, from the tip of the nandle to the bridle, is therefore 6 feet $7 \frac{1}{4}$ inches. The whole length on the land side is 2 feet $8 \frac{1}{4}$ inches, and from the point to the rear edge of the mould-board is 3 feet $\frac{1}{2}$ inch.

\section{Vertical Measurements.} Inches.

From the tip of the handles to base line $\ldots \ldots \ldots \ldots \ldots \ldots \ldots \ldots \ldots \ldots \ldots \ldots \ldots$

From the highest point of the handles to base line $\ldots \ldots \ldots \ldots \ldots . . . .38$

From the second cross-brace to base line.................... $31 \frac{1}{2}$

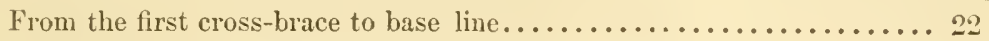

From the lighest point of the handle flanges to base line......... $19 \frac{1}{2}$

From the upper and rear end of beam to base line............ 17

From the upper edge of beam, where the standard passes, to base line.. $22 \frac{1}{2}$

From the upper edge of beam, in front of coulter, to base line......22

From the upper edge of beam, extrene front, to base line......... 20

From the centre of lower hole in bridle to base line $\ldots \ldots \ldots \ldots \ldots \ldots 16 \frac{\text { th }}{2}$

From the centre of upper hole to base line..................22

\section{The IIandles}

Are made of oak wood. The left one lies $6 \frac{3}{4}$ inches to the left of the plane of the land side. The right handle is 30 inches from the tip of the left one. The distance (measured on the inside) between the handles at first cross-brace is $2 \frac{3}{4}$ inches; at the second cross-brace, 17 inches. Width between them where they enter the flinges, $1 \frac{1}{8}$ inches. From the lower end of the handles to the top of the flange, $9 \frac{3}{4}$ inches; to first cross-brace, 16 inches; to second eross-brace, 31 inches. The three last measurements are made upward in the line of the slope of the hanalles. They are $2 \frac{1}{2}$ inches wide and $1 \frac{1}{2}$ inches thick. The first cross-brace is made of iron, cast hollow in the middle, and with flanges at either end bevelled to suit the spread of the handles; a bolt rod runs through it, headed on the right side and secured by a nut on the outside of the left one. The second brace is made of wood, shouldered, with the ends projecting through holes in the handles made to receive them, an iron bolt passing through half an inch above them, headed on the left and nutted on the outsicle of the right one brings their upper part firmly together and prevents their outward flexure as the wooden one prevents their inner flexure. The rear standard, Fig. 115, B, rises upward and backward, haring on its upper extremity flanges, $c d$, three-quarter's of an inch decp on both sides and on the front and rear faces which receive the lower ends of the handles, and which are bolted through it. 


\section{beam.}

A step, Fig. 115, b, projects $1 \frac{3}{4}$ inches forward from the front edge of the rear standard; a nipple, e, also projects forward a little above the step which enters the rear end of the beam, and resists its lateral movement. The heam rests upon the step, and is secured by a bolt ruming diagonally through it and through the rear standard, which is headed on the beam and nutted on the standard. Its size, Fig. 114, $a$, at this point is 3 inches vertically and $2 \frac{1}{4}$ inches horizontally. At the point, Fig. 114, $b$, where the standard bolt passes through it, it is vertically $4 \frac{1}{2}$ inches and horizontally $2 \frac{3}{4}$ inches. At the extreme front, $c$, its cross section is $2 \frac{1}{2}$ inches square. Its whole length, from firont to rear, measmed along the line of its upper curves, is 5 feet $\frac{1}{2}$ inch. Measured along a straight line, from heol to point, it is 4 feet 11 inches. Its upper surface rises from the heel, curving upward and forward to the centre of the front standard; from thence it descends in a slight eurve to its front extrenity. The following measurements, vertically from the base line to the top of the beam, will more clearly show the character of the curves:

From the top of the heel of the beam, $a$, where it joins the rear standard, 16 inches; one foot in advance of this point it is $21 \frac{1}{4}$ inches; at three fect it is $22 \frac{1}{2}$ inches; at four feet it is $20 \frac{3}{8}$ inches; at the fore end ii is 193 inches.

The vertical measmements from the same points on the base line to the under side of the beam are: At the heel, 15 inches; one foot in arlvance, $17 \frac{1}{2}$ inches; at two feet, $17 \frac{5}{8}$ inches; at three feet it is $17 \frac{3}{4}$ inches; at four feet it is $17 \frac{1}{2}$ inches; at its front it is $17 \frac{3}{5}$ inches. 'The material is of white oak, and its line of direction is parallel with the plane of the land side. The land side face of the beam at the heel is $1 \frac{1}{8}$ inches within the land side plane, and at the front it is $1 \frac{3}{8}$ inches within it. The attachments to the beam are, first, the bridle; seeond, the wheel; third, the coulter; fourth, the skim-plow.

\section{The Brille,}

Fig. 114, $d$, consists of a semi-circular iron are three-fourths or an inch in front of the fore end of the beam, pierced with seven holes which pass horizontally through it, the upper one being six inches above the lower one. A strap extends backward from the upper and lower part of the are $8 \frac{1}{2}$ inches in length, embracing the rpper and lower fices of the beam, which are pierced with 
three holes respectively $3 \frac{1}{2}, 4 \frac{1}{2}$ and 8 inches hehind the are. A bolt passes through the rearmost holes, on which the briclle rotates as a centre horizontally. A bolt passes through either the $3 \frac{1}{2} \mathrm{or}^{\circ}$ $4 \frac{1}{2}$ inch holes, which secures the bridle in the line of the beam,or it may be thrust through holes drilled in the beam, one inch to the right or left of the central holes, which eauses the plow to lake more or less land. An extent of latelal motion, amounting to $3 \frac{1}{2}$ inches, is secured hy this arrangenent, while the tendency earthward is regulated by the vertical holes in the bridle.

The Wheel.

Fig. 114, $f$, is made of cast inom, $10 \frac{1}{4}$ inches in diameter and $1 \frac{1}{8}$ inches wide. The land side face is a tiat plate, perforated by five holes, each 3 inches in diameter, and having lateral ribs on each side between the holes. Its centre, when rmuning at a depth of 8 inches, is 9 inches behind the fore end of the beam. It is hung on a U shaped attachment, $a c b$, Fig. 84, having its right limb at its upper extremity sharply curved and prolonged to the right. Eighteen inches behind the fore end of the beam a bolt passes horizontally through the right extremity of the limb and through the beam of the plow, on which it rotates vertically. The axle of the wheel projects towards the left from the lowest portion of the curve. A cast iron button, hariug a pin on its rear extremity which projects towards the right and enters the beam about half an inch, is its centre of rotation. It has a shomler cut at its fore end, through which the left limb slides upward and downward. A holt passes througl the middle of the button and through the beam, having a thumb screw on the right side of the beam, by which the left limb of the wheel attachment is securely clamped at any point through a vertical range of ten inches.

\section{The Coulter,}

Fig. 114, $h$, is 2 fect $2 \frac{1}{2}$ inches long; cutting edge, $10 \frac{1}{2}$ inches; it is 3 inches wide and $\frac{1}{2}$ inch thick, and has a curved taper from the bick to the point. The angle which its entting edge forms with the base line is 64 degrees. Its point stands 4 inches above the sole and $\frac{1}{4}$ of an inch inward from the plane of the land side, in which respect it varies very materially from most plows. It is set against the land side of the beam, to which it is secured by a clamp formed on three sides by a $\frac{5}{8}$-inch round iron rod, having serews ent on the ends which project beyond the right fuce of the beam. Cast iron plates, $k$ and $i$, fumished with three semi-cylin- 
drieal and horizontal depressions, are placed one alove the beam in front of the coulter, and the other below the beam and behind the coulter. On these the rods rest, fitting into the semi-cylindrical depressions. When the cutting angle is as above described, the rods aresplaced in the middle depression in each plate. If it is desired to valy the angle, so as to make it greater of less, the rods are shifted into corresponding depressions. An iron strap, $m$, perforated with holes at each end, passes over the projecting ends of these cross-rods, and is serewed tightly against the beam by nuts, which keeps the coulter firmly in the angle in which it has been set. The conlter is kneed inward to the furrow side so as to bring its land-side fice nearly into the plane of the land sicle.

The reader will obscrve, on examining the figure of this plow, which we have given above, or, still better, the plow itself in our museum, that the line of the shin or breast varies considerably from any other's. Instead of being enrved, it is nearly in a straight line; it is a long taper wedge which insinuates itself into the ground very easily; and then, when the slice is once raised into the air, there is a sharp and sudden twist of the wing of the mould-board which breaks it in pieces and completes the pulverization. As an illustration of the lifting power of the plow, we may mention that we repeatedly found, on measurement, that the upper edge of the slice, when it was at the extreme point of the wing of the mould-board, was 28 inches above the bottom of the furrow. It may be further observed that this plow, like all those exhibited by Mr. Holbrook, are susceptible of four changes: first, they may be used as sod plows; second, by a change of mouldhoard, it may be converted into a stubble plow; third, by the addition of a skim plow on the front of the beam, it may be changed to a sod and subsoil plow; fourth, by a change in the position of the coulter, it may be made to turn a lap furrow or a flat furrow.

\section{The Slim Plow}

Is attached to the land side of the beam by two bolts passing through the standard and fistened by nuts on the mould-board side.

\section{The Land Side, Moutd-Board and Standard}

Are all cast in one piece, and are braced by a rod running from the rear of the mould-board to the land side cast in the same piece with them. The lower end of the mould-board has a 
shoulder into which the share is fitted and secued by one bolt. The standird, Fig. 116, H, is 10 mehes high and 6 inches wide, and, including the Hange, which runs around the top and both sides, is 1 inch thick. It has an oblong opening, $c$, of 7 inches by $2 \frac{1}{2}$, the sicles of which are also ribbed. There are tire noles on each side of this opening which permit a vertical range of six inches to the sole of the share. The land side is a continuation of the standard, and the breast is a continuation of its curre. The length of the sole of the land side is $6 \frac{5}{8}$ inches. The curve of the mould-board differs from that of the plow. The tirst line, eoinciding with a straight edge, runs from the point of junction between the share and land side at the breast back to a point on the lower edge of the mould-board, $2 \frac{3}{16}$ inches abore the plane of the sole, which makes an angle with that plane of $6^{\circ} 11^{\prime}$. The upper line runs firom a point on the upper edge of the mouldboatrd, $7 \frac{1}{4}$ inches above the sole, to a point in the rear edge, $8 \frac{1}{8}$ inches above it, and makes an angle with it of $4^{\circ} 3 t^{\prime}$; the intermediate lines vary in proportion. The vertical lines, in which a straight edge coincides with the surface, vary more in their angles with the first horizontal line than the lower share. Near the standard this angle is $71^{\circ}$; the next towards the rear makes an allyle of $83^{\circ}$; the next, $85^{\circ}$; the next, $87^{\circ}$; the next, $94^{\circ}$; the next, $97^{\circ}$, and the one nearest to the rear edge is $113^{\circ}$.

\section{Share.}

Length of the land side of the share, $4 \frac{3}{4}$ inches; length of the point, $1 \frac{1}{2}$ inches; length of the feather, 9 inches; distance of angle of feather from bottom of the nomb-board, $2 \frac{1}{4}$ inches. The coulter is cast in the same piece with the share; it rises at an angle of $43^{\circ}$, and is concarve on its edge. The point is $1 \frac{1}{4}$ inches broad. The sole of the share and of the land side both slope upward. A straight edge laid from the heel to the point forms the base of a triangle whose apex is at the jumetion of the sharc and land side, and whose height is $\frac{1}{2}$ inch. The face of the land side slopes towards the furrow side; at 4 inches above the base line it is $\frac{1}{8}$ inch inward. The top of the coulter is $\frac{1}{4}$ of an inch inward from the land side plane. The breadth from the ancle of the feather to the land side is $7_{4}^{3}$ inches.

Wre now come to the plow proper, or to those parts which are directly concerned in turning over the furrow. These are the shate, the land side and the mould-board, with their attachments. 


\section{The Share,}

Fig. 114, $n$ (outside), Fig. 116, g, (inside view), is made of cast iron, and forms part of the land side and part of the mould-board side of the plow. Its length on the land side is 9 inches; length of point, 2 inches; length of share on the mould-board side, Fig. $116, a b$, measured from the point, over the feather, to its intersection with the mould-board, $16_{2}^{\frac{1}{2}}$ inches; width from land side to the angle of the feather, Fig. 114, o, 10 $\frac{1}{8}$ inches; length of feather, Fig. 114, o p, Fig. 116, $c d, 13 \frac{1}{2}$ inches (measured on the sole); width of point, Fig. 116, $a a^{\prime}, 1 \frac{1}{4}$ inches. The feather extends 2 inches beyond the edge of the mould-board to the right, and is bolted to it by two bolts, Fig. 116, ef, seeured hy nuts. At the line where the mould-board meets the share at the breast its vertical height above the base line is $3 \frac{7}{8}$ inches. At the point where the upper surface of the mould-board meets the share the height is 2 inches. Distance fiom the angle of the feather to the lower edge of the monld-board is $3 \frac{1}{4}$ inches. The land-side of the share begins to depart from the plane of the land side towards the left from the point of its junction with it. at its fore end, at the point it stands $\frac{1}{4}$ of an inch more to the left than the plane of the land side. The land side fice of the share slopes vertically inwarl towards the furrow side, in conformity with the slope of the lamd side.

\section{The Land Side.}

The sole of the land side, ', Fig. 115, is cast in a separlate piece, 1 inch deep and 2 inches wide at the rear end, and ${ }_{16}^{5}$ of : 11 inch deep and $\frac{3}{4}$ of an inch wide at the front end. It receives the lower edge of the land side plate on its upper surfice. On the furrow side it has two semi-circular steps of $1 \frac{1}{2}$ inch radius, $e$ and $f$, one being 6 inches and the other 21 inches in the rear of its fore end, through which it is bolted to the land side plate. Through these the sole is bolted to the land side plate, the heads being on the outside and the nuts on the inside. The holes in the plate are countersunk to receive the hearls of the bolts, so that they lie in its plane. The sole extends $\frac{1}{2}$ an inch to the left of the plane on the land side, at the rear end, running ont to nothing on the front end, where it joins the share. A straight edge, extending firom the heel of the land side to the point of the share, will form the base of a triangle whose apex is at the point of junction of the land side and the shatre, and whose altitude will be $\frac{1}{4}$ of an inch. If the sole of the land side is producest to the proint, the end of the 
line will be $\frac{3}{8}$ of an inch ahove it; or it may be otherwise stated, that the sole of the lamel slopes upward and forward, and the sole of the share slopes upward and backward to the point of their junction. The object of giving it this concavity is to diminish friction and to give dip or earthward tendency at all times, together with steadiness of motion. The land side is inelined vertically inward, so that at 12 inches aloove the sole it inclines $1 \frac{1}{2}$ inches from the perpendicular. The front standard, A, is cast in the same piece with the land-side plate; its front fice forms a continuous curve with the breast, its radius growing smaller as it rises, until at length the line of the curve moves forward. It is flat on the laud side and convex on the furrow side. It is cast hollow, which permits a bolt to pass vertically throngh it, its head being on the under side and a nut which serews on the upper surface of the beam. It is 3 inches wide and $1 \frac{1}{2}$ inches thick. Its upper termination is in a plate, $a, 6$ inches long and nearly as broad as the beam which rests upon it. The rear standard is cast in the same piece with the land side plate, and is provicled with flanges at its upper end, which reccives the lower ends of the hamlles, as described above.

We give the annexed cut (Fig. 115) of the front and rear standard, A and B; $a$ and $b$ are the flanges upon which the beam rests; $c$ and $d$ the flanges which support the haudles. $\mathrm{D}$, the

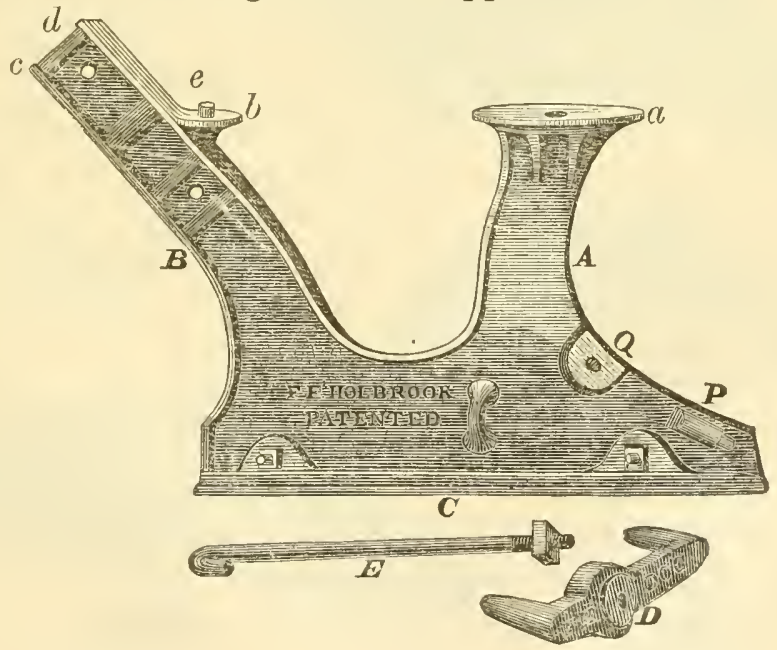

Fig. 115.

dog-hrace. One of the teeth enters the staple seen on the inside of the land side; the other enter into a corresponding staple, $i$ (Fig. 116), in the mould-bond. The hook on the left end of the 
dog-rod eatches into a staple, $k$ (Fig. 116), on the mould-board; the screw end passes through the hole seen in $\mathrm{D}$, and is secured by the nut. By this arrangement the land side and mould-board are held firmly together as one piece.

\section{The Breast.}

A straight line drawn from the point of the share to its junction with the standard measures 2234 inches. The ordinates to the breast curve, measured along this line, are, at 4 inches from the standard, $\frac{1}{2}$ of an inch; at 8 inches, $1 \frac{13}{16}$ of an inch; at 12 inches, $\frac{13}{16}$ of an inch; at 16 inches, $\frac{10}{16}$ of an inch; at 20 inches, $\frac{5}{16}$ of an incl.

\section{The Mould-Board,}

Fig. 114, $r$, Fig. 116, g, rises regularly from the base line and forms a continuous curve with the upper surface of the share; but a vertical flinge, $s$, descends from its front lower edge to the sole. The rear edge of this flange is $19 \frac{1}{2}$ inches behind the point
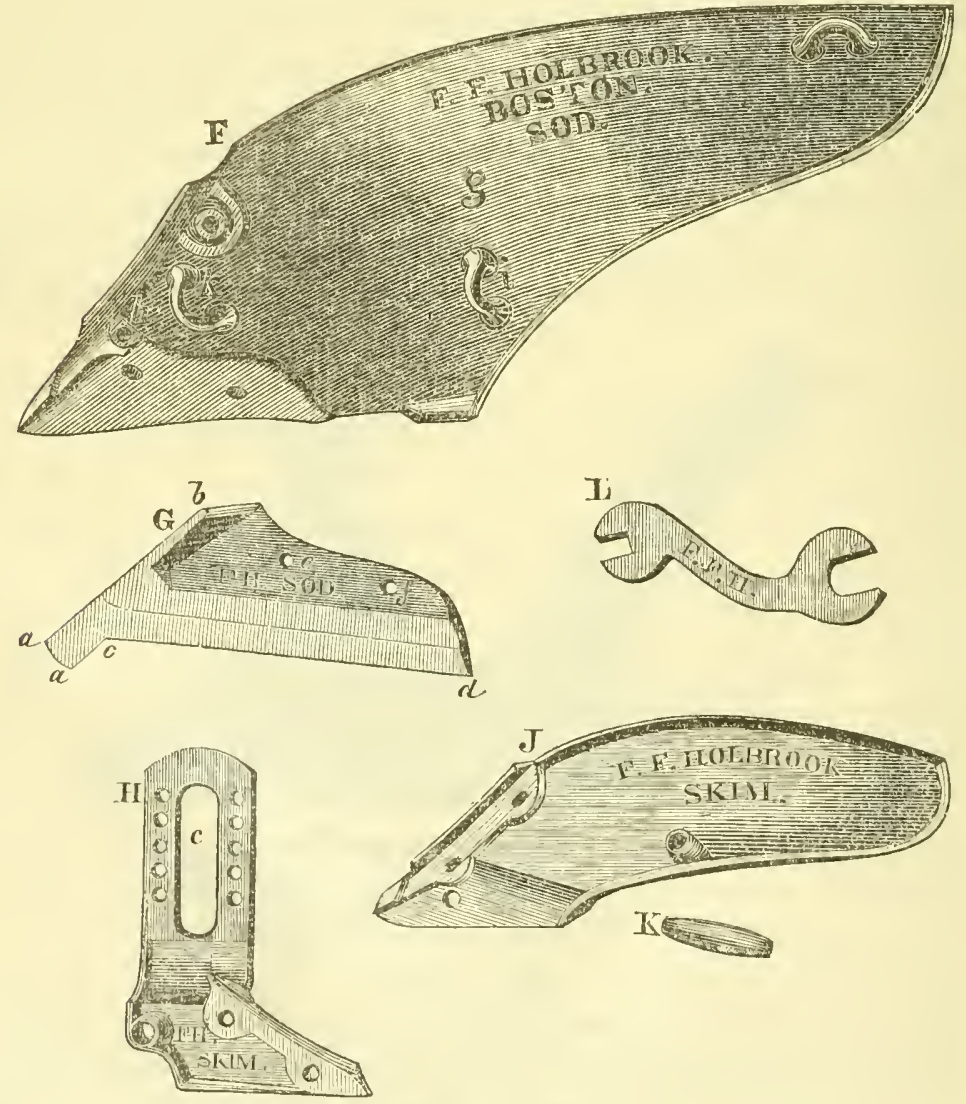

Hig. Iis. 
of the share, measured on the base line. The dog-brace I), and dog-rod E, Fig. 115, take the place of the thimble-brace formerly used. The dog $\mathrm{D}$ being more convenient, is preferred. A $\frac{5}{8}$ wrought iron brace extends from the top of the rear standard diagonally across to the rear of the mould-board. It is $\mathbf{1 5}$ inches long, and hooks at hoth ends into staples which are calst on these plates, and which, on the mould-board, is $4 \frac{1}{4}$ inches below its upper edge, and 5 inches in front of its rear edge. A series of straight lines, which coincide at all points with a straightedge rumning from the front to the back part of the mouldboard. The first of these extends from the land side of the point of the share to a point in the lower edge of the mouldboard, which is $2 \frac{3}{8}$ inches vertically distant from the plane of the sole, and 18 inches distant from the point forms an angle with the plane of the sole of $5^{\circ} 02^{\prime}$. Another of these lines, drawn from the point where the land side joins the mould-board on the breast, to a point in the lower edge of the monld-board $7 \frac{1}{8}$ inches vertically distant from the base line, forms an angle of $4^{\circ} 08^{\prime}$. Another of these lines runs from the top of the breast to a point in the lower edge of the moukl-board $11 \frac{5}{8}$ inches vertically above the base line. The nppermost coinciding line at the top of the mould-board forms an angle of $3^{\circ} 20^{\prime}$. It will be seen that these lines form angles with the plane of the sole gradually though not absolutely regularly diminishing as they rise vertically on the mould-board. Another set of lines may be drawn from front to rear forming angles with the first named line at the point of $62^{\circ}$, and at the rear of the mond-board of $85^{\circ}$, the intermediate lines forming angles gradually increasing from front to rear, but, as in the case of the other set of lines, the rate of increment is not cntirely regu'ar. If these lines are drawn upon the surface of the mould-bourd their intersections will form trapezoids; if the diagonals are drawn on any of these it will be found that a straightedge applied to one of them will show a concave surfice, while at ihe eross diagonal it will show at convex surface.

The mould-board closes over the land side at the breast by a lip; it also has a flange around its upper and lower edge onehalf an inch broad. The mould-board is attached to the stmdard by means of the pin seen in Fig. 115, and marked P, which enters a thimble cast at the lower end of the inside of the mould-board, h, Fig. 116; it also rests on the projecting ear, O, Fig. 115, to which it is fastened by a bolt and nut. By this simple arrange- 
ment the mould-board can be readily changed from a sod to a stubble plow, and vice versa. The $\log$, D, hooks into $g$, Fig. 115, and into $i$, Fig. 116. The rod, E, hooks into $k$, and the nutted end passes through the hole in the middle of the dog, which braces all parts firmly together.

While we have been compelled by the results of the trial to give a very decided preference to the Holbrook plow, we intend to bestow a strong commendation upon its competitor, which is in all respects a very excellent plow, though not as well adapted to deep plowing as Hollorook's. The material of which it is made is the hardest and least frangible steel that ever came under our notice. This was very strikingly exemplified, when a stone two feet long, eighteen inches wide and three inches thick was caught between the revolving cutter and the breast of the plow and torn out from ten inches beneath the surface of the ground. The cutter was pressed by this operation fully three inches to the right of its natural plane, but when released it sprang back to it again without injury to it or to any part of the plow.

We know nothing of the process by which these desirable properties are imparted to the steel, but we can fully testify to the excellence of the article. It pulverizes the ground remarkably well for a concave plow, and buries the weeds and stubl)le tolerably well. In our opinion it would be better if it were longer and less abrupt; and we think the breacith from the land side to the angle of the feather on the share is too great, as it does not leave a hinge sufficiently wide for the furrow slice to turn in. We give the following full description of it:

Turf and Stubble Plow C No. 3. Collins \& Co., Hartford. F. F. Simth, Patent. Class IV, Entry No. 13.

This plow is of east steel, with the exception of the standard, which is of wrought iron, and the bolts and brace rods, which are also of wrought iron, and the bridle, which is of cast iron; the beams, handles and one cross-brace are of wood.

\section{General Dimensions.}

From zero to rear end of mould-board.................. $4 \frac{1}{2}$

From zero to heel of land side........................ 5

From zero to first cross-brace $\ldots \ldots \ldots \ldots \ldots \ldots \ldots \ldots \ldots \ldots \ldots \ldots$

From zero to second cross-brace..................... $10_{8}^{\frac{5}{8}}$

From zero to extreme tip of left handle................... 33

From zero to rear edge of standard........................ $8 \frac{1}{2}$

From zero to rear corner of feather . . . . . . . . . . . . . 12 
From zero to junction of land side with share.............. 17

From zero to point of share......................... 28

From zero to extreme front of beam.................... 52

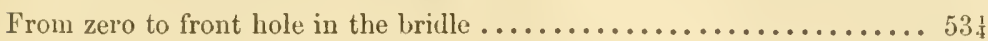

These points are all referred to the base line by a plumb line, and then measured horizontally backward and forward from the zero line. This line is found on the mould-board at the point where the furrow slice touches it when it is set perpendicularly on its edge, or by finding the point where a line at right angles from the land side as long as the breadth of the furrow slice touches the mould-board, and also above the sole as much as the furrow is broad.

It will be seen from the above that the extreme length of this plow is 7 feet $2 \frac{1}{4}$ inches from the tip of the handles to the front of the bridle. And the whole length from the heel of the land side to the point is 2 feet 9 inches. The tip of the left handle lies $3 \frac{3}{4}$ inches to the left of the plane of the land side.

\section{Vertical Measurements.}

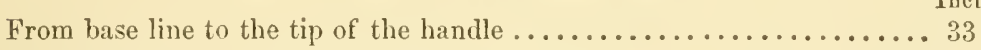

From base line to the highest point of the handle............. $35 \frac{1}{2}$

From base line to third eross-brace between handles... ......... 28

From base line to seeond cross-brace between handles ........... 18 $\frac{1}{2}$

From base line to first cross-brace between handles ............ $11 \frac{1}{2}$

From base line to top of beam at rear edge of standard.......... 23

From base line to top of beam at front end................ $18{ }^{3}$

From base line to upper hole of bridle.................. $20 \frac{1}{2}$

From base line to lower hole of bridle.................... $14 \frac{1}{2}$

\section{Handles.}

An iron strap, one-half an inch thick and $2 \frac{1}{4}$ inches wide, is bolted to the inner face of the land side, 8 inches in arlvance of the heel and $3 \frac{1}{4}$ inches above the sole. It rises upward and backward, making an angle of $48^{\circ}$ with the hase line, and is continued 15 inches ahove the bolt. It is twisted or kneed inward so is to make its onter or left plane coincide with the inner or right hand face of the left handle, which is bolted to it and is in contact with it for $6 \frac{1}{2}$ inches. This handle passes upward through a mortise in the beam, and after ascending 6 inches above begins to deflect towards the left from the plane in which it previonsly stood. It is two inches broad ( $i$. $e$. on its sides) and $1 \frac{1}{2}$ inches thick ( $i$.e. on its front and rear ediges). Below the beam its form is semi-cylindrieal, and the bolts which hold it in contact with the 
iron strap are headed with a clip which embraces their whole circumference and correspond with them in form. Above the beam the sides are trimmed off on the edges so as to give them a well marked convexity.

The right handle is bolted by two bolts, 6 inches apart, to the mould-board. A half inch wrought iron brace rod, 15 inches above the bolt, which fastens the iron strap to the land side, passes between the handles, and is $7 \frac{1}{4}$ inches long. Another iron brace rod, curred upward in the middle and having a screw cut upon both ends, passes through the beam and both handles; each end is secured by two nuts, one on the outside, the other inside, thus resisting both outward and inward pressure. It is $10_{4}^{3}$ inches in length, and is 11 inches above the first one measured on the left handle, and 14 inches measured on the left one. A third brace rod of wood, 15 inches above the last one, as measured on the left handle, and $17 \frac{1}{2}$ inches on the right handle, is 18 inches long, measured as the others have been on the inside of the handles. One inch above this is a quarter-inch iron rod, which passes through both handles, and is secured by a nut on the left one. The distance between the tips of the handles is 28 inches, and as we have before stated, the tip of the left handle lies $3 \frac{3}{4}$ inches to the left of the plane of the land side, the tip of the right handle must lie $24 \frac{1}{4}$ inches to the right of that plane. Both handles are made from wood.

\section{Beam.}

The beam is made of oak wood. Measured along the top, in conformity with the curves, it is 5 feet $7 \frac{1}{2}$ inches long. Measured in a straight line, it is 5 feet 6 inches long.

The following measurements, made vertically from the base line to the top of the beam at the points indicated, will give a tolerably distinct idea of its curves:

Inehes.

From base line to extreme rear end of the beam $\ldots \ldots \ldots \ldots \ldots \ldots 18$

From base line to the point where the front edge of the left handle passes through the beam............................... $44_{4}^{\frac{1}{4}}$

In advance of the preceding measurement................ $19_{8}^{5}$

From base line at 1 foot in advance of first measurement......... $21 \frac{\mathrm{b}}{8}$

From base line at 2 feet in advance of first measurement, which corresponds with the rear edge of the standard.............. $23 \frac{1}{2}$

From base line at 3 feet in advance of first measurement......... $22 \frac{1}{4}$

From base line at 4 feet in advance of first measurement.......... $20 \frac{3}{8}$

From base line at 5 feet in advance of first measurement......... 18 $\frac{1}{2}$

From base line at the extreme front of the bean............. 181 
Similar measurements to the under side of the beam:

At the heel

Inches.

It 41 iuches in advance. ...............................

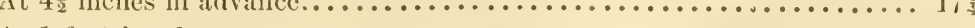

At 1 foot in adrance................................. 18

At 2 feet in advance.................................. $19 \ldots \ldots$

It 3 feet in advance................................ $18, \frac{1}{2}$

At 4 feet in advance................................. $17_{\frac{1}{8}}^{\frac{1}{8}}$

At 5 feet in advance................................ $16 \ldots \ldots$

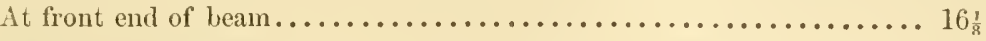

The beam projects 2 inches behind the left handle of the plow. At the hinder end it is 3 inches deep and $2 \frac{5}{8}$ inches wide. At the standard it is $4 \frac{1}{4}$ inches deep and $2 \frac{3}{4}$ inches wide. At the front it is 3 inches deep by $2 \frac{1}{2}$ inches widle.

\section{The Land Side}

Is made by a single plate of cast steel, 21 inches long, and 5 inches deep, and three-eighths of an inch thick, bevelled off' at its upper front edge to meet the breast curve of the share and mould-board. At its rear end a wear iron projects three-fourths of an inch laterally towards the land, which extends $8 \frac{1}{4}$ inches forwards and then runs out, the land side and share being thenceforward in one plane. The wear iron also extends 2 inches diagonally upward, and is then lost in the plane of the land side. At its junction with the share the plate is thickened on the inside, and a gain is eut on the end outside face, which extends 2 inches over the interior face of the share at the point they are bolted together.

From a point 11 inches in front of the heel and 3 inches above the sole, a wrought iron brace, seven-eighths of an inch wide and three-eighths of an inch thick, crosses over to the mould-board. It is bolted to both through flanges which turn downward at angles corresponding with each plate. The land side is exactly perpendicular to the plane of the sole for six inches vertically.

\section{Share.}

A straight edge laid from the heel of the land side to the point of the share forms the base of a triangle, the apex of which is at the point of junction between the land side plate and the share, its altitude being one-half an inch. A straight edge litid upon the sole of the land side and produced is a qurter of an inch rertically above the point. The point is exactly in the planc of the land side and not set towards the left as is usually the ease. It is also in a straight line with the sole of the share. The angle 
of the feather is 12 inches, measured at right angles with the exterior face of the land side. There is no marked line of separation between the point and the rest of the share; its breadth is one-half an inch. The edge of the feather from the point to the angle is regularly concave on the sole. The length of the chord connecting the point with the angle is $19 \frac{3}{4}$ inches, and the longest ordinate to the curve is three-fourths of an inch. The distance of the angle from the bottom of the mould-board is $5 \frac{1}{8}$ inches; it is brought to a cutting elge along the sole for its entire length, and does not villy anywhere from the plane of the sole. The vertical height of the breast at the junction of the share and land side is 4 inches, and at the standard 10 inches. The length of the share on the land side is $10_{4}^{3}$ inches. The upper edge of the share coincides with the lower edge of the mould-board in a straight line. An iron plate three inches wide is applied along the line of junction on the inner face aud unites the two by means of two bolts passing through the plate and the upper edge of the land side, and two through the lower edge of the mouldboard.

\section{The Standard}

Is of wrought iron, $2_{4}^{3}$ inches wide and three-quarters of an inch thick; it is straight until it reaches the breast of the plow; it then curves forward to correspond with it. It twists inward when it meets the land side and has a gain eut in the lower end to receive the land side plate which is bolted to it; it terminates above in a plate six inches long and three inches wide, having transverse slots ent at each end, through which bolts pass upward through the beam secured by nuts upon its upper surfuce. By this arrangement the angle made by the beam and the plane of the land side may be varied at pleasure. The land side is perpendicular to the sole for six inches; from thence upward the standard inclines to the furrow side; at 12 inches above the sole it deflects three-fourths of an inch. A line drawn from the point to the top of the breast where it meets the standard is $19 \frac{1}{2}$ inches, and the longest ordinate to the curve of the breast is 13 inches.

\section{The Mould-Board}

Is of cast steel, which is three-eighths of an inch thick. It has straight transverse lines, but its vertical liues are concave. We 
did not perceive that the twist conformed to any mathematical principle, but it worked very well in practice.

Class V-Som and Subsoll Plows.

The only entry in this class was by F. F. Holbuok, of Boston, and consisted of the plow used in Class IV, with a slim plow attached to the beam in flont, as seen in Fig. 117. Entry No, 20. Weight, 150 llss. Price, $\$ 27$.

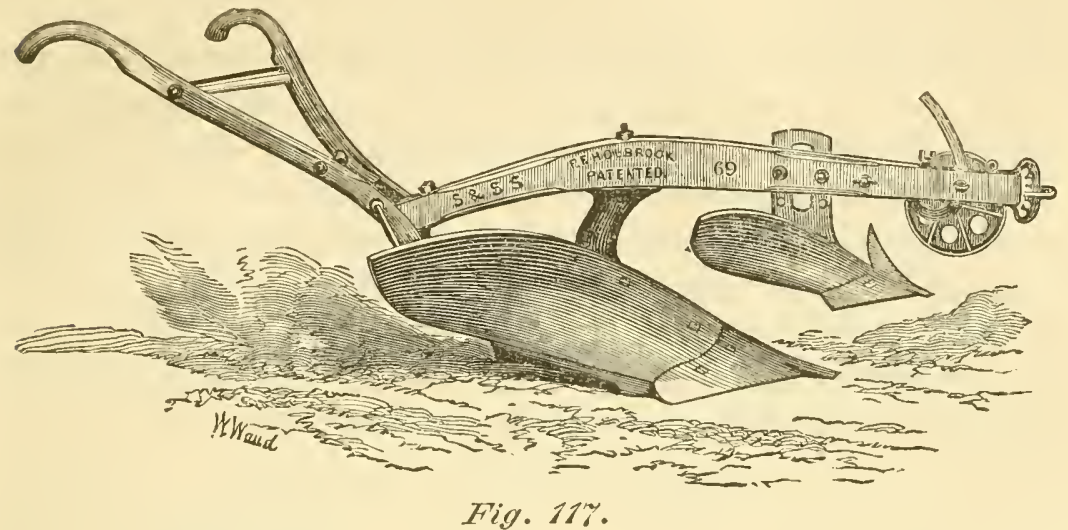

A full description of the stubble plow will be found in Class IV. The sod and subsoil plow is No. 69, with a stubble mould-board and the skim plow attached. It works from 8 to 14 inches deep, by 10 to 14 inches wide, according to the wishes of the plowman.

In our trials at Utica, on ground as adverse to its good performance as conld well be imagined, it worked 11 inches deep and 11 inches wide for the first two furrows, and 11 inches deep and 12 inches wide for the second two furrows.

The following table shows the force which was consumed:

\begin{tabular}{|c|c|c|}
\hline FURROWS. & $\begin{array}{l}\text { Distance in } \\
\text { yards. }\end{array}$ & $\begin{array}{l}\text { Half power in } \\
\text { pound yards. }\end{array}$ \\
\hline 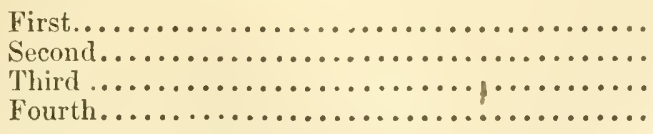 & $\begin{array}{l}153 \\
151 \\
153 \\
152 \frac{1}{2}\end{array}$ & $\begin{array}{l}45,000 \\
43,500 \\
57,500 \\
55,600\end{array}$ \\
\hline
\end{tabular}

The amnexed table gives actual dranght reduced firom the above table, the draught per cubic foot, and the averages. 


\begin{tabular}{|c|c|c|c|c|c|}
\hline \multicolumn{2}{|c|}{ SIZE OF FURROW. } & \multicolumn{2}{|c|}{ DRAUGHT. } & \multicolumn{2}{|c|}{ AVERAGES. } \\
\hline $\begin{array}{l}\text { Width in } \\
\text { inches. }\end{array}$ & $\begin{array}{l}\text { Depth in } \\
\text { inches. }\end{array}$ & Actual. & $\begin{array}{c}\text { Per cubic foot } \\
\text { of earth. }\end{array}$ & Actual. & $\begin{array}{c}\text { Per cubic } \\
\text { foot. }\end{array}$ \\
\hline $\begin{array}{l}11 \\
11 \\
12 \\
12\end{array}$ & $\begin{array}{l}11 \\
11 \\
11 \\
11\end{array}$ & $\begin{array}{l}588 \\
576 \\
752 \\
730\end{array}$ & $\begin{array}{l}700 \\
686 \\
820 \\
795\end{array}$ & $\left\{\begin{array}{l}582 \\
741\end{array}\right.$ & 807 \\
\hline
\end{tabular}

It will be observed that the average difference between the two first and two last, amounting to 159 pounds, is altogether too great to be aceounted for by the very slight increase of one inch in the width of the furrow, and was obviously due to the heterogeneous character of the soil, which varied very greatly in tenteity and density in the space of a few feet.

In order to determine this matter more fully, we made experiments with this plough at various depths, the results of which are recorded in the following tables:

\section{Holbrook's Sod and Subsoil.}

\begin{tabular}{|c|c|c|c|}
\hline Width of furrow, 12 inches. & $\begin{array}{l}\text { Depth in } \\
\text { inches. }\end{array}$ & $\begin{array}{c}\text { Distance in } \\
\text { yards. }\end{array}$ & $\begin{array}{l}\text { Half power in } \\
\text { pound yards. }\end{array}$ \\
\hline $\begin{array}{l}\text { First furrow } \ldots \ldots \ldots \ldots \ldots \ldots \ldots \ldots \\
\text { Second furrow } \ldots \ldots \ldots \ldots \ldots \ldots \ldots \ldots \\
\text { Third furrow } \ldots \ldots \ldots \ldots \ldots \ldots \ldots\end{array}$ & $\begin{array}{r}8 \frac{1}{2} \\
10 \frac{1}{2} \\
12 \frac{1}{4}\end{array}$ & $\begin{array}{l}154 \\
146 \\
149\end{array}$ & $\begin{array}{l}50,800 \\
55,000 \\
59,700\end{array}$ \\
\hline
\end{tabular}

In the following table these numbers are reduced to actual draft and draft per cubic foot in pound yards:

\begin{tabular}{|c|c|c|}
\hline DEPTH OF FURROW & $\begin{array}{l}\text { Actual } \\
\text { draught. }\end{array}$ & $\begin{array}{l}\text { Draught per } \\
\text { cubic foot. }\end{array}$ \\
\hline 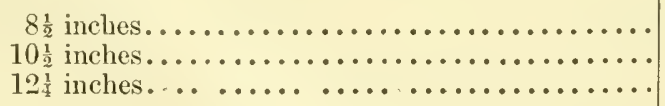 & $\begin{array}{l}660 \\
753 \\
801\end{array}$ & $\begin{array}{l}931 \\
861 \\
785\end{array}$ \\
\hline
\end{tabular}

This shows the heterogeneous character of the soil in a very striking manner. In the first experiment 121 square inches of furrow slice were turned over, with a foree of 582 yard pounds; in the second experiment 660 yard pounds were required to turn over a furrow sliee of 102 square inches.

In the first experiment, 741 yard pounds were required to turn 
132 square inches; in the second, it required 753 yard pounds to turn a slice of 126 squatre inches.

The work performed by this plow was entirely satisfactory. The furrow chamel was perfectly cleared; the earth was thoroughly pulverized; the grass, weeds and stubbles were entirely buried, so that they could not possibly spring up again; the plow ran very truly, so that a boy could hold it, and, as will be seen on inspecting the talsle, it consumed very little power in proportion to the work performed. The workmanship throughout was excellent and conscientious, and the material was as good as wood and cast iron could make them.

We have no hesitation in awarding a gold medal to this plow.

As heretofore remarked, plow No. 69 has a stubble mouldboard, for stubble plowing, as in Class IV; a skim plow, to be used in connection with the stubble mould-board, for sod and subsoil plowing, as in Class V; and a sod mould-board, for sod plowing, as represented in Fig. 118,-turning either lap or flat furrows by a change of cutter, and working from seven to ten inches deep.

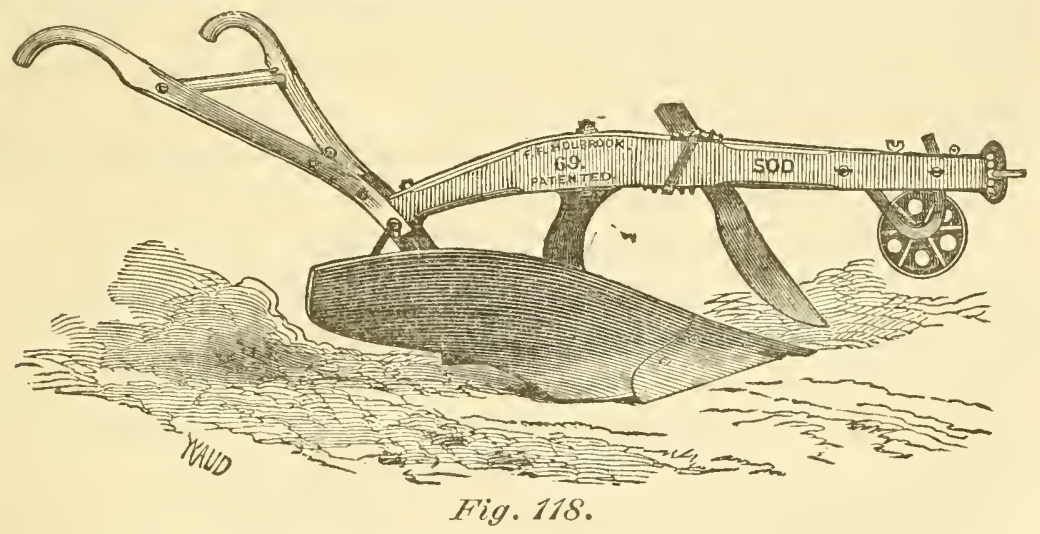

Class VI-Subsom Plow in connection with an Ordinary Plow.

The only entry in this class was by R. J. Wheatly, Du Quoin, Illinois.

Entry No. 6. Weight of attachment, $20 \mathrm{lbs}$. Price, $\$ 10$.

This is intended to be affixed to any plow, and is not intended for any one in particular.

An ordinary elevis is affixed to the beam of the plow abont one inch in advance of the standard. From the centre of the right side of the clevis a shaft extends $3_{4}^{3}$ inches to the right. A plate of iron is bolted to the rear end of the beam, near the handles, 4 inches 
long and $1 \frac{1}{4}$ jnches wide. A vertical projection descends from it 2 inches long. From this a horizontal projection extends $2 \frac{1}{2}$ inches; from the end of this a vertical plate descends 8 inches, and is perforated with five holes, 1 inch apart and $\frac{1}{2}$ inch in diameter. A strong clamp on the right side of the standard is bolted to these holes, according to the desired depth of subsoiling. The stem hinges on the first mentioned shaft on the clevis, which is 16 inches long and 1 inch by $\frac{3}{4}$ inch. It passes backward, and is fastened by the clamp; it then bifureates into two curved arms, 11 inches long and 8 inches apart at the rear extremity. A knife shaped like the letter $\mathrm{U}$, but brought to a lancet-shaped point beneath, which is 13 inches below the bifurcated arms, and 3 inches wide, is fastened to the arms by two bolts. The upper arms of the knife are eurved over towards the plow, having a slot in their extremitios so as to change the angle at which it enters the gromnd at pleasure. The lower part of the knife is not in the same plane on both sides, the hinder part being an inch and three-quarters higher than the front edge; the soil dug up by the front edge is therefore raised vertically $\mathbf{1}_{4}^{3}$ inches, and falls the same distance back into the furrow chammel from the back edge, which pulverizes it very well.

The plow was first tried alone, without the attachment for subsoiling, with the following result:

Furrow, 7 inches deep and 8 inches wide.

132 yards-Half power in pound yards, 34,600 pounds; actual power in yard pounds, 524 pomds.

After the attachment was applied, the furrow was ten inches deep, or three inches lower than before, which was therefore the amount of subsoiling actually performed. The power required to accomplish this work, viz., a furrow slice 7 inches deep and 8 inches wide, turned over, and 3 inches deep and 8 inches wide, pulverized at the bottom of the furrow, was 74 yards. 34,400 pounds half power in pound yards; actual power in pound yards, 876.

The power required, therefore, to subsoil three inches deep was 352 pounds, or 117 pounds for each inch that was subsoiled.

Mr. Holbrook's Sod and Subsoil, groing in one inch deeper and taking a furrow three inches hroader, ahsorbed 194 pounds less of power than did this of Mr. Wheatley's.

We were all very much pleased with the appearance of the invention and we confidently expected that a trial would demon- 
strate its usefuluess; but in the fuce of the facts disclosed by the trial we were reluctantly compelled to withhold a testimonial of the approval of the Society.

\section{Class VII-A Ditciing Plow for Opening Drains.}

It will be seen by the list of entries that A. P. Routt, of Somerset, Va., was the only competitor, while the premium is awarded to N. Hawks, of Maine. Mr. Routt has addressed a protest to the board of judges, and it is acknowledged that the award was an improper one.

The blame of this transaction rests wholly on the shoulders of the chairman of the board of judges, whose duty it was to see that every implement competing for a prize was properly entered in the class for which it was competing. On account of sickness in Mr. Routt's family his plow was tried out of its regular order so that he might go home. Mr. Hawk's plow was tried in the regular order, and Mr. Routt was therefore not present to challenge his right to do so. The chairman having seen his name on the entry list supposed it was quite right, and permitted him to make the trial, without actually looking, as he ought to have done, to see whether this was the class for which he had entered. The mistake was not discovered until the premium was awarded, and after this it was of course impossible to withdraw it.

The ditcher consists of a double mould-board plow, which makes the ditch, and is followed by a roller formed of two cones united by their bases, which are two feet in diameter, the axis being 13 feet long. Two wrought iron arms proceeding from the rear of the plow frame and extending laterally and backward embrace each end of the axis, and draws the cones after the plow which pack and smooth the side of the ditch. After seeing it work, we did not think that it was a desirable implement for the farmer, and we should not, therefore, have awarded a premium to it under any circumstances.

The ditching plow of Mr. Hawks is one part of a machine which may be employed for various purposes. It can be used as a ditching plow, a cultivator, as a seed planter and a potato digger. Weight of the whole combined machine 180 pounds. Price, $\$ 50$. We took a memorandum of the weight and price of the ditching plow alone, but it is now obliterated, and therefore we are unable to give it.

Considered as a seed planter, it may be described as a double 
mould-board plow cast in two pieces, viz.: the point and shares, and the wings or mould-boards. The beam is of oak, and is 45 inches long. The wheel, which is attached in the same way as Gor. Holbrook's, which we have already described, is 7 inches in diumeter and 2 inches broad. The clevis is the same also as Gov. Holbrook's. A pair of cast iron arms rise from the upper edge of the mould-boards on each side, 9 inches to the rear of the breast, in a curved direction towards beam and bolt, through its heel. These arms descend six inches, and are flanged below. From these flanges a box is supported in which are inserted the gudgeons of the driving wheel, which ean be raised or lowered at pleasure. The driving wheel is 11 inches in diameter and 1 inch wide. Two pins are inserted on each side of the driving wheel, which strike on cones which communicate a vibratory motion to the slides, which open the valves for the deposit of the seed. By increasing the pins, the quickness of the vibrations and consequently the amount of seed sown is increased; by diminishing the number of pins, the quantity sown can be diminished. A pair of hinged ears, 8 inches above the sole of the mould-boards, project in the rear of the handles, from which brace-rods (half an inch in diancter) extend backwards 12 inches to the covering irons. Another pair of brace-rods extend from the first pair, at the front of the covering irons, upwards to the handles. Eighteen inches above the sole of the mould-board one end has a ring which embraces the first pair of braces, and the other is bolted to the handles. The covering irons are 1 inch apart behind and 9 inches apart in front, sloping to the right and left as they descend to the ground. They are 14 inches long, and are curved upward and backward from below. A rib is calst about the middle of the cover's, 10 inches high in front and 2 inches high behind, which flure outward. A pair of ear's are calst about the middle of the covers, to which a cross-rod is bolted, from the centre of which a standard rises, which is surmounted by a crossbar; from the ends braces extend to the hamdles; on each side a thumb-screw, on the top of the standard, regulates the depth of the hill. A pair of eyes, 1 inch in diameter and ten inches apart, are serewed into the top of the beam; between these a wooden roller is inserted, from the centre of which a wooden bar runs laterally. A marker is placed at the end of this bar, which can be moved backward and forward, and secured by a thumb-serew at any point, so as to make the marks for the furrow at any 
required distance. A drawer vibrates at each motion of the slide, which regulates the egress of the seed. 'Two projecting pins in the downward channel play up and down and prevent clogging.

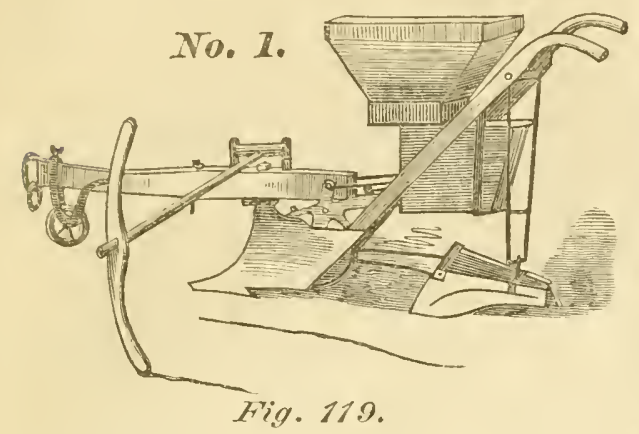

The description above given, in commection with the drawing, Fig. 119, will, we trust, give a tolerable idea of the implement when adjusted for planting seed.

When the boxes and planting machinery are detached it is converted into a horse hoe or cultivator, by hinging a bar from the rear end of each mould-board to which cultivator teeth are attached; these arms are expansible to any required width by means of a pair of wrought iron arcs, one of which is attached to the middle of each bar; they are perforited with holes, and can therefore be used to set the arms at any angle by thrusting a pin through these holes.

Fig. 120 shows the machine when used as a cultivator. When used as a diteher, the coverer's seen behind in Fig. 119 are reversed and hinged to the rear of the mouldboards by means of slots in the sides and serew bolts they may be raised higher as the ditch deepens. It really did excellent work

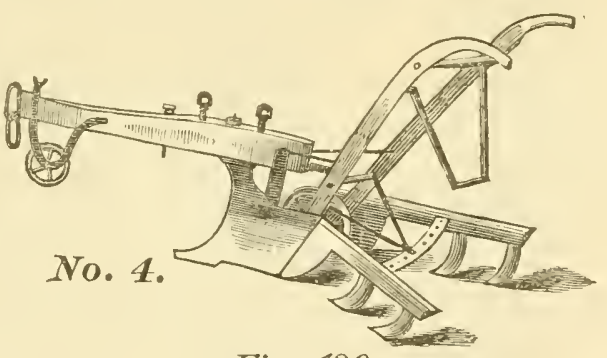

Fig. 120. as a ditcher, and by passing backward and forward a few times a single horse would cut out a rery neat ditch with very little labor and great neatness of execution. We deemed its work much better thim Rontt's in all respects.

Class VIII-A Machine for Excavating Drtches for UnderDRAINING.

There was only a single entry in this class, which was made by E. Heath,.of Fowlerville, N. Y.

We have mislaid our notes of the weight and price of this machine, or we neglected to procure them. Some idea of the mathine will be ohtamed hy an examination of the amexerl 
Fig. 121. It runs upon a light wooden railroad, or rather tram road; as soon as it has passed over one pair of rails they are taken up by an attendant and replaced in front of the machine. What is called the shovel is more like a chisel which enters the ground diagonally. It is moved forward by means of a chain which is anchored to a stake at some distance ahead, and the other end is slowly wound round a pulley which revolves on the machine. The shovel runs down to the bottom of the ditch at each plunge, and raises the earth to the surface, where it is caught by the scrapers, by which it is removed about two feet from the sides of the ditch. The power required to operate the machine is two horses, a driver, and a man to remove the rails, or an expert man may do both. It will cut a tile drain at the rate of from four to six rods an hour in ordinary ground. It eut a ditch in our presence, in a very adhesive clay soil, two feet deep, taking out six lineal inches at every revolution of the sweep; while doing this it was worked with only one horse and one man. It appears complieated on looking at the figure; but it is in reality very simple. There is not a single geared wheel used in its construction; it can all be made by any blacksmith or earpenter, and if anything breaks it can be repaired in any village in the country. There are only 100 pounds of castings used about the whole machine, and any one that is competent to run a mowing machine or a threshing machine will have no difficulty in operating this one.

We were unanimously of the opinion that this machine is very far in advance of any contrivance for the excavation of ditches that we have ever seen, and that it is a practical, economical and useful implement which is greatly demanded at the present time. We do not doubt that its proprietors will be enabled to simplify and improve its details, and to strengthen some of its parts; but in our judgment the principle is a good one, and will meet the approbation of the increasing number who desire to increase the produets of their farms by underdraining. We therefore award to it a gold medal.

Class IX-A Steel Plow for Allutial and Unctuous Lande.

The only plow entered in this class was that of Collins \& Co., of New York.

Plow C, No. 3. Entry No. 4. Weight, 90 pounds. Price, $\$ 25$. There was no land in the vieinity of Utica which was adlapted 


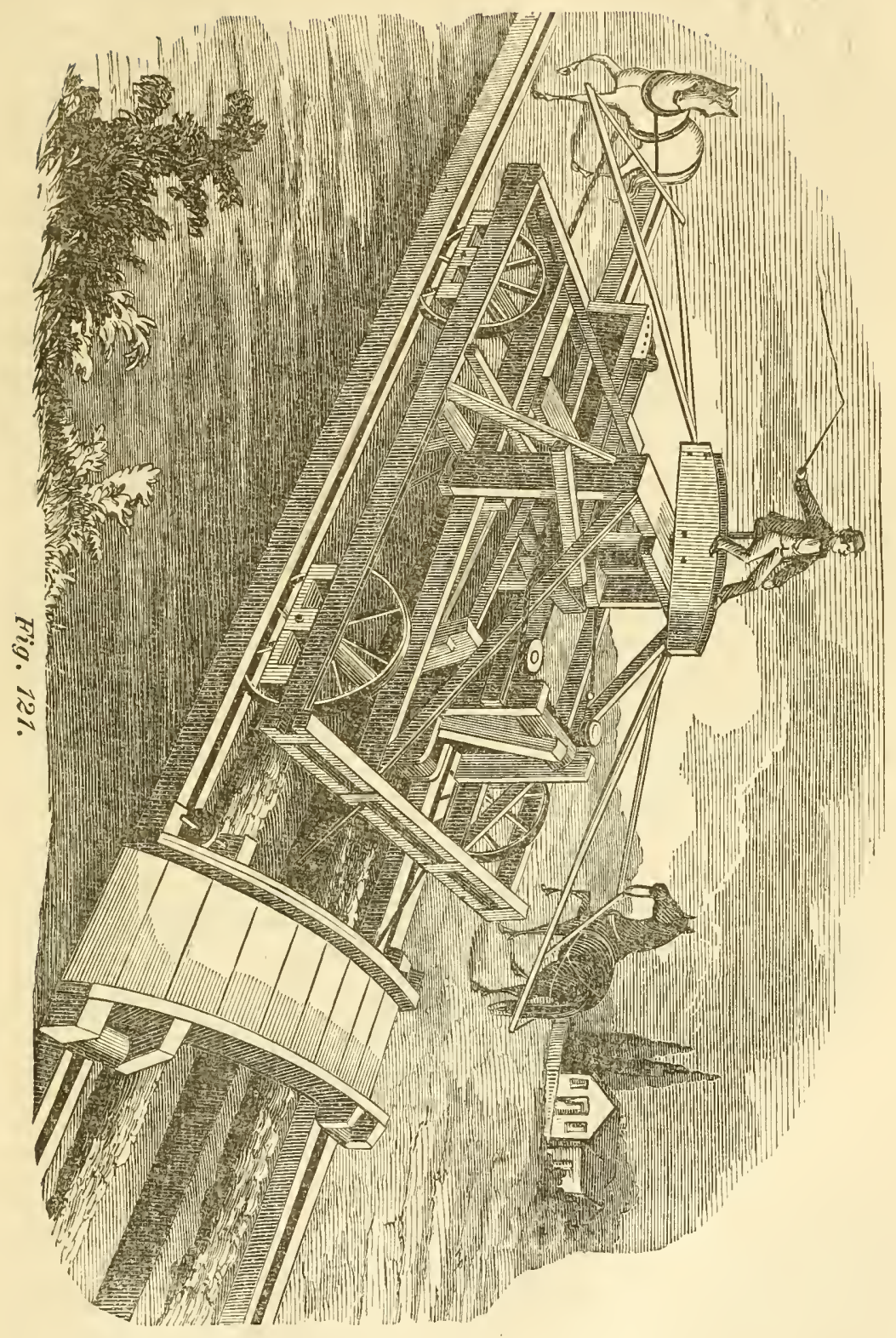


for an actual trial of this plow in the kind of land for which it was specially intended; but from the trials which we made in adhesive soils, from a study of its shape and a test of the material of which it was composed, we had not the shadow of a doubt of its admirable adaptation to work in this kind of soil with entire success, and therefore awarded to it a gold medal.

\section{Class X-A Swing or Sidemill Plow.}

Two entries were made in this class, viz.: F. F. Holbrook, No. 6, Swivel Plow; weight, 136 pounds; price, \$20. Lyman D. Burch, Sherburne; weight, 110 pounds; price, \$15.

The plow made by Mr. Holbrook is laid out by an exceedingly ingenious process, with which we were made fully acquainted, but which we camnot make public, as it is not patented. We exceedingly regret the necessity for this enforced reticence, as the diagrams given in full would elucidate very clearly some important points in the general theory of the plow, and in the special theory of swivel plows, which we think are at present very ill understood by the user's of plows. A very good idea of Mr. Holbrook's plow will be obtained by an examination of the ammexed Fig. 122.

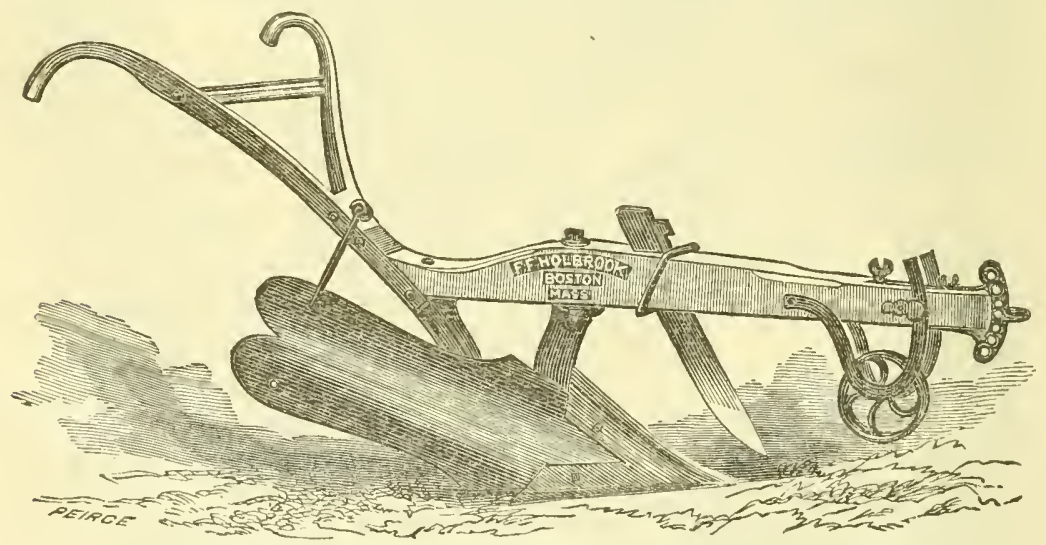

Fig. 122.

It, like all other swivel plows, consists of a half of two mouldboards combined in one; but, mnlike others, it is so combined as that the one-balf shall help the other all the way from the zero line forwards, so that a full sized furrow slice may be properly turned. It worked well in all respects, was very strong, and was thoroughly well made in all its parts. It pulverized the ground very thoroughly, and hured the weeds very well. Its chicf 
eharacteristic was its pulverizing power. and the soft, velvety feel of the furrows under the foot which hat been plowed with it.

Burch's plow was a very peculiar one, and was quite novel in its eonstruction. The leading ideas sought to be cmbodied in it are lightness, strength and cheapness. We have no drawing of this plow, but will try to describe it as well as we are able. The beam is of east iron, strengthened by a frame work of wrought iron rods. A hook east on the rear end of the beam holds a brace. An irou bar, six inches in advance of the hook, projects laterally on each side of the beam, another bar of the same size is placed on the front end of the beam. One-half inch rods are stretched between these eross-bars, parallel to the beam; are carried round through the front bar, and connect in the middle $1 \frac{1}{2}$ inches from the front bar. At either end 13 -inch hooks are inserted, which liold the head block to which the elevis is attacher. One foot in advance of the first mentioned hook is a hor'n. Nineteen inches in advance is a pair of straps eurving laterally ontward, downward and backward. The coulter perforated through the shank is held by this rod passing the ends of these straps. The coulter ean be shifted laterally on this rod, and the upper end catches in the horn on either side of the beam. The coulter is spatula-shaped, nune inches long and three inches broad, sharpened on both sides. We give a figure of share:

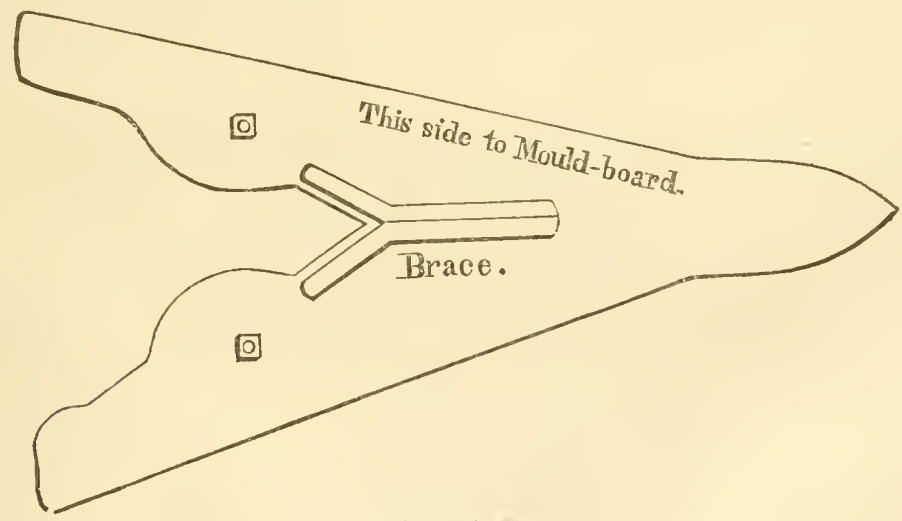

Fig. 123.

It will be seen that the share has on its uncler side a hrace or strengthener of the point which is cast with it. It extends through a slot or cavity of the monld-board, back along the two wings or prongs of the point, its object being to give strength to the point and allow of its heing mate of hard iron, which makes it much 
more durable. It is difficult to describe the mould-board, which is of no regular figure. It approximates in its general ontline to a cone, but has been pared away at different points to suit the views of the maker, and to adapt it to what he conceives to be the wants of the farmer.

The distance across, from the land side to the point of the feather, is $10 \frac{1}{2}$ inches. The length from the point of the plow to the point of the feather is 14 inches. Length of the land side, $23 \frac{1}{2}$ inches. From the point to the standard is 15 inches.

It worked very easily, and was very strongly made, and was of durable materials. Its great defect was a want of pulverizing power; the earth was hard after being plowed.

The judges decided as follows between these two plows:

First. Pulverizing power: Very greatly in fivor of Holbrook's. Second. Non-liability to ehoke in stubble: Equal in this respect. Third. Lightness of draft.

\begin{tabular}{|c|c|c|c|c|c|c|}
\hline \multirow{2}{*}{ PLOWS. } & \multicolumn{2}{|c|}{ FURROW. } & \multicolumn{2}{|c|}{ DRAUGHT. } & \multicolumn{2}{|c|}{ AVERAGES. } \\
\hline & $\begin{array}{l}\text { Width, } \\
\text { inches. }\end{array}$ & $\begin{array}{l}\text { Depth, } \\
\text { inches. }\end{array}$ & Actual. & $\begin{array}{l}\text { Per cubic foot } \\
\text { of earth. }\end{array}$ & Actual. & $\begin{array}{l}\text { Per cubic foot } \\
\text { of earth. }\end{array}$ \\
\hline $\begin{array}{l}\text { Holbrook's Swivel } \\
\text { Burch's Swivel... }\end{array}$ & $\begin{array}{l}12 \\
12 \\
12 \\
12\end{array}$ & $\begin{array}{l}7 \\
7 \\
7 \\
7\end{array}$ & $\begin{array}{l}618 \\
593 \\
507 \\
514\end{array}$ & $\begin{array}{r}1,059 \\
1,015 \\
869 \\
881\end{array}$ & $\left\{\begin{array}{l}605 \\
510\end{array}\right.$ & 1,037 \\
\hline
\end{tabular}

At a subsequent trial of their draft, side by side, in soil as nearly alike as possible, Holbrook's average draft was 502 pound yards. Burch's average draft was 432 pounds. In the first ease, Buch's was lightest by 95 pounds, or 15.7 per cent. In the seeond case he was lighter by 70 pounds, or 13.9 per ecnt. The merit of lightness of draft was therefore awarded to Burch.

Fourth-Ease of holding: Decided in favor of Burch.

Fifth-Duribility: Both equal in this respect.

Sixth-Cheapness: In favor of Burch.

Seventh-Excellence of mechanieal work: In favol of Holbrook.

Eighth-Excellence of material: Both equal in this respect. Ninth-Thorough inversion and burial of weds: Holbrook. Tenth-Even clistribution of wear: Holbrook, slightly.

Elerenth-Regularity or trueness of turning: Hollowok. 
It will be seen that five of these points were decided in favor of Holbrook, three in favor of Burch, and in three points they were judged to be equal.

On this state of facts the question was discussed which was entitled to the medal, and the question finally turned on the comparative merits of easy draft and thorough pulverization. One portion of the judges held that if Holbrook consumed more power he did the most work; that is, he did that which it was the object of plowing to accomplish, viz., thorough pulverization, while Burch did not. Others contended that the greater ease of draught of Burch's plow entitled him to the premium. On a division it was found that four of the judges were in favor of awarding the premium to Holbrook and four to Burch. After a full reconsid. eration the vote remained the same, and therefore no premium can be given in this class.

In point of cheapness Mr. Burch's plow was very remarkable. The following statement shows the cost of each part:

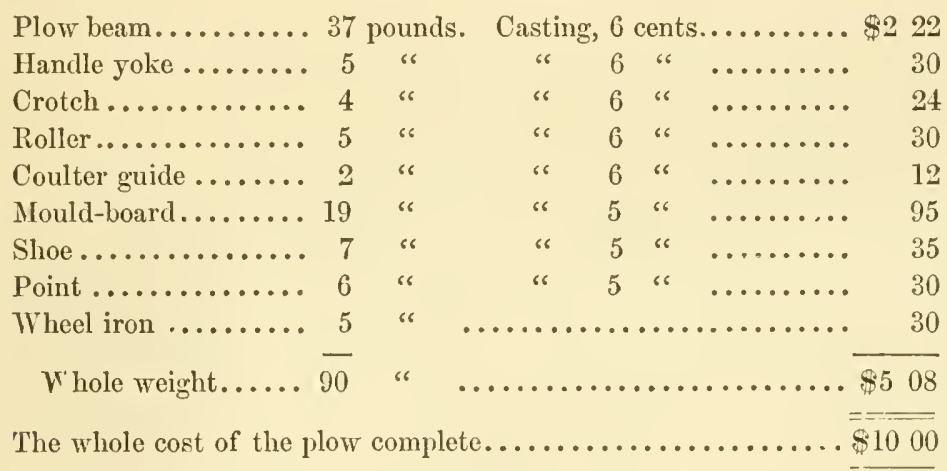

\section{HARROWS.}

Only one class of harrows was made in the programme of the Society, and only two were entered for competition, viz.:

J. E. Morgan, Decrfield, Oneida county, N. Y. Weight, 200 pounds. Price, $\$ 30$.

The extreme width of the harrow is 7 feet 4 inches. Its extreme length is 5 feet 3 inches. It has 48 teeth three-fourths of an inch square and $5 \frac{1}{2}$ inches long below the lower surfuce of the frame, which are steel pointed; a bolt passes through the frame behind each tooth to prevent splitting. It is made in two separate pieces, rectangular in form; each of the pices has two huge bolts passing through all its bar's, secured by a nut on the onter side of the outer bar; these huge bolts are furnished with 
an elongated eye, C D E F, the axis of which forms an angle of $20^{\circ}$ with the vertical line, the upper end of the eye being directed to the opposite harrow; these eyes are connected by a threequarter inch iron rod, A B, running through them. By this arlangement a backward and forward motion to the extent of nine inches, and an upward and downward motion to the extent of six inches is allowed to each side of the harrow, which adapts them admirably to work in rough and uneven ground. The draught is taken by rods hooking over a bar of iron between the two inner beams two feet long, vibrating on an iron are of a circle having a chord of 32 inches. These rods run back to hinge on the third tooth of the harrow. The evener is attached by a link to one end, and by a chain to the other 18 inches long. The chord of the right arc is 25 inches. The frame of the harrow is made of white oak. The wooden bar's are $2_{4}^{3}$ inches square and $8 \frac{1}{2}$ inches apart. The tracks of the teeth are 4 inches apart. It is drawn diagonally.

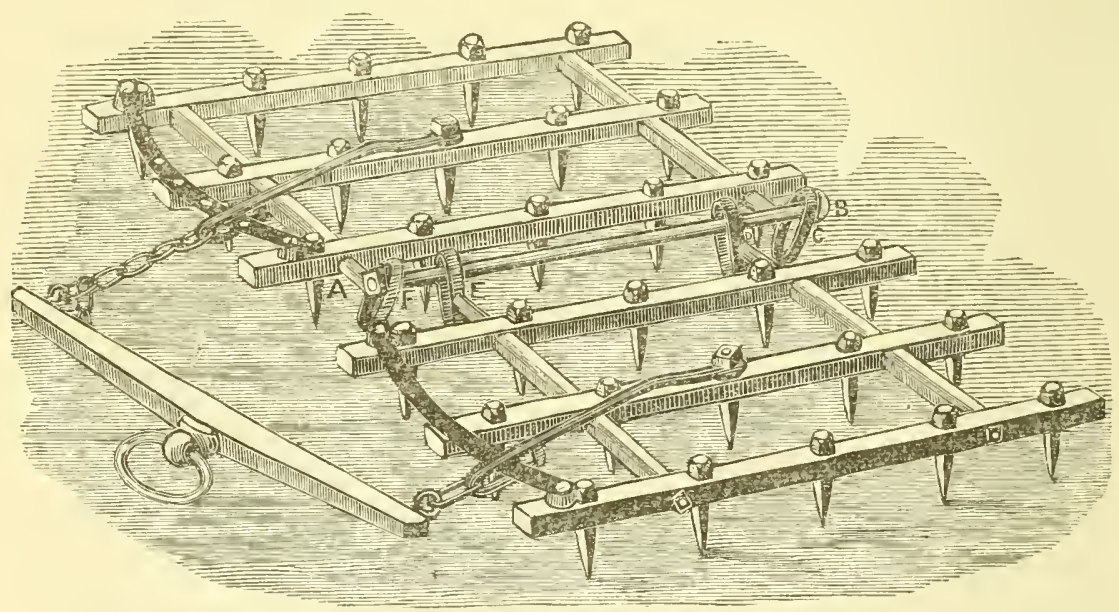

Frig. 124.

The draft of this harrow over ground which had been previously harrowed was 314 pounds; over ground which hat not been previously harrowed, 371 pounds.

The harrow is made in the best possible manner, the materials are of the best quality, and the rorkmanship is most thorough and conscientious throughont. It will be seen from the description given above that it has a wide range of self-adjustment and selt-adaptation, and is easily kept clear of weeds and other aremmulations. The teeth track rery well, no one tooth in 
ordinary circumstances following in the track of the other. It is a most excellent instrument in all respects, and we were unanimonsly of the opinion that it deserved the gold medal.

The other harrow was entered by 15 . Nishwitz. Weight. 250 pounds. Price, $\$ 40$.

It is exceedingly ingenious in its construction; and if not cutirely unique, we have never met with any similar one, nor have we met with any description of anything resembling it.

It consists of two expansahle arms, hinged in front and contiguous to each other. They are expanded behind to any desired width by eircular arms springing laterally and inwardly from the main arms at a point $2 \frac{1}{2}$ feet behind the angular point. These pass one above the other, and are secured at any desired expansion by a pin thrust through them both. The main frame is of oak, 8 inches wide and 2 inches thick. It runs on wheels 20 inches in diameter and $2 \frac{1}{2}$ inches wide, which are placed on a crank axle, the arms of which are $5 \frac{1}{2}$ inches long, and which regulate the depth.

The cutting action of this implement is by a series of rolling plates attached to each arm of the harrow. These plates are in the form of hollow segments of a sphere; the length of the chord is 11 inches, and the versed side ${ }_{4}^{3}$ inch. They are made of gray iron chilled on the edge, which is quite sharp; the convex side is turned outward. Seven of these concare plates are attached to one of the expanding arms, and six to the other. There is a socket attached to the center of each plate, upon which it rotates. A hollow cone, the opening at the base being $2 \frac{1}{2}$ inches in cliameter, and having a flange which is $\frac{5}{8}$ inch wide, is placed on the lower side of the expanding arms; an eye-bolt passes through the cone, which is fastened by a nut on the upper side of the arms; the eye fits into shoulders cut in the lower part of the cone. A steel pin from the eye projects inward, upon which the socket of the plates run; on the outside a seraper is attached to the under side of the oak arms, which takes off the adhering earth from the convex surface, and also prevents the plates from rumning off the steel pins upon which they rotate. They can be moved on a slot $1 \frac{1}{4}$ inches backward and forward. The plane of rotation of the plates make an angle of 15 degrees with the line of the harrow's motion.

The effect of this machine as a pulverizer was most astonishing. It worked most effectually diagonally across the furrows, going 
across in this way and returning at a reverse angle, so as to cut the furrow diamond wise, reduced it to powder like flour. It also worked most admirably in scarifying sod. It makes one of the most perfect implements that can be imagined for mellowing the surface of moss bound meadows, and for scarifying meadows and pastures where the grass has run out, which it is desirable to re-seed without plowing.

We did not test among lumps and clods, but it was very evident from its mode of action that it would be a most effectual mode of breaking these down, and it will probably prove a better implement for this purpose than Crosskill's elod crusher, or any of the numerous imitations of that implement with which the market abounds. It is also admirably adapted to working fallows. It is not well adlapted to level uneven land or to cover seed. In these respects it would not answer as well as Mr. Morgan's; but as a superficial pulverizer we cannot speak too highly of it. As it is designed to meet a difficulty in practical husbandry which no preceding machine accomplishes as well, we recommend to the Executive Committee to award a special gold medal to Mr. Nishwitz for this invention.

\section{CULTIVATORS.}

Class I-For Corn and Root Crops, Best One-morse CultiVATOR, ONE ROW.

There were two entries in this class, one by Alden \& Co., Auburn, and by N. Hawks, Appleton, Maine. The weight of Alden's machine is pounds. Price, $\$ 12.50$.

The frame, A B C D E F G H, Fig. 125, with various additions and substitutions, is made to accomplish a great variety of services in practical husbandry, as seen in Fig. 125. It is used simply as a cultivator for ordinary purposes. The thills, A B and $C D$, are of white ash; as seen in the figure they are 22 inches above the bars, $\mathrm{E} \mathrm{F}$ and $\mathrm{G} \mathrm{H}$, but may be raised or lowered $1_{\frac{1}{2}}$ inches. The upright and diagonal braces are of hoop iron; the bars of oak. The teeth are of steel; the hind tooth is in the form of a double diamond, the three front ones are half diamond. The teeth are reversible, so as to throw the earth to or from the row. Throwing the earth from the row he went within an inch of it. The piece of ground assigned to him for trial was excessively weedy. On going twice over it, it was thoroughly 
cleared of weeds, and the ground was well mellowed two inehes deep. It is converted into a marker for planting corn by taking off the four teeth and bolting a bar long enough to mark three rows on the under side of the arm, G H. It is shown as a cornmarker in Fig. 126. The teeth are wood, and their action will be understood by an inspection of the figure. Pegs, not shown in the figure, are driven diagonally into the upper eorners of the cross bar, which support weights when it is desired to press the markers deeper into the ground. It is arranged as a quack rake by inserting fifteen teeth eurved forward in an arm similar to the potato marker. The price of these teeth is $\$ 2.25$.

For hilling corn, a diamond tooth is placed in front, having expansible wings. Two other teeth are placed at $H$ and $G$, which throw the earth towards the corn.

To cover two rows of potatoes, four small plows, with long wings (it takes twenty minutes to make this change) are serewed on to the arms of the machine. With this arrangement the potatoes were covered in going backward

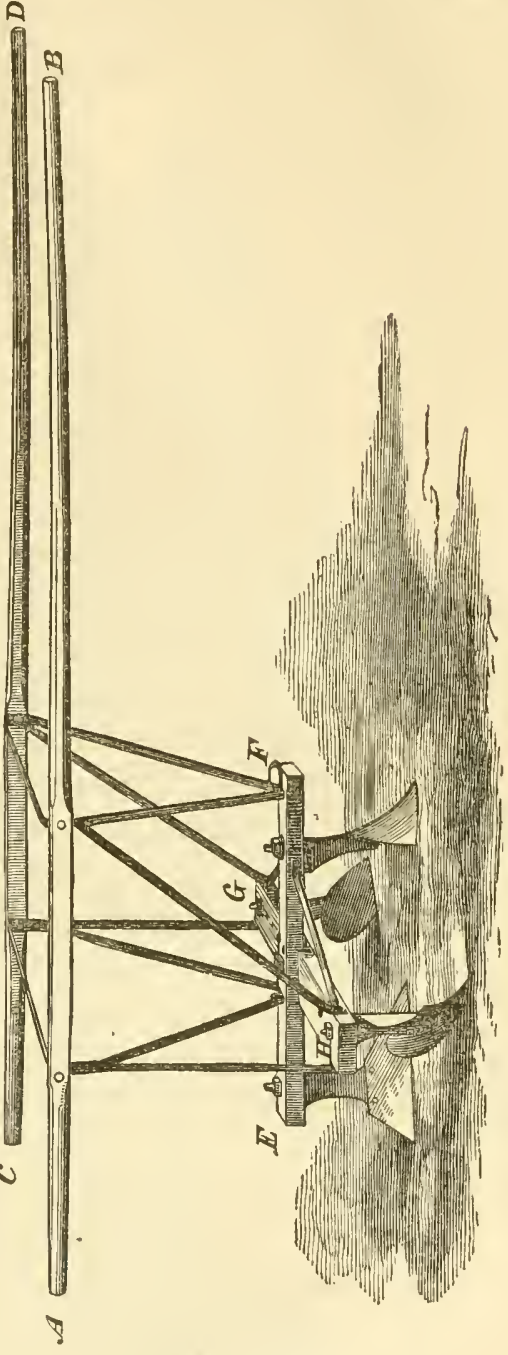

Fig. 125. and forward, raising a ridge 4 inches high.

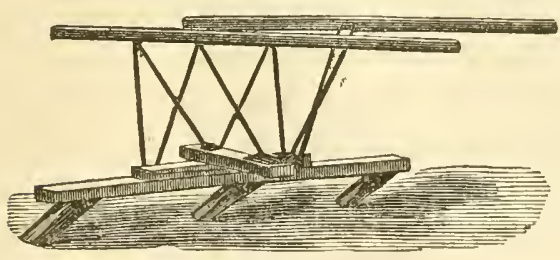

Fig. 126.

In a word, this machine cultivates between the rows in the usual manner. It marks furrows for corn, potatoes, or any other crop requiring to be planted in straight lines; rakes quack or other roots out 
of the soil, leaving them in rows upon the surfice. It makes the furrows for any crops requiring to be planted in hills, and covers them, ridging them as much as is required. It was tried by very severe tests in the most difficult soils and circumstances, and did good work in all.

The work of Mr. Hawks' machine has been described under the head of "Ditching Plows," in Class VII, as a seed-planter, cultivator, potato-digger, etc. As the two machines were entered only as cultivators, we can only compare them strictly as such. We are of opinion that Alden's Cultivator cut up the weeds, and mellowed the ground, and performed the legitimate work of a cultivator better than Hawks, and we therefore award it the gold medal in this section of Class I.

For the same section of Class I, only one entry was made by A. L. Brierly \& Co., of Trenton, N. J., who entered Phifers' Improved Wheel Corn, Cotton and Potato Plow and Cultivator, which is represented in Fig. 127.

The diameter of the wheel is 4 feet 6 inches; length of axle or distance between the wheels at their maximum separation is 5 feet 4 inches. The axle is of wrought iron, $1 \frac{3}{8}$ inches in diameter. The wheels may be run together by means of a sliding collar and pinching screw, so that their distance from each other will be only 2 feet 6 inches. They may be made to take any intermediate place between these maximum and minimum points.

Four wooden bars seen in the figure, each 21 inches long, are adjusted over the axle by a circular clip, the shank of which passes through the bar and is fistened by a nut. A slotted iron bar is bolted to the inner ends of each pair of bars. A vertical bar, with slots in both directions, is bolted to each bar just in advance of the axle, and secured by fangs on the top and bottom; from this vertical bar and jointed to it a lever extends backwards 2 feet 7 inches, and 1 foot 10 inches downward. It is curved downward at its lower end, and slit so as to embrace the head of the plow or cultivator tooth.

A projection extending backward at an acute angle receives a brace, which hinges on a bar below the lifting lever, as showu in the cut. The brace is perforated by nine holes, which are keyed to the projection from the curved end of the lever; the inner end of the lever is adjusted by a rod and screw ruming through the wooden bars. The cultivator teeth are fastened to the lever by an iron bolt and wooden pin. If the plow or cultivator tooth 





eneounters any sudden strain, the wooden pin breaks at onee, and its connection by the bolt leaves it simply as a loose joint, and takes off all the strain until the obstacle is passed.

It will be seen by a careful study of this arrangement that it provides for a very wide range of adjustment. The wheels may be set at any distance apart by raising or lowering the eurved levers in the slots of the vertical bars. The plow points may be made to take more or less depth by meaus of the lifting lever. Any one or more of the plows eam be lifted from the ground, either wholly or in part, by the holes at the slot ends of the curved levers; they ean be lengthened or shortened, and the plow ean be made to go as deep or as shallow as is desired.

There is a semicircular areh shown in the figure, one end of which rests on the axle and the other on the slotted bars; it is furnished on the outer circle with notehes. A thumb lateh at the upper end of the lifting lever works a rod comnected with a spiral spring, and permits a bolt to enter the notches, by which the teeth are raised out of the ground.

A convenient seat for the driver, resting on a stecl spring, is seen in the figme. An arm projecting laterally can be bolted to the end of either of the curved levers, by which the number of plow or eultivator teeth ein be increased at pleasure.

The machine is also provided with a steering apparatus. An iron bar is bolted to the under side of the axle, having a circular disk in the eenter, in which is a circular slot. The pin of the tongue is inserted in the slot, but is fastened by a bolt kept in place by a spiral spring. When the spring is raised by a lever the tongue has a motion of rotation to the extent of the circular slots. An iron bar 1 foot 4 inches long projects from the tongue on each side, and a ehain passes from either end of it to the ends of the under bar. A lever ean therefore elange the angle of the tongue with the axle at pleasure. The machine was tried in all the operations that it professed to perform, although we conld only consider it officially as a eultivator.

It first operated as a seed-sower, scattering rye very evenly, and eovering it with four plows rumning shallow and turning the earth all one way. Next it worked with seven cultivator teeth, throwing the earth in opposite direetions. It eultivated two rows of corn, one plow on eteh side throwing earth towards the corn and one throwing it away from it. Again, all the plows threw earth towards the corn, and then both threw it away from it. 
The changes to accomplish these different objects c:m be made very easily; in no case did it require more than six minutes for that purpose. It did all the work, and went through all the tests to which it was subjected in a very perfect manner. It worked close to the corn rows, and, by means of the steering apparatus, it could be made to move around a hill or a single stalk which happened to stand out of line, without injuring it or tonching it. It destroyed the weeds very satisfactorily, and it was tested in as weedy a patch and as tough a soil as we ever saw. It pulverized the soil as well as could be desired. The only funlt that we noticed in the whole course of the protracted trial which we gave to it was that, in some very bad places, it clogged somewhat. It is very strong in all its parts, and we think it is not liable to get out of order. The material is very skillfully distributed, the greatest amount of material being distributed to the parts where the strain is greatest.

We award the gold medal to this machine in the second section of the first eliass.

\section{Class II-For Mellowing Soil and Killuing Weeds.}

Ford \& Howe, of Oneonta, N. Y., entered for this section of Class II. Weight, 480 pounds. Price, $\$ 60$.

The drawing, Fig. 128, will give a very clear idea of its construction. The evener A B swings on the under side of the tongue, from the evener iron bars run backward diagonally to a little beyond the middle of the bars of the frame from which the cultivator teeth are suspended; hence, although the horses are hooked to the end of these bars, neither horse can pull more than another, their action being equalized by the evener as in the common whiffietree. It will be seen that a brace runs forward from about the middle of each shank of the tooth, and bolts into the bars of the frame. There are several holes pierced through these bars near the lower end; by changing the pins through these bolts a greater or less angle can be given to the plane of the teeth as they enter the ground. The tongue has an opening in the middle, from $\mathrm{D}$ to $\mathrm{E}$, which enables the driver more easily to strike a straight line. It can rotate from right to left around the pin C. There is a friction wheel on the under side of the tongue, which rolls on the iron are G. The driver, seated in the chair, with a foot on each of the outer bars, carries himself to the 


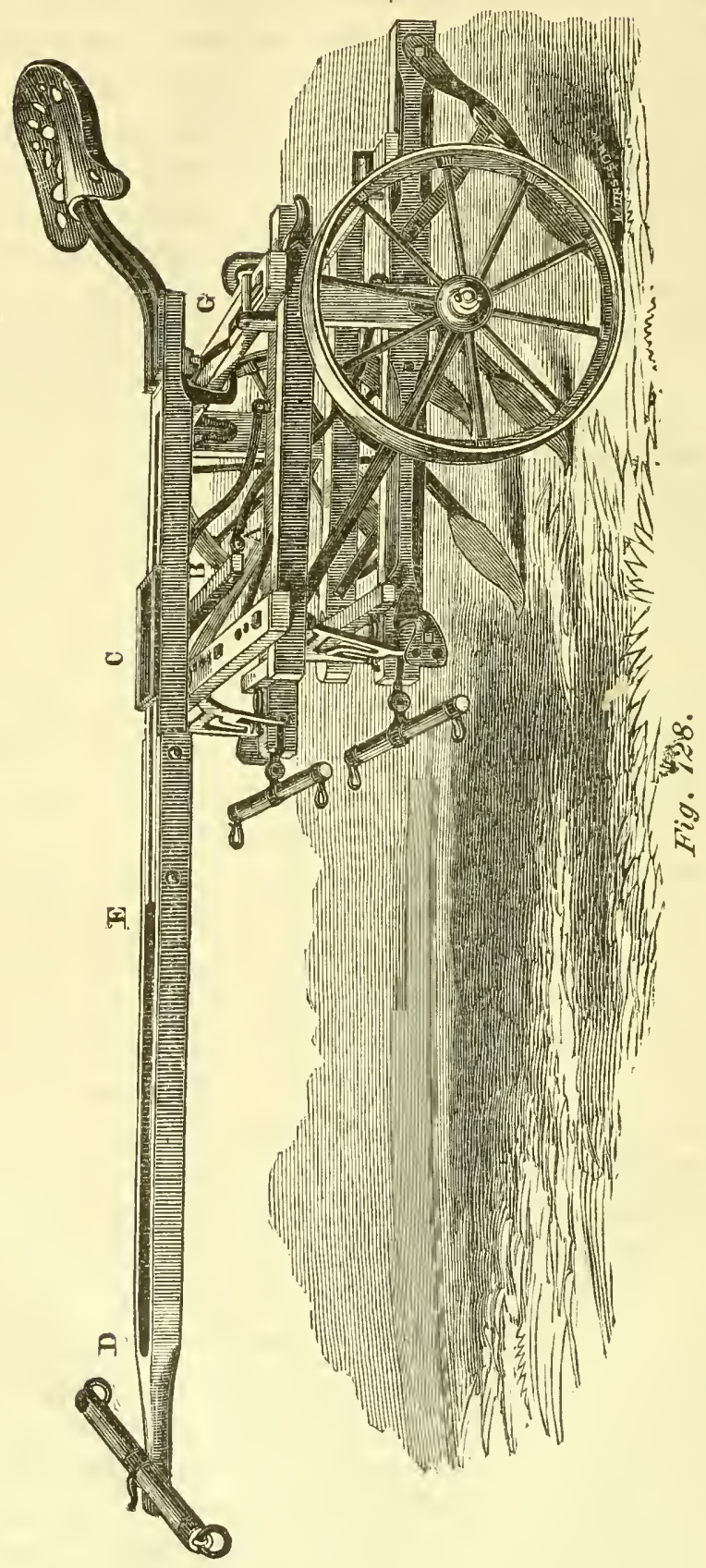


right or the left, as he chooses; he thus turns the machine at his pleasure, and avoids any plant which may stand out of the line. By means of a crank not seen in the figure, the tecth may be entircly lifted out of the ground or made to run deeper or shallower. By drawing out the pin at E, the tongue may be turned on the other pin as pivot. By this arangement it is stowed away when not in use with much economy of space. The blades of the teeth may be turned from the right to the left so as to throw the earth either to or trom the corn. Where used as a gang plow, three beams and three rows of teeth are used; for cultivating in cor'n only two sets are employed. It does its work extremely well, and the only objection to it that we observed is that it takes considerable time to make the changes, viz.: twenty minutes to change it from a gang plow to a corn cultivator, and twelve minutes to chinge the angle of the teeth so as to throw earth to the corn when it had been throwing it away from it. We award it a gold medal in this section of the class.

In the sceond section of Class II, William H. Burtis \& Co., Maltaville, Saratoga county, entered McQueston's Improved Cultivator.

This implement will be understood by an inspection of the annexed Fig. 129, without any further description. Weight, 100 pounds. Price, $\$ 35$.

It will be observed that the point of each spade has a horizontal range of nine inches on the diagonal rod which passes through the shank just above the base of the spade. Each of the beams to which the spades are attached work freely on a centre at the front end, which enables the attendant to raise out of the ground or press them into it at pleasure; they also have a lateral range of a complete semicircle. The wrought iron arch in front is two inches wide and one-half an inch thick. The wheels are of cast iron, 14 inches in diameter by 2 inches wide. The shovels are of steel, $5 \frac{1}{2}$ inches wide and 10 inches long. The work was well done in all places where it was tried; it stirred the soil to a depth of 6 inches, which was about $1 \frac{1}{2}$ inches deeper than any of the others. It never was observed to elog. It has one peculiarity in which it differs from all the others, which we must confess we do not quite understand-it leaves the grass and weeds on the top of the ground without burying them, while all the others bury them. The greatest oljection to it is that it malies 
very hard work for the attendant. Where a machine is desired to be regulated by handles and without permitting the attendant

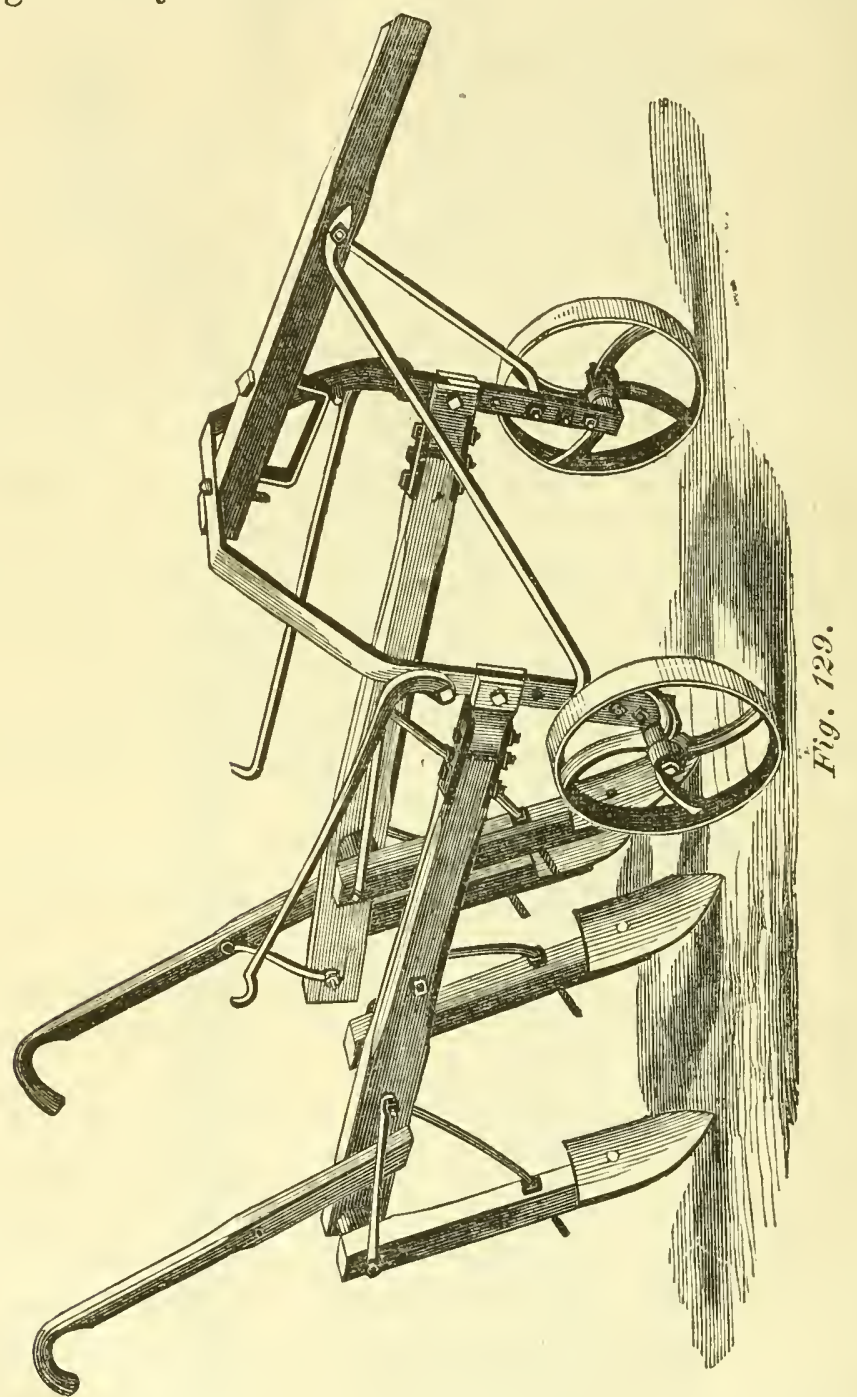

to ride, this machine can be confidently recommended. We :wward the gold medal to this section of the class.
JOHN STANTON GOULD, ELISHA R. POTTER, B. P. JOIINSON, SANFORD HOWARD, PETER CRISPELL, JR., JOSEPII MCGRAW.
HENRY WATERMAN,

Note.-Mr. Conger was not present at the trial. Mr. Geddes was only present for a single day, and took no part in the decision. Prof. Pierce declines to have his name appended to the report, as he does nut concur in some of its statements. 


\title{
REPORT OF THE SPECIAL COMMITTEE
}

\author{
ON TILE
}

\section{SUPPLEMENTARY PLOW TRTALS,}

Held at Brattleboro', June 2, 3 and 4, 1868.

'Ine Executive Committee of the New York State Agricultural Society, having been informed by the report of the judges of the plow trial instituted by the Society at Utica, last year, that, from aceidental circumstances, they were unable to complete the trials necessary to ascertain the facts in relation to the plow and its working, which were of great importance to the plow-wright and the farmer, it appointed a special committee, consisting of the chairman of the board of judges and the consulting engineer of the Society, who were requested to complete the trials at such time and place as they might deem most desirable in order to obtain correct results.

In pursuance of this appointment, they fixed on Brattleboro', Vermont, as the place, and June 2, 1868, as the time for obtaining the supplementary facts which were necessary to the completion of the plow report.

The points upon which we endeavored to obtain light were the following:

I. What is the increase of power required for each successive inch of depth in plowing?

II. What is the increase of power required for each successive inch of width in plowing?

III. What is the increase of power required when the furrow slice remains of the same size for each successive increment of velocity?

IV. What proportion of the total amount of power consumed in plowing is absorbed by the different parts of the plow, viz., the land side, the share, the mould-board?

V. What is the influence of the coulter on dranght? 
VI. Does the skim-plow consume more or less power than the coulter?

VII. What is the elasticity of different soils?

VIII. What is the influence of the wheel on draught?

IX. What is the influence of the plowman on draught?

We had ascertained by previous trials that one furrow varied very greatly in tenacity from another lying closely contiguons to it, and this difference was so great that it sometimes required a force of three hundred pounds to overcome it.

It was, therefore, in our judgment, of great importance to obtain a piece of laxd for the trials as homogeneous as possible in its texture and as free from local obstacles, such as stumps, stones and roots, as could be obtained. In order to guard against interruptions from continuous rainy weather, it was desirable to select land which drained easily and rapidly. The lands on the Connecticut river, near Brattleboro', met these conditions more narly than any other's with which we were acquainted, and the trial was accordingly appointed for that locality.

The plowing was done on the meadow belonging to the Brattleboro' Lunatic Asylum, which lies about ten feet above the summer level of the Connecticut river, but which is often entirely covered by the spring floods. The soil is a sandy loam, somewhat stiffer than is usual in that class of lands, and very full of micaceous scales. It has been in sod for twelve years past; the grass, which was chiefly blue grass, poa pratensis, was very thick upon the ground, and the roots were tough and thick. In some of the furrows there were found thick masses of quack roots (Triticum repens); in others there was a great deal of hardhack (Spircea tomentosa); in some other's, both kinds of roots were combined. Although the general appearance of the meadow was level, yet it was nevertheless considerably rolling, and it was found that there was considerable difference in the draught of the furrows which were turned so as to fall down hill or up hill.

As examples of the differences thus caused, we refer to the seventy-sceond experiment, where the furrow was turned down hill, and the seventy-third, where it was turned up hill; the difference in draught being 76 pounds in fivor of the down-hill furrow. The same result is also exhibited in the seventh-sixth and seventy-seventh experiments, where the difference was 96 pounds. The difference hetween the seventy-fourth and seventy- 
fifth experiments was 136 pounds, which was caused by the seventy-fifth being turned up hill, and also to the roots of the hardhack, which varied from one-eighth to three-eighths of an inch in diameter. The soil was very moist from recent copious rains.

Governor F. Holbrook was kind enough to procure for us the various plows, with the necessary adjustments required for the trial; and also, at our request, negotiated for the use of the land and for the the teams and assistants.

We obtained the assistance of Mr. Henry Brooks, of Concord, well known as a very skillful plowman, and his services as such were perfectly satisfactory.

Governor Holbrook, of Vermont; Governor Brown, of Massachusetts, and Mr. Joel Nourse, of Boston, the inventor of the well known Eagle plow, were present with us at all the trials, and their advice and assistance were of great value. Mr. G. Tucker, of the Country Gentleman, was also with us during the whole time.

We began our experiments with two horses, but finding it difficult to preserve a perfectly uniform breadth of furrow, owing to the irregularity of their walking, we used four horses, walking in pairs, so that the irregular walk of one team compensated for the irregularity of the other. Finding that four horses made the experiments so much more satisfactory, we continued the use of them throughout.

I. Experiments to determine the increase of power required for each successive inch of depth in plowing with

Holbrook's Swivel Plow, No. 4:

\begin{tabular}{|c|c|c|c|c|}
\hline 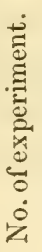 & 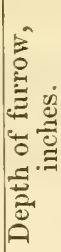 & 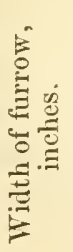 & 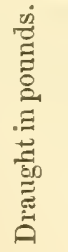 & REMARKS. \\
\hline 1 & $6 \frac{1}{2}$ & $13 \frac{1}{2}$ & 494 & \multirow{5}{*}{$\begin{array}{l}\left\{\begin{array}{c}\text { This was probably a mis-reading of the dynamometer, } \\
\text { and is rejected in making up the averages. }\end{array}\right. \\
\left\{\begin{array}{c}\text { Average of third and fourth experiments, with a furrow } \\
\text { slice of the same size, } 566 \text { pounds. }\end{array}\right.\end{array}$} \\
\hline 2 & 7 & $13 \frac{1}{2}$ & 611 & \\
\hline 3 & 7 & $13 \frac{1}{2}$ & 557 & \\
\hline 4 & 7 & $13 \frac{1}{2}$ & 575 & \\
\hline 5 & $7 \frac{1}{2}$ & $13 \frac{1}{2}$ & 584 & \\
\hline
\end{tabular}


Holbrook's Swivel Plow, No. 4 (Continued).

\begin{tabular}{|c|c|c|c|c|}
\hline 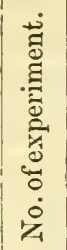 & 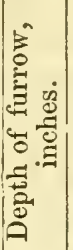 & 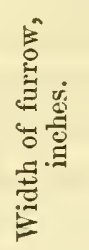 & 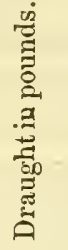 & REMARKS. \\
\hline 6 & $7 \frac{1}{2}$ & 14 & 634 & $\left\{\begin{array}{l}\text { The average of the fifth and sixth experiments is } 609 \\
\text { pounds. Although the sixth is half an inch wider } \\
\text { than the fifth, the excess is chiefly due to the turn- } \\
\text { ing of the furrow up hill in the sixth. }\end{array}\right.$ \\
\hline 7 & 8 & 15 & 641 & A Average of the seventh and eighth experiments, 651 \\
\hline 8 & 8 & 15 & 660 & $\begin{array}{l}\text { pounds. } \\
\text { Average of the ninth and tenth experiments, } 469\end{array}$ \\
\hline 9 & 6 & 12 & 482 & pounds. The excess of draught of the ninth over \\
\hline 10 & 6 & 13 & 457 & $\begin{array}{l}\text { the tenth was due to old bones which lay in the } \\
\text { bottom of the furrow. }\end{array}$ \\
\hline *11 & 6 & 13 & 582 & $\left\{\begin{array}{l}\text { The work without the coulter was very poor; the } \\
\text { furrow slice was torn and jagged; the furrows did } \\
\text { not lap well; the grass was ill covered, and the } \\
\text { pulverization was imperfect. }\end{array}\right.$ \\
\hline$\dagger 12$ & 6 & 13 & 504 & Work good in all respects. \\
\hline$\ddagger 13$ & 6 & 13 & 505 & S Average of thirteenth and fourteenth experiments, \\
\hline 14 & 6 & 13 & 501 & $502 \frac{1}{2}$ pounds. \\
\hline
\end{tabular}

* The coulter was here removed, and the plow was worked, cutting the sod with the shin.

$\dagger$ The coulter was here replaced, but was set so that it only penetrated one inch into the soil.

$\ddagger$ The coulter was here brought down within three inches of the sole of the plow.

This plow made the best pulverization at a depth of seven inches. It was slightly worse at eight inches; but at depths greater or less than these the inferiority of its worls was very marked.

The average depth of the first ten experiments was 7.05 inches; the average breadth of the first ten experiments was 13.65 inches; the average draught of the first ten experiments was 565 pounds.

This average draught of all the trials agrees within one pound with the average dranght of the third and fourth experiments, which correspond with it in the size of the furrow slice.

Recapitulation of Averages.

\begin{tabular}{|c|c|c|c|}
\hline Inches. & Inches. & Pounds. & Differences, pounds. \\
\hline 6 & $12 \frac{1}{2}$ & 469 & $\ldots$ \\
$6 \frac{1}{2}$ & $13 \frac{1}{2}$ & 494 & 25 \\
7 & $13 \frac{1}{2}$ & 566 & 72 \\
$7 \frac{1}{2}$ & $13 \frac{3}{2}$ & 609 & 43 \\
8 & 15 & 651 & 42 \\
\hline
\end{tabular}


The average difference of draught for each half inch of depth is 45.5 pounds, or 91 pounds to each inch. The accuracy of this average is somewhat impaired by the fact that there is a difference in the breadth of the furrows, the extremes being $2 \frac{1}{2}$ inches apart.

We next began a series of experiments to determine the rates of draught to depth with Holbrook's Plow No. 69, with a coulter and sod mould-board:

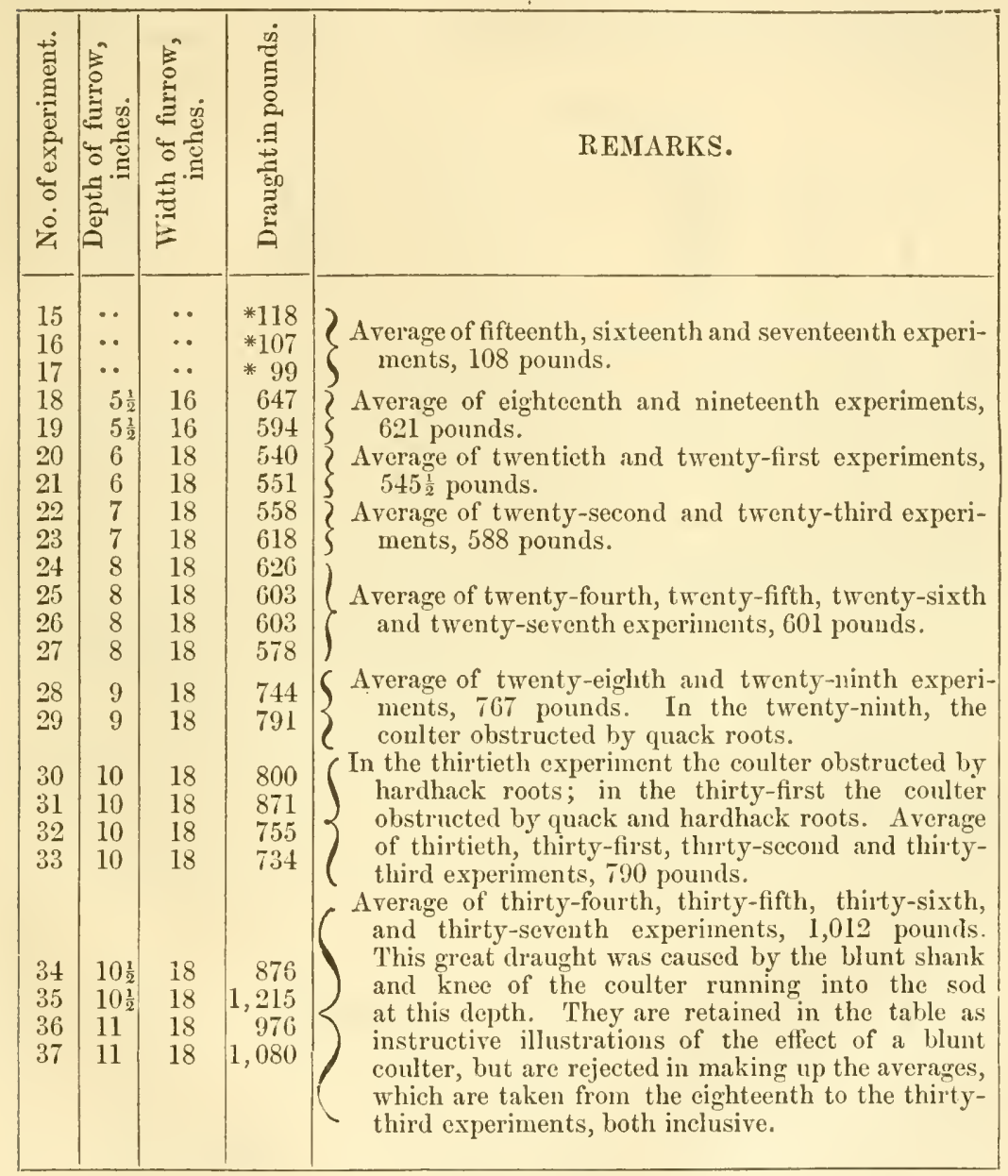

* Surface draught.

Average depth from eighteenth to thirty-third experiments, 7.94 inches; average width, 17.80 inches; average dranght, 663 pounds; average prism, 141.33 square inches. Average prism from twenty-fourth to twenty-seventh experiments, 144 square inches; average draught, 601 pounds. 
In this series, with Plow No. 69, the average draught of the whole series exceeds the average draught of the series of experiments which agree with it in the size of the furrow slice by 62 pounds. (Experiments twenty-four, twenty-five, twenty-six and twenty-seven, eight inches deep and eighteen inches wide.)

Recapitulation of Experiments with Plow No. 69.

\begin{tabular}{|c|c|c|c|c|}
\hline $\begin{array}{c}\text { Average depth, } \\
\text { of furrow, } \\
\text { inches. }\end{array}$ & $\begin{array}{c}\text { Average width, } \\
\text { of furrow, } \\
\text { inches. }\end{array}$ & $\begin{array}{c}\text { Average draug't } \\
\text { in pounds. }\end{array}$ & $\begin{array}{c}\text { Difference, } \\
\text { pounds. }\end{array}$ & $\begin{array}{c}\text { Size of prism, } \\
\text { square inches. }\end{array}$ \\
\hline $5 \frac{1}{2}$ & 16 & 621 & $\ldots$ & 88 \\
6 & 18 & $545 \frac{1}{2}$ & $75 \frac{1}{2}$ & 108 \\
7 & 18 & 588 & $42 \frac{1}{2}$ & 126 \\
8 & 18 & 601 & 13 & 144 \\
9 & 18 & 767 & 166 & 162 \\
10 & 18 & 790 & 23 & 180 \\
\hline
\end{tabular}

The average difference in the dranght of each inch in depth was 61 pounds. The excess of $75 \frac{1}{2}$ pounds of draught in the furrow of 88 square inches over the furrow with 108 square inches is anomalous, and was caused either by an error in reading of the dynamometer indication or by some local obstruction. The anomaly did not appear until the indications were computed, and it was then too late to ascertain the cause of it. This difference was not, therefore, included in the average of 61 pounds.

The next set of experiments to determine the rates of draught to depth was made with Holbrook's Plow No. 65, the coulter being adjusted to lay flat furrows:

\begin{tabular}{|c|c|c|c|c|}
\hline 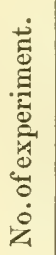 & 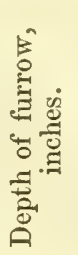 & 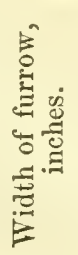 & 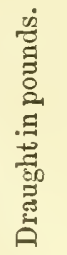 & REMARKS. \\
\hline $\begin{array}{l}38 \\
39 \\
40 \\
41 \\
42 \\
43 \\
44\end{array}$ & $\begin{array}{l}2 \\
2 \frac{1}{2} \\
2 \frac{1}{2} \\
3 \frac{1}{2} \\
3 \frac{1}{2} \\
4 \frac{1}{2} \\
4 \frac{1}{2}\end{array}$ & $\begin{array}{l}\text { 11 } \\
11 \\
11 \\
11 \\
11 \\
11\end{array}$ & $\begin{array}{l}* 77 \\
324 \\
328 \\
404 \\
392 \\
459 \\
419\end{array}$ & $\begin{array}{l}\text { Average of thirty-ninth and fortieth experiments, } \\
326 \text { pounds. } \\
\text { Average of forty-first and forty-second experiments, } \\
398 \text { pounds. } \\
\text { Average of forty-third and forty-fourth experiments, } \\
439 \text { pounds. }\end{array}$ \\
\hline
\end{tabular}

* Surfice draught. 


\begin{tabular}{|c|c|c|c|c|}
\hline 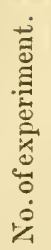 & 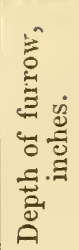 & 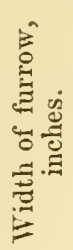 & 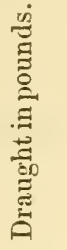 & REMARKS \\
\hline $\begin{array}{l}45 \\
46 \\
47 \\
48 \\
49 \\
50 \\
51 \\
52 \\
53 \\
54 \\
55\end{array}$ & $\begin{array}{l}5 \frac{1}{2} \\
5 \frac{1}{2} \\
5 \frac{1}{2} \\
5 \frac{1}{2} \\
7 \\
7 \\
7 \\
8 \\
8 \\
8 \\
8\end{array}$ & $\begin{array}{l}11 \\
11 \\
11 \\
11 \\
11 \\
11 \\
11 \\
11 \\
11 \\
11 \\
11\end{array}$ & $\begin{array}{l}451 \\
463 \\
428 \\
424 \\
520 \\
504 \\
512 \\
574 \\
545 \\
564 \\
528\end{array}$ & 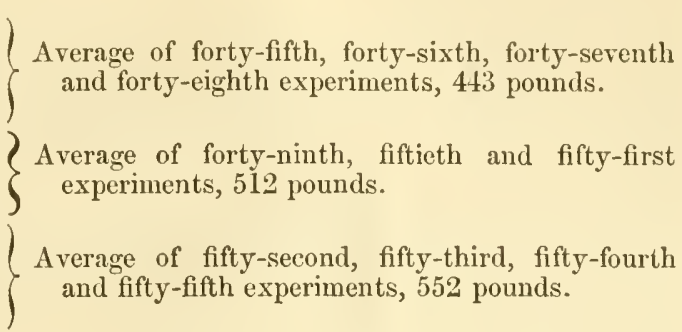 \\
\hline
\end{tabular}

Average depth from thirty-ninth to fifty-fifth experiments, both inclusive, 5.64 inches; average width from thirty-ninth to fiftyfifth experiment, both inclusive, 11 inches; average draught from thirty-ninth to fifty-fifth experiments, both inclusive, 463 pounds.

The average dranght of the whole series of experiments exceeds the average of the forty-ifth, forty-sixth, forty-seventh and forty-eighth experiments, which agree most nearly with it in the size of the furrow slice, by 20 pounds.

Recapitulation of Experiments with Plow No. 65-Flat furrow.

\begin{tabular}{|c|c|c|c|c|}
\hline $\begin{array}{c}\text { Depth of fur- } \\
\text { row, inches. }\end{array}$ & $\begin{array}{c}\text { Width of fur- } \\
\text { row, inches. }\end{array}$ & $\begin{array}{c}\text { Draught in } \\
\text { pounds. }\end{array}$ & $\begin{array}{c}\text { Difference, } \\
\text { pounds. }\end{array}$ & $\begin{array}{c}\text { Size of prism, } \\
\text { square inches. }\end{array}$ \\
\cline { 1 - 2 }$\ldots$ & $\ldots$ & $* 77$ & $\ldots$ & $\ldots .$. \\
$2 \frac{1}{2}$ & 11 & 326 & 72 & 27.5 \\
$34^{\frac{1}{2}}$ & 11 & 398 & 41 & 48.5 \\
$5 \frac{1}{2}$ & 11 & 439 & 4 & 60.5 \\
7 & 11 & 443 & 69 & 77 \\
8 & 11 & 512 & 40 & 88 \\
\hline
\end{tabular}

* Surface draught.

The average difference in the draught of each inch in depth was 45.20 pounds.

Experiments to determine the rates of draught to depth made with Holbrook's Plow No. 65. with a coulter adjusted to lup furrows: 


\begin{tabular}{|c|c|c|c|c|}
\hline 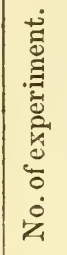 & 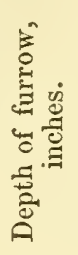 & 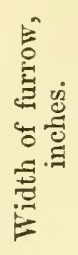 & 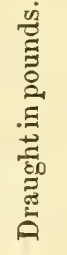 & REMARKS \\
\hline *56 & 8 & 11 & 485 & The furrow was not of full width; not averaged. \\
\hline $\begin{array}{l}* 57 \\
* 58\end{array}$ & $\begin{array}{l}8 \\
8\end{array}$ & 11 & $\begin{array}{l}520 \\
557\end{array}$ & A Average of fifty-seventh, fifty-eighth and fifty- \\
\hline *59 & $\begin{array}{l}\circ \\
8\end{array}$ & 11 & 558 & ninth experiments, 545 pounds. \\
\hline$\dagger 60$ & 8 & 11 & 515 & Average of sixtieth and sixty-first experiments, \\
\hline+61 & 8 & 11 & 509 & 512 pounds. \\
\hline 62 & 8 & 11 & 452 & \\
\hline 63 & 8 & 11 & 458 & (Average of sixty-second, sixty-third, sixty-fourth \\
\hline 64 & 8 & 11 & 444 & C and sixty-fifth experiments, 453 pounds. \\
\hline 65 & 8 & 11 & 459 & \\
\hline \pm 66 & 7 & 10 & 384 & Average of sixty-sixth and sixty-seventh experi- \\
\hline$\ddagger 67$ & 7 & 10 & 460 & $\zeta \quad$ ments, 422 pounds. \\
\hline 68 & 7 & 10 & 370 & \\
\hline 69 & 7 & 10 & 420 & Average of sixty-eighth, sixty-ninth, seventieth \\
\hline 70 & 7 & 10 & 390 & and seventy-first experiments, 389 pounds. \\
\hline 71 & 7 & 10 & 379 & \\
\hline
\end{tabular}

* On examining the plow after it had been used in these four experiments, it was found that the coulter was excessively dull; it was, in fact, an unfinished one which had been put in inadvertently when the change was made for a lap furrow. A sharp coulter was then inserted.

$\uparrow$ The coulter in these two experiments was very badly choaked with roots which collected across its edge. To remedy this the rake was very considerably increased.

‡ It was found that the coulter, in these two experiments, had slipped down so as to loose the extra rake which had been given to it, and the grass roots again gathered on its edge. More rake was then given to it.

The difference between plowing seven inches or eight inches deep, according to these experiments, is 64 pounds. The same plow showed a difference between seven inches and eight inches, when turning a flat furrow, of 40 pounds. (Experiments forty-nine to fifty-five.)

Experiments to determine the rates of draught to depth with Holbrook's Sod and Subsoil Plow No. 69, with a stubble mouldboard and a skim plow attached to the front of the beam:

The skim plow turned a furrow two and a half inches deep in all cases; the remainder of the furrow slice was turned by the main plow.

The column headed "Depth of furrow" indicates the whole depth turned by the skim and the main plow.

The point of the skim plow was eleven inches in advance of the point of the main plow. 


\begin{tabular}{|c|c|c|c|c|}
\hline 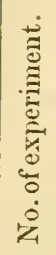 & 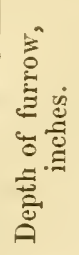 & 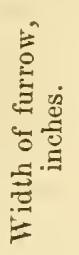 & 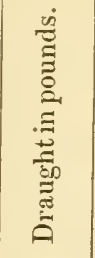 & REMARKS \\
\hline $\begin{array}{r}72 \\
73 \\
* 74 \\
* 75 \\
76 \\
* 77 \\
78 \\
79 \\
80 \\
81 \\
+82 \\
83\end{array}$ & $\begin{array}{r}9 \\
9 \\
10 \\
10 \\
11 \\
11 \\
12 \\
12 \\
13 \\
13 \\
14 \\
14\end{array}$ & $\begin{array}{l}12 \\
12 \\
12 \\
12 \\
12 \\
12 \\
12 \\
12 \\
12 \\
12 \\
12 \\
12\end{array}$ & $\begin{array}{r}621 \\
697 \\
733 \\
869 \\
800 \\
896 \\
947 \\
1,003 \\
1,012 \\
1,082 \\
966 \\
1,143\end{array}$ & $\begin{array}{l}\text { Average of seventy-second and seventy-third experi- } \\
\text { ments, } 659 \text { pounds. } \\
\text { Average of serenty-fourth and seventy-fifth experi- } \\
\text { ments, } 801 \text { pounds. } \\
\text { Average of seventy-sixth and seventy-seventh exper- } \\
\text { iments, } 848 \text { pounds. } \\
\text { Average of seventy-eighth and seventy-ninth experi- } \\
\text { ments, } 990 \text { pounds. } \\
\text { Average of eightieth and eighty-first experiments, } \\
1,047 \text { pounds. } \\
\text { Average of eighty-second and eighty-third experi- } \\
\text { ments, } 1,054 \text { pounds. }\end{array}$ \\
\hline
\end{tabular}

* Many stones in the bottom of furrow. † This was not quite full depth.

Average depth from seventy-second to eighty-third experiments, 11.5 inches; average wilth, 12 inches; avelage draught, 897 pounds.

The average draught of the whole series of experiments falls below the mean of 11 and 12 inches, which corresponds with it in size, 21 pounds.

Recapitulation of Experiments with Sod and Subsoil Plow.

\begin{tabular}{|c|c|c|c|c|}
\hline $\begin{array}{c}\text { Depth of fur- } \\
\text { row, inches. }\end{array}$ & $\begin{array}{c}\text { Width of fur- } \\
\text { row, inches. }\end{array}$ & $\begin{array}{c}\text { Draught in } \\
\text { pounds. }\end{array}$ & $\begin{array}{c}\text { Difference, } \\
\text { pounds. }\end{array}$ & $\begin{array}{c}\text { Size of prism, } \\
\text { square inches. }\end{array}$ \\
\hline 9 & 12 & 659 & $\ldots$ & 108 \\
10 & 12 & 801 & 142 & 120 \\
11 & 12 & 848 & 47 & 132 \\
12 & 12 & 990 & 42 & 144 \\
14 & 12 & 1,047 & 57 & 156 \\
\hline
\end{tabular}

The average difference in the dranght of each inch in depth was 59 pounds.

The work of this plow at all depths was very perfect; the ground was thoroughly pulverized; the vegetation was perfectly buried, and the surface was left smooth and level as a garden. There can be no doubt that the work was much better done than it could have been done by a spade. 
In making these experiments, several things interesting to the practical plowman were very fully exemplified:

1. The unequal tenacity of the soil. The plowing was round a centre back furrow. As the land grew wider the furrows, of course, receded farther from each other. While testing the sod and subsoil plow (seventy-second to eighty-third experiments), one of the furrows ran for half its length through a sandy soil, while the other ran through a moist, tenacious loam. The even numbers of the experiments mark the sandy furrows; the odd numbers the tenacious loams. The average draught of the loamy furrows is 102 pounds greater than the sandy furrows.

2. The importance of a proper aljustment of the several parts of the plow. The draught as indieated in all the tables given above is mueh heavier than it would have been if one uniform depth and width of furrow had been arthered to throughout. The ehange from one sized furrow to another, of course, involved a change in the adjustment of the plow, and this was not always ascertained on the first or even on the second trial. When this was not accurately done, the plowman exerted his strength at the end of a long lever to counteraet the effect of the malidjustment, which was at once indieated by the index of the dynmometer, sometimes to the extent of 150 pounds. Some of the experiments were made by plowing two furrows, or onee around; others by four furrows, or twice around. In most cases the two last furrows showed less dranght than the two first, because the plow swam more freely and required less interposition on the part of the plowman. As examples of this, we refer to the forty-fifth ancl forty-sixth experiments, showing an averaged draught of 457 pounds, and the two next furrows of the same size, which only averaged 426 pounds, showing an advantage of draught amomiting to 31 pounds, arising from more perfeet adjustment. In these last furrows the plow ran for more than two-thirds of the distance by itself, without a touch of the plowman's finger, and for the remaining third his touch was the lightest possible. The stme thing is shown by a comparison of the sixty-second and sixtythird with the sixty-fourth and sixty-fifth experiments, the latter being 35 pounds lighter than the former, for the same reason. The neeessity of accurate adjustment was very elemrly illustrated in the action of plow No. 69. We resired to aljust it for a furrow 12 inches deep and 16 inches wide, but Mr. Brooks, though perfectly aequinted with the implement, was utterly 
mable to make it take such a furrow; his utmost efforts could not force it more than eight inches into the gromud, nor conld it take a furrow wider than twelve inches. More than two hours were spent in trying to make it swim freely in the desired furrow, but without suecess, although Gov. Holbrook and Mr. Nourse, both eminent masters of the art of plowing, exerted all the resourees of their skill to make it work. We all knew that the plow would work admirably in such a furrow, for we had seen it to it again and again. We broke off our work for dimner, quite in desparr of being able to accomplish what we designed to do with that plow. While sitting at dimner, it occurred to Mr. Nourse that the difficulty might lie in the beam. Accordingly, on reassembling in the field, after dimner, we found that the workman had carelessly set the beam out of its true direction, so that it turned from land and out of the ground to such an extent that the clevis could not afford vertical or lateral motion enough to correct it. These. tendencies were then counteracted by an opposite adjustment of the coulter to make it take more land, and by hooking the chain into the wheel gururds to make it run deeper. WTe then had no difficulty in performing the experiments from the fifteenth to the thirty-seventh with relative correctuess, although the alsolute draught was undoubtedly considerably greater than it would have been had the beam been in its right place.

3. The importance of still in the plowman was also very clearly manifested. This skill is desirable to hold the plow to advantage. Delicacy and sensitiveness of tonch are almost as much required in plowing as in line engraving. The plow manifests its intention to go astray to the sympathetic plowman before it actually does so; a very slight, an almost inappreciable counter resistunce on his part, promptly applied, will cheek the rolition of the plow before it is manifested in action, but if the golden moment is lost. it is gone forever. The volition is manifest in action, and an unsightly alteration in the size of the furrow slice reveals the plowman's awkwardness to every spectator. But the skill of the plowman is not alone manifested in his manner of holding; it is even more clearly shown in his mode of tempering the plow. A good plowman is nerer satisfied until his plow swims absolutely free; he will not use any more of his own strength than is really necessary, knowing as he does that, as his force is exerted through levers, every pound of exertion which he uses reacts on the horses with a tenfold foree. He will, therefore, alter his adjustments, 
if need be, twenty times until this result is fully aceomplished When the plow does not run level, but is frequently ehanged by the plowman from one side to the other, the two sides of the furrow sliee will be found to be unequal in thickness, and, therefore, the soil of the thinner edge has been left undisturbed at the bottom. We found in every case that the draught of the plow was lightest when it was going smoothly and steadily by itself, untouched by the plownan. It was really interesting to watch its motions when rumning thus freely; if it encountered any obstacle In the soil, which had a tendeney to throw it out, it would turn of its own aceord to take more land, or if the obstacle directed it inward, toward the land, it would turn to throw itself out; and when it accomplished the object it would quietly settle down again to its level and proper work. It was truly automatic in its motions, but this was only so when the different parts were adjusted with absolute accuracy, which ean only be done by an aceomplished plowman. Seeing these fiuts brought out so clearly before our eyes, it was a cause of deep regret to us that the race of finished plowman was rapidly running out in the State of New York.

Our plows have been very greatly improved within the last quarter of a century; Jut the sons of farmers who were in the noon of their vigor at that time do not understand the art of plowing as well as their fathers did. We think that the State Agrieultural Society could exert its great power for good in no direction where it would be more beneficial to farmers than in taking measures to stimulate a taste for good plowing among the rising generation of farmers in New York. The growing class in our State, who farm for pleasure as well as profit, might do much to encourage this taste. If they would adopt a high standard of plowing, and insist upon their workmen approximating elosely to it, rewarding the closest approximations to it by a suitable pecuniary recompense, the fastion of good plowing would soon spread. Just as the fatshion of skating hats produced an albundance of elexint skaters, and the fishion of bakci-ball playing has produced an abundant erop of admirable batsmen, throwers and catehers, so the fashion of good plowing would supply us with first-class plowmen.

4. The actual results of the trial. These are shown in the following tables: 
Table showing the average depth and width of furrow, the average draught, the average size of prism, and the average of the whole.

\begin{tabular}{|c|c|c|c|c|c|}
\hline PLOWS. & 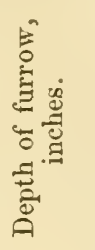 & 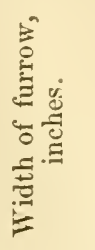 & 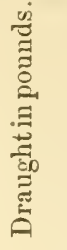 & 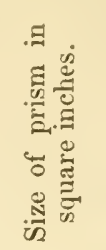 & 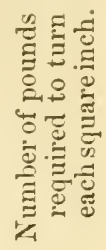 \\
\hline 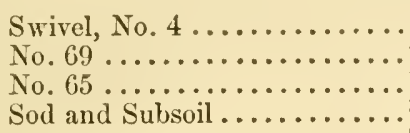 & $\begin{array}{r}7.05 \\
7.94 \\
5.65 \\
11.50\end{array}$ & $\begin{array}{l}13.65 \\
17.80 \\
11 \\
12\end{array}$ & $\begin{array}{l}505 \\
663 \\
463 \\
897\end{array}$ & $\begin{array}{r}96.23 \\
141.33 \\
62.15 \\
138.00\end{array}$ & $\begin{array}{l}5.87 \\
4.69 \\
7.45 \\
6.50\end{array}$ \\
\hline Average .............. & 8.03 & 13.61 & 647 & 109.43 & 6.10 \\
\hline
\end{tabular}

(a) We learn from this table that, with prisms varying very much in size, the largest being nearly two and one half times greater than the smallest, the power required for cutting and turning a lap furrow is expressed by 6.10 pounds for each seetional square inch of the furrow slice.

(b) We learn also that large furrow slices are turned with more economy of power than smaller ones. The average power. required to turn the two smaller furrow sliees of 79.19 square inches was 6.66 pounds per square inch, while the power required to turn the two larger ones of 139.66 square inches was 5.55 pounds, or the smaller required 1.11 pounds more power than the former. This result appear's less favorably when considered with reference to the average deptl of the furrows than it does in relation to the square inches. The two shallowest furrows average 6.35 inches in depth, and require 80.94 pounds for each inch of depth. The two deepest furrows average 9.72 inches in depth, and require 80.24 pounds for each ineh of depth.

(c) 'The sod and subsoil plow seems to require nore power' than it does when it is worked with a coulter. Considered with reference to the sectional area of the slice, the sod and subsoil requires 6.50 pounds of power for each square inch, while it only requires 4.69 pounds per square inch when used with the coulter. Considered with reference to the depth, each inch of the sod and subsoil requires 78.00 pounds of power, while with the coulter it requires 83.50 pounds, showing a greater expense of power in the sod and subsoil plow of 1.81 pounds for each square inch of sectional area, and 5.50 pounds less power for each inch in depth. 
(d) No. 69 requires 1.18 pounds less power for each square inch of sectional area than the swivel and 2.14 pounds less for each inch in depth. The swivel consumes 80.14 pounds and No. 69 consumes 78.00 pounds of power for each inch of depth.

(e) No. 65 consumes 0.95 pounds more of power for each square inch of sectional area of furrow than the sod and subsoil plow, and 3.94 pounds more for each inch of depth. No. 65 consumes 81.94 pounds, and the sod and subsoil 78.00 pounds for each inch of depth.

In order to afford the means of comparison, we here insert some of the results arrived at by Mr. Pusey and Mr. Morton, which are given in full in the report on the trials of plows at Utica, in September, 1867:

The average draught of Mr. Pusey's first four furrows of 5, 6, 7 and 8 inches deep was 53.84 pounds for each inch in depth. The average draught of his last four furrows, $y, 10,11$ and 12 inches deep, was 57 pounds for each inch in depth. In both cases the furrow was nine inches wide.

In Mr. Morton's experiments the shallower furrows showed an average dranght of 85.40 pounds for each inch in depth; the deeper ones averaged 94.62 pounds; the furrow in both cases was nine inches.

The power required in Mr. Pusey's experiments for each square inch of arerage sectional area of the furrow slice in the four shallowest furrows was 5.98 pounds; the four deepest furrows required 6.33 pounds.

In Mr. Morton's, each square inch of sectional area in the shallowest furrows required 9.49 pounds, and for the deepest 10.51 pounds.

The experiments of Messrs. Pusey and Morton agree in making the power required to turn each square inch of the sectional area greater in deep than in shallow furrows, the excess, according to Mr. Pusey, being six per cent, and according to Mr. Morton it is ten per cent. According to oul experiments it is seventeen per cent less. Ours were made with different plows, while each of theirs was made with the same plow, which may partly account for the discrepancy. But the practical point is very clear, from all the experiments, that the power required for deep plowing is not materially greater in proportion to the work done. A fiurrow twelve inches deep ean be plowed with about twice as much power as a furrow six inches deep. The actual power consumed by each successive inch in depth was, alecording to the average of 
our experiments for all the plows, 64.05 pounds. According to Mr. Pusey's experiments the difference for each inch was 63.33 pounds. According to Mr. Morton's, the difference was 86.66 pouncls.

II. What is the increase of power required for each successive inch of wilth in plowing?

We answer this question by the following table, showing the result of experiments made for the purpose with Holbrook's Plow No. 65. The coulter was set with its point two inches above the sole of the plow. We began with the narrowest furrow, working gradually wider. All the furrows were intended to be seven inches deep, and all were so except the eighty-fourth, which was six inches deep:

\begin{tabular}{|c|c|c|c|}
\hline 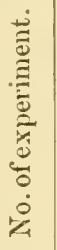 & 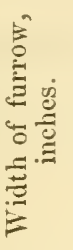 & 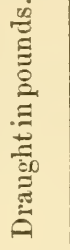 & REMARKS. \\
\hline *84 & 8 & 363 & \\
\hline *85 & 8 & 415 & Average of eighty-fifth and eighty-sixth experiments, 441 \\
\hline *86 & 8 & 467 & $\zeta$ pounds. \\
\hline *87 & 9 & 438 & Average of eighty-seventh anci eigthy-eighth experiments, \\
\hline $\begin{aligned} * 88 \\
89\end{aligned}$ & 9 & 453 & 443 pounds: \\
\hline $\begin{array}{l}89 \\
90\end{array}$ & 16 & 525 & Average of eighty-ninth and ninetieth experiments, 522 \\
\hline 90 & 16 & 519 & 3 pounds. \\
\hline 92 & $\begin{array}{l}15 \\
15\end{array}$ & 509 & $\begin{array}{l}\text { Average of ninety-first and ninety-second experiments, } \\
496 \text { pounds. }\end{array}$ \\
\hline$† 93$ & 14 & 513 & Average of ninety-third and ninety-fourth experiments, \\
\hline 94 & 14 & 485 & 499 pounds. \\
\hline 95 & 13 & 453 & Average of ninety-fifth and ninety-sixth experiments, 454 \\
\hline 96 & 13 & 455 & S pouids. \\
\hline 97 & 12 & 451 & Average of ninety-seventh and ninety-eighth experiments, \\
\hline 98 & 12 & 458 & $\zeta 454$ pounds. \\
\hline 99 & 10 & 454 & Average of ninety-ninth and one hundredth experiments, \\
\hline 100 & $\begin{array}{r}10 \\
8\end{array}$ & 459 & 456 pounds. \\
\hline 102 & 8 & $\begin{array}{l}421 \\
389\end{array}$ & $\begin{array}{l}\text { Average of one hundred and first and one hundred and } \\
\text { second experiment, } 405 \text { pounds. }\end{array}$ \\
\hline
\end{tabular}

* These experiments made it evident that the plow was working unnaturally. Each successive furrow was wider than the next succeding one; the sole of the plow was therefore wedged by the shoulder thus formed, and required more power than it would if the channel on the right hand had been free. We, therefore, concluded to begin with the widest furrow and work down to the narrowest. The coulter was set flush with the land side.

$\dagger$ Stones in the bottom of the furrow.

$\mp$ At this point we set the point of the coulter one-quarter of an inch in from the land side. 
The average wilth of the furrows from the eighty-ninth to one hundred and second experiment was 12.57 inches; the average draught was 469 pounds; the average increase of draught for each inch is $19 \frac{1}{2}$ pounds.

Recapitulation.

\begin{tabular}{|c|c|c|c|c|}
\hline $\begin{array}{l}\text { Width of fur- } \\
\text { row, inches. }\end{array}$ & $\begin{array}{l}\text { Draught in } \\
\text { pounds. }\end{array}$ & $\begin{array}{l}\text { Difference, } \\
\text { pounds. }\end{array}$ & $\begin{array}{l}\text { Size of prism, } \\
\text { square inches. }\end{array}$ & $\begin{array}{l}\text { Draught of each square } \\
\text { inch of sectional area, } \\
\text { in pounds. }\end{array}$ \\
\hline $\begin{array}{r}16 \\
15 \\
14 \\
13 \\
12 \\
10 \\
8\end{array}$ & $\begin{array}{l}522 \\
496 \\
499 \\
454 \\
454 \\
456 \\
405\end{array}$ & $\begin{array}{l}\ddot{26} \\
3+ \\
45 \\
\ddot{2}+ \\
51\end{array}$ & $\begin{array}{r}112 \\
105 \\
98 \\
91 \\
84 \\
70 \\
56\end{array}$ & $\begin{array}{l}4.64 \\
4.72 \\
5.09 \\
4.99 \\
5.40 \\
6.51 \\
7.30\end{array}$ \\
\hline
\end{tabular}

It will be observed that the draught required for each square inch of sectional area increases as the size of the area diminishes. This accounts for the greater amount of draught of this plow, as shown in the table on pages $268,269$.

III. What is the increase of power required when the furrow slice remains of the same size for each suecessive increment of velocity?

We endeavored to answer this question by the following experiments made with Holbrook's Plow No. 65, cutting a furrow seven inches deep and fourteen inches wide:

\begin{tabular}{|c|c|c|c|c|c|c|}
\hline \multirow{2}{*}{$\begin{array}{l}\text { No. of ex- } \\
\text { periment. }\end{array}$} & \multirow{2}{*}{ Seconds. } & \multirow{2}{*}{ Yards. } & \multirow{2}{*}{ Pounds. } & \multicolumn{3}{|c|}{ AVERAGE. } \\
\hline & & & & Seconds. & Yards. & Pounds \\
\hline $103 \ldots$ & 96 & 76 & 450 & $\cdots$ & .. & $\cdots$ \\
\hline $104 \ldots$ & 125 & 76 & 519 & 110 & 76 & $484 \frac{1}{2}$ \\
\hline $105 \ldots$ & 57 & 75 & 480 & $57 \frac{1}{2}$ & 74 & 500 \\
\hline $106 \ldots$ & 58 & 73 & 520 & $\ldots$ & .. & $\ldots$ \\
\hline $107 \ldots$ & 25 & 68 & 685 & $\dddot{0 ;}$ & $\because \ddot{0}$ & $\ddot{\cdots}$ \\
\hline $108 \ldots$ & 26 & 68 & 676 & $25 \frac{1}{2}$ & 68 & 680 \\
\hline
\end{tabular}

In order to facilitate a comparison of our experiments with those of Mr. Pusey, which are given in the report on plows, we give the following table, in which the preceding experiments are repeated in another form: 


\begin{tabular}{|c|c|c|}
\hline $\begin{array}{c}\text { Rate of going per } \\
\text { hour. }\end{array}$ & $\begin{array}{c}\text { Time required to plow } \\
\text { an acre. }\end{array}$ & Draught of plow. \\
\hline $\begin{array}{l}1_{1 \frac{5}{0} \sigma} \text { miles. } \\
2 \frac{67}{100}\end{array}$ & $\begin{array}{l}4 \text { hours, } 25 \text { minutes. } \\
2 \text { " } 39 \text { " }\end{array}$ & $\begin{array}{l}48+H_{2}^{1} \text { pounds. } \\
500 \quad \text { " }\end{array}$ \\
\hline $5 \frac{45}{100}$ & 1 “ 18 “ & 680 \\
\hline
\end{tabular}

It appears from the foregoing that, when the speed on the seeond trial was very nearly doubled, the draught was only increased $15 \frac{1}{2}$ pounds, which was probably dne to inequalities in the soil; and when, in the third trial, the speed was again more than doubled, the dranght was only increased 180 pounds. It may be considered as fully settled that velocity has very little influence on dranght. The last experiment does, indeed, show that the dranght was somewhat inereased, and this was also the case in the experiments of Messrs. Morton and Pusey; but the eause of this increase was very apparent in our trials; and we have no doubt that it was also the case in theirs. When the speed rose to five and one-half miles an hour (nearly), the soil was thrown upwards thirty inches high, and laterally four feet, so that four of the preceding furrows were covered with pulverized earth. It was this upward and lateral throw of the earth which consumed the 180 pounds of power. So long as the speed is not increased to the point where the earth is thrown upward and laterally, we think it is demonstrated beyond all possibility of doubt that the power required in plowing is not increased by an increase of speed.

IV. What proportion of the total amount of power consumed in plowing is absorbed by the different parts of the plow, viz., the sole, the land side, the share, the mould board?

Experiment No.38.-The surface draught of No. 65 (weight, 130 pounds) was 78 pounds.

Experiment No. 15. - The surface draught of No. 69 (weight, 140 pounds) was 118 pounds.

The greater surfice draught of the latter was probably owing to the greater breadth of the sole, measured from the land side to the angle of the feather.

The average draught of No. 65, plowing seven inches deep, as shown in experiments Nos. 49, 50 and 51 , was 512 pounds. 
The mould-board was removed from No. 65, and the plow was made to run seven inches deep, with the following results:

\begin{tabular}{|c|c|c|}
$\begin{array}{l}\text { No. of ex- } \\
\text { periments. }\end{array}$ & $\begin{array}{c}\text { Draught, } \\
\text { pounds. }\end{array}$ & REMARKS \\
\hline $109 \ldots .$. & 478 \\
$110 \ldots$. & 485 & $\begin{array}{c}\text { Average of one hundred and ninth and one hundred } \\
\text { tenth experiments, 482 pounds. }\end{array}$ \\
\hline
\end{tabular}

The consumption of power by the mould-board would thus appear to be $482-512=30$ pounds, or 5.8 per cent, of the whole amount; the consumption by the sole, 14.5 per cent of the whole amount.

In Mr. Morton's experiments, 10 per cent of the whole power was consumed in turning the furrow, which is very small, but 4.2 per ecnt less than our experiments would indicate. In Mr. Pusey's experiments, 50 per cent of the power was consumed.in what he calls surface draught; but it must be observed that this was oltained by rumning the plow through an empty furrow, and embraces the friction of the land side as well as of the sole, whereas ours was obtained by simply allowing the plow to run over the top of the ground, and we therefore obtained the friction of the sole without being complicated by the land side.

The plows which we used were so constructed that the land side could not be detached from the share, and we were, therefore, unable to determine the power required by the land side and the share separately.

The power required to draw the plow through a furrow seven inches deep was, as we have seen, 512 pounds. Power absorbed by the sole, 77 pounds; power absorbed by the mould-board, 30 pounds. Now, if we assume with Mr. Pusey, that the sole and land side together consume 50 per cent of the whole power, then $50-1.45=35.5$ per cent, which is absorbed by the land side; therefore, the power consumed by the land side is 179 pounds, leaving for the power required for share and coalter 226 pounds.

\section{What is the influence of the coulter on dranght?}

Mr. Stephens has stated the result of a very remarkable experiment tried by him to ascertain the influence of the conlter upon the dranght. He adjusted a plow with a coulter which projected seven inches below the sole of the plow, and having adjusted the hook of the whiftle-trees in the bridle, so that the sole wonld 
swim freely on the surface without any tendency to dip into the ground, he proceeded to measure the surfuce dranght and the entting action of the coulter seven inches beneath the surface of the ground. The draught in this case was 304 pounds. The draught when the coulter was removed and the plow was drawn over the surface of the ground was 112 pounds, which, being deducted from the whole draught, leaves 252 pounds as the draught of the coulter. Mr. Stephens further states, that a well trimmed plow, turning a furrow seven inches deep and ten inches broad, was at work in the same field, the draught of which wats only 364 pounds. The same plow, after the coulter was removed, was put to plow a furrow seven inches by ten inches, and its draught was also 364 pounds. It would, therefore, appear from this experiment that the surface draught, and the coulter running seven inches into the ground, required as much power as it does to turn a complete furrow seven inches by ten inches.

Experiment No. 111.-We desired to verify this experiment, and we accordingly affixed a coulter which had been specially prepared for the purpose to No. 65, so that it projected six inches below the sole. The bridle of the plow was not long enough to enable us to bring it into proper trim, so as to prevent it from running into the ground, but finally, by attaching a chain to the guides of the wheel it worked very satisfactorily. The draught (including the surface draught) was 296 pounds; deducting the surface dranght, which is 77 pounds, we have 219 pounds for the power consumed by the coulter, which is 33 pounds less than Mr. Stephens found; but as his coulter ran one inch deeper than ours, and would therefore necessarily consume more power, the agreement is quite as close as could be expected.

Experiment No. 112.-We then removed the coulter, and plowed a furrow six inches deep and eleven inches wide. The draft was now 417 pounds, or 121 pounds more than was required for the surface draught of the plow, and to cut six inches into the ground.

In order to complete this experiment on the influence of the coulter, we should have plowed a few furrows of the same size, with the coulter adjusted in the ordinary way; but the importanee of the experiment escaped our attention at the moment.

Experiment No. 113.-We thought of it afterwards, and tried the experiment, but we were at that time plowing in a denser soll, and the comparison was, therefore, not exact. The draught in the 
soil where we tried it was 443 pounds, or 26 pounds more than it was without a coulter. We record the experiment exaetly as it was made, leaving each one to draw his own conclusions; but, in our judgment, although the use of a coulter in sod ground makes much better work, it does not have much effect on the draught in any way.

This opinion must, however, be modified with respect to the swivel plows, which evidently worked much more easily with a coulter, as appear's by comparing the results of experiments Nos. 9,10 and 11 :

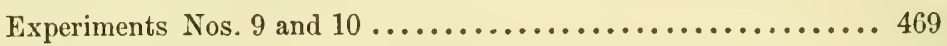

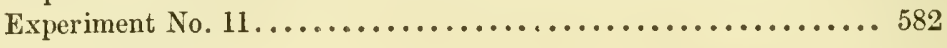

Difference in favor of coulter 113

It does not appear from our experiments that the depth of the coulter in the soil, so long as it does not run below the sole of the plow, affects the draught. (See experiments Nos. 12, 13 and 14.) But, if the conlter is used, our experiments show very decidedly that much depends upon its being in a proper condition. On comparing the average of the fifty-sixth, fifty-seventh and fiftyeighth experiments (545 pounds) with the average of the sixtieth and sixty-first (512 pounds), it will be seen that 33 pounds were saved by the use of a sharp coulter.

It was not found that the rake of the conlter made any material difference when plowing among fibrous roots, but it beeame necessary to give it more rake when plowing among rhizomes, such as quack roots. This fact was well exemplified in experiments sixty and sixty-one (512 pounds). The rake was then increased very considerably in experiments sixty-two to sixty-five (452 pounds), showing a reduction in power of 59 pounds. On examining the edge of the cutter it was found that there was a rough wire edge on it, and it was then rubbed down smooth with a scythe-stone, and the draught fell, in the sixty-sixth and sixty-seventh experiments, to 422 pounds. It was then found that the coulter had slipped and lost most of the rake that had been given to it during the last two experiments. It was again adjusted properly, and from the sixty-eighth to the seventy-first experiment the draught was 389 pounds. These experiments show a reduction in draught of 156 pounds by putting the coulter in proper order.

VI. Does the skim plow consume more or less power than the coulter ? 
Experiment No. 114-No. 69 was furnished with a coulter and a stubble mould-board, the furrow being nine inches deep and twelve inches wide. The draught of the plow, thus adjusted, was 729 pounds.

Experiment No. 115.-The coulter was then withdrawn from the plow, and a skim plow was placed on the beam and set to work with a furrow of the same size; draught, 659 pounds, showing a difference of 70 pounds in fuvor of the skim plow. These experiments are believed to give a sufficient answer to the question.

\section{What is the elasticity of different soils ?}

We did not try this experiment as fully as it deserves, as we found it would require more time and expense to do so than we could well afford; but we performed it carefully in different parts of the same field, which differed considerably in consistency.

Experiment No.116.-Referring to the report of the judges of the Utica trial for the method of making it, we have to state that, with a furrow eleven inches deep and sixteen inches broad, the upper part of the slice in the most tenacious part of the field would stretch seven and a half inches beyoud the lower portion before breaking; in the least tenacious part it would stretch four and three-quarter inches; and soils of intermediate tenacity would stretch in proportion.

Experiment No. 117. - The stretch diminished according to the shallowness of the furrow slice. At four inches deep it would not stretch much more than an inch in the toughest part of the field, and in the loosest part it would not much exceed half an inch. At six inches deep it stretched two and a half inches, and at eight inches deep, a little over three inches.

This great difference in the elasticity of soils shows how impossible it is to make any one plow which shall work equally well in all soils. If it has a sufficient twist to break the least tenacions soils, it will utterly fail to disintegrate those which are more tenacious. If, on the other hand, it has enough sharpness of twist to disintegrate the most tenacious soils, it will cause a great waste of power when used in less tenacious soils. All that can be reasonably asked of a plowmaker is that, a soil and depth of furrow being given, he shall make a plow which will disintegrate it most thoroughly with the least expenditure of power. It by no means follows that it will be the best plow in any other soil? 
VIII. What is the influence of the wheel on draught?

We are ashamed to be obliged to state that we quite overlooked this part of our programme, and are therefore unable to give an experimental answer to this question.

IX. What is the influence of the plowman on draught?

We have already answered this question incidentally in the earlier portions of this report. In some cases, where he was obliged to exert his force through a lever to counteract a tendency to irregularity, in consequence of a maladjustment of the parts, the extra power required rose up to 115 pounds. In all cases the lightest draught was shown where the plow ran with the least interference on the part of the plowman.

We cannot close our report of these trials without the expression of our sincere thanks to Gov. Holbrook and Mr. Joel Nourse for the very valuable assistance which they rendered to us, without which our labors would have been much less fruitful.

$$
\begin{aligned}
& \text { JOHN STANTON GOULD, } \\
& \text { HENRY WATERMAN, }
\end{aligned}
$$

Committee. 


\section{INDEX.}

Alden \& Co., cultivator........... 254

Alger, Cyrus, annealing cast iron plows, $1839 . \ldots \ldots \ldots \ldots \ldots \ldots . . . \ldots$

American, early plow............ 65

Berkshire plow, preferred by Tull... 17

Brand's (Suffolk) plow ........... 22

Burch, L. D., Swirel plow ......... 249

Burden, Henry, plow ........... 90

Burrall, T. D., patent for diminishing friction of land side, $1843 \ldots \ldots \ldots 117$

Carbonic acid a solvent ............ 143

Carpenter, Levi ................. 101

Caschrom (British plow)......... 9

Centre draught (Mears' invention).. 100

(Prouty \& Mears).......... 165

Chapman \& Barnum, device for diminishing friction of land side.. 127

Chenoweth, R. B., patent......... 71

Chinese plow.................. 13

Conkling, James H.............. 151

Coulter, devices for clearing....... 200

draught of ............... 182

elevation and set of ......... 183

Mr. Stephens' experiments on draught of.............. 182 varieties of form and attachment................. 180

Cultivators, Alden \& Co.......... 254 Ford \& Howe's ............ 259

Hawks' ................ 256

McQueston's .............. 261

Phifer's .................. 256

Rules for trial............ 208

Davis, Gideon, patent and construction..................... 72

Deep plowing, effect of .......... 146

Denver, John, patented a plow 1803. 69

Ditching machine.............. 243

for under-draining ........ 245

Draught of plows (see "Plows,

draught of ") ................ 154

Draught of plows, planes of resistance 167 point of resistance ........ 168 angle of .................. 169 experiments on ............ 177 difference of plowmen......... 179 $1820 \ldots \ldots \ldots \ldots \ldots \ldots \ldots .69$

Dutcher, J., letter on the "History of the Plow" ................

Dynamometer at trial of plows, $1820 . \quad 89$

East Indian plow.............. 10

East Lothian plow ............. 35

Egyptian plow, ancient ........... 8 now in use.............. 12

Elasticity of furrow slice......... 153

English plow, A. D. 1470 ........ 13

F ast-walking draught beasts, value of 165

Fertility, causes of............. 136

Fords \& Howe, cultivator......... 259

Four-coultered plow............... 18

Four coulters, use of ........... 18

French (Canadian) plow .......... 16

Grant's Iona plow.............. 129

Handley, Mr., experiments between

Swivel plows and wheel plows .... 177

II arris, Hezekiah, patent $1804 \ldots . .669$

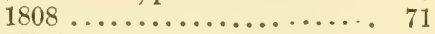

Harris, Zadock, pat. and specification $8:$

Harrows, rules for trial .......... 207

J. E. Morgan's............ 251

F. Nishwitz's ............ 253

Hawks', N., Ditching plow .......... 243 cultivator............... 256

Heath, E., Ditching machine ...... 245

Hingham's Self-holding plow ....... 91

Ilitchcock, David, plow, 1823 ..... 91

Ilolbrook, F. F., method.......... 129

Horton, Frost................ 101

Iona plow, Grant's ............. 129

Jacobs, James, patent $1834 \ldots \ldots \ldots 10-$

Jefferson, $\mathrm{Mr}$, construction of his plow 23

objections to the same...... 32

suggestions of cast iron for nould-boards ............ 33 suggestion of two wedges.... 22

Klay, John, patent .............. 72

Kilmer, J. \& A., invention ........ 200

Knox, James A., patent 1852 ..... 117

Lanarkshire plow .............. 50

McCormick's plow............... 99

McQueston's cultivator........... 251

Mead's patent, $1863 \ldots \ldots \ldots \ldots \ldots . . . . .27$

Mears, John .................. 100

Mexican plow................. 12

Mid-Lothian plow............... 51

Minor \& Horton................. 101

Minor, Truman ................ 101

94 Modern English plows ............ 59 
Morgan \& IIarris' patent......... PAGE.

Morgan, J. E., harrow........... 251

Morton, J.C., experiments in draught of plows ........... 157, 161. 164

Mould-board, F. F. Holbrook's ..... 128 G. Davis'.............. 72 Mr. Jefferson's...... 23, 32, 33 Rham's............... 62 should be adapted to the soil. 150 Stephens' construction....... 51 twist of, splits the furrow slice 151 Newbold, Chas., first cast-iron plow in America ..................

New York State Agricultural Society, trial draught plows, 1850 ....... 158

Nishwitz, F., harrow ............ 253

Nourse, Joel................. 91 Eagle plow .............. 93

Patrick, M., patent............ 72

Peacock, David, patent 1807 ...... 69

$1817 \ldots \ldots \ldots \ldots \ldots \ldots \ldots \ldots .72$

Pease, Horace, patent .......... 72

Peekskill plow................. 101

Phifer's cultivator............. 256

Pickering, T., letter on lines of the

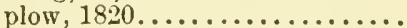

Plants, growth and food of ........ 136

Platt, H. M., Screw-Auger plow, '58. 127

Plow of Asia Minor .............

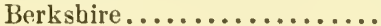

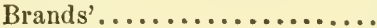

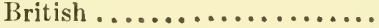

Burch's.................. 249

Burden, Henry .......... 90

Chinese................. 13

Collins \& Co., B 14........ 213

Collius \& Co., C $3 \ldots . . . . . .234$

Fast Indian............. 10

East Lothian ............

Egyptian, ancient ..........

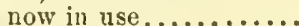

English. A. D. 1470 ........

Four-coultered............

French (Canadian).........

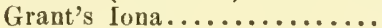

Hawks' Ditching............ 243

Hingham's Selt-holding...... 91

Hitchicock', David ..........s 91

Holbrook's No. 65.......... 210 No. $66 \ldots \ldots \ldots \ldots \ldots . . .213$ No. $69 . \ldots \ldots \ldots \ldots \ldots .224$

No. 6 Swivel..........248

Mr. Jefferson's.............

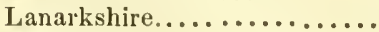

MlcCormick's..............

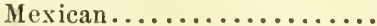

Mid-Lothian ..............

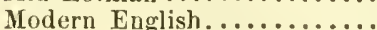

Newbold's, Charles.........

Nourse's, Joel, Eagle........

Peekskill ............... 101

Pront's I)itching ........... 243

Platt, 11. M., Screw-Auger ... 127

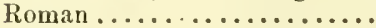

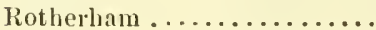

Saxon, elevent li century......
Plow, Side-hill ............. 248

Small, James............ 35

Steel, for alluvial land...... 246

Sod and Subsoil .......... 239

Webster, Daniel .......... 103

Wilkie's................. 50

Wood, Jethro:........... 72

improved $1819 \ldots \ldots \ldots 84$

Plows, draught of ............... 154 comparison, different soils.... 157

J. C. Morton's experiments .. 157

161,164

Philip Pusey's experiments... 155

$161,163,177$

ratio to depth............ 160

ratio to velocity........... 163

trials of, by N.Y.S.A.S., 1850. 158

(See "Supplementary Trials.")

list of entries . ........... 209

rules for trials ............ 205

Sod, for stiff soils .......... 210

Stubble, for stiff soils....... 211

Plowing, adjustment for turning under

weeds, etc........... 198

attachment of the team ..... 193

crested furrow ........... 89

flat furrow.............. 191

lap furrows, use of......... 185

proportion of depth to

widtb ........... 187

left hand ................201

Plowing, objects of, enumerated . 148

sod and subsoil ............ 190

stubble................ 192

withont dead furrows........ 191

Programme of trials............ 204

Prouty, David ................ 100

Pulverization .................. 149

Pusey, Philip, experiments on draught of plows ...... 155. 161, 163, 177

Ransome, Robert, improvement..... 60

case-hardened or chilled shares 60

Rham, Rev. IV. L., lines for plow... 62

Roberts', M. L., invention ......... 127

Roman plow ................. 9

Roots of plants, extent of ........ 144

Rotherham plow.............. 16

Routt's, A. P., Ditching plow ...... 243

Rules of trials .................20t

Saxon plow, eleventh century ...... 14

Seltz, John, patent............ 72

Small's, James, plows .......... 35

Smith, Aaron, patent 1814 ........ 111

Col. John, cast share ...... 68

Soil, absorbing porver........... 139

mechanical condition........ 139

deepening of ............. 218

Soils, Voleker's experiments...... 139

Way's experiments........ 139

Stephens'. Mr., construction of mould-

$$
\text { board ................. }
$$

experiments on drauglit of coulter.............. 182

Stevers, Edwin A., improvement... 89

16 Stubble. to turn under........... 198

14 Subsoil, attachment to plow....... 241 
Supplementary trials........... 263 points of .............. 263 draught experiments to determine inerease of power for each inch of depth. 265-271 remarks on same...... 272-276 trials to determine increase of power fol each ineh of width ............. 277 to determine increase of power for increase of veloeity.278, 279 to determine the proportion of power absorbed by different parts of the plow. 279,280

to determine the influence of the coulter upon the draught ........... 280-282

to determine relative draughts of Skim plow and coulter. 282

to determine the elasticity of different soils ..........283
PAGE.

Swan, Joln, patent............ 72

Swing plow, advantages of ....... 175

Tousley, Robert, patent.......... 72

Tull, Jethro, experiment on range of roots of plants .............. 145

Voelcker's experiments........... 139

Way's deductions as to separating power of soils............... 141

Webster, Daniel, his plow........ 103

Weeds and stubble, to bury........ 198

Wheatley, R. J., subsoil attachment. 241

Wheel of the plow .............. 173 mode of attaching.......... 179

Whiffle-trees, observations on..... 194 for three horses .......... 195

Wiley, James................ 101

Wilkie's plow................ 50

Witherow \& Pierce, patent $1839 . . .114$

Wood, Jethro, patent........... 72 improved plow, $1819 \ldots . . \ldots 84$

\section{LIST OF FIGURES.}

Frg.

1. Plow of Asia Minor .........

2. Aneient Egyptian plow.......

3. Roman plow...........

4, 5. Form of plow as used by Cincinnatus and Cato .......

6. Casehrom (British plow) .....

7. East Indian plow ............

8. Egyptian plow now in use ....

9. Hexican plow ...............

10. Chinese plow...............

11. English plow, A. D. $1470 \ldots$.

12. Saxon plow of eleventh century

13. French (Canadian) plow .....

14. Land side of Rotherham plow.

15. Furrow side same............

16. Bridle, \&c., same............

17. Brand's (Suffolk) plow ........

18 to 27 . Diagrams illustrating $\mathrm{Mr}$. Jefferson's formation of mouldboard ..............24 to 31

28. East Lothian plow ......... 35

29. Body frame of the same ..... 39

30. Sole bar of the same inverted. 39

31. Vertical section same . .... 40

32 to 37 . Share of the same ...... 41

38. Form of sock plate same..... 42

$39,40,41$. Sole shoe same...... 43

42. Edge view of the coulter, same 43

43. Side view of the coulter, same 43

44. Plan of bridle of same....... 44

45. Side view same........... 44

46. Elevation of the body in working position, same ...........

47. Horizontal sole shoe, same....

48. Diagram of the formation of the mould-board ............. 46

49. Diagram do do do 49

50. Plow statf .............. 51

51. Hammer nut key .......... 51
Fig.

52. Diagram illustrating formation

block for mould-board ....... 57

$53 a$. Shares, showing chilled parts 61

$\begin{array}{lllll}53 & b & \text { do do } & 61\end{array}$

54. Mortised shoe ............. 61

55. Cast plow frames .......... 61

56. Mould-board and share showing attachment to the frame..

57 to 60 . Diagram showing Rham's

formation of mould-board.. 63,64

61. Newbold's plow............ 67

62. Chenoweth's plow.......... 71

63 . Harris' plow, $1819 \ldots \ldots \ldots \ldots .82$

64 . Wood's plow ............ 85

65. Burden's plow............. 90

66. Nourse's Eagle No. 2...... 94

A. B. Dutchers' diagrams of formation of mould-board ....... 98

Daniel Webster's plow, land side... 104

Daniel Webster's plow, furrow side. 104

Daniel Webster's plow, dimensions . 105

67. Jacobs' plow ................ 108

68. Diagram of Smith's Michigan plow .................. 111

69. Diagram of the right hand or face view of Smith's mouldboard .................... 112

$69 a$ to $69 f$. Parts of the same ... 113 [Figs. 9, 12, 14, 15, 16, 17, referred to on page 114, are not reprodueed in this report, but all that is necessary for the description is contained in figs. $69 a$ to $69 b$, p. 113.]

70. Diagram of Witherow \& Pierce's mould-board.............. 115

71. Diagram of generating eurve.. 115

72 . Elevation of Gibbs' plow ...... 126

73. Mead's share and mould-board 128 - fig. 1. Iona turuing plow .... 129 
FIG.

73. fig. 2. Inclined plane or share of same............. 130

- fig. 3. Transformed No.1, Iona 130

- fig. 4. Great Trench No.1 do 131

- fig. 5. Great Trench No.2 do 131

- fig. 6. Trenching plow for loams and clay, do ...... 132

- fig. 7. Large trenching plow .. 132

- fig. 1 to 8. Diagrams illustrating the operations of trenching plow .. 133, 134

74 to 79. Diagrams illustrating fracture of furrow slice ..... 150-152

80. Section of Prouty \& Mears' plow, showing obliquity of land side .................. 168

81. Diagram of line of draught... 170

82. Diagram showing increase of resistance of wheel ......... 174

82 to 86 . Forms of plow wheels... 180 87 to 91 . Coulters ............. 181

92. Fin share ............. 182

93. Position of coulter, Prouty \& Mears'................. 184

94, 95. Diagrams of lap furrows, 185, 186 96,97 . Diagrams of rotation of furrow slice.............. 188

98. Trapezoidal furrow ......... 190

99. Sod and subsoil furrow ......... 191

100. Flat furrow sod............ 191

101. Stubble furrow ........... 192

102. Holbrook's snd and subsoil plow 193

103 Whiffletrees for three horses .. 195

104. Metlod of attaching three horses in New York............ 196
Fig. PAGE.

105. Stephens' method of attaching four horses to the plow ...... 197

106. Chain attachment for plowing under weeds, \&c........... 199

107. Kilmer's adjustment for do 199

108. Device for cleaning the coulter 199

109. Left hand plow ............ 201

- figs. 1, 2. 3, 4. Diagrams for plowing grounds withcut a dead furrow, 201, 202

110. Holbrook's No. 66 for stubble lands in stiff soils.......... 211

111. Holbrook's No. 66 ......... 214 112,113 . Collinsville plow ....... 214

Holbrook's No. 66 sod plow 217 114. Holbrook's No. 69 stubble plow 222 115. Front and rear standard of same 231

116. Parts of the same......... 232

117. Holbrook's No. 69 sod and subsoil .................. 239

118. Holbrook's No. 69 sod....... 241

119. Hawks' ditching plow....... 243 120. do do as cultivator 245 121. Heatl's ditching machine.... 247

122. Holbrook's swing or side-hill plow .................. 248

123. Diagram of Bnrch's share.... 249

124. Morgan's harrow ......... 252

125. Alden's cultivator ......... 255

126. do do as corn-markel 255

127. Phifer's two-horse cultivator.. 257

128. Fords \& Howe, cultivator..... 260

129. McQueston's improved cultivator.................. 262

\section{PLATES.}

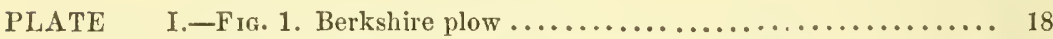

Fig. 2. Four-coultered plow, with parts of same .......... 19

PLATE II._East Lothian or Small's plow ..................... 36

PLATE III.-Analytical section of mould-boards:-East Lothian plow; Mid-

Lothian plow; Berwickshire plow; Lanarkshire plow..... 46

PLATE IV.-Analytical sections of mould-boards:-Western Fifeshire plow ;

Ransom's F F new mould-board ................. 53

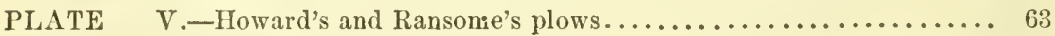

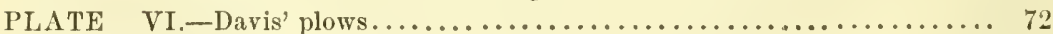

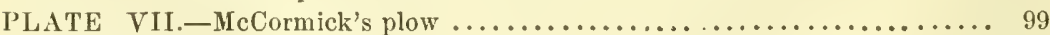

PLATE VIII -Knox's forming mould-boards of plows................ 118 








\section{DIGEST OF THE}

\section{LIBRARY REGULATIONS.}

No book shall be taken from the Library without the record of the Librarian.

No person shall be allowed to retain more than five volumes at any oue time, unless by special vote of the Council.

Books may be kept out one calendar month; no longer without renewal, and renewal may not be granted more than twice.

A fine of five cents per dily incurred for every volume not returned within the time specified by the rules.

The Librarian may demand the return of a book after the expiration of ten days from the date of borrowing.

Certain books, so designated, cannot be taken from the Library without special permissiou.

All books must be returned at least two weeks previous to the Annual Meeting.

Each member is responsible for all injury or loss of books charged to his name. 
